\title{
DEVELOPMENT OF PALLADIUM L-EDGE X-RAY ABSORPTION SPECTROSCOPY AND ITS APPLICATION ON CHLORO PALLADIUM COMPLEXES
}

\author{
by \\ Ryan Bradley Boysen
}

A thesis submitted in partial fulfillment of the requirements for the degree

of

Master of Science

in

Chemistry

MONTANA STATE UNIVERSITY

Bozeman, Montana

December 2005 
(C) COPYRIGHT

by

Ryan Boysen

2005

All Rights Reserved 


\author{
APPROVAL \\ of a thesis submitted by \\ Ryan Bradley Boysen
}

This thesis has been read by each member of the thesis committee and has been found to be satisfactory regarding content, English usage, format, citations, bibliographic style, and consistency, and is ready for submission to the College of Graduate Studies.

Dr. Robert K. Szilagyi

Approved for the Department of Chemistry and Biochemistry

Dr. David J. Singel

Approved for the College of Graduate Studies

Dr. Joseph J. Fedock 


\section{STATEMENT OF PERMISSION TO USE}

In presenting this thesis in partial fulfillment of the requirements for a master's degree at Montana State University, I agree that the Library shall make it available to borrowers under rules of the Library.

If I have indicated my intention to copyright this thesis by including a copyright notice page, copying is allowable only for scholarly purposes, consistent with "fair use" as prescribed in the U.S. Copyright Law. Requests for permission for extended quotation from or reproduction of this thesis in whole or in parts may be granted only by the copyright holder.

Ryan Bradley Boysen

December 2005 
TABLE OF CONTENTS

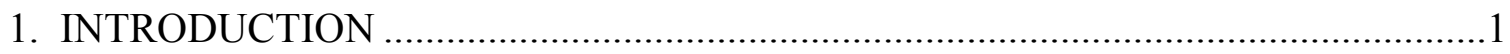

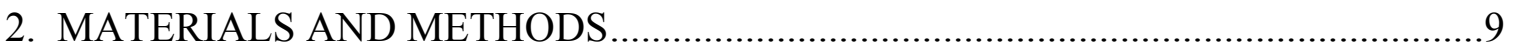

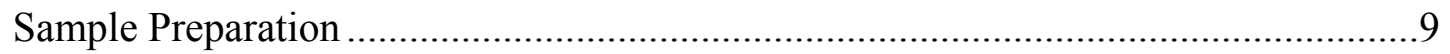

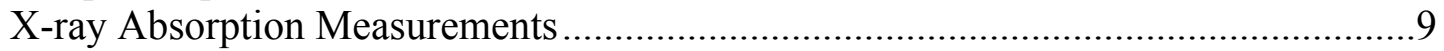

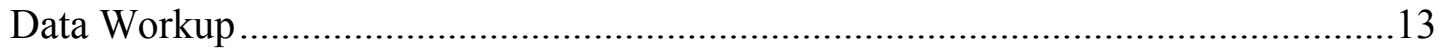

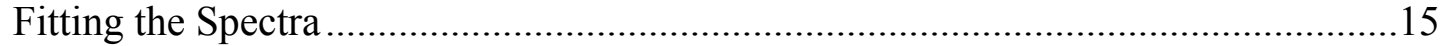

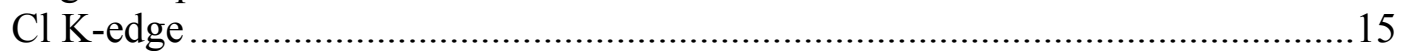

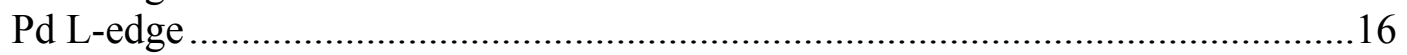

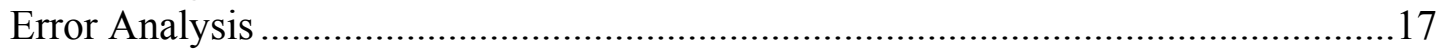

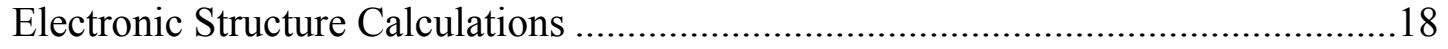

Modeling the chloro palladium complexes..................................................... 18

Finding the Theoretically Converged Basis sets..............................................19

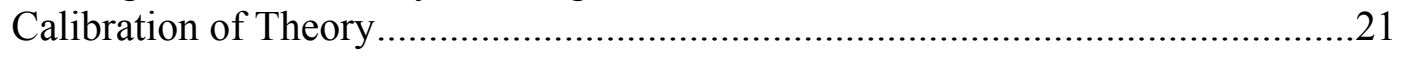

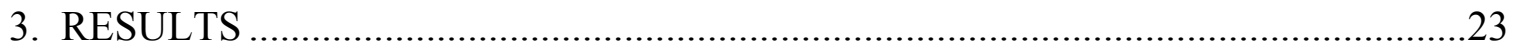

Data Quality Dependence on Beamline Setup and Optics.....................................23

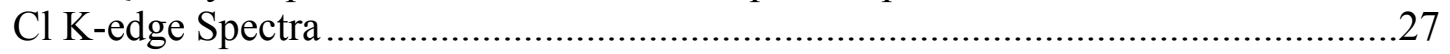

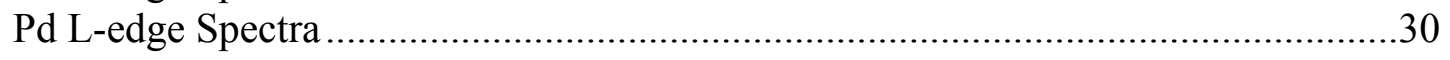

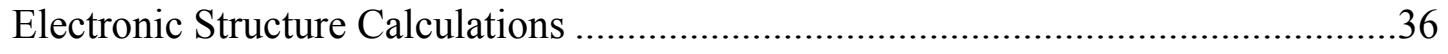

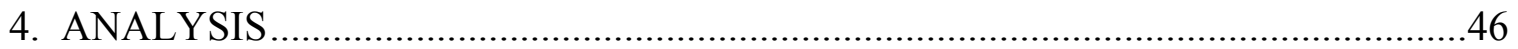

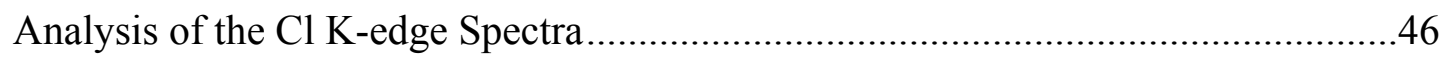

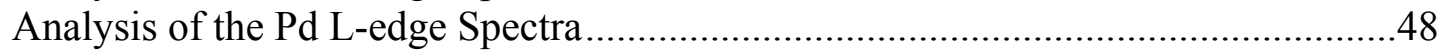

Application of the Calibrated Level of Theory and Pd L-edge

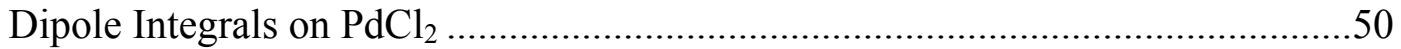

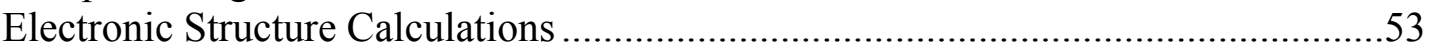

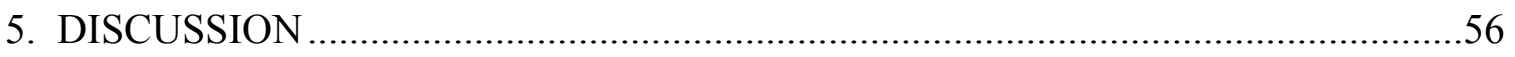

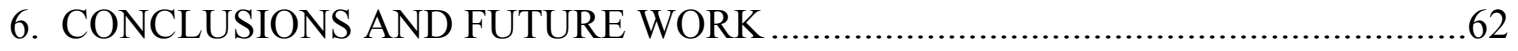

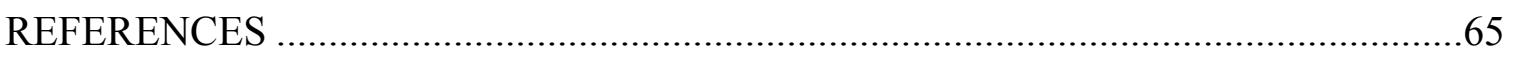

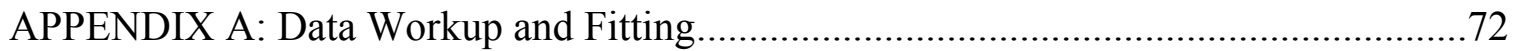




\section{LIST OF TABLES}

Table

1. List of basis sets evaluated in this study and their contraction schemes

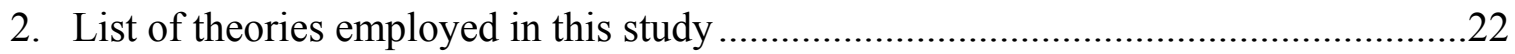

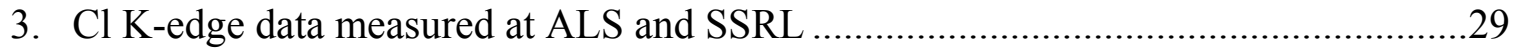

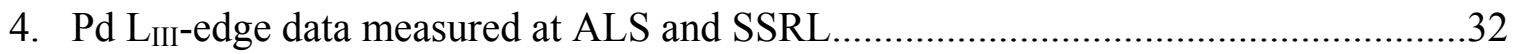

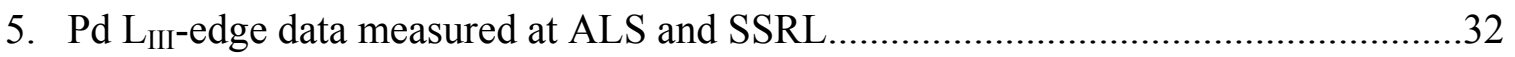

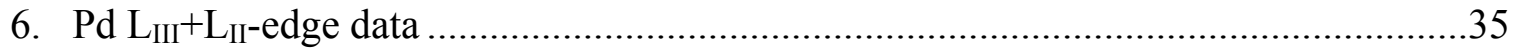

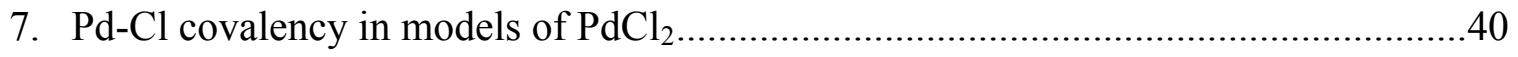

8. Relativistic correction effects on $\mathrm{Pd}-\mathrm{Cl}$ covalency in $\left[\mathrm{PdCl}_{4}\right]^{2-}$ calculations .............41

9. Relativistic correction effects on the geometry of $\left[\mathrm{PdCl}_{4}\right]^{2-}$ and $\left[\mathrm{PtCl}_{4}\right]^{2-} \ldots \ldots \ldots \ldots \ldots . . . . . .41$

10. Calculated atomic orbital character in the LUMOs of $\left[\mathrm{PdCl}_{4}\right]^{2-},\left[\mathrm{PdCl}_{6}\right]^{2-}$, and $\mathrm{PdCl}_{2}$

11. NPA, ESP, and AIM calculated charges on $\mathrm{Pd}$ and $\mathrm{Cl}$ in $\left[\mathrm{PdCl}_{4}\right]^{2-},\left[\mathrm{PdCl}_{6}\right]^{2-}$, and $\mathrm{PdCl}_{2}$.

12. NPA showing the calculated electron configurations of $\left[\mathrm{PdCl}_{4}\right]^{2-},\left[\mathrm{PdCl}_{6}\right]^{2-}$, and $\mathrm{PdCl}_{2}$

13. $\mathrm{PdCl}_{2} \mathrm{~L}_{\mathrm{III}}$ - and $\mathrm{L}_{\mathrm{II}}$-edge data .51

14. $\mathrm{PdCl}_{2} \mathrm{~L}_{\mathrm{III}}+\mathrm{L}_{\mathrm{II}}$-edge data .51

15. $\mathrm{PdCl}_{2} \mathrm{Cl} \mathrm{K-edge} \mathrm{data} \mathrm{.}$

16. Relativistic effects on thermodynamic calculations on $\mathrm{CO}$ insertion to Pt complex 


\section{LIST OF FIGURES}

Figure $\quad$ Page

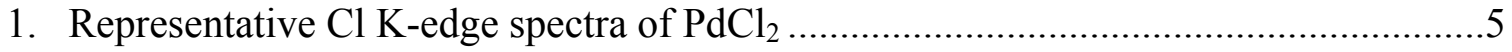

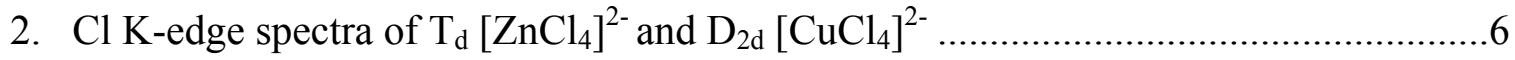

3. Schematic representation of the end station setup at the ALS BL9.3.1 ....................10

4. Schematic representation of the experiment setup at SSRL BL6-2 .........................12

5. Sample background correction and normalization of $\mathrm{Cl} \mathrm{K}$-edge and $\mathrm{Pd} \mathrm{L}$-edges......14

6. Three successive XAS scans of photoreduced sample .........................................15

7. The $\mathrm{Cl} \mathrm{K}$-edge and $\mathrm{Pd} \mathrm{L}$-edge spectra of $\left[\mathrm{PdCl}_{6}\right]^{2-},\left[\mathrm{PdCl}_{4}\right]^{2-}$, and $\mathrm{PdCl}_{2}$ as a function of measurement locations (ALS vrs SSRL)

8. $\mathrm{Cl} \mathrm{K}$-edge spctra of $\left[\mathrm{PdCl}_{4}\right]^{2-}$ measured at SSRL with different beamline setups

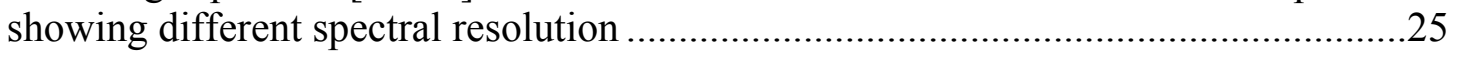

9. Fits of $\mathrm{PdCl}_{2} \mathrm{Pd} \mathrm{L}_{\mathrm{III}}$-pre-edge feature with different Gaussian/Lorentzian ratio line shapes .26

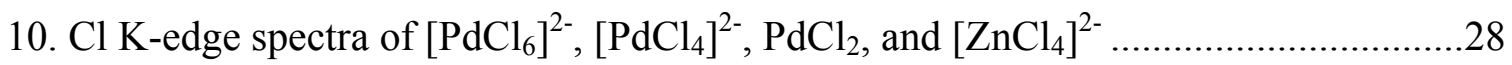

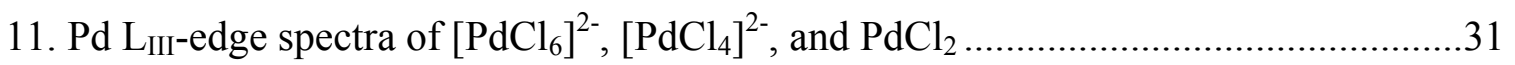

12. $\mathrm{Cl} \mathrm{K-edge} \mathrm{and} \mathrm{second} \mathrm{derivative} \mathrm{of} \mathrm{Pd} \mathrm{L} \mathrm{LIII}_{-}$edge spectra of $\left[\mathrm{PdCl}_{6}\right]^{2-}$ with percentages of $\mathrm{Pd}(\mathrm{II})$ complexes subtracted.

13. $\mathrm{Pd} \mathrm{L}_{\mathrm{III}}+\mathrm{L}_{\mathrm{II}}-$ edge spectra of $\left[\mathrm{PdCl}_{6}\right]^{2-},\left[\mathrm{PdCl}_{4}\right]^{2-}$, and $\mathrm{PdCl}_{2}$. 34

14. $\mathrm{Cl}$ basis set effect on the $\mathrm{Cl} 3 \mathrm{p}$ character in the LUMO of $\left[\mathrm{PdCl}_{4}\right]^{2-}$ 37

15. Pd basis set effect on the $\mathrm{Cl} 3 p$ character in the LUMO of $\left[\mathrm{PdCl}_{4}\right]^{2-}$ 37

16. Calibration of theory to $\left[\mathrm{PdCl}_{4}\right]^{2-}$ experimental XAS Pd-Cl covalency .38

17. Calibration of theory to $\left[\mathrm{PdCl}_{6}\right]^{2-}$ experimental XAS Pd-Cl covalency 39

18. Cluster model for infinite $\mathrm{PdCl}_{2}$ chain 40 


\section{LIST OF FIGURES-CONTINUED}

Figure $\quad$ Page

19. $\mathrm{MO}$ diagram of electron excitation calculations simulating $\mathrm{Cl} \mathrm{K}$-edge

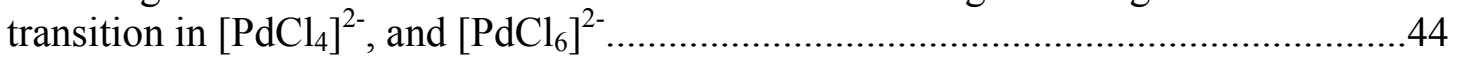

20. MO diagram of electron excitation calculations simulating Pd L-edge transition in $\left[\mathrm{PdCl}_{4}\right]^{2-}$, and $\left[\mathrm{PdCl}_{6}\right]^{2-}$

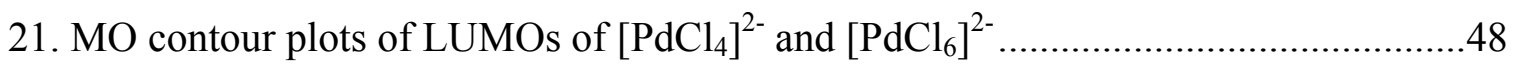

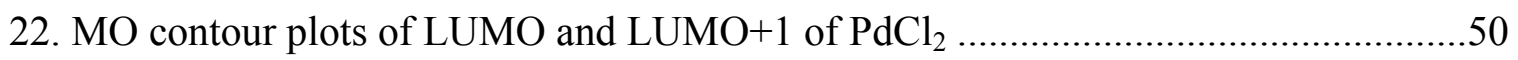

23. Calculated metal-Cl covalencies for Group VIIIB complexes using different

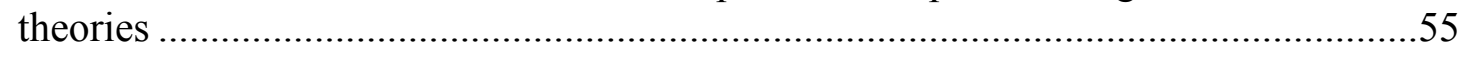

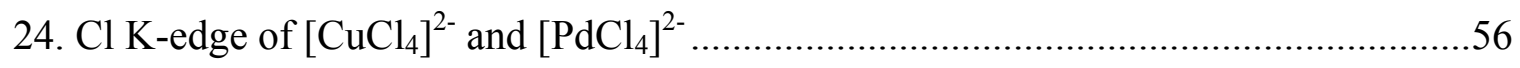

25. Energy positions of $\mathrm{Pd} \mathrm{L}_{\mathrm{III}}$ and $\mathrm{L}_{\mathrm{II}}$-edges and other absorbers with

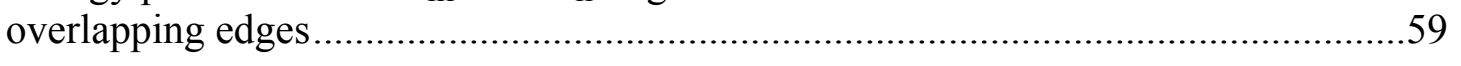

26. XAS transition dipole integrals and rising edge positions for series at the

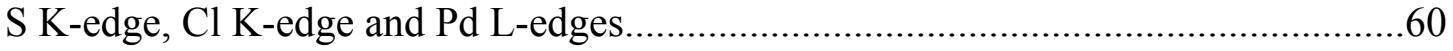

27. $\mathrm{Cl} \mathrm{K}$-edge and $\mathrm{Pd} \mathrm{L}$-edge XAS spectra for $\left(\mathrm{PCy}_{3}\right)_{2} \mathrm{PdCl}_{2}$ without normalization.......63

28. Phosphorus K-edge XAS spectra of $\left(\mathrm{PCy}_{3}\right)_{2} \mathrm{PdCl}_{2}$ without normalization ................64 
viii

\section{LIST OF SCHEMES}

Scheme

Page

1. Mechanisms of palladium catalyzed Heck reaction................................................

2. Arylation reaction of butyl vinyl ether.................................................................2

3. Palladium catalyzed allylic substitution polymerization .........................................2

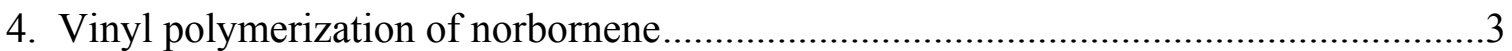

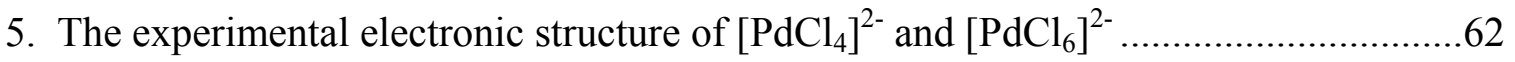




\section{LIST OF EQUATIONS}

Equation

Page

1. $\mathrm{D}_{0}=\frac{1}{3 N} I \alpha^{2}$

2. $\Psi^{*}=c_{1} \varphi(P d 4 d)-\sqrt{\left(1-c_{1}^{2}\right)}\left(c_{2} \varphi(C l 3 p)+c_{3} \varphi(P 3 p)\right)$ 


\begin{abstract}
X-ray Absorption Spectroscopy (XAS) is a synchrotron-based experimental technique that can provide information about geometric and electronic structures of transition metal complexes with unoccupied d orbitals. Combination of metal L-edge and ligand K-edge XAS has the potential to define the experimental ground state electronic structure. We developed a quantitative treatment for Pd L-edge spectroscopy based on the already established $\mathrm{Cl} \mathrm{K}$-edge XAS for a series of chloro palladium complexes, which are precatalysts in numerous organic transformations. We found that $\mathrm{Pd}-\mathrm{Cl}$ bonds are highly covalent $\left(23 \%\right.$ per $\mathrm{Cl}$ in $\left[\mathrm{PdCl}_{4}\right]^{2-}, 34 \%$ per $\mathrm{Cl}$ in $\left[\mathrm{PdCl}_{6}\right]^{2-}$, and $46 \%$ in $\left.\mathrm{PdCl}_{2}\right)$. Dipole integrals for $\mathrm{Pd}(2 \mathrm{p} \rightarrow 4 \mathrm{~d})$ transitions of $42 \mathrm{eV}$ for $\mathrm{Pd}(\mathrm{II})$ and $48 \mathrm{eV}$ for $\mathrm{Pd}(\mathrm{IV}) \mathrm{L}_{\mathrm{III}}{ }^{-}$ edges and $39 \mathrm{eV}$ and $35 \mathrm{eV}$, respectively, at these Pd oxidation states for the $\mathrm{L}_{\mathrm{II}}$-edges were determined. Application of the metal-ligand covalencies and transition dipole integrals by describing the ground state bonding in $\mathrm{PdCl}_{2}$ with bridging $\mathrm{Cl}$ ligands was demonstrated. In future studies, a similar approach will be utilized for palladium phosphine, allyl, olefin complexes in order to define their experimental electronic structure and correlate this with their observed reactivity.
\end{abstract}




\section{INTRODUCTION}

Palladium complexes have long been known to be important in the formation of carbon-carbon bonds. The palladium catalyzed Heck reaction, which is widely used in the production of substituted olefins, dienes and other unsaturated compounds ${ }^{1,2}$ is an example of this importance. The general mechanism for the Heck reaction is presented in Scheme 1 and shows the initial pre activation of the $\mathrm{Pd}(\mathrm{II})$ species by reduction and multiple ligand exchange equilibria. This species subsequently undergoes oxidative addition with an arylhalide followed by migratory insertion. Reductive elimination is the last step before the recycling of the Pd catalyst. Since Mizoroki ${ }^{3}$ and Heck's ${ }^{4}$ independent discoveries of the arylation and alkylation of olefins in the early 1970's that was subsequently developed by Heck into a general method for organic chemistry, interest in this general series of reactions has only increased.

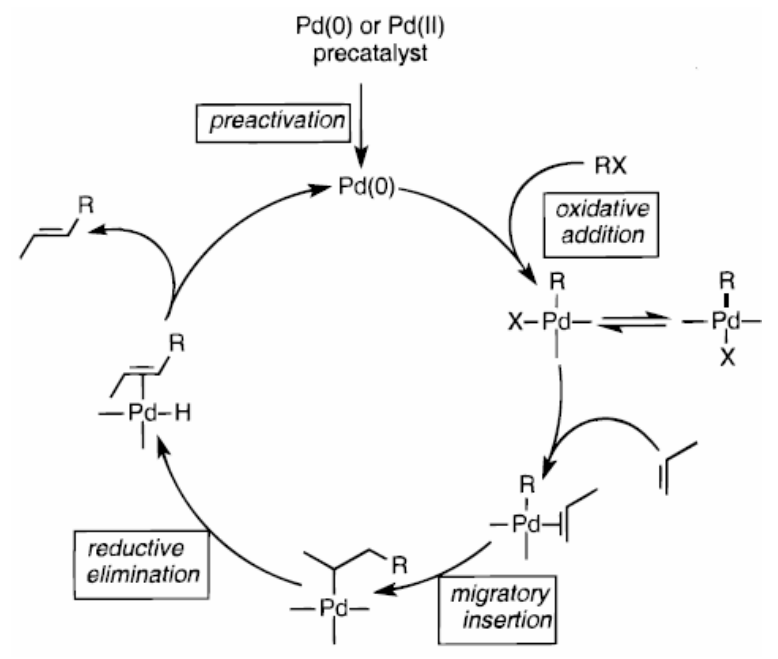

Scheme 1. General scheme for Pd catalyzed Heck reaction. 
By varying the structure of the ligand (tuning the electronic and geometric structures) in the activated Pd catalyst, such properties as selectivity and reactivity can be adjusted. Recently, ligand tuning of palladium based catalysts has shown to be effective for controlling the regiochemistry of olefins in the intramolecular Heck reactions ${ }^{5,6}$. Changing the functional group (L) attached to the 1,2-bis(diphenylphosphino) ligand in Scheme 2 from ethane or propane to methane, ferrocene, butane, or binaphthyl will change the $\alpha / \beta$ selectivity in the product from $>99 / 1$ to about $50 / 50$ in the Pd catalyzed arylation of butyl vinyl ether ${ }^{6}$.

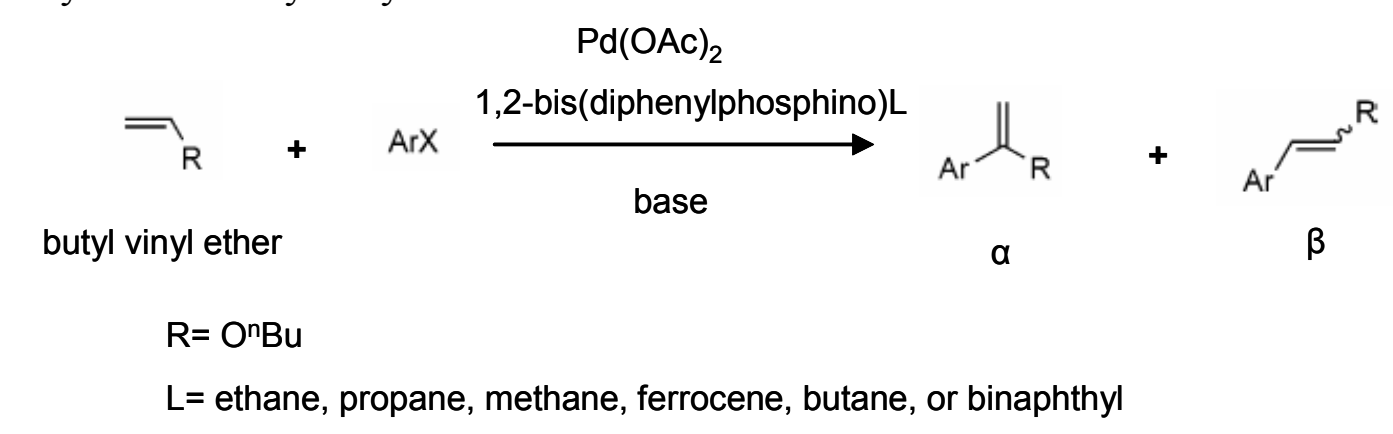

Scheme 2. General scheme for the arylation of butyl vinyl ether.

Further, tuning of the diphenylphosphino type ligand electronic structure in the $\operatorname{Pd}(0)$ catalyzed allylic substitution polymerization reactions in Scheme 3 has been shown to have an effect on both the reaction pathway (cascade allylation or dissociation) and the catalytic rate ${ }^{7}$.

$$
\begin{aligned}
& \text { AcO } ح \text { OAc }+\mathrm{CH}_{3} \mathrm{CHE}_{2} \frac{\mathrm{Pd}(0)+\mathrm{L}}{\mathrm{Ch}_{2} \mathrm{Cl}_{2}, 25^{\circ} \mathrm{C}} \longrightarrow \underbrace{\mathrm{EE}}_{\text {allylation }}+\underbrace{\mathrm{AcO}}_{\text {dissociation }} \\
& E=-\mathrm{CO}_{2} \mathrm{Et}
\end{aligned}
$$

Scheme 3. General scheme for an allylic substitution polymerization. 
Industrial interest in the polymerization of olefins, particularly the vinyl polymerization of norbornene (Scheme 4), has been sparked by the polymers unique properties of extended thermal stability, high optical transparency, low moisture absorption and low birefringence ${ }^{8-10}$. There is still a need for the development of new catalysts that aren't poisoned by the functional groups on the norbornene while maintaining high catalytic activity. Pd based catalysts are of particular interest because they have been shown to have greater functional group tolerance than their Ni analogues. However, slower Pd reaction rates necessitates further development in this area as well ${ }^{10,11}$.

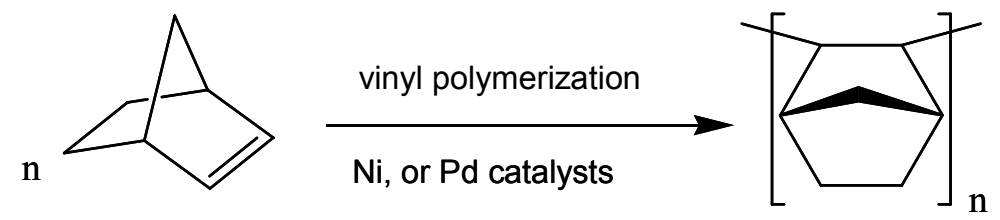

Scheme 4. Vinyl polymerization of norbornene.

An allyl ligand, a neutral two-electron-donor phosphine ligand, and a weakly coordinating counter ion coordinated to $\mathrm{Pd}(\mathrm{II})$ shows high acitivity and selectivity by producing $>1$ ton per hour of 5-butylnorbornene and 5-tirethoxysilylnorbornoene copolymer $^{10}$. Similar results were found for other norbornene polymerization reactions as catalysts of the type $\left[\mathrm{PdCl}_{2}\left\{\mathrm{Ph}_{2}\left(\mathrm{CH}_{2}\right)_{\mathrm{n}} \mathrm{PPh}_{2}\right\}\right]$ have been shown to give up to $10^{7} \mathrm{~g}$ norbornene polymer per mol Pd catalyst ${ }^{12}$. Ligand tuning is a promising avenue for further development of these Pd catalysts. Our aim is to develop an experimental technique for investigating the electronic structure of Pd compounds. The general strategy for accomplishing this can be broken into three steps. First, palladium chlorine 
bonding interactions are studied and quantifed using X-ray Absorption Spectroscopy (XAS) and these measurements are used to calibrate electronic structure calculations. Secondly, XAS is performed on $\mathrm{PdCl}_{x} \mathrm{P}_{\mathrm{x}}$ complexes to investigate the $\mathrm{Pd}-\mathrm{P}$ and $\mathrm{Pd}-\mathrm{Cl}$ bonding interactions. Thirdly, these experimentally determined bonding interactions are utilized in calibrated potential energy surface calculations. The first step in this process has been accomplished and is presented in this study.

XAS can give both electronic and geometric structural information about a transition metal complex. The extended X-ray absorption fine structure (EXAFS) region in Figure 1 shows the spectrum that originates from the excited electrons leaving the core orbital scattering from neighboring atoms. The peaks in this energy range are from constructive interference and the wells are due to destructive interference of the excited electron's wave and back scattered wave. A Fourier transform and subsequent fitting of this region yields a high resolution radial distribution of the atoms within the studied complex. This can be useful for catalytic intermediates or other metal complexes where the geometry is unknown. Because the crystal structures of the complexes measured in this study are known, the region of interest is the X-ray Absorption Near Edge Structure (XANES) in Figure 1 where the pre-edge and rising edge regions are located. The position of the rising edge jump for XAS is determined by the oxidation state of the atom as the effective nuclear charge affects the energy of the core orbitals. XAS utilizes the dipole allowed $\mathrm{s} \rightarrow \mathrm{p}$ (in the K-edge) or $\mathrm{p} \rightarrow \mathrm{d}$ (in the L-edges) transitions. The intense features in the L-edges are split due to the two spin orbit coupled states $2 \mathrm{p}_{3 / 2}$ and $2 \mathrm{p}_{1 / 2}$ corresponding to the $\mathrm{L}_{\mathrm{III}}$ and $\mathrm{L}_{\mathrm{II}}$-edges, respectively $\left(\mathrm{p}_{3 / 2}: 1+\mathrm{s}=3 / 2\right.$ and $\left.\mathrm{p}_{1 / 2}: 1-\mathrm{s}=1 / 2\right)$. The 
position of the pre-edge feature of a metal complex is a function of both the oxidation state and d-manifold shift of the metal center. Furthermore, the intensity of the pre-edge feature is a measure of the metal ligand covalency so the experimental electronic structure can be obtained.

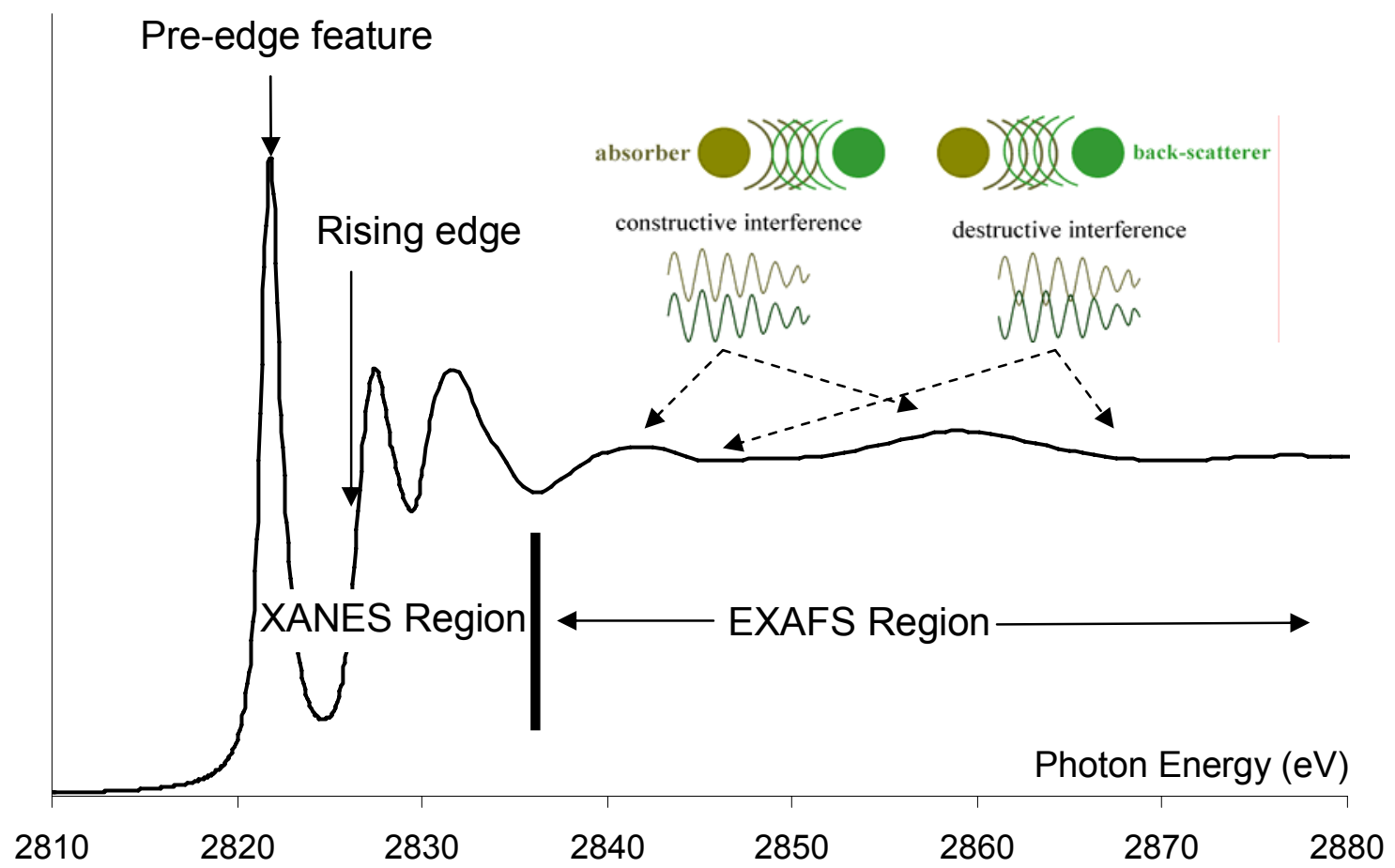

Figure 1. $\mathrm{PdCl}_{2} \mathrm{Cl} \mathrm{K}$-edge spectra showing the different regions and features.

Quantitation of metal-ligand covalency utilizing chlorine K-edge XAS was developed in the early 1990's by the Solomon, Hodgson and Hedman groups at Stanford ${ }^{13-15}$. Figure 2 shows a comparison the $\mathrm{Cl} \mathrm{K-edge} \mathrm{NEXAS} \mathrm{region} \mathrm{of} \mathrm{T}_{\mathrm{d}}\left[\mathrm{ZnCl}_{4}\right]^{2-}$ and $\mathrm{D}_{2 \mathrm{~d}}\left[\mathrm{CuCl}_{4}\right]^{2-}$. No pre-edge feature is observed in the closed shell $\mathrm{d}^{10} \mathrm{Zn}(\mathrm{II})$ metal ion complex $\left[\mathrm{ZnCl}_{4}\right]^{2-}$ because the lowest energy transition available for a $\mathrm{Cl} 1 \mathrm{~s}$ electron is 


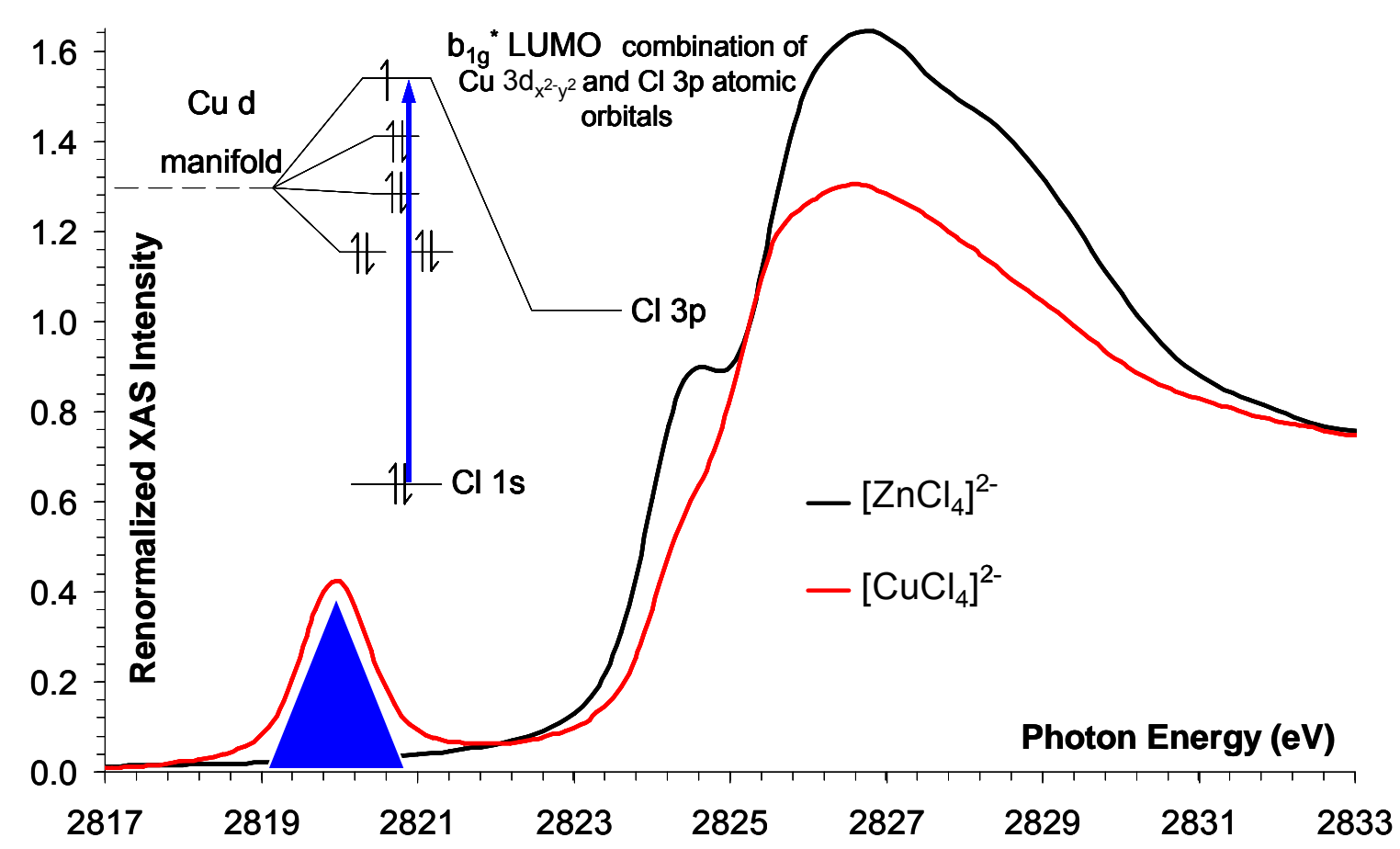

Figure 2. $\mathrm{Cl} \mathrm{K}$-edge spectra of $\mathrm{T}_{\mathrm{d}}\left[\mathrm{ZnCl}_{4}\right]^{2-}$ and $\mathrm{D}_{2 \mathrm{~d}}\left[\mathrm{CuCl}_{4}\right]^{2-}$ showing the difference in the pre-edge region. The inset is a simplified MO diagram showing the origin of the $\left[\mathrm{CuCl}_{4}\right]^{2-}$ pre-edge feature.

into the $\mathrm{Cl} 4 \mathrm{~s}$ or $4 \mathrm{p}$ orbitals. The intense rising edge feature between $2823-2827 \mathrm{eV}$ corresponds to $\mathrm{Cl} 1 \mathrm{~s} \rightarrow 4 \mathrm{p}$ excitation. In contrast, the $\mathrm{Cu}(\mathrm{II})$ in $\left[\mathrm{CuCl}_{4}\right]^{2-}$ is an open shell $d^{9}$ metal ion with an electron hole in the antibonding $\mathrm{Cu} 3 \mathrm{~d}_{x^{2}-y^{2}}$ as shown in the inset in Figure 2. The $3 \mathrm{~d}_{x^{2}-y^{2}}$ orbital must have a significant amount of $\mathrm{Cl} 3 \mathrm{p}$ character due to the localized nature of the $\mathrm{Cl} \mathrm{K}$-edge transition and the presence of a pre-edge feature in the $\left[\mathrm{CuCl}_{4}\right]^{2-}$ spectra. The area under the pre-edge feature $\left(\mathrm{D}_{0}(\mathrm{eV})=2\right.$ half height line width

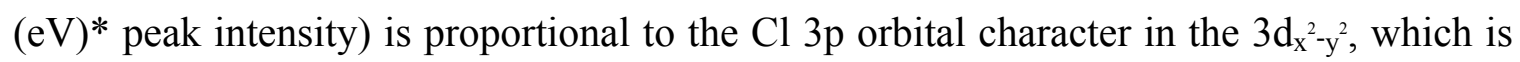
the measure of metal-ligand covalency $\left(\alpha^{2}\right)$. $\mathrm{Cu}-\mathrm{Cl}$ covalency for $\mathrm{D}_{4 \mathrm{~h}}\left[\mathrm{CuCl}_{4}\right]^{2-}$ is known to be $9.75 \%$ per $\mathrm{Cl}$ from EPR data ${ }^{16}$ and was used to determine that the transition 
dipole integral $(\mathrm{I}(\mathrm{eV}))$ for the $\mathrm{Cl} \mathrm{K}$-edge in Equation 1 is $21.04 \mathrm{eV}^{13}$, where $N$ is the number of metal d-manifold holes.

Equation 1. $\quad \mathrm{D}_{0}=\frac{1}{3 N} I \alpha^{2}$

Using the $\mathrm{Cl} \mathrm{K}$-edge as a reference, the quantitation methods for metal ligand bonding can be extended to study the palladium $\mathrm{L}_{\mathrm{III}}$ and $\mathrm{L}_{\mathrm{II}}$-edges, which in turn can be utilized to analyze the posphorus K-edge. For example, for a simple $\mathrm{PdCl}_{\mathrm{x}}$ compound, the chlorine $3 p$ orbital contribution to the LUMO can be experimentally determined from XAS and Molecular Orbital (MO) theory predicts that the remainder of the palladiumchlorine bonding interaction is comprised primarily of $\mathrm{Pd} 4 \mathrm{~d}$-orbital character with minor contributions from $\mathrm{Cl} 3 \mathrm{~s}$ and $3 \mathrm{~d}$ and $\mathrm{Pd} 5 \mathrm{~s}$ and $5 \mathrm{p}$ orbitals. Equation 2 shows the formula for the ground state electronic structure of a $\mathrm{PdCl}_{\mathrm{x}} \mathrm{P}_{\mathrm{y}}$ complex with the assumption that the $\mathrm{Pd} 5 \mathrm{~s}$ and $5 \mathrm{p}$ and $\mathrm{Cl}$ and $\mathrm{P} 3 \mathrm{~s}$ and $3 \mathrm{~d}$ contributions are negligible (less than $3 \%$ ).

Equation 2. $\left.\quad \Psi^{*}=c_{1} \varphi(P d 4 d)-\sqrt{\left(1-c_{1}{ }^{2}\right.}\right)\left(c_{2} \varphi(C l 3 p)+c_{3} \varphi(P 3 p)\right)$

The remainder of the bonding interaction not present in the $\mathrm{Cl} \mathrm{K}$-edge for $\mathrm{PdCl}_{\mathrm{x}}$ is $\mathrm{Pd} 4 \mathrm{~d}$ orbital character which can be obtained from the $\mathrm{Pd} \mathrm{L}_{\mathrm{III}}$ and $\mathrm{L}_{\mathrm{II}}$-pre-edge features and used to develop the $\mathrm{Pd}(\mathrm{II})$ and $\mathrm{Pd}(\mathrm{IV})$ transition dipole integrals. It then becomes possible to determine the phosphorus $3 \mathrm{p}$ orbital character in the palladium-phosphorus bonding interaction in a $\mathrm{PdCl}_{\mathrm{x}} \mathrm{P}_{\mathrm{y}}$ complex by measuring the $\mathrm{Cl} \mathrm{K}$-edge and the $\mathrm{Pd} \mathrm{L}_{\mathrm{III}}$-and $\mathrm{L}_{\mathrm{II}}$-edges. In this manner, the most important metal-ligand interactions in Pd chemistry can be experimentally probed.

In the 1980 's the chlorine $\mathrm{K}$-edges and palladium $\mathrm{L}_{\mathrm{III}}$-edges of $\left[\mathrm{PdCl}_{4}\right]^{2-}, \mathrm{PdCl}_{2}$ and $\left[\mathrm{PdCl}_{6}\right]^{2-}$ were measured ${ }^{17-21}$. However, only the peak positions were identified and 
the covalency was not quantified. In this study the XAS technique was applied in the measurement and interpretation of the pre-edge intensities and energies of the $\mathrm{Pd} \mathrm{L}_{\mathrm{III}}$ - and $\mathrm{L}_{\mathrm{II}}$-edges. This was done at the most common palladium oxidation states of 0 , II, and IV using the series $\mathrm{Pd}(0)$ powder, $\left[\mathrm{PdCl}_{4}\right]^{2-}$ and $\left[\mathrm{PdCl}_{6}\right]^{2-}$. Ligand-metal covalency for each $\mathrm{Pd}-\mathrm{Cl}$ bond were determined by measuring the $\mathrm{Cl} \mathrm{K}$-edge pre-edge intensities. The remainder of the bonding interaction not accounted for in the $\mathrm{Cl} \mathrm{K}$-edge was then used to develop the transition dipole integrals for the $\mathrm{Pd}_{\mathrm{LII}}$ and $\mathrm{L}_{\mathrm{II}}$-edges so that quantization of Pd 4d orbital covalency by XAS in a Pd-ligand bond could be performed. Electronic structure calculations on the Pd series were correlated with experimental XAS data to aid the spectral assignments and to find a calibrated level of theory for accurate computations.

An application of this method is also presented in this study. The new Pd(II) Ledge dipole integrals are applied to the $\mathrm{PdCl}_{2}$ spectra to quantify the $\mathrm{Pd} 4 \mathrm{~d}$ orbital covalency. The remainder of the bond is $\mathrm{Cl} 3 \mathrm{p}$ character and was used to develop a new $\mathrm{Cl}$ K-edge transition dipole integral for the bridging $\mathrm{Cl}^{\prime}$ s of $\mathrm{PdCl}_{2}$. 


\section{MATERIALS AND METHODS}

\section{$\underline{\text { Sample Preparation }}$}

$\mathrm{K}_{2} \mathrm{PdCl}_{6}, \mathrm{~K}_{2} \mathrm{PdCl}_{4}, \mathrm{PdCl}_{2}, \mathrm{Pd}(0), \mathrm{CsCl}$ and $\mathrm{CuCl}_{2} 2 \mathrm{H}_{2} \mathrm{O}$ were purchased from STREM Chemical and were of the purity $>99 \%,>99 \%$, and $>99.9 \%,>99.99 \%$, and $>99.999 \%$ respectively. $\mathrm{D}_{2 \mathrm{~d}} \mathrm{Cs}_{2} \mathrm{CuCl}_{4}$ was prepared as described in the literature ${ }^{22}$ and involved dissolving stoichiometric amounts of $\mathrm{CsCl}$ and $\mathrm{CuCl}_{2} \cdot 2 \mathrm{H}_{2} \mathrm{O}$ in methanol and evaporating the solvent to obtain a solid sample.

Samples were ground into a fine powder that was spread on the sticky side of Kapton tape purchesed from SHERCON. This procedure has been shown to minimize self absorption ${ }^{15}$. The tape with the powder on it was mounted across the window of an aluminum plate and placed in the sample chamber for measurement.

\section{$\underline{\text { X-ray Absorption Measurements }}$}

Palladium $\mathrm{L}_{\mathrm{III}}$ and $\mathrm{L}_{\mathrm{II}}$-edge, and chlorine $\mathrm{K}$-edge X-ray absorption spectra of $\mathrm{K}_{2} \mathrm{PdCl}_{6}, \mathrm{~K}_{2} \mathrm{PdCl}_{4}, \mathrm{PdCl}_{2}$ were measured at Advanced Light Source (ALS) on beam line 9.3.1 and at Stanford Synchrotron Radiation Laboratory (SSRL) on beam line 6.2. The $\operatorname{Pd}(0) \mathrm{L}_{\mathrm{III}}$-edge and the $\mathrm{Cs}_{2} \mathrm{CuCl}_{4} \mathrm{Cl} \mathrm{K}$-edge were measured at ALS.

Fluorescence data was collected at ALS in an ultra high vacuum $\left(10^{-7}\right.$ torr) with a Si-photodiode (Hamamatsu model S3584) aligned parallel with the sample cell. The incident beam was approximately $45^{\circ}$ relative to the sample and Beamline conditions, such as sample cell position, detector position, beam focus, and beam size, were 


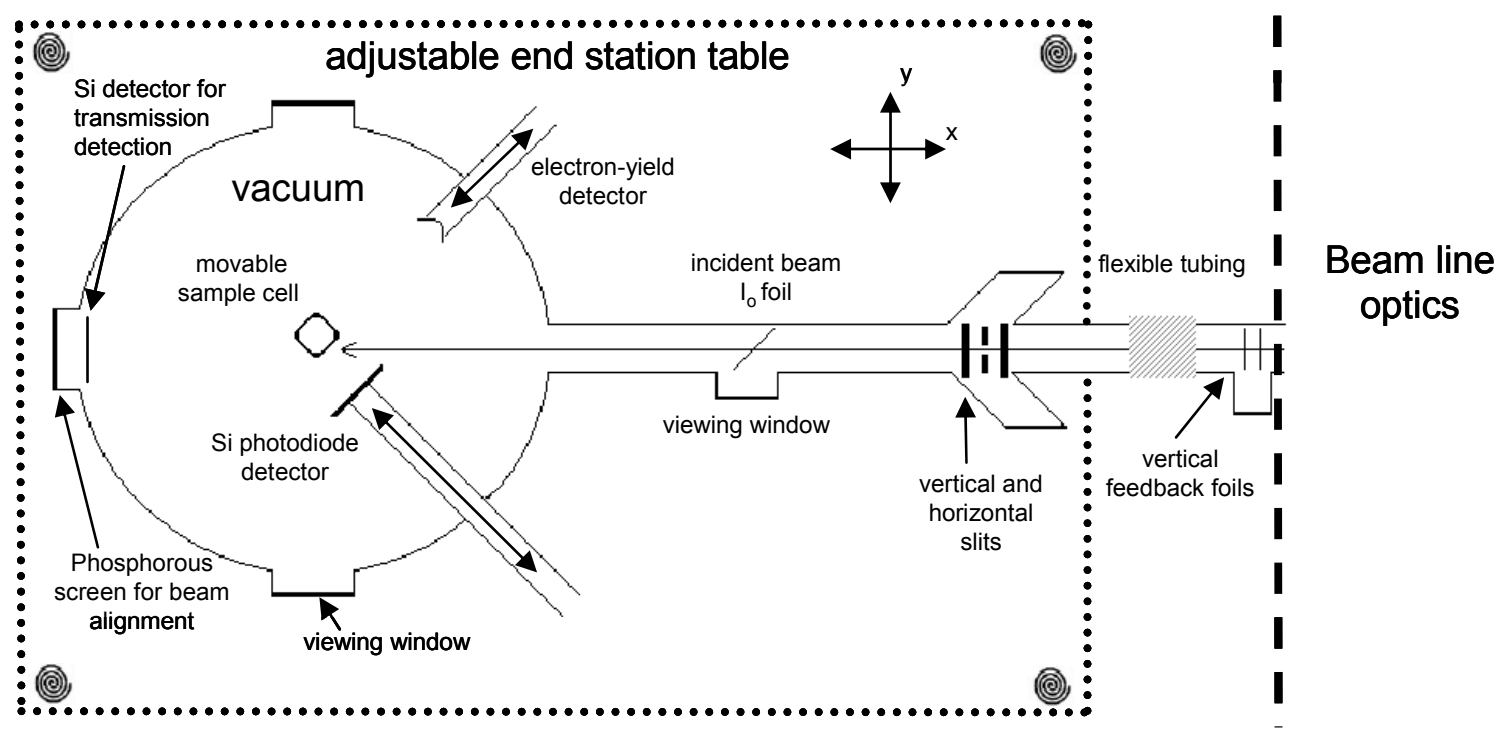

Figure 3. Schematic representation of the end station setup at the ALS BL9.3.1

optimized at $3000 \mathrm{eV}$ and $3300 \mathrm{eV}$ for the $\mathrm{Cl} \mathrm{K}$-edge and Pd L-edges, respectively, in order to maximize the signal to noise ratio. A schematic representation of the end station is shown in Figure 3. Optimization procedure at this beamline was performed in four steps. First, the beam was focused and upstream jaws were adjusted to obtain maximum flux with minimum beam halo. Clipping the top and bottom portion of the beam was the best way to achieve this. The residual beam halo is due to the irregularities in the focusing mirror because clipping the beam before the focusing cannot completely eliminate the halo. Secondly, the beam was centered on the sample and vertical feedback foils were adjusted to the proper positions. At the time of the measurements, horizontal feedback was not yet implemented and the foils were removed from the beam to maximize flux. Thirdly the sample and detector positions were optimized to achieve the maximum signal. The detector was positioned so that it was nearly clipping the beam. The $\mathrm{x}$ axis was then adjusted until maximum detector signal was obtained followed by 
slight rotation of the sample cell to further increase the signal. A small amount of horizontal beam motion occurs throughout the scans, so the detector was backed away from the sample by $2 \mathrm{~mm}$. Fourthly, the gains on the detector and $\mathrm{I}_{0}$ foil amplifiers were adjusted to a level where the signal was in the linear range of the detector without an overload during the scan. This usually occurred at $200 \mathrm{nA}$ for the Pd L-edges and $20 \mathrm{nA}$ for the $\mathrm{Cl} \mathrm{K}$-edges. A small amount of the fluorescence signal was detected on the back of the $\mathrm{I}_{0}$ foil. Therefore, the $\mathrm{I}_{0}$ foil was rotated 45 degrees so that it presented less area for detection of the fluorescence signal. Resting and dwell times were set to $400 \mathrm{~ms}$ and 1s respectively while the energy was scanned in $0.1 \mathrm{eV}$ step sizes in the rising edge region and between 0.5 and $2.0 \mathrm{eV}$ step sizes outside the region. $\mathrm{A} \mathrm{Si}\left(\begin{array}{lll}1 & 1 & 1\end{array}\right)$ double crystal monochromator was used to scan through the energy range. When the $\mathrm{Cl} \mathrm{K}$-edges of $\mathrm{K}_{2} \mathrm{PdCl}_{6}, \mathrm{~K}_{2} \mathrm{PdCl}_{4}$, and $\mathrm{PdCl}_{2}$ were collected at room temperature, photoreduction was observed in the $\mathrm{K}_{2} \mathrm{PdCl}_{6}$ and $\mathrm{PdCl}_{2}$ spectra. Photoreduction is the most common radiation damage in XAS and is caused by free electrons (resulting from ionizing excitation) in the sample reducing the metal center in the complex being measured. In order to prevent radiation damage, the spectra of the $\mathrm{Cl} \mathrm{K}$-edge and $\mathrm{Pd} \mathrm{L}_{\mathrm{III}}$ and $\mathrm{L}_{\mathrm{II}}-$ edges were subsequently collected while the sample rod was cooled with liquid nitrogen. An average of 2 or 3 scans was analyzed for samples that were not photoreduced. The samples that showed radiation damage are treated separately in the data workup. 


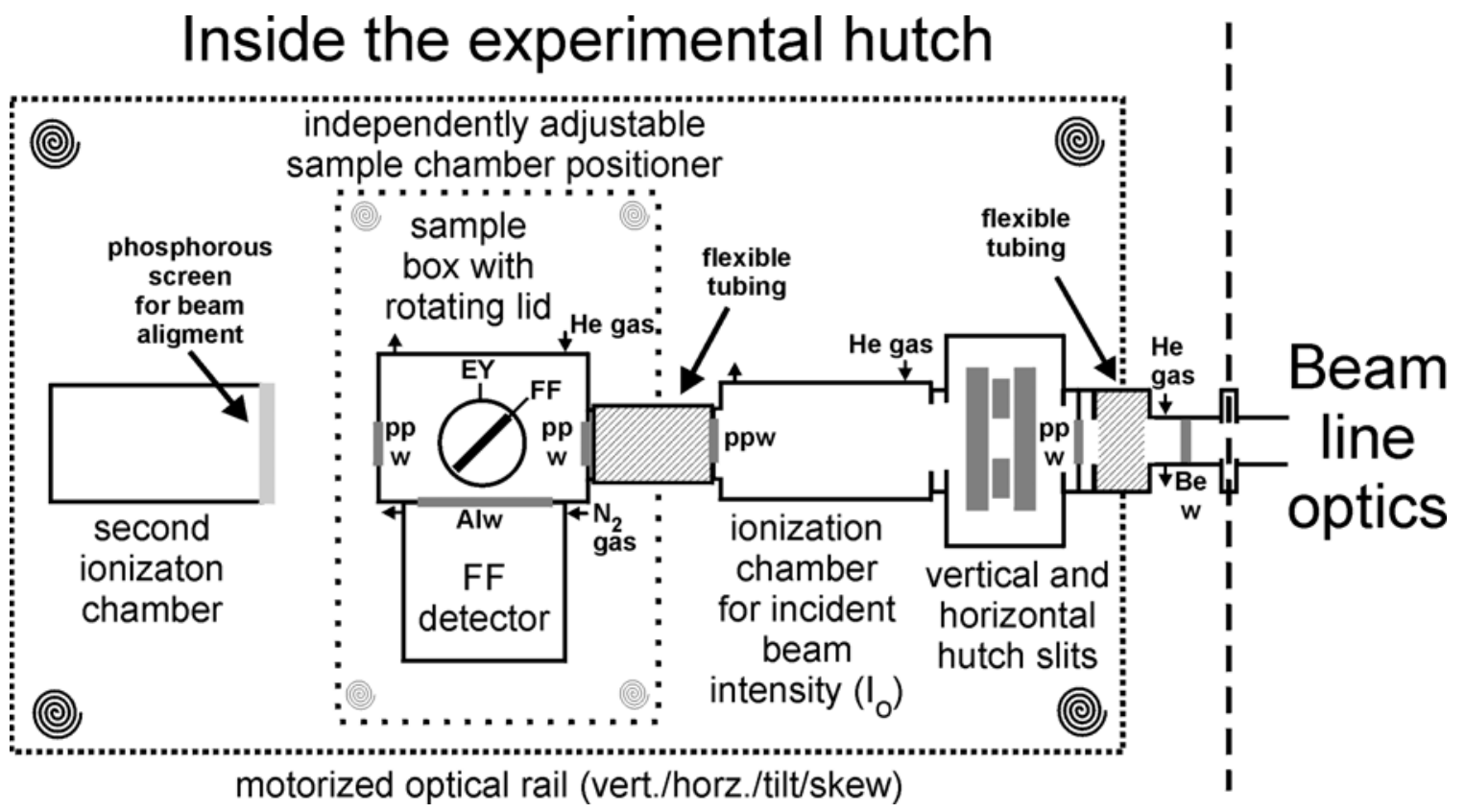

Figure 4. Schematic representation of the experiment setup at SSRL BL6-2 (ppw: polypropylene window, Alw: aluminized Mylar window, Bew: beryllium window, EY: electron-yield, F: fluorescence). Figure was adapted from reference 80.

SSRL XAS fluorescence spectra were collected at room temperature in helium atmosphere with a $\mathrm{N}_{2}$-purged Lytle detector without using a filter or Soller slits. A 127 $\mu \mathrm{m}$ Be window separated the vacuum in the ring from the experimental end station while a He gas path protected this window from oxidation. The gas path was sealed on the downstream side by a $6.35 \mu \mathrm{m}$ polypropylene window. He gas was again used as atmosphere as the beam passed through vertical and horizontal slits and an ionization chamber to detect the $\mathrm{I}_{0}$ signal. Another $6.35 \mu \mathrm{m}$ polypropylene window was used to separate the sample chamber from the ionization chamber. The sample was rotated $45^{\circ}$ relative to the incident beam and the detector was parallel to the sample as shown in Figure 4. The X-ray beam and sample chamber positions were optimized at $3150 \mathrm{eV}$ which is the end of the $\mathrm{Cl} \mathrm{K}$-edge scan. Because the beam was already focused and the 
detector and sample were stationary relative to each other, optimization involved centering the beam on the sample and adjusting the end station slits so that the $\mathrm{I}_{0}$ and FF detectors were not overloaded by the signal. The beam was first centered in the beampipe, then in the $\mathrm{I}_{0}$ chamber, by moving the end station table. Lastly, the beam was centered on the sample by moving the sample chamber. The slits were closed to $2 \mathrm{~mm}$ vertical and $7 \mathrm{~mm}$ horizontal producing a rectangular shaped beam in the end station. A $\operatorname{Si}\left(\begin{array}{lll}1 & 1 & 1\end{array}\right)$ double crystal monochromator was utilized to scan the rising edge region at 0.1 $\mathrm{eV}$ steps and $0.5-2.0 \mathrm{eV}$ steps outside the region with a dwell time of $1 \mathrm{~s}$. Minimal radiation damage ( $<1 \%$ change in individual peak intensity) occurred for $\mathrm{K}_{2} \mathrm{PdCl}_{6}$ and $\mathrm{PdCl}_{2}$ while none was observed for $\mathrm{K}_{2} \mathrm{PdCl}_{4}$. For all spectra radiation damage was determined to be negligible and an average of the 2 or 3 scans was analyzed.

\section{Data Workup}

The energy of the $\mathrm{Cl} \mathrm{K}$-edges and $\mathrm{Pd} \mathrm{L}_{\mathrm{III}}$ and $\mathrm{L}_{\mathrm{II}}$-edges were calibrated to the first absorption maximum of the $\mathrm{Cl} \mathrm{K}$-edge spectrum of $\mathrm{D}_{2 \mathrm{~d}} \mathrm{Cs}_{2} \mathrm{CuCl}_{4}$ which was assigned to $2820.20 \mathrm{eV}^{14}$. Figure 5a illustrates how a smooth background was removed from all spectra by fitting a second order polynomial to the pre-edge region and subtracting this from the entire spectra. Data was then normalized to one absorber by fitting a polynomial spline to the region above the edge and normalizing the edge-jump to one at $2840 \mathrm{eV}$ for the chlorine $\mathrm{K}$-edges as shown in Figure 5b. The palladium $\mathrm{L}_{\mathrm{III}}$-edges and $\mathrm{L}_{\mathrm{II}}$-edges were normalized to one at $3195 \mathrm{eV}$ and $3345 \mathrm{eV}$ respectively. For the $\mathrm{Pd} \mathrm{L}_{\mathrm{III}}$ and $\mathrm{L}_{\mathrm{II}}$-edges together, a smooth background was fit to the $\mathrm{L}_{\mathrm{III}}$-pre-edge region and 

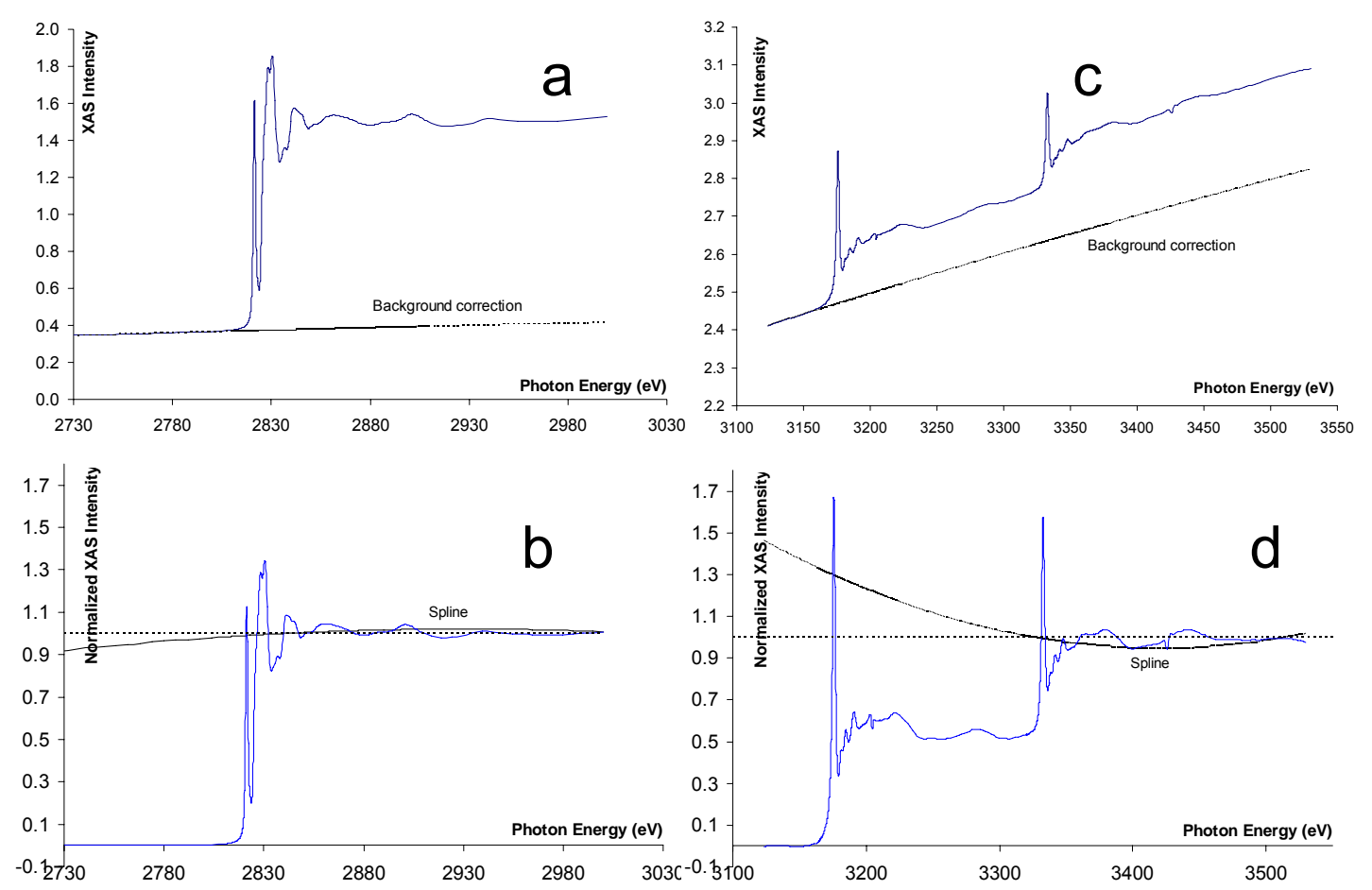

Figure 5. Sample background correction and normalization of $\mathrm{Cl}$ K-edge (a,b), and $\mathrm{Pd}$ L-edges $(\mathrm{c}, \mathrm{d})$.

subtracted from the entire spectra (Figure 5c). This corrected spectra was then normalized to one at $3345 \mathrm{eV}$ (Figure 5d). The Appendix contains a detailed description of the data workup of each spectra used in the analysis.

Photoreduction was observed in the $\mathrm{Cl} \mathrm{K}$-edges of $\mathrm{PdCl}_{2}$ and $\left[\mathrm{PdCl}_{6}\right]^{2-}$ measured at ALS at room temperature. The isobestic points visible in Figure 6 are evidence of this phenomena. A logarithmic extrapolation (also seen in Figure 6) of the first three spectra collected for each compound was performed to yield an extrapolated spectra to zero radiation exposure. This extrapolation was performed by finding the rate of change for each energy position measured within a spectra. The natural logarithmic function was used to extrapolate from the first scanned spectra to find the XAS intensity at each energy at zero radiation exposure. The data workup procedure discussed above was then 
performed on the extrapolated spectra. Less than $1 \%$ variation in peak intensity was observed if a linear extrapolation of the photoreduced data was used instead of a logarithmic extrapolation.

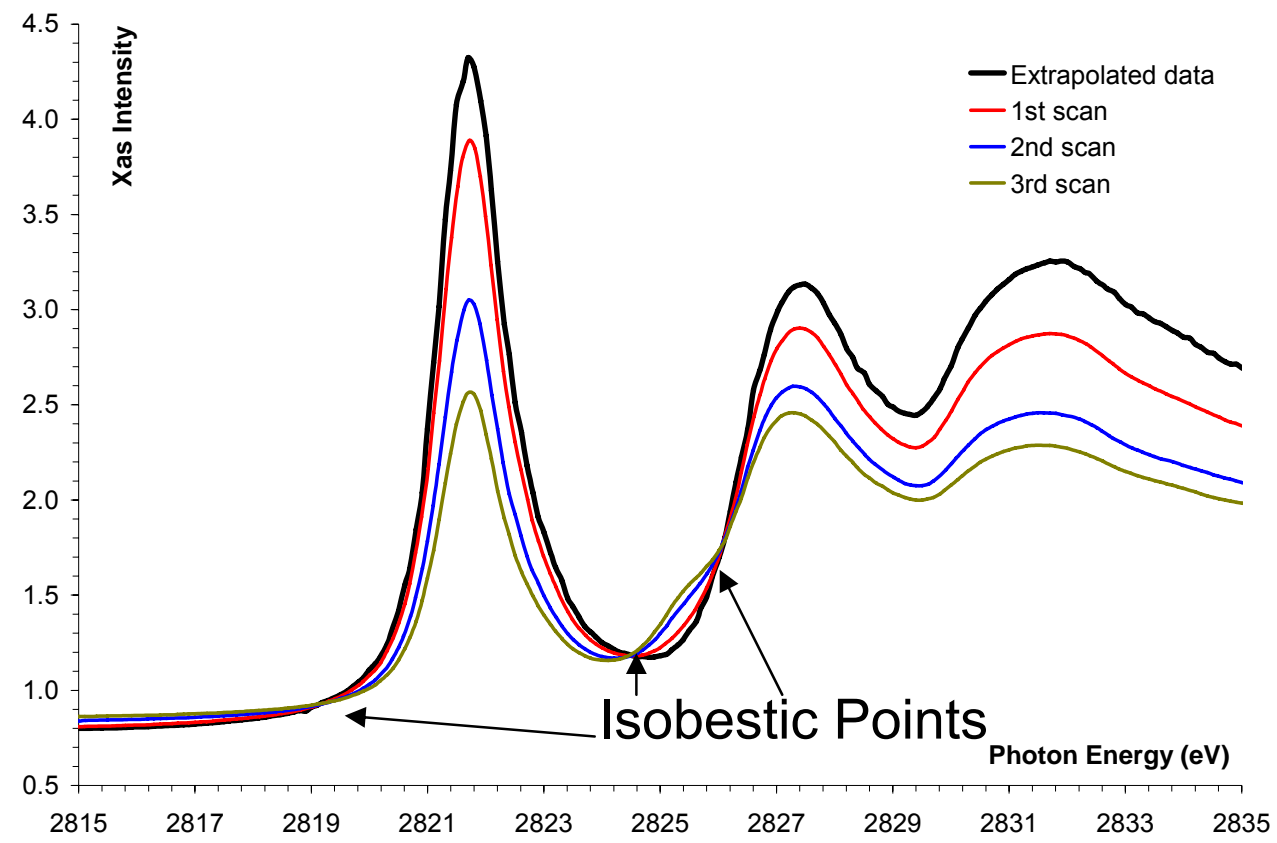

Figure 6. Three consecutive scans (red, blue, green) of photoreduced XAS spectra with extrapolated to zero radiation exposure (black) showing isosbestic points.

Peak positions were obtained from the minima in the second derivative of the spectra and the inflection point of the rising edge or the maxima of the first derivative was used to determine the rising edge positions.

\section{Fitting}

\section{Chlorine K-edge}

The normalized $\mathrm{Cl} \mathrm{K}$-edge spectra of $\mathrm{Cs}_{2} \mathrm{ZnCl}_{4}$ was used for a rising edge correction. It was shifted to the rising edge of each normalized $\mathrm{PdCl}$ spectra and 
subtracted from the spectra. This yielded only the pre-edge features which arise from the $\mathrm{Cl} 3 \mathrm{p}$ covalent bonding interaction. The pre-edge features were then fit with pseudoVoigt lines (1:1 sum of Gaussian and Lorentzian line shapes) over the energy range 2815 $\mathrm{eV}$ to $2827 \mathrm{eV}$. The minimum number of peaks were used to fit the data and this number was determined from the minima seen in the second derivative. All pre-edge peaks in a spectra were fit with linked half-height line widths (HHLW) because these peaks arise from the same state (the $\mathrm{Cl} 1 \mathrm{~s}$ orbital electron transitioning into the $\mathrm{Cl} 3 \mathrm{p}$ based orbital) and should have the same core-hole lifetime broadening.

\section{$\underline{\text { Palladium L-edges }}$}

The $\operatorname{Pd}(0)$ L-edge spectra does not have any pre-edge features due to it's $\mathrm{d}^{10}$ electron configuration and simulates the environment of a $\mathrm{Pd}$ without any covalent bonding interaction. Similarly to the $\mathrm{Cl}$ K-edge, the normalized $\operatorname{Pd}(0) \mathrm{L}_{\mathrm{III}}$-edge spectra was shifted and subtracted from each renormalized $\mathrm{Pd} \mathrm{L}_{\mathrm{III}}$-edge spectra to leave only the pre-edge features for fitting. Because the $\mathrm{Pd} \mathrm{L}_{\mathrm{III}}$ and $\mathrm{L}_{\mathrm{II}}$-edges for each compound measured look nearly identical when shifted by $150 \mathrm{eV}$, the $\operatorname{Pd}(0) \mathrm{L}_{\mathrm{III}}$-edge was also shifted, scaled and subtracted from the normalized $\mathrm{Pd} \mathrm{L}_{\mathrm{II}}$-edge spectra for fitting. The remaining $\mathrm{Pd} \mathrm{L}_{\mathrm{III}}$ and $\mathrm{L}_{\mathrm{II}}$-pre-edge features were fit with $35 \%$ Gaussian and $65 \%$ Lorentzian lines over the energy ranges $3165-3185 \mathrm{eV}$ and $3325-3345 \mathrm{eV}$, respectively. Deviation from the established pseudo Voigt line shape was necessary to achieve reasonable fits for these spectra. The pre-edge features were fit with linked HHLW. The number of peaks used to fit each spectra was determined by the minima in the second 
derivitive. Are under the pre-edge features were determined from the product of the amplitude and HHLW

The $\operatorname{Pd}(0) \mathrm{L}_{\mathrm{III}}$-edge was shifted to the $\mathrm{L}_{\mathrm{III}}$-rising edge of each $\mathrm{L}_{\mathrm{III}}+\mathrm{L}_{\mathrm{II}}$ spectra and scaled so that the spectra with $\operatorname{Pd}(0)$ subtracted would be zero at $3325 \mathrm{eV}$. This allowed for both the fitting of the $\mathrm{L}_{\mathrm{III}}$-pre-edge features, and the subsequent shift, scaling, and subtraction of the $\operatorname{Pd}(0) \mathrm{L}_{\mathrm{III}}$-edge from the newly subtracted $\mathrm{L}_{\mathrm{III}}+\mathrm{L}_{\mathrm{II}}$ edge for fitting of the $\mathrm{L}_{\mathrm{II}}$-pre-edge features. The EDG_FIT ${ }^{23}$ program was used for deconvolution and fitting of all spectra.

\section{$\underline{\text { Error Analysis }}$}

The amount of uncertainty in the energy positions of the peaks is a function of the reproducibility of the spectra. It is established ${ }^{14}$ and can be seen in the Appendix that the resolution allows for an error of $0.1 \mathrm{eV}$ in peak positions. The absolute uncertainty at the Pd L-edges is $0.5 \mathrm{eV}$ between beamlines due to different $\mathrm{Si}\left(\begin{array}{lll}1 & 1 & 1\end{array}\right)$ double crystal stepping motors at ALS and SSRL and the calibration point being $\sim 300$ or $500 \mathrm{eV}$ away from the edges.

Errors in peak intensity and covalency come from several possible sources. The amount of shift applied to $\mathrm{Cs}_{2} \mathrm{ZnCl}_{4}$ or $\operatorname{Pd}(0)$ when subtracting the edge-jump as discussed in the fitting section can introduce up to $1 \%$ error for both the $\mathrm{Cl} \mathrm{K}$-edge and Pd L-edges. In order to estimate the error in the normalization procedure, normalization parameters were varied and the average normalized spectra was taken. For the $\mathrm{Cl}$ Kedges and the Pd L-edges, 3-5\% and 4-6\% error, respectively, in peak intensity was 
introduced from the entire data workup and fitting. For the $\mathrm{Pd}_{\mathrm{III}}+\mathrm{L}_{\mathrm{II}}$-edges together, $5-7 \%$ error in peak intensity was introduced from data workup in addition to the $1 \%$ from fitting. Self-absorption could result in artificially low intensities. While it is believed that the samples were thin enough at SSRL to make this effect negligible, samples at ALS had to be thicker in order to get a good signal to noise ratio. Consequently, peak intensities for room temperature ALS measurements are slightly lower than their analogous measurements at SSRL. As discussed in the results section, different transition dipole integrals are used in this study at SSRL and ALS in order to compensate for the different spectral backgrounds under different beamline conditions. Self-absorption is factored into the different dipole integral at ALS. It is then important to note that the transition dipole integral is a semi-empirical value and has limited relevance to theoretically predicted $\mathrm{Cl} 1 \mathrm{~s} \rightarrow 3 \mathrm{p}$ and $\mathrm{Pd} 2 \mathrm{p} \rightarrow 4 \mathrm{~d}$ transitions.

\section{Electronic Structure Calculations}

\section{Modeling of Chloro Palladium Complexes}

Unless otherwise noted, electronic structure calculations were performed using Gaussian $03^{24}$. Single point ab initio MO and gradient-corrected Density Functional Theory (DFT) calculations were employed to quantify $\mathrm{Cl} 3 \mathrm{p}$ character in the LUMO. A calculation was considered converged when the change in energy between cycles was less than $10^{-8}$ a.u. (tight convergence criterion). Exact $\mathrm{D}_{4 \mathrm{~h}}$ symmetry for $\left[\mathrm{PdCl}_{4}\right]^{2-}$ with Pd-Cl bond distances of $2.30 \AA$ as determined by Takazawa ${ }^{25}$ was used as input geometry. The converged basis sets for both $\mathrm{Pd}$ and $\mathrm{Cl}$ were employed while adding 
neighboring atoms to the central $\left[\mathrm{PdCl}_{4}\right]^{2-}$ in the crystal structure positions in an increasing sphere to find the smallest model needed for DFT calculations (point where adding additional atoms does not change the $\mathrm{Cl} p$ orbital character in the LUMO $\mathrm{b}_{1 \mathrm{~g}}{ }^{*}$ ). This is an appropriate method for determining the necessary model size as crystal packing can affect the frontier orbitals and thus the $\mathrm{Pd}-\mathrm{Cl}$ covalency. The crystal structure of $\left[\mathrm{PdCl}_{6}\right]^{2-}$ shows octahedral symmetry with Pd-Cl bond distances of $2.29 \AA^{25}$. The necessary size of the model was determined in the same manner as $\left[\mathrm{PdCl}_{4}\right]^{2-}$ except that, due to different symmetry, the $\mathrm{Cl} p$ orbital character in the LUMO $\mathrm{e}_{\mathrm{g}}{ }^{*}$ was the criteria used for model convergence.

The chlorines in $\mathrm{PdCl}_{2}$ are all in the same plane and bridging two $\mathrm{Pd}$ atoms placing the molecule in the $\mathrm{D}_{2 \mathrm{~h}}$ symmetry group. Within chains the $\mathrm{Pd}-\mathrm{Cl}$ bond is $2.31 \AA$ and the Pd-Cl-Pd bonds form a $93^{\circ}$ angle ${ }^{26}$. The shortest necessary chain length required for accurate computations was determined by continually increasing the size of the $\mathrm{Pd}_{\mathrm{x}} \mathrm{Cl}_{2 \mathrm{x}+2}$ chain until the $\mathrm{SCF}$ population of the $\mathrm{Cl} 3 \mathrm{p}$ orbital for the central $\mathrm{Cl}$ in the LUMO converged. The cystal packing effects were determined by adding neighboring $\mathrm{PdCl}_{2}$ molecules to the central chain and monitoring the $\mathrm{Cl}$ character in the LUMO.

\section{Finding the Theoretically Converged Basis Sets}

A basis set was considered converged if additional Gaussian functions did not change the $\mathrm{Cl} 3 \mathrm{p}$ orbital character in the LUMO $\mathrm{b}_{1 \mathrm{~g}}{ }^{*}$ for $\mathrm{D}_{4 \mathrm{~h}}\left[\mathrm{PdCl}_{4}\right]^{2-}$. The GGA type Becke $88^{27}$ exchange and Perdew $86^{28}$ correlation functionals (BP86) were employed along with the SDD basis set for Pd using all the $\mathrm{Cl}$ basis sets in Table 1 in order to find the converged $\mathrm{Cl}$ basis set. This $\mathrm{Cl}$ basis set was subsequently employed while 
evaluating the Pd basis sets in Table 1 using both BP86 DFT and Hartree Fock ${ }^{29-31}$ (HF) ab initio calculations.

Table 1. List of basis sets evaluated in this study and their contraction schemes.

Effective Core Potential Basis Sets

\begin{tabular}{clllcc}
\hline element & \multicolumn{1}{c}{ description } & & contraction scheme & $\begin{array}{c}\text { pol.function } \\
\text { coeffient }\end{array}$ & ref \\
\hline $\mathrm{Cl}$ & SDD & $(4 \mathrm{~s}, 5 \mathrm{p})$ & $31 / 311$ & & 32 \\
$\mathrm{Cl}$ & $\mathrm{CEP}-31 \mathrm{~g}$ & $(4 \mathrm{~s}, 4 \mathrm{p})$ & $31 / 31$ & & 33 \\
$\mathrm{Pd}$ & $\mathrm{SDD}$ & $(8 \mathrm{~s}, 7 \mathrm{p}, 6 \mathrm{~d})$ & $311111 / 22111 / 411$ & & 34 \\
$\mathrm{Pd}$ & $\mathrm{SDD}(\mathrm{f})$ & $(8 \mathrm{~s}, 7 \mathrm{p}, 6 \mathrm{~d}, 1 \mathrm{f})$ & $311111 / 22111 / 411 / 1$ & $\mathrm{f} 1.472$ & 34 \\
$\mathrm{Pd}$ & LANL1DZ & $(5 \mathrm{~s}, 6 \mathrm{p}, 4 \mathrm{~d})$ & $31 / 321 / 31$ & & 35 \\
$\mathrm{Pd}$ & CEP-121g & $(8 \mathrm{~s}, 8 \mathrm{p}, 5 \mathrm{~d})$ & $4211 / 4211 / 311$ & & 36,37 \\
$\mathrm{Pd}$ & CEP-121g(f) & $(8 \mathrm{~s}, 8 \mathrm{p}, 5 \mathrm{~d}, 1 \mathrm{f})$ & $4211 / 4211 / 311 / 1$ & $\mathrm{f} 1.472$ & 36,37 \\
$\mathrm{Pd}$ & HAY-WADT ECP & $(8 \mathrm{~s}, 6 \mathrm{p}, 4 \mathrm{~d})$ & $341 / 321 / 31$ & & 35 \\
\hline
\end{tabular}

\begin{tabular}{|c|c|c|c|c|c|}
\hline \multicolumn{2}{|c|}{ element description } & \multicolumn{2}{|c|}{ contraction scheme } & \multirow[t]{2}{*}{$\begin{array}{c}\text { pol.function } \\
\text { coeffient }\end{array}$} & \multirow{2}{*}{$\frac{\text { ref }}{38}$} \\
\hline $\mathrm{Cl}$ & sto-3g & $(9 s, 6 p)$ & $333 / 33$ & & \\
\hline $\mathrm{Cl}$ & $3-21 g$ & $(9 s, 6 p)$ & $3321 / 321$ & & 39 \\
\hline $\mathrm{Cl}$ & $6-31 \mathrm{~g}$ & $(16 s, 10 p)$ & $6631 / 631$ & & 40 \\
\hline $\mathrm{Cl}$ & $6-311 \mathrm{~g}$ & $(12 s, 10 p)$ & $63111 / 52111$ & & 41 \\
\hline $\mathrm{Cl}$ & $6-31 \mathrm{~g}(\mathrm{~d})$ & $(16 s, 10 p, 1 d)$ & $6631 / 631 / 1$ & d 0.75 & 40 \\
\hline $\mathrm{Cl}$ & $6-311 \mathrm{~g}(\mathrm{~d})$ & $(12 s, 10 p, 1 d)$ & $63111 / 52111 / 1$ & d 0.75 & 41 \\
\hline $\mathrm{Cl}$ & $6-311 \mathrm{~g}(\mathrm{df})$ & $(12 s, 10 p, 1 d, 1 f)$ & $63111 / 52111 / 1 / 1$ & $d 0.75, f 70$ & 41 \\
\hline $\mathrm{Pd}$ & WTBS & $(27 s, 20 p, 17 d)$ & 252525 25/20 20 20/17 17 & & 42,43 \\
\hline $\mathrm{Pd}$ & WTBS-Split & $(27 s, 20 p, 17 d)$ & $1262221 / 104222 / 844441$ & & 42,43 \\
\hline$P d$ & DZVP & $(18 s, 12 p, 9 d)$ & $633321 / 53211 / 531$ & & 44 \\
\hline $\mathrm{Pd}$ & STO-3g & $(15 s, 12 p, 6 d)$ & $33333 / 3333 / 33$ & & 45 \\
\hline $\mathrm{Pd}$ & $3-21 g$ & $(15 s, 12 p, 6 d)$ & $333321 / 33321 / 321$ & & 46 \\
\hline
\end{tabular}

Relativistic effects were accounted for by utilizing the Douglas-Kroll-Hess second order scalar relativistic ${ }^{47}(\mathrm{DKH})$ and Relativistic Elimination of Small Components $^{48}$ (RESC) approaches in Gaussian03 and comparing the results to the uncorrected calculations. Amsterdam Density Functional ${ }^{49,50}$ (ADF) was used to evaluate the Zero Order Relativistic Approximation ${ }^{51}$ (ZORA) with the TZP all electron basis for $\mathrm{Pd}$ and $\mathrm{Cl}$ and the BP86 exchange correlation. Because Pt has a greater nuclear charge 
than Pd and relativistic effects are expected to be more important in this atom, geometry optimization as well as $\mathrm{Cl} \mathrm{p}$ orbital $\mathrm{SCF}$ population analysis was done on $\mathrm{D}_{4 \mathrm{~h}}\left[\mathrm{PtCl}_{4}\right]^{2-}$ to see if the relativistic correction methods at least treat the electrons differently than the non corrected methods.

\section{Calibration of Theory}

A basis set and theory is considered calibrated if it reproduces the covalency obtained from Pd L-edge and Cl K-edge XAS. In order to find the calibrated level of theory, the converged basis sets for $\mathrm{Cl}$ and $\mathrm{Pd}$ were employed while evaluating various DFT and ab initio methods as shown in Table 2 for $\left[\mathrm{PdCl}_{4}\right]^{2-}$ and $\left[\mathrm{PdCl}_{6}\right]^{2-}$. The calibrated theory for $\mathrm{Pd}(\mathrm{II})$ and optimal basis sets were utilized to verify that computations on the $\mathrm{PdCl}_{2}$ model reproduce the experimental XAS covalency.

Table 2. List of theories employed in this study.

Density Functional Theory

\begin{tabular}{|c|c|c|c|}
\hline description & exchange & correlation & reference \\
\hline BP86 & B88 & P86 & 27,28 \\
\hline PBEPBE & PBE & PBE & 52,53 \\
\hline PW91PW91 & PW91 & PW91 & 54,55 \\
\hline \multicolumn{4}{|c|}{ Density Functional Theory hybrid functionals } \\
\hline & $50 \% \mathrm{HF} 50 \% \mathrm{R} 88$ & $50 \%$ & 56 \\
\hline PBIPBE & $50 \%$ ПГ $50 \%$ БО8 & $50 \%$ & 56 \\
\hline PBI1PBE & $25 \%$ HF $75 \%$ B88 & $75 \%$ & 53 \\
\hline B3LYP & $20 \%$ HF $80 \%$ B88 & $\begin{array}{l}\text { LYP non-local correlation } \\
\text { VWN local correlation }\end{array}$ & 56 \\
\hline \multicolumn{4}{|c|}{ ab initio MO theory } \\
\hline description & definition & & reference \\
\hline HF & Hartree Fock & & $29-31$ \\
\hline MP2 & $\begin{array}{l}\text { Moller-Plesset corr } \\
\text { correction trucated }\end{array}$ & $\begin{array}{l}\text { elation energy } \\
\text { at second order }\end{array}$ & $57-59$ \\
\hline MP4 & $\begin{array}{l}\text { Moller-Plesset corr } \\
\text { correction trucated }\end{array}$ & $\begin{array}{l}\text { elation energy } \\
\text { at fourth order }\end{array}$ & 60 \\
\hline CCD & $\begin{array}{l}\text { Coupled Cluster ce } \\
\text { using double subs }\end{array}$ & $\begin{array}{l}\text { alculations } \\
\text { titutions }\end{array}$ & 61 \\
\hline CCSD & $\begin{array}{l}\text { Coupled Cluster ce } \\
\text { single and double }\end{array}$ & $\begin{array}{l}\text { alculations using } \\
\text { substitutions }\end{array}$ & $62-65$ \\
\hline QCISD & $\begin{array}{l}\text { Quadratic } \mathrm{Cl} \text { calcu } \\
\text { single and double }\end{array}$ & $\begin{array}{l}\text { lation using } \\
\text { substitutions }\end{array}$ & $66-68$ \\
\hline
\end{tabular}


Atomic charges were calculated with calibrated basis sets and levels of theory utilizing the Atoms In Molecules ${ }^{69}$ (AIM), Natural Population Analysis ${ }^{70}$ (NPA), and Electrostatic Potential ${ }^{71}$ (ESP) approaches. The polarized continuum model for the United Atom Topological Model was used to find the radii for Pd to be utilized in the ESP charge calculations ${ }^{72}$. NPA was also performed to determine the amount of Pd $5 \mathrm{~s} / 5 \mathrm{p}$. and $\mathrm{Cl} 3 \mathrm{~s} / 3 \mathrm{~d}$ mixing. This information is essential as it affects covalency, and thus the ground state electronic structure. 


\section{RESULTS}

\section{Data Quality Dependence on Beamline Setup and Optics}

Figure 7a-c shows the $\mathrm{Cl} \mathrm{K}$-edge and $\mathrm{Pd} \mathrm{L}_{\mathrm{III}}$-edge XAS spectra for $\left[\mathrm{PdCl}_{4}\right]^{2-}$, $\mathrm{PdCl}_{2}$, and $\left[\mathrm{PdCl}_{6}\right]^{2-}$. The difference in areas under the pre-edge features when the sample is cooled with liquid nitrogen and when the sample is measured at room temperature is due to both self absorption and a different spectral background. Self absorption is the result of the necessary thicker samples needed at ALS. The Pd $\mathrm{L}_{\mathrm{III}}$-edge spectra for $\left[\mathrm{PdCl}_{4}\right]^{2-}$ (Figure $\left.7 \mathrm{~d}\right), \mathrm{PdCl}_{2}$ (Figure 7e) and $\left[\mathrm{PdCl}_{6}\right]^{2-}$ (Figure $7 \mathrm{f}$ ) look nearly identical to the corresponding $\mathrm{Pd} \mathrm{L}_{\mathrm{II}}$-edges (in the Appendix pages 88-92) when shifted $150 \mathrm{eV}$ so

only the $\mathrm{L}_{\mathrm{III}}$-edge is shown. The same background subtraction procedure was done for all spectra and it is apparent that a different procedure is needed for samples measured at ALS while being cooled with liquid nitrogen (see the Appendix pages 77, 79, 81, 83, 85, $86,88,90,92,94,96$, and 98 for background corrections and raw data). Until more data is collected and a general data workup procedure is established, different dipole integrals are used for both the $\mathrm{Cl} \mathrm{K-edge} \mathrm{and} \mathrm{the} \mathrm{Pd} \mathrm{L-edges} \mathrm{at} \mathrm{SSRL} \mathrm{and} \mathrm{ALS} \mathrm{if} \mathrm{the} \mathrm{sample} \mathrm{is}$ cooled with $\mathrm{LN}_{2}$. A new $\mathrm{Cl} \mathrm{K-edge} \mathrm{ALS} \mathrm{dipole} \mathrm{integral} \mathrm{was} \mathrm{found} \mathrm{to} \mathrm{be} 19.3 \mathrm{eV}$ and is based on the pre-edge feature of $\mathrm{D}_{2 \mathrm{~d}} \mathrm{Cs}_{2} \mathrm{CuCl}_{4}$. The chlorine covalency is known to be 7.3\% per $\mathrm{Cl}$ from previous XAS studies ${ }^{14}$. The spectra and fit are shown in the supporting information and the peak intensity, half height line widths (HHLW), and integrated areas $\left(\mathrm{D}_{0}\right)$ are shown in Table 3 located in the $\mathrm{Cl}$ K-edge results section $(\mathrm{p} 27)$. 

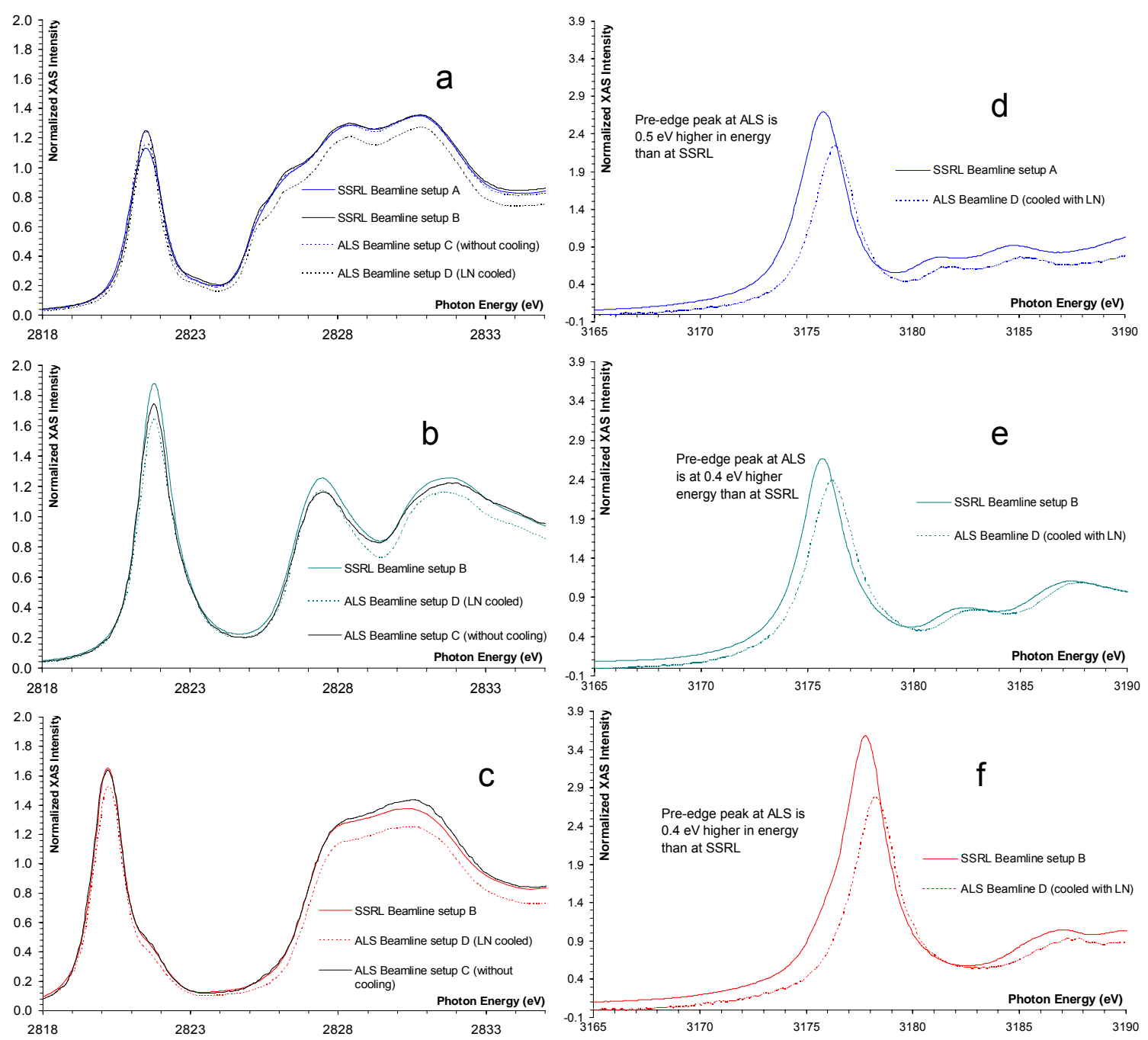

Figure 7. The $\mathrm{Cl} \mathrm{K}$-edge spectra of a) $\left[\mathrm{PdCl}_{4}\right]^{2-}$, b) $\mathrm{PdCl}_{2}$ and c) $\left[\mathrm{PdCl}_{6}\right]^{2-}$ measured at

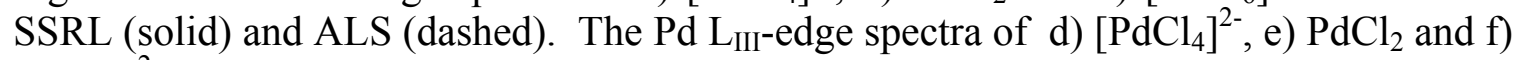
$\left[\mathrm{PdCl}_{6}\right]^{2-}$ measured at SSRL (solid) and ALS (dashed).

Separate dipole integrals at $\mathrm{LN}_{2}$ temperatures at ALS and at room temperature at SSRL for the Pd L-edge are also calculated and are presented in Tables 4-6 located in the Pd Ledge results section. Experimental $\mathrm{Pd}-\mathrm{Cl}$ covalencies for $\left[\mathrm{PdCl}_{4}\right]^{2-}$ measured at room temperature at ALS compared to SSRL indicated that $~ 4 \%$ self absoption occurs at ALS due to the necessary thicker samples. This phenomenon most likely occurs during all 
measurements at ALS an thus factored into the separate $\mathrm{Cl}(1 \mathrm{~s} \rightarrow 3 \mathrm{p})$ and $\operatorname{Pd}(2 \mathrm{p} \rightarrow 4 \mathrm{~d})$ transition dipole integrals.

Figure 8 shows the $\mathrm{Cl} \mathrm{K}$-edge spectra of $\left[\mathrm{PdCl}_{4}\right]^{2-}$ measured two separate times at SSRL giving nearly identical pre-edge peak areas $\left(\mathrm{D}_{0}\right)$ while having an intensity difference of nearly $9 \%$. This is caused by different upstream beamline setups, which were not accessible for the general users, yielding different spectral resolution. The $\mathrm{Cl}$ K-edge linewidths at ALS are between (0.57-0.68) and are slightly smaller than the SSRL linewidths, which are 0.64-0.69 suggesting greater spectral resolution. These linewidths are listed in Tables 3-5.

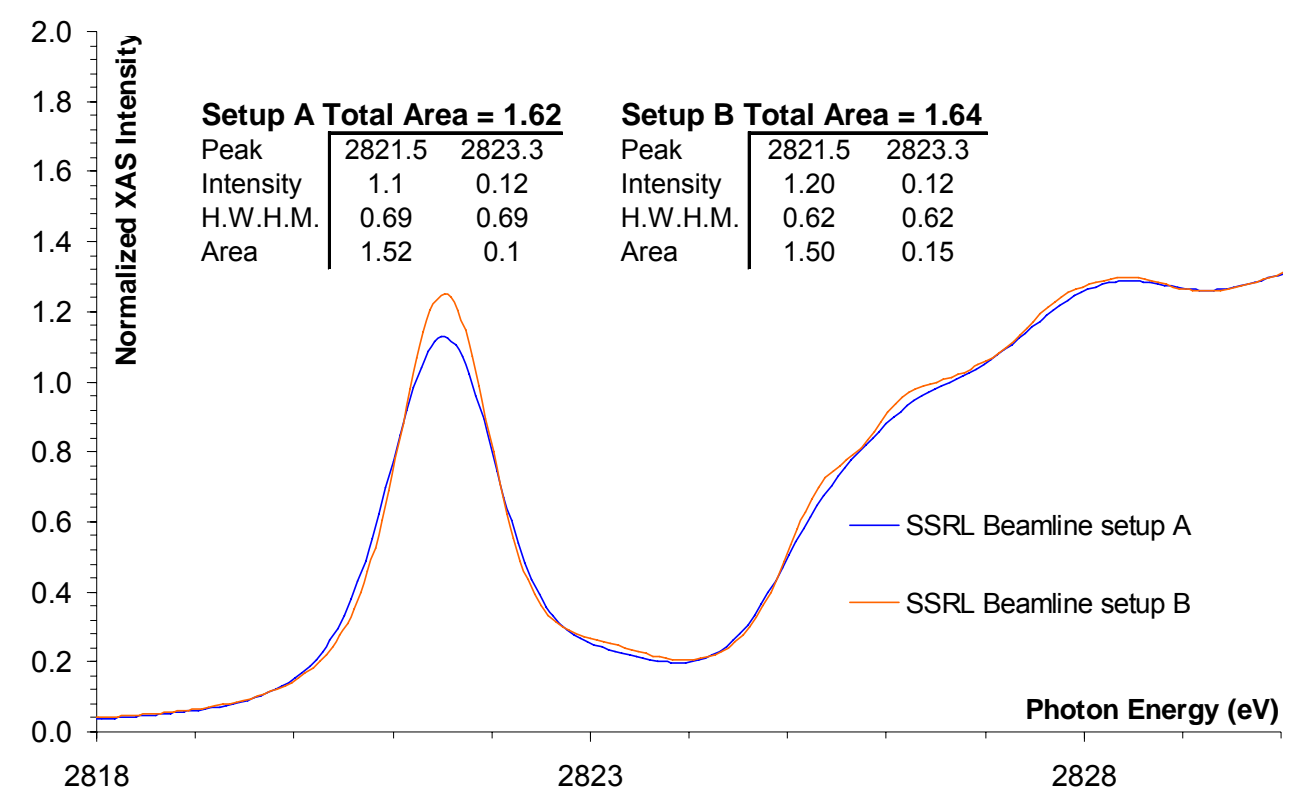

Figure 8 . The $\mathrm{Cl} \mathrm{K}$-edge spectra of $\left[\mathrm{PdCl}_{4}\right]^{2-}$ measured at SSRL with beamline setup A (orange) and beamline setup B (blue) showing different resolutions. 

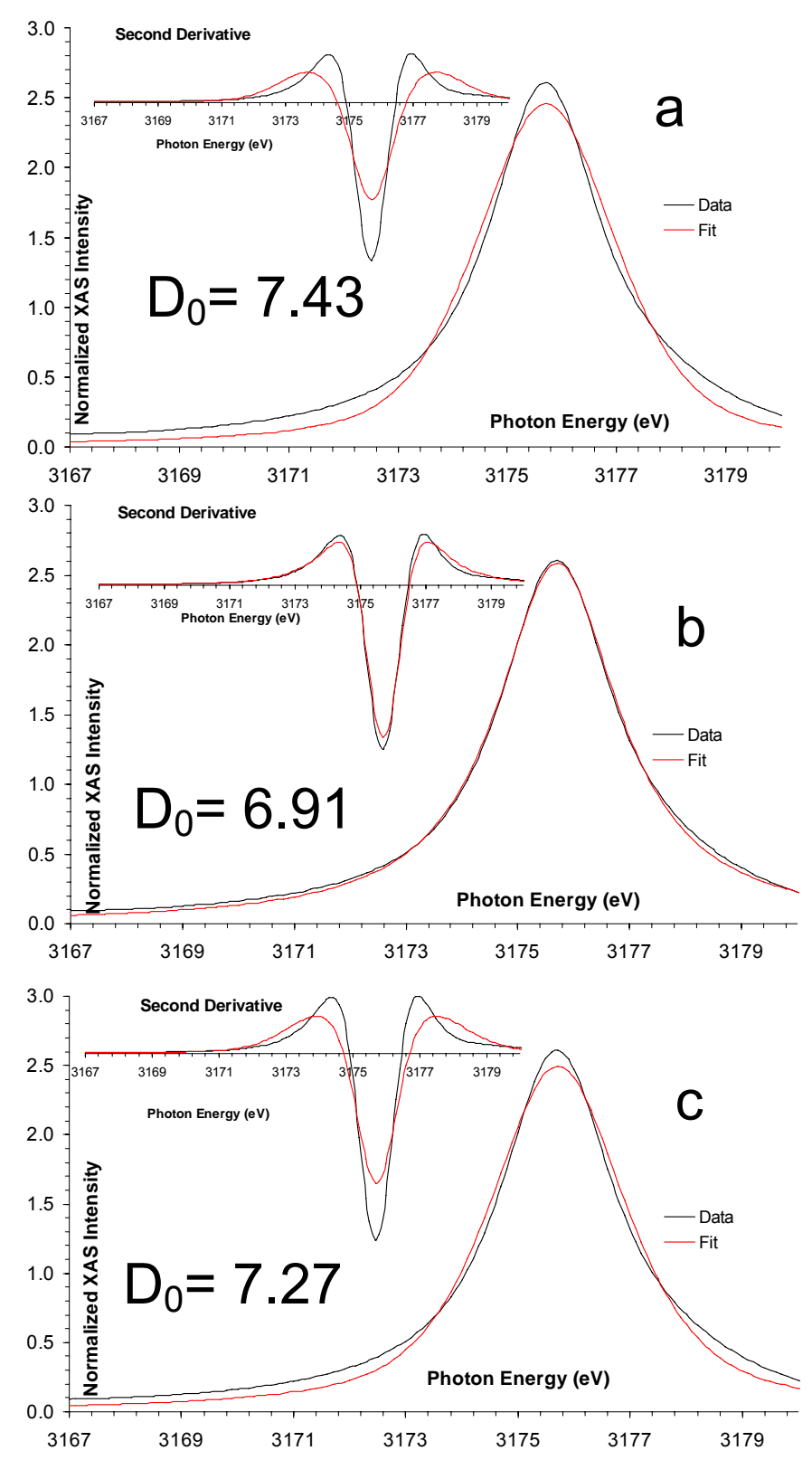

Figure 9. Fits and the second derivative fits of the $\mathrm{Pd} \mathrm{L}_{\mathrm{III}}$-edge of $\mathrm{PdCl}_{2}$ using a) the pseudo Voigt line, b) $0 \%$ Gaussian and 100\% Lorentzian line shape and c) 35\% Gaussian and 65\% Lorentzian line shape. 
Fits of the $\mathrm{Pd} \mathrm{L}_{\mathrm{III}}$-edge of $\mathrm{PdCl}_{2}$ in Figure 9 show that the pseudo Voigt line is reasonable, but not the best fit for the spectra. The $0 \%$ Gaussian $100 \%$ Lorentzian line shape in Figure 9b appears to be the best fit of the spectra. Because the generally used line shape is pseudo Voigt and there is little theoretical evidence to deviate from this, the line shape with Gaussian/Lorentzian ratio of $0.35 / 0.65$ in Figure 9c was chosen as a compromise to fit all the L-pre-edge features.. The excited state lifetime is represented by the Gaussian line shape and the beamline optics are represented by the Lorentzian line shape.

As discussed in the materials and methods error analysis, the $\mathrm{Pd} \mathrm{L}_{\mathrm{III}}$ and $\mathrm{L}_{\mathrm{II}}$ preedge peaks at the ALS are 0.4-0.5 eV and 0.6-0.7 eV higher in energy than at SSRL (see Figure 7 and Tables 4 and 5). We propose setting the first $\mathrm{L}_{\mathrm{III}}$-pre-edge peak of $\left[\mathrm{PdCl}_{4}\right]^{2-}$ to $3175.8 \mathrm{eV}$ and using it as a calibration point for both the $\mathrm{Pd} \mathrm{L}_{\mathrm{III}}$ and $\mathrm{L}_{\mathrm{II}}$-edges.

\section{$\underline{\text { Cl K-edge Spectra Results }}$}

A comparison of the $\mathrm{Cl} \mathrm{K}$-edge spectra of $\left[\mathrm{PdCl}_{4}\right]^{2-}, \mathrm{PdCl}_{2},\left[\mathrm{PdCl}_{6}\right]^{2-}$, and $\mathrm{Cs}_{2} \mathrm{ZnCl}_{4}$ is shown in Figure 10. The rising edge-inflection points, peak positions, intensities, HHLW and $\mathrm{Cl} \mathrm{3p}$ character in the LUMOs are listed in Table 3 and the Appendix show the fits and data workup. The rising edge-inflection points and pre- edge

peak positions for the series are marked in Figure 10. Many of the $\mathrm{PdCl}_{2}$ results and spectra are included here, but will be analyzed in more detail later (page 47). 


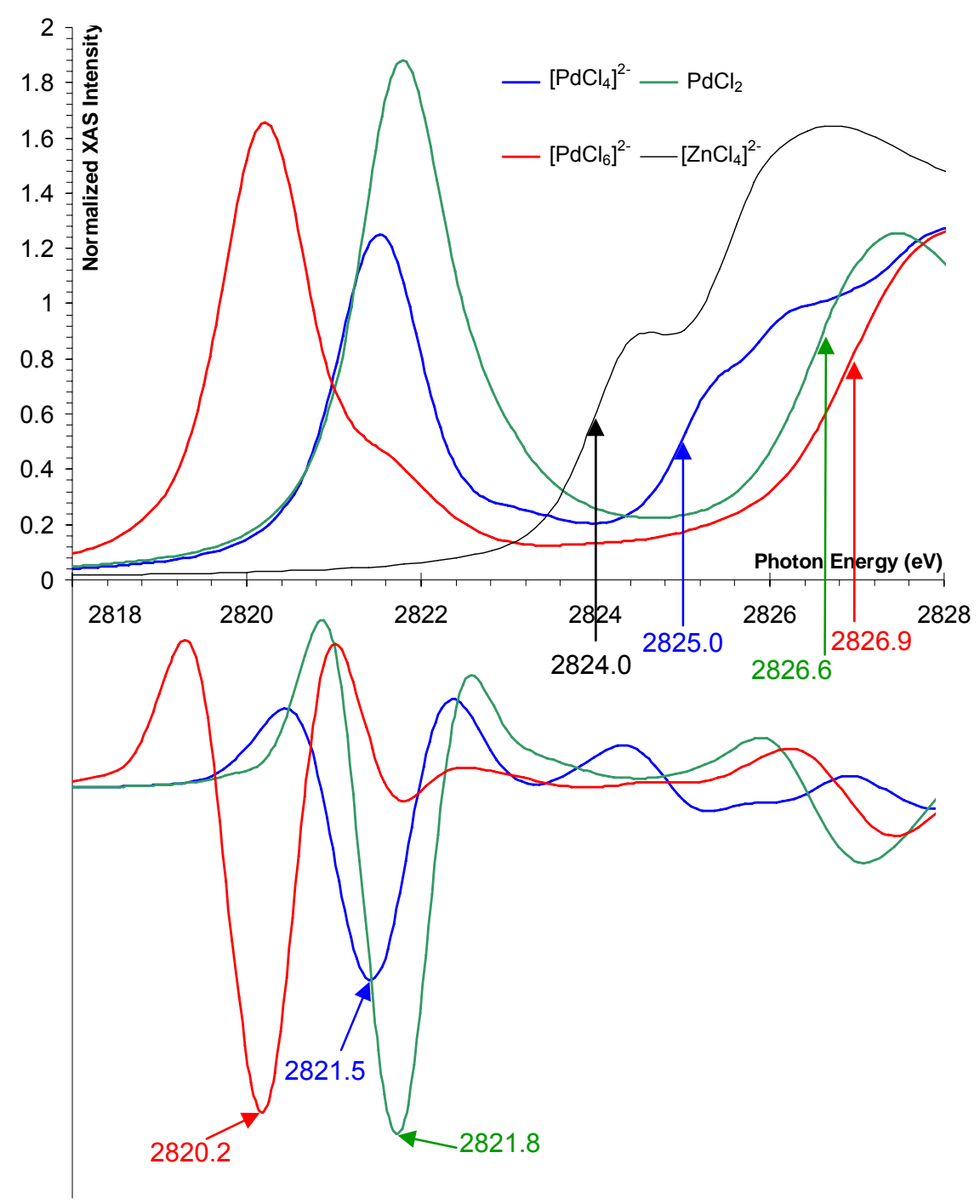

Figure 10. $\mathrm{Cl} \mathrm{K}$-edge spectra and second derivative or the spectra of $\left[\mathrm{PdCl}_{4}\right]^{2-}$ (blue), $\mathrm{PdCl}_{2}$ (green), $\left[\mathrm{PdCl}_{6}\right]^{2-}$ (red), and $\left[\mathrm{ZnCl}_{4}\right]^{2+}$ (black) measured at SSRL showing the difference in peak intensities, peak positions and rising edge positions.

As the palladium-chlorine bond becomes more covalent and the effective nuclear charge of the $\mathrm{Cl}$ goes up, the rising edge-inflection points shift to higher energy in the order of $\left[\mathrm{CuCl}_{4}\right]^{2-},\left[\mathrm{PdCl}_{4}\right]^{2-},\left[\mathrm{PdCl}_{6}\right]^{2-}$. The pre-edge peaks are assigned to the transitions from the $\mathrm{Cl} 1 \mathrm{~s}$ orbitals into the doubly unoccupied LUMO $\mathrm{b}_{1 \mathrm{~g}}{ }^{*}$ for $\left[\mathrm{PdCl}_{4}\right]^{2-}$ and into the quadruply unoccupied LUMO $e_{\mathrm{g}}{ }^{*}$ for $\left[\mathrm{PdCl}_{6}\right]^{2-}$. The higher energy shoulders on these 
peaks are shake-up satellite transitions caused by electron excitation from the $\mathrm{Cl} 1 \mathrm{~s}$ orbitals due to core hole induced electronic relaxation into the fixed excited state. (See the electronic structure calculations results section for a more detailed description of the electronic relaxation.) Because these excited states originate from the same ground state, they are both included in $\mathrm{D}_{0}$ and covalency calculations.

Table 3. The $\mathrm{Cl} \mathrm{K}$-edge data measured at ALS and SSRL.

\begin{tabular}{|c|c|c|c|c|c|c|c|c|c|}
\hline complex & $\begin{array}{l}\text { location } \\
\text { and setup }\end{array}$ & $\begin{array}{c}\text { rising edge } \\
\text { inflection } \\
\text { point }(\mathrm{eV})\end{array}$ & \begin{tabular}{|c} 
peak \\
position
\end{tabular} & $\begin{array}{r}\text { intensity } \\
\text { of peak }\end{array}$ & HHLW & $\mathrm{D}_{0}$ & $\Sigma \mathrm{D}_{0}$ & $\begin{array}{l}\text { total } \mathrm{Cl} 3 \mathrm{p} \\
\text { covalency }\end{array}$ & $\begin{array}{c}\text { average total } \\
\mathrm{Cl} 3 p \text { covalency }\end{array}$ \\
\hline$\left[\mathrm{PdCl}_{4}\right]^{2}$ & SSRL & 2825.0 & 2821.5 & 1.10 & 0.69 & 1.5 & 1.6 & $92 \%$ & $92 \% \pm 3$ \\
\hline absorbers & setup A & & 2823.4 & 0.12 & 0.69 & 0.2 & & & \\
\hline 4 & SSRL & 2825.0 & 2821.5 & 1.2 & 0.62 & 1.5 & 1.6 & $94 \%$ & \\
\hline \multirow{2}{*}{\multicolumn{10}{|c|}{ electron holes }} \\
\hline & & & & & & & & & \\
\hline \multirow[t]{4}{*}{2} & ALS & 2825.0 & 2821.5 & 1.21 & 0.60 & 1.5 & 1.6 & $89 \%$ & \\
\hline & Setup C & & 2823.3 & 0.10 & 0.60 & 0.1 & & & \\
\hline & ALS & 2825.0 & 2821.5 & 1.21 & 0.57 & 1.4 & 1.5 & $92 \%$ & \\
\hline & Setup D & & 2823.3 & 0.10 & 0.57 & 0.1 & & & \\
\hline \multirow[t]{2}{*}[\mathrm{PdCl}_{6}]{$^{2-}$} & SSRL & 2826.9 & 2820.2 & 1.60 & 0.64 & 2.0 & 2.4 & $203 \%$ & $202 \% \pm 8$ \\
\hline & setup $B$ & & 2821.8 & 0.27 & 0.64 & 0.3 & & & \\
\hline \multirow{2}{*}{$\begin{array}{c}\text { absorbers } \\
6\end{array}$} & ALS & & 2820.2 & 1.63 & 0.62 & 2.0 & 2.4 & $203 \%$ & \\
\hline & setup $C^{\dagger}$ & & 2821.7 & 0.30 & 0.62 & 0.4 & & & \\
\hline \multicolumn{10}{|l|}{ electron holes } \\
\hline \multirow[t]{2}{*}{4} & ALS & 2827.0 & 2820.2 & 1.47 & 0.62 & 1.8 & 2.1 & $200 \%$ * & \\
\hline & setup D & & 2821.9 & 0.23 & 0.62 & 0.3 & & & $\begin{array}{l}\mathrm{LN}_{2} \text { cooled dipole } \\
\text { integral at the ALS }\end{array}$ \\
\hline \multirow[t]{2}{*}[\mathrm{CuCl}_{4}]{$^{2-}$} & ALS & 2825.3 & 2820.2 & 0.41 & 0.54 & 0.4 & 0.5 & $29 \%^{\ddagger}$ & 19.3 \\
\hline & setup D & $4 \mathrm{a}$ & orbers a & 1 elec & hole & & & & \\
\hline
\end{tabular}

*ALS dipole integral while the sample is cooled with LN was used for covalency calculation.

${ }^{\dagger}$ Extrapolated data due to photoreduction radiation damage.

${ }^{\ddagger}$ Covalency was obtained from previous XAS study ${ }^{14}$.

Fits of the pre-edge features reveal total areas of 1.6 and 2.4 at the SSRL for $\left[\mathrm{PdCl}_{4}\right]^{2-}$ and $\left[\mathrm{PdCl}_{6}\right]^{2-}$, respectively, and 1.4 and 2.1 , respectively, at the ALS while 
cooled with $\mathrm{LN}_{2}$. The total $\mathrm{Cl}$ covalency per $\mathrm{d}$ orbital hole was found to be $46 \%$ and $50 \%$ for $\left[\mathrm{PdCl}_{4}\right]^{2-}$ and $\left[\mathrm{PdCl}_{6}\right]^{2-}$, respectively, with an error bar of $\pm 2 \%$ for each. Covalency was defined as the total $\mathrm{Cl}$ character in the LUMO so that Pd character and thus the Pd L-edge dipole integrals could be calculated.

\section{$\underline{\text { Pd L-edge Spectra Results }}$}

There are three possibilities to define the transition dipole integral for the palladium L-edges. Different methods can be useful when the measurement of both the $\mathrm{L}_{\mathrm{III}}$ - and $\mathrm{L}_{\mathrm{II}}$-edges together in hindered, such as when crystal glitches or other absorbers with overlapping edges are present. The first, method I, is to measure only the $\mathrm{L}_{\mathrm{III}}$-edge and use it to define the dipole integral. The second, method II, is to measure only the $\mathrm{L}_{\mathrm{II}^{-}}$ edge and use it to define the dipole integral. The third, method III, is to measure both edges and use the combination of the two to define a total dipole integral for the Pd Ledges. In addition, multiple quanitation of these data can reduce the statistical error in these data.

Figure 11 compares the $\mathrm{Pd} \mathrm{L}_{\mathrm{III}}$-edge spectra of $\left[\mathrm{PdCl}_{4}\right]^{2-}, \mathrm{PdCl}_{2},\left[\mathrm{PdCl}_{6}\right]^{2-}$ and $\operatorname{Pd}(0)$. The rising edge positions (listed in Table 2 ) and pre-edge peak positions are also marked on Figure 11. Although the rising edge positions of the Pd L-edges are not as well resolved as the $\mathrm{Cl} \mathrm{K}$-edge, the first derivatives shown in the Appendix (pages 83-87) clearly show maxima at these points. The order of this series reflects the difference in the effective nuclear charge of each palladium as greater charge gives rise to a higher energy 
rising edge. Tables 3 and 4 also list the peak positions, intensities, HHLW, and dipole integrals for the Pd L-edges.

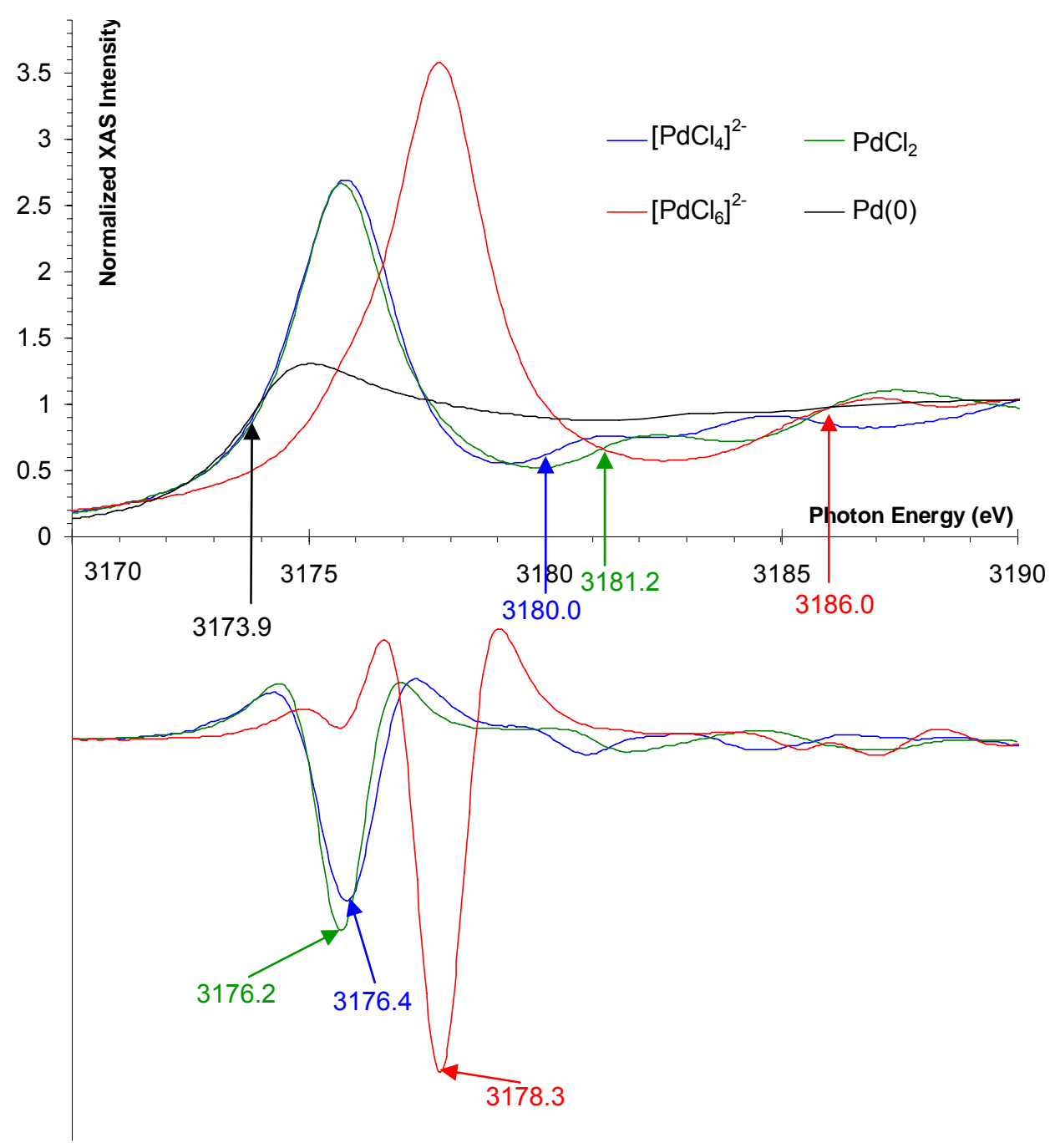

Figure 11. The Pd $\mathrm{L}_{\mathrm{III}}$-edge spectra and second derivative of the spectra of $\left[\mathrm{PdCl}_{4}\right]^{2-}$ (blue), $\mathrm{PdCl}_{2}$ (green), $\left[\mathrm{PdCl}_{6}\right]^{2-}$ (red), measured at SSRL and $\mathrm{Pd}(0)$ (black) measured at ALS showing the difference in peak intensities, peak positions and rising edge positions. 
Table 4. Pd $\mathrm{L}_{\mathrm{III}}$-edge data measured at ALS and SSRL.

\begin{tabular}{|c|c|c|c|c|c|c|c|c|}
\hline complex & $\begin{array}{l}\text { location } \\
\text { and setup }\end{array}$ & $\begin{array}{l}\text { rising edge } \\
\text { inflection } \\
\text { point }(\mathrm{eV}) \\
\end{array}$ & $\begin{array}{c}\text { peak } \\
\text { position }\end{array}$ & $\begin{array}{l}\text { intensity } \\
\text { of peak }\end{array}$ & HHLW & $\Sigma \mathrm{D}_{0}$ & $\begin{array}{l}\text { total Pd d } \\
\text { character* }^{*}\end{array}$ & $\begin{array}{c}\text { tranistion } \\
\text { dipole integral } \\
\text { for } L_{\text {III }}(\mathrm{eV}) \\
\end{array}$ \\
\hline$\left[\mathrm{PdCl}_{4}\right]^{2-}$ & SSRL setup A & 3180.2 & 3175.8 & 2.57 & 1.42 & 7.3 & $104 \%$ & $42 \pm 4$ \\
\hline $\begin{array}{c}\text { absorbers (1) } \\
\text { electron holes (2) }\end{array}$ & ALS setup D & 3181.0 & 3176.4 & 2.29 & 1.26 & 5.7 & $104 \%$ & $33 \pm 3$ \\
\hline $\begin{array}{c}\left.\mathrm{PdCl}_{6}\right]^{2-} \\
\text { absorbers (1) } \\
\text { electron holes (4) }\end{array}$ & SSRL setup B & 3185.0 & $\begin{array}{l}3177.8 \\
3175.6 \\
3178.3\end{array}$ & $\begin{array}{l}3.25 \\
0.31\end{array}$ & $\begin{array}{l}1.47 \\
1.47\end{array}$ & 10.5 & $176 \%$ & $48 \pm 5$ \\
\hline
\end{tabular}

* Pd d character comes from the remainder not measured in the $\mathrm{Cl} \mathrm{K}$-edge XAS such as $\mathrm{Cl} 3 \mathrm{~s}$ and $3 \mathrm{~d}$ and $\mathrm{Pd} 5 \mathrm{~s}$ and $5 \mathrm{p}$ characters from calibrated electronic structure calculations and analysis of rising edge positions.

Table 5. Pd $\mathrm{L}_{\mathrm{II}}$-edge data measured at the ALS and SSRL.

\begin{tabular}{|c|c|c|c|c|c|c|c|c|}
\hline complex & $\begin{array}{l}\text { location } \\
\text { and setup }\end{array}$ & $\begin{array}{c}\text { rising edge } \\
\text { inflection } \\
\text { point }(\mathrm{eV})\end{array}$ & $\begin{array}{c}\text { peak } \\
\text { position }\end{array}$ & $\begin{array}{l}\text { intensity } \\
\text { of peak }\end{array}$ & HHLW & $\Sigma D_{0}$ & $\begin{array}{l}\text { total Pd d } \\
\text { character* }\end{array}$ & $\begin{array}{c}\text { tranistion } \\
\text { dipole integral } \\
\text { for } L_{\| 1}(e V)\end{array}$ \\
\hline$\left[\mathrm{PdCl}_{4}\right]^{2-}$ & SSRL setup A & 3337.4 & 3332.7 & 2.47 & 1.32 & 6.7 & $104 \%$ & $39 \pm 4$ \\
\hline $\begin{array}{c}\text { absorbers (1) } \\
\text { electron holes (2) }\end{array}$ & ALS setup D & 3338.1 & 3334.5 & 2.45 & 1.20 & 5.9 & $104 \%$ & $34 \pm 3$ \\
\hline $\begin{array}{c}{\left[\mathrm{PdCl}_{6}\right]^{2-}} \\
\text { absorbers (1) }\end{array}$ & SSRL setup B & 3341.9 & 3334.7 & 2.57 & 1.47 & 7.7 & $176 \%$ & $35 \pm 3$ \\
\hline electron holes (4) & ALS setup D & 3342.7 & 3335.4 & 2.60 & 1.39 & 7.2 & $176 \%$ & $33 \pm 3$ \\
\hline
\end{tabular}

*Pd d character comes from the remainder not measured in the $\mathrm{Cl} \mathrm{K}$-edge XAS such as $\mathrm{Cl} 3 \mathrm{~s}$ and $3 \mathrm{~d}$ and $\mathrm{Pd} 5 \mathrm{~s}$ and $5 \mathrm{p}$ characters from calibrated electronic structure calculations and analysis of rising edge positions.

Figure 12 is included to verify that the lower energy shoulder in the $\left[\mathrm{PdCl}_{6}\right]^{2-} \mathrm{L}$ edge spectra in Figure 11 and higher energy shoulder in the $\mathrm{Cl}$ K-edge spectra of $\left[\mathrm{PdCl}_{6}\right]^{2-}$ in Figure 10 was not a result of contamination by one of the chloro-Pd(II) 

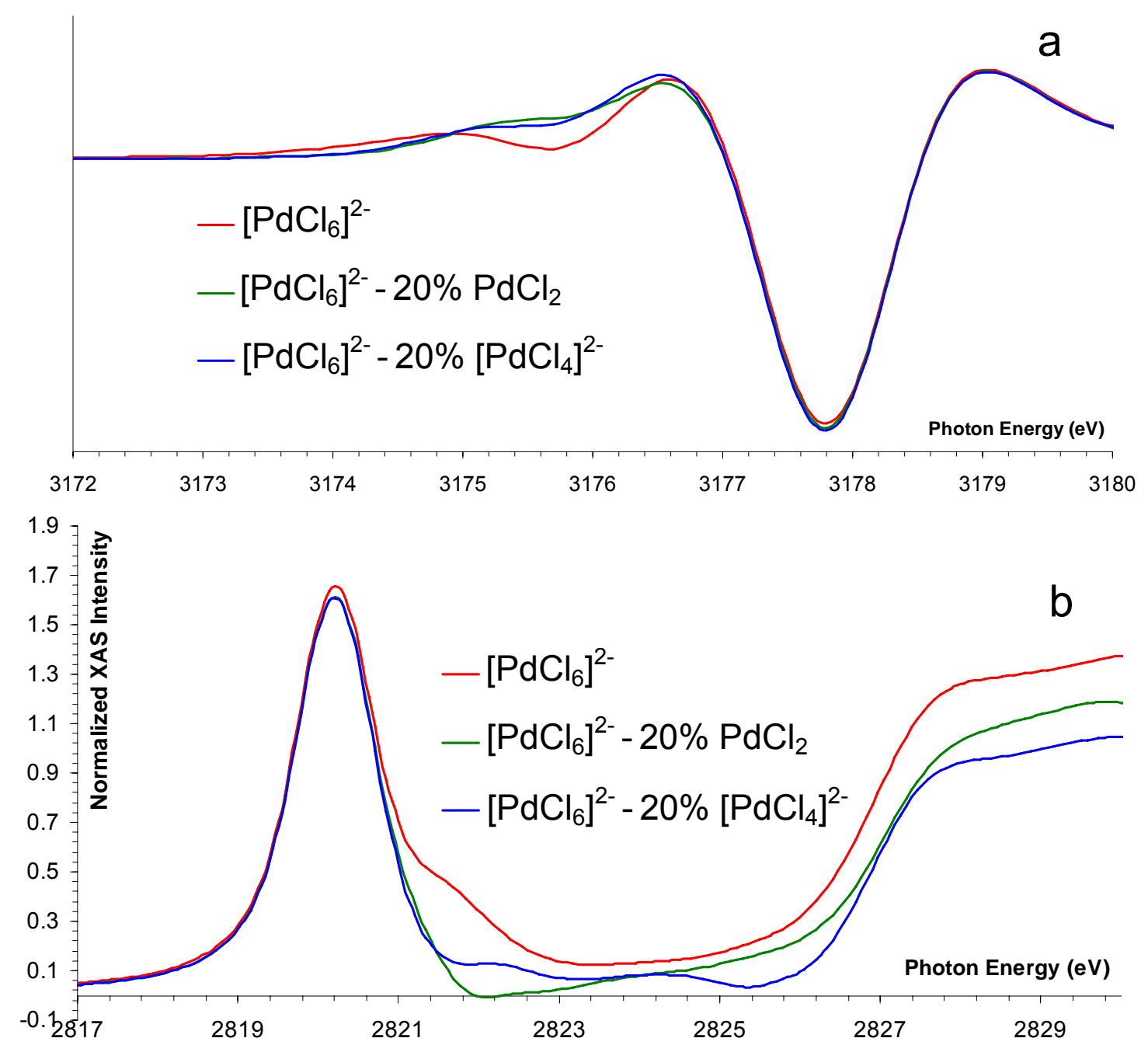

Figure 12. The second derivative of the $\mathrm{Pd} \mathrm{L}_{\mathrm{III}}$-edge spectra of $\left[\mathrm{PdCl}_{6}\right]^{2-}$ spectra a) and normalized $\mathrm{Cl} \mathrm{K}$-edge spectra of $\left[\mathrm{PdCl}_{6}\right]^{2-}$ b) with $20 \%$ of the chloro-Pd(II) spectra removed to verify that the shoulder in the $\left[\mathrm{PdCl}_{6}\right]^{2-}$ spectra was not the result of contamination.

complexes. At least $20 \%$ of either $\mathrm{PdCl}_{2}$ or $\left[\mathrm{PdCl}_{4}\right]^{2-}$ L-edge spectra must be subtracted from the $\left[\mathrm{PdCl}_{6}\right]^{2-}$ spectrum to achieve a second derivative where this shoulder is not present. If this shoulder were due to contamination of the complex by $20 \%$ of either of the chloro-Pd(II) complexes, then this contamination would also be evident in the $\mathrm{Cl} \mathrm{K}$ - 
edge. This is not the case as subtracting $20 \%$ of each chloro-Pd(II) Cl K-edge spectra from the $\left[\mathrm{PdCl}_{6}\right]^{2-}$ spectra gives an unreasonable XAS spectra with negative absorbance.

The most intense pre-edge features for $\left[\mathrm{PdCl}_{4}\right]^{2-}$ and $\left[\mathrm{PdCl}_{6}\right]^{2-} \mathrm{L}_{\mathrm{III}}$-edges at ALS are at 3176.4 and $3178.3 \mathrm{eV}$ respectively and, similar to the $\mathrm{Cl} \mathrm{K}$-edge, are assigned to the transition into the unoccupied $b_{1 \mathrm{~g}}{ }^{*}$ for $\left[\mathrm{PdCl}_{4}\right]^{2-}$ and the unoccupied $\mathrm{e}_{\mathrm{g}}{ }^{*}$ for $\left[\mathrm{PdCl}_{6}\right]^{2-}$. As discussed earlier, a distinction must be made between sample measurement locations as the calibration at this energy is different at each beamline. The lower energy shoulder in the $\left[\mathrm{PdCl}_{6}\right]^{2-}$ spectra is a satellite feature. (Further discussion of this occurs in the Electronic Structure Calculations results section). Similar transitions are expected for the $\left[\mathrm{PdCl}_{4}\right]^{2-}$ and $\mathrm{PdCl}_{2}$ spectra, but are very close to the main peak and thus not resolvable with the current beamline setup. The transition envelop nature of the pre-edge peak was taken into account by a non pseudo-Voigt line shape used in fitting.

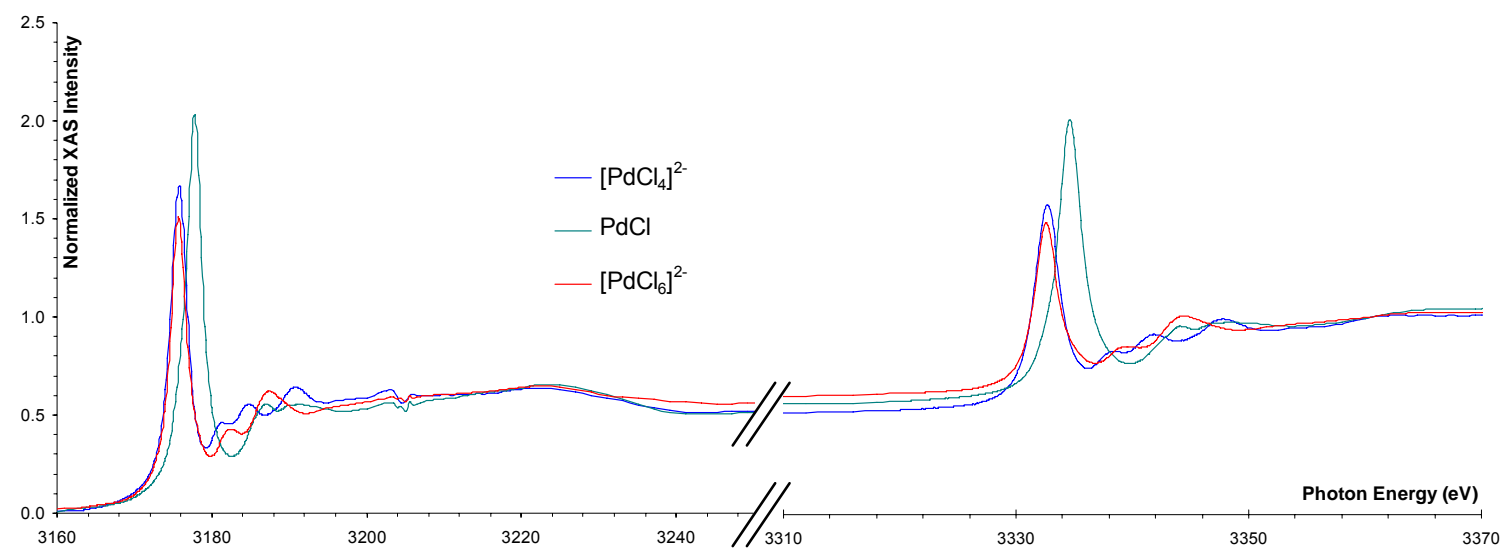

Figure 13. The $\mathrm{Pd} \mathrm{L}_{\mathrm{III}}+\mathrm{L}_{\mathrm{II}}$-edge spectra of $\left[\mathrm{PdCl}_{4}\right]^{2-}$ (blue), $\mathrm{PdCl}_{2}$ (green), and $\left[\mathrm{PdCl}_{6}\right]^{2-}$ (red) shows the relative intensities of each edge-jump. 
The spectra of the $\mathrm{Pd} \mathrm{L}_{\mathrm{III}}$ and $\mathrm{L}_{\mathrm{II}}$-edges measured and normalized together are shown in Figure 13. Table 4 lists the area under the pre-edge features and the ratio of the $\mathrm{L}_{\text {III }}$ to the $\mathrm{L}_{\mathrm{II}}$-edge jump. In all three cases this ratio is about 1.5 to 1.0 while the theoretical value is 2.0 to $1.0^{73}$.

Table 6. Pd $\mathrm{L}_{\mathrm{III}}+\mathrm{L}_{\mathrm{II}}$-edge data measured at ALS and SSRL.

\begin{tabular}{|c|c|c|c|c|c|c|c|c|c|c|c|c|c|}
\hline complex & $\begin{array}{l}\text { location } \\
\text { and setup }\end{array}$ & $\begin{array}{c}\mathrm{L}_{\text {III }} \\
\text { peak } \\
\text { positions }\end{array}$ & $\begin{array}{r}\text { intensity } \\
\text { of peak }\end{array}$ & HHLW & $\begin{array}{c}\mathrm{L}_{\text {IIII }} \\
\Sigma \mathrm{D}_{0} \\
\end{array}$ & $\begin{array}{c}\mathrm{L}_{\|} \\
\text {peak } \\
\text { positions }\end{array}$ & $\begin{array}{r}\text { intensity } \\
\text { of peak }\end{array}$ & HHLW & $\begin{array}{r}\mathrm{L}_{\| 1} \\
\Sigma \mathrm{D}_{0} \\
\end{array}$ & $\begin{array}{r}\mathrm{L}_{111}+\mathrm{L} \\
\Sigma \mathrm{D}_{0} \\
\end{array}$ & $\begin{array}{c}\text { LIIIILLIIIedge } \\
\text { jumps }\end{array}$ & $\begin{array}{l}\text { total Pd d } \\
\text { character }^{*}\end{array}$ & $\begin{array}{c}\text { tranistion } \\
\text { dipole integral } \\
\text { for } L_{\| 1}+L_{\| 1}(e V)\end{array}$ \\
\hline$\left[\mathrm{PdCl}_{4}\right]^{2-}$ & SSRL setup $A$ & 3175.8 & 1.56 & 1.42 & 4.4 & 3332.7 & 0.99 & 1.35 & 2.7 & 7.1 & 0.6 & $104 \%$ & $41 \pm 4$ \\
\hline $\begin{array}{c}\text { absorbers (1) } \\
\text { electron holes (2) } \\
\end{array}$ & ALS setup D & 3176.6 & 1.23 & 1.28 & 3.2 & 3333.4 & 0.93 & 1.19 & 2.2 & 5.4 & 0.6 & $104 \%$ & $31 \pm 3$ \\
\hline$\left[\mathrm{PdCl}_{6}\right]^{2-}$ & SSRL setup B & $\begin{array}{l}3177.8 \\
3175.4\end{array}$ & $\begin{array}{l}1.86 \\
0.20\end{array}$ & $\begin{array}{l}1.38 \\
1.38\end{array}$ & 5.7 & 3334.7 & 1.35 & 1.39 & 3.8 & 9.4 & 0.6 & $176 \%$ & $32 \pm 3$ \\
\hline electron holes (4) & ALS setup $D$ & 3178.3 & 1.45 & 1.36 & 3.9 & 3335.4 & 1.25 & 1.41 & 3.5 & 7.5 & 0.6 & $176 \%$ & $25 \pm 3$ \\
\hline
\end{tabular}

* Pd 4d character per hole comes from $\mathrm{Cl} \mathrm{K}$-edge XAS and $\mathrm{Cl} 3 \mathrm{~s}$ and $3 \mathrm{~d}$ and $\mathrm{Pd} 5 \mathrm{~s}$ and $5 \mathrm{p}$ character is taken from calibrated electronic structure calculations.

The LUMO is a combination of the $\mathrm{Cl} 3 \mathrm{p}$ orbital and the $\mathrm{Pd} 4 \mathrm{~d}$ orbitals with minor contributions from the $\mathrm{Pd} 5 \mathrm{~s} / 5 \mathrm{p}$ and $\mathrm{Cl} 3 \mathrm{~s} / 3 \mathrm{~d}$ orbitals. Consequently, an estimate of the $\mathrm{Pd} 5 \mathrm{~s} / 5 \mathrm{p}$ and $\mathrm{Cl} 3 \mathrm{~s} / 3 \mathrm{~d}$ character in the LUMO is needed to find accurate transition dipole integrals for the Pd L-edges. Results from electronic structure calculations presented below employing the calibrated basis sets and levels of theory reveal a total of $4 \% \mathrm{Cl} 3 \mathrm{~d}$ and $3 \mathrm{~s}$ character and $0 \% \mathrm{Pd} 5 \mathrm{p}$ and $5 \mathrm{~s}$ character for $\left[\mathrm{PdCl}_{4}\right]^{2-}$. Subtracting this from the remaining $108 \%$ from the $\mathrm{Cl}$ K-edge yields $104 \% \mathrm{Pd} 4 \mathrm{~d}$ character that should correspond to the pre-edge intensities in the Pd L-edges. Calibrated electronic structure calculations indicate $11 \%$ total $\mathrm{Cl} 3 \mathrm{~s}$ and $3 \mathrm{~d}$ and $0 \% \mathrm{Pd} 5 \mathrm{p}$ and $5 \mathrm{~s}$ character in the LUMO of $\left[\mathrm{PdCl}_{6}\right]^{2-}$. However, insights gained from the analysis of the $\mathrm{Cl} \mathrm{K}$ - and $\mathrm{Pd} \mathrm{L}$-edge rising edge positions and covalencies indicate some mixing of $\mathrm{Pd} 5 \mathrm{~s} / 5 \mathrm{p}$ orbital character in the bond. Therefore, an additional estimated $11 \% \mathrm{Pd} 5 \mathrm{~s} / 5 \mathrm{p}$ bond character is added to 
$\left[\mathrm{PdCl}_{6}\right]^{2-}$ leaving $175 \% \mathrm{Pd} \mathrm{d}$ orbital character that should be present in the L-pre-edge features.

\section{Electronic Structure Calculations}

Electronic structure calculations were performed on the $\mathrm{Pd}$ series to find a spectroscopically calibrated level of theory for $\mathrm{Pd}(\mathrm{II})$ and $\mathrm{Pd}(\mathrm{IV})$ which can accurately describe the potential energy surfaces for catalytic mechanisms of $\mathrm{Pd}$ complexes. In order to establish this, it was necessary to find the appropriate basis sets for $\mathrm{Cl}$ and $\mathrm{Pd}$. The calibrated computations were subsequently used as an aid in the assignment and interpretation of the XAS spectra.

While Figure 14 shows that the 6-31G(d) basis set for $\mathrm{Cl}$ can be considered theoretically converged for $\mathrm{Cl} 3 \mathrm{p}$ orbital character in the LUMO from single point $\left[\mathrm{PdCl}_{4}\right]^{2-}$ calculations, the $6-311 \mathrm{G}(\mathrm{d})$ was employed for all further models to ensure that the basis set was converged.

The Pd basis set dependence in Figure 15 shows an increase in the covalency of the $\mathrm{Pd}-\mathrm{Cl}$ bond as the size of the all electron basis sets increase and the covalency decrease as the size of the basis sets with effective core potentials are increased. This is a similar trend as the one found in $\left[\mathrm{CuCl}_{4}\right]^{2-}$. . Although the WTBS-Split uses more Guassians to define the orbitals than the SDD basis set with $\mathrm{f}$ orbitals ( $\operatorname{SDD}(\mathrm{f})$ ), the $\operatorname{SDD}(\mathrm{f})$ basis was employed for this study because the WTBS basis is too computationally expensive for calculations on larger systems. 


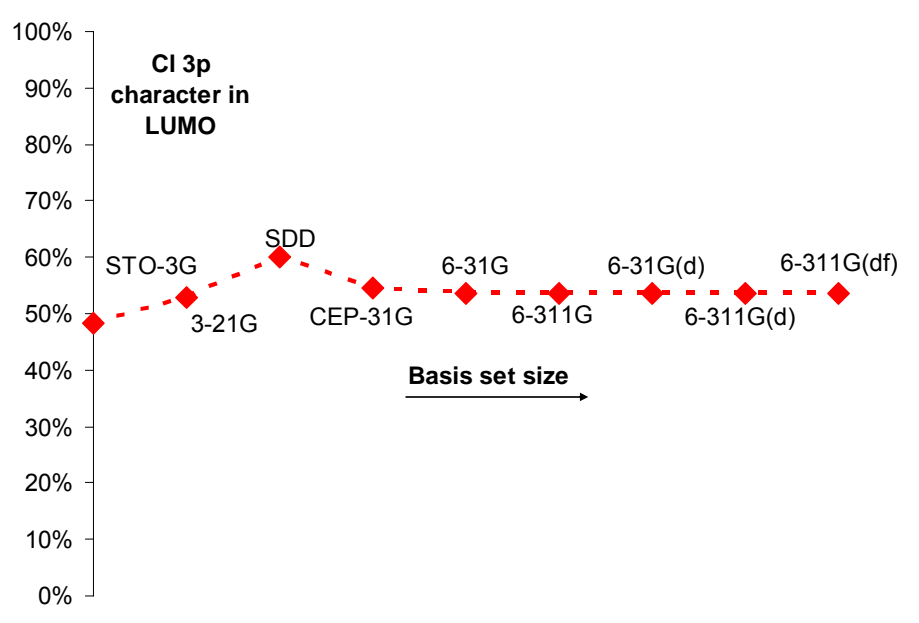

Figure 14. Chlorine basis set effect comparing the $\mathrm{Cl} 3 \mathrm{p}$ orbital character in the LUMO $\mathrm{b}_{1 \mathrm{~g}} *$ in $\left[\mathrm{PdCl}_{4}\right]^{2-}$ using the BP86 exchange functional.

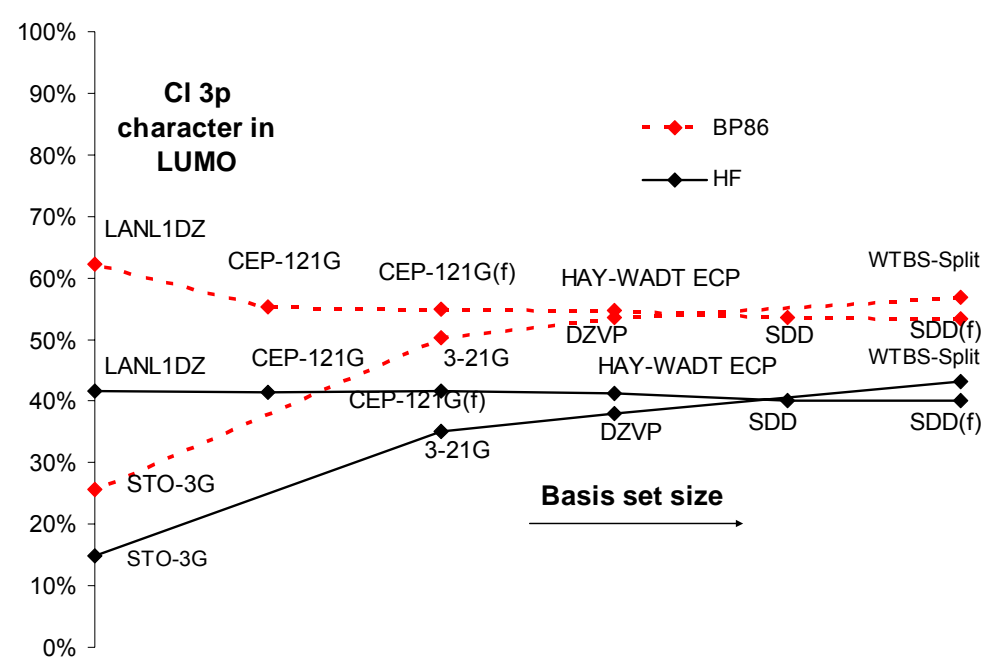

Figure 15. Palladium basis set effect on the SCF population. Comparing the $\mathrm{Cl} 3 \mathrm{p}$ orbital character per LUMO $b_{1 \mathrm{~g}}{ }^{*}$ in $\left[\mathrm{PdCl}_{4}\right]^{2-}$ using both BP86 (dashed) and HF (solid) theories. The red marks the all electron basis sets and the black marks the basis sets with effective core potentials.

Adding external point charges, or counterions around the central $\left[\mathrm{PdCl}_{4}\right]^{2-}$ or $\left[\mathrm{PdCl}_{6}\right]^{2-}$ as in the crystal structure to simulate crystal packing effects had little effect $(<1 \%)$ on the $\mathrm{Cl}$ character in the LUMO $\sigma^{*}$. Therefore, gas phase calculations were employed when calibrating the theory to XAS covalency data. Results of the gas phase 
SCF population analysis calculations of $\left[\mathrm{PdCl}_{4}\right]^{2-}$, plotted in Figure 16, show the ab initio calculations with increasing electron correlation converge to $36 \% \mathrm{Cl} 3 \mathrm{p}$ orbital character in the LUMO $\sigma^{*}$ of $\left[\mathrm{PdCl}_{4}\right]^{2-}$ for the QCISD method. The density functionals converge at $47 \% \mathrm{Cl}$ character for the 50/50 exchange BHandHLYP and this most accurately reproduces the $46 \%$ experimental $\mathrm{Cl}$ character from $\mathrm{Cl} \mathrm{K}$-edge XAS.

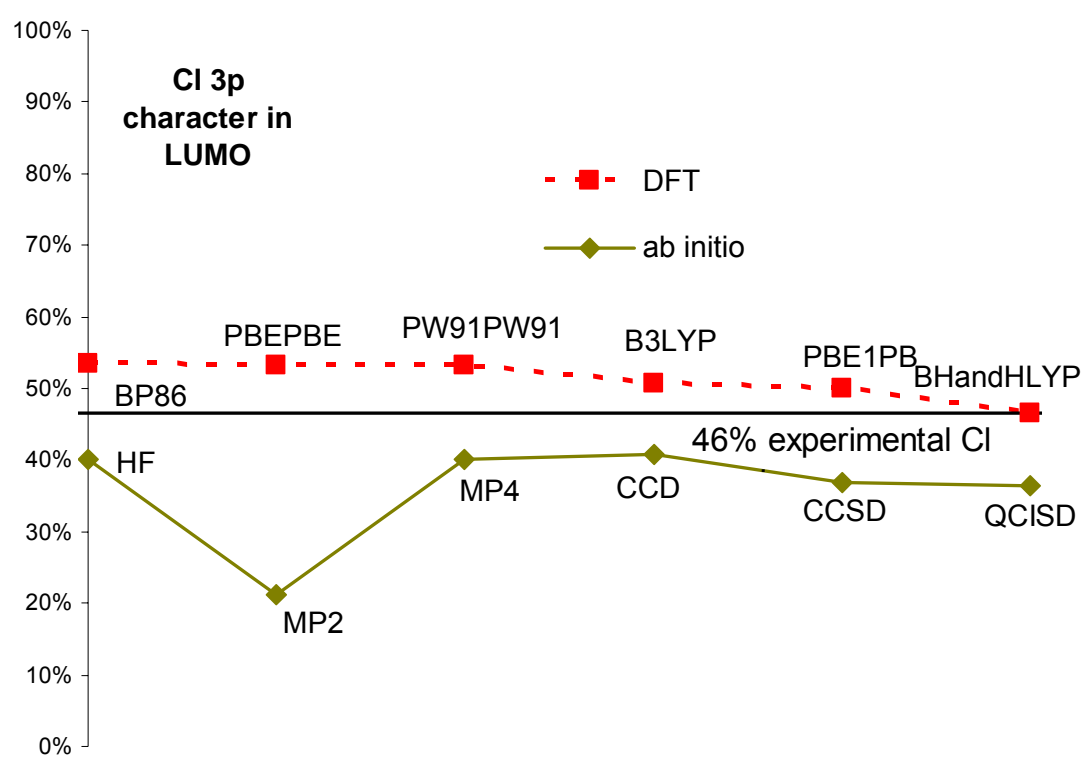

Figure 16. The calibration of theory to experimental XAS Pd-Cl covalency for $\left[\mathrm{PdCl}_{4}\right]^{2-}$ using the $\operatorname{SDD}(\mathrm{f})$ basis set for Pd and the 6-311G(d) basis set for $\mathrm{Cl}$.

A similar trend is observed in the theory calibration calculations of $\left[\mathrm{PdCl}_{6}\right]^{2-}$ in Figure 17. The exchange functionals show a decrease in $\mathrm{Cl} 3 \mathrm{p}$ character in the LUMO as more HF exchange is added and the ab initio electron correlation methods also show a decrease in palladium-chlorine covalency as higher order electron correlation is considered. However, the QCISD level of theory proved to be calibrated for the Pd(IV) complex as it calculates $51 \% \mathrm{Cl}$ character, which most accurately reproduces the experimental XAS Pd-Cl covalency of 50\%. Due to the high computational cost of the 
QCISD method on large Pd systems, the BHandHLYP will be considered the most reasonable level of theory for $\mathrm{Pd}(\mathrm{IV})$ as well as $\mathrm{Pd}(\mathrm{II})$. A discussion of the difference in QCISD calculations on $\operatorname{Pd}(\mathrm{II})$ and $\operatorname{Pd}(\mathrm{IV})$ occurs in the electronic structure analysis section (page 50).

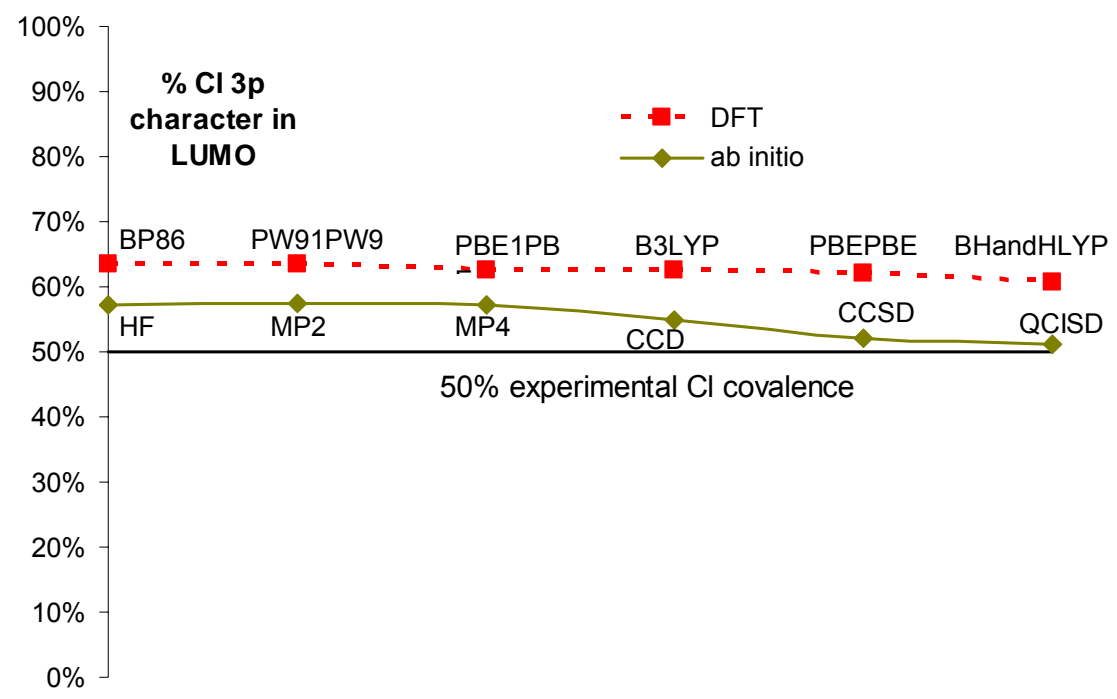

Figure 17. The calibration of theory to XAS experimental $\mathrm{Cl}$ covalence for $\left[\mathrm{PdCl}_{6}\right]^{2-}$ using the $\operatorname{SDD}(\mathrm{f})$ basis for $\mathrm{Pd}$ and the 6-311g(d) basis for $\mathrm{Cl}$.

As discussed in the materials and methods, the bridging chlorines in $\mathrm{PdCl}_{2}$ are all in the same plane effectively forming an infinitely long chain. By finding that the calculated $\mathrm{Pd} 4 \mathrm{~d}$ character in the palladium-chlorine bond for the central Pd converged to $54 \%$ (Table 7) using the theoretically converged basis sets and the BHandHLYP exchange functional, it was observed that this chain can be approximated with a cluster model that is 3 palladium atoms long and terminated with potassium atoms between 2.6$3.4 \AA$ away from the terminal Pd as pictured in Figure 18. This is in reasonable agreement with the experimental XAS value of $52 \% \mathrm{Pd} 4 \mathrm{~d}$ character. In this case, $\mathrm{Pd} 4 \mathrm{~d}$ character in the palladium chlorine bond was used to determine the appropriate model 
because Pd character was experimentally quantitated using Pd L-edge XAS. Because $\mathrm{K}_{2} \mathrm{Pd}_{2} \mathrm{Cl}_{6}$ will not effectively model the infinitely long $\mathrm{PdCl}_{2}$ chain, it was concluded that the terminal chlorides are bonding differently to Pd than bridging chlorides.

Table 7. Models of $\mathrm{PdCl}_{2}$ with $\mathrm{Cl} 3 \mathrm{p}$ and $\mathrm{Pd} 4 \mathrm{~d}$ covalency in $\mathrm{Pd}-\mathrm{Cl}$ bonds.

\begin{tabular}{cccc} 
distance $(\AA)$ & & \\
terminal alkali & & central Cl & central Pd \\
metal from Pd & covalency & $\begin{array}{c}\text { covalency } \\
\text { complex }\end{array}$ \\
\hline $\mathrm{K}_{2}\left[\mathrm{Pd}_{2} \mathrm{Cl}_{6}\right]$ & 3.0 & $27 \%$ & $39 \%$ \\
$\mathrm{~K}_{2}\left[\mathrm{Pd}_{2} \mathrm{Cl}_{6}\right]$ & 3.4 & $26 \%$ & $40 \%$ \\
$\mathrm{~K}_{2}\left[\mathrm{Pd}_{2} \mathrm{Cl}_{6}\right]$ & 3.8 & $25 \%$ & $41 \%$ \\
$\mathrm{~K}_{2}\left[\mathrm{Pd}_{2} \mathrm{Cl}_{6}\right]$ & 4.0 & $24 \%$ & $41 \%$ \\
$\mathrm{~K}_{2}\left[\mathrm{Pd}_{2} \mathrm{Cl}_{6}\right]$ & 4.1 & $30 \%$ & $24 \%$ \\
$\mathrm{~K}_{2}\left[\mathrm{Pd}_{2} \mathrm{Cl}_{6}\right]$ & 4.2 & $30 \%$ & $29 \%$ \\
\hline $\mathrm{K}_{2}\left[\mathrm{Pd}_{3} \mathrm{Cl}_{8}\right]$ & 2.6 & $22 \%$ & $53 \%$ \\
$\mathrm{~K}_{2}\left[\mathrm{Pd}_{3} \mathrm{Cl}_{8}\right]$ & 3.0 & $21 \%$ & $53 \%$ \\
$\mathrm{~K}_{2}\left[\mathrm{Pd}_{3} \mathrm{Cl}_{8}\right]$ & 3.4 & $21 \%$ & $53 \%$ \\
\hline $\mathrm{Rb}_{2}\left[\mathrm{Pd}_{3} \mathrm{Cl}_{8}\right]$ & 3.2 & $21 \%$ & $53 \%$ \\
$\mathrm{Na}_{2}\left[\mathrm{Pd}_{3} \mathrm{Cl}_{8}\right]$ & 2.8 & $22 \%$ & $53 \%$ \\
\hline $\mathrm{K}_{2}\left[\mathrm{Pd}_{4} \mathrm{Cl}_{10}\right]$ & 3.0 & $21 \%$ & $54 \%$
\end{tabular}

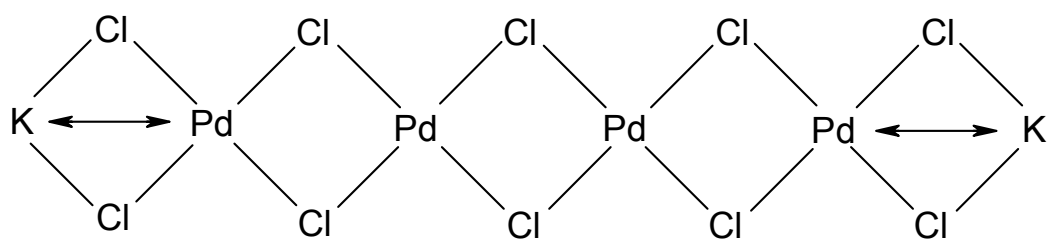

Figure 18. Varying the distance of $\mathrm{K}$ from $\mathrm{Pd}$ to find an appropriate model for $\mathrm{PdCl}_{2}$ that simulates an infinitely long chain for the $\mathrm{Cl}$ covalency of the central $\mathrm{Cl}$.

Table 8 summarizes the results of calculations with relativistic corrections and indicates that ZORA in ADF changed the $\mathrm{Cl} 3 \mathrm{p}$ orbital character in the LUMO by $5 \%$ and $1 \%$ for $\mathrm{D}_{4 \mathrm{~h}}\left[\mathrm{PtCl}_{4}\right]^{2-}$ and $\left[\mathrm{PdCl}_{4}\right]^{2-}$, respectively, compared to non-relativistic calculations. Gaussian relativistic DKH and RESC revealed $<<1 \%$ change in covalency for both the 50/50 exchange BHandHLYP and BP86 on both compounds. The results of 
the geometry optimization in Table 9 show a larger bond length difference between ZORA correction and uncorrected calculations for $\left[\mathrm{PtCl}_{4}\right]^{2-}$ compared to $\left[\mathrm{PdCl}_{4}\right]^{2-}$. No bond length change was observed for either molecule using the correction implemented in Gaussian. It was concluded that relativistic effects do not have a significant affect on Pd-ligand covalency.

Table 8. Effects of relativistic corrections on $\mathrm{Cl} \mathrm{p}$ orbital character in the LUMO of $\left[\mathrm{PdCl}_{4}\right]^{2-}$ and $\left[\mathrm{PtCl}_{4}\right]^{2-}$ using both ADF ZORA corrections and DKH, and RESC corrections in Gaussian.

\begin{tabular}{ccccc} 
complex & theory & Pd basis & $\begin{array}{c}\text { relativistic } \\
\text { correction }\end{array}$ & $\begin{array}{c}\text { total Cl 3p covalency } \\
\text { per d manifold hole }\end{array}$ \\
\hline$\left[\mathrm{PdCl}_{4}\right]^{2-}$ & BP86 & $\mathrm{SDD}(\mathrm{f})$ & None & $54 \%$ \\
& & & DKH & $54 \%$ \\
& & & RESC & $54 \%$ \\
\hline$\left[\mathrm{PtCl}_{4}\right]^{2-}$ & BP86 & SDD & None & $53 \%$ \\
& & & DKH & $53 \%$ \\
& & & RESC & $53 \%$ \\
\hline$\left[\mathrm{PdCl}_{4}\right]^{2-}$ & BP86 & TZP & None & $55 \%$ \\
& & & ZORA & $55 \%$ \\
\hline$\left[\mathrm{PtCl}_{4}\right]^{2-}$ & BP86 & TZP & None & $58 \%$ \\
& & & ZORA & $53 \%$ \\
\hline$\left[\mathrm{PdCl}_{4}\right]^{2-}$ & BHandHLYP & SDD(f) & None & $47 \%$ \\
& & & DKH & $47 \%$ \\
& & & RESC & $47 \%$ \\
\hline$\left[\mathrm{PtCl}_{4}\right]^{2-}$ & BHandHLYP & SDD & None & $47 \%$ \\
& & & DKH & $47 \%$ \\
& & & RESC & $47 \%$
\end{tabular}

Table 9. Effects of relativistic corrections in ADF and Gaussian on the Pd-Cl and Pt-Cl bond lengths in $\mathrm{D}_{4 \mathrm{~h}}$ compounds.

\begin{tabular}{ccccc} 
complex & theory & Pd basis & $\begin{array}{c}\text { relativistic } \\
\text { correction }\end{array}$ & $\begin{array}{c}\text { Metal -Cl } \\
\text { bond length }(\AA)\end{array}$ \\
\hline$\left[\mathrm{PdCl}_{4}\right]^{2-}$ & BP86 & TZP & None & 2.42 \\
& & & ZORA & 2.39 \\
\hline$\left[\mathrm{PtCl}_{4}\right]^{2-}$ & BP86 & TZP & None & 2.44 \\
& & & ZORA & 2.38 \\
\hline$\left[\mathrm{PdCl}_{4}\right]^{2-}$ & BHandHLYP & SDD(f) & None & 2.39 \\
& & & DKH & 2.39 \\
& & & RESC & 2.39 \\
\hline$\left[\mathrm{PtCl}_{4}\right]^{2-}$ & BHandHLYP & SDD(f) & None & 2.41 \\
& & & DKH & 2.41 \\
& & & RESC & 2.41
\end{tabular}


Calibrated electronic structure calculations presented in Table 10 on the $\mathrm{Cl}$ orbital characters in the LUMOs of $\left[\mathrm{PdCl}_{4}\right]^{2-}$ and $\left[\mathrm{PdCl}_{6}\right]^{2-}$ show that $\mathrm{Pd}-\mathrm{Cl}$ bond covalency from XAS is reproduced by the calculations. Chlorine $3 \mathrm{~s}$ and $3 \mathrm{~d}$ character in the LUMOs of $\left[\mathrm{PdCl}_{4}\right]^{2-}$ and $\left[\mathrm{PdCl}_{6}\right]^{2-}$ was found to be $2 \%$ and $\mathrm{Pd} 5 \mathrm{~s}$ and $5 \mathrm{p}$ character was found to be less than $0.5 \%$. Table 11 lists the calculated atomic charges for AIM, NPA, and ESP on each atom using the calibrated theory. While the charges are definitely method dependent, the relative differences in charges between species are consistent from method to method. For the AIM calculations, the chlorines in $\left[\mathrm{PdCl}_{4}\right]^{2-}$ have a charge of -0.66 and the $\mathrm{Pd}$ has a charge of +0.64 while the $\mathrm{Cl}$ 's in $\left[\mathrm{PdCl}_{6}\right]^{2-}$ have a -0.51 charge and $\mathrm{Pd}$ has a +1.04 charge. The chlorines and $\mathrm{Pd}$ in $\mathrm{PdCl}_{2}$ have charges of -0.35 and +0.69 , respectively.

NPA, summarized in Table 12 , of $\left[\mathrm{PdCl}_{4}\right]^{2-}, \mathrm{PdCl}_{2}$, and $\left[\mathrm{PdCl}_{6}\right]^{2-}$ reveals that orbital occupations of the tetrachloro and dichloro Pd species are nearly the same with populations of $\mathrm{Pd} 5 \mathrm{~s}^{0.4}, 4 \mathrm{~d}^{9}$, and $5 \mathrm{p}^{0.4}$ and $\mathrm{Cl} 3 \mathrm{~s}^{1.9}$ and $3 \mathrm{p}^{5.5}$ and $\left[\mathrm{PdCl}_{6}\right]^{2-}$ has populations of $\mathrm{Pd} 5 \mathrm{~s}^{0.4}, 4 \mathrm{~d}^{8.6}$, and $5 \mathrm{p}^{1}$ and $\mathrm{Cl} 3 \mathrm{~s}^{1.9}$ and $3 \mathrm{p}^{5.4}$ corresponding to an overall more covalent bonding interaction in $\left[\mathrm{PdCl}_{6}\right]^{2-}$ compared to $\mathrm{PdCl}_{2}$ or $\left[\mathrm{PdCl}_{4}\right]^{2-}$.

Table 10. Atomic orbital character in the LUMO of $\left[\mathrm{PdCl}_{4}\right]^{2-}, \mathrm{PdCl}_{2}$, and $\left[\mathrm{PdCl}_{6}\right]^{2-}$ using calibrated electronic structure calculations on the experimental crystal structure.

\begin{tabular}{cccccc} 
complex & theory used & $\begin{array}{c}\mathrm{Cl} 3 p \text { character } \\
\text { in LUMO }\end{array}$ & $\begin{array}{c}\mathrm{Pd} 4 \mathrm{~d} \text { character } \\
\text { in LUMO }\end{array}$ & $\begin{array}{c}\mathrm{Cl} \text { 3s and 3d } \\
\text { character in LUMO }\end{array}$ & $\begin{array}{c}\text { Pd 5s and 5p } \\
\text { character in LUMO }\end{array}$ \\
\hline$\left[\mathrm{PdCl}_{4}\right]^{2-}$ & BHandHLYP & $47 \%$ & $51 \%$ & $2 \%$ & $0 \%$ \\
{$\left[\mathrm{PdCl}_{6}\right]^{2-}$} & BHandHLYP & $61 \%$ & $38 \%$ & $2 \%$ & $0 \%$ \\
$\mathrm{PdCl}_{2}$ & BHandHLYP & $43 \%$ & $54 \%$ & $2 \%$ & $1 \%$
\end{tabular}


Table 11. NPA, AIM, ESP atomic charges of $\left[\mathrm{PdCl}_{4}\right]^{2-}, \mathrm{PdCl}_{2}$, and $\left[\mathrm{PdCl}_{6}\right]^{2-}$ using the calibrated level and theory and basis sets.

\begin{tabular}{cccccc} 
complex & theory used & atom & ESP & AIM & NPA \\
\hline$\left[\mathrm{PdCl}_{4}\right]^{2-}$ & BHandHLYP & $\mathrm{Pd}$ & 0.60 & 0.64 & 0.67 \\
& & $\mathrm{Cl}$ & -0.65 & -0.66 & -0.67 \\
& & & & & \\
{$\left[\mathrm{PdCl}_{6}\right]^{2-}$} & BHandHLYP & $\mathrm{Pd}$ & 0.56 & 1.04 & 0.86 \\
& & $\mathrm{Cl}$ & -0.43 & -0.51 & -0.48 \\
$\mathrm{PdCl}_{2}$ & \multirow{2}{*}{ BHandHLYP } & $\mathrm{Pd}$ & 0.25 & 0.69 & 0.68 \\
& & $\mathrm{Cl}$ & -0.13 & -0.35 & -0.36
\end{tabular}

Table 12. NPA showing the electron configuration of the valence orbitals in $\left[\mathrm{PdCl}_{4}\right]^{2-}$, $\mathrm{PdCl}_{2}$, and $\left[\mathrm{PdCl}_{6}\right]^{2-}$ with the calibrated level of theory. Orbitals with $\leq 0.02$ electron occupation are omitted.

\begin{tabular}{cccccc} 
Compound & Theory & Atom & \multicolumn{2}{c}{ valence orbital (occupation) } \\
\hline$\left[\mathrm{PdCl}_{4}\right]^{2-}$ & BHandHLYP & $\mathrm{Pd}$ & $5 \mathrm{~S}(0.43)$ & $4 \mathrm{~d}(9.09)$ & $5 \mathrm{p}(0.47)$ \\
& & $\mathrm{Cl}$ & $3 \mathrm{~S}(1.90)$ & $3 \mathrm{p}(5.59)$ & \\
& & & & & \\
{$\left[\mathrm{PdCl}_{6}\right]^{2-}$} & $\mathrm{BHandHLYP}$ & $\mathrm{Pd}$ & $5 \mathrm{~S}(0.43)$ & $4 \mathrm{~d}(8.64)$ & $5 \mathrm{p}(0.98)$ \\
& & $\mathrm{Cl}$ & $3 \mathrm{~S}(1.87)$ & $3 \mathrm{p}(5.44)$ & $3 \mathrm{~d}(0.01)$ \\
$\mathrm{PdCl}_{2}$ & BHandHLYP & $\mathrm{Pd}$ & $5 \mathrm{~S}(0.35)$ & $4 \mathrm{~d}(8.91)$ & $5 \mathrm{p}(0.41)$ \\
& & Bridging Cl & $3 \mathrm{~S}(1.83)$ & $3 \mathrm{p}(5.32)$ & $3 \mathrm{~d}(0.01)$
\end{tabular}

Specifying the electron occupations in $\mathrm{ADF}$, a $\mathrm{Cl} 1 \mathrm{~s}$ electron was excited to the appropriate LUMO to simulate the $\mathrm{Cl} \mathrm{K}$-edge pre-edge transition for $\left[\mathrm{PdCl}_{4}\right]^{2-}$ and $\left[\mathrm{PdCl}_{6}\right]^{2-}$. Figure 19 illustrate that in both compounds these electron transitions resulted in the LUMO orbital, along with it's bonding combination, rising in energy relative to the unoccupied $\mathrm{Pd} 5 \mathrm{~s}$ orbital. In addition, for $\left[\mathrm{PdCl}_{4}\right]^{2-}$, the Pd d-orbital character in the antibonding combination increases while the $\mathrm{Cl} \mathrm{p}$ orbital character decreases. The 
reverse trend is true for $\left[\mathrm{PdCl}_{6}\right]^{2-}$ as the $\mathrm{Pd} d$-orbital character decreases while the $\mathrm{Cl} \mathrm{p}$ orbital character increases in the LUMO.
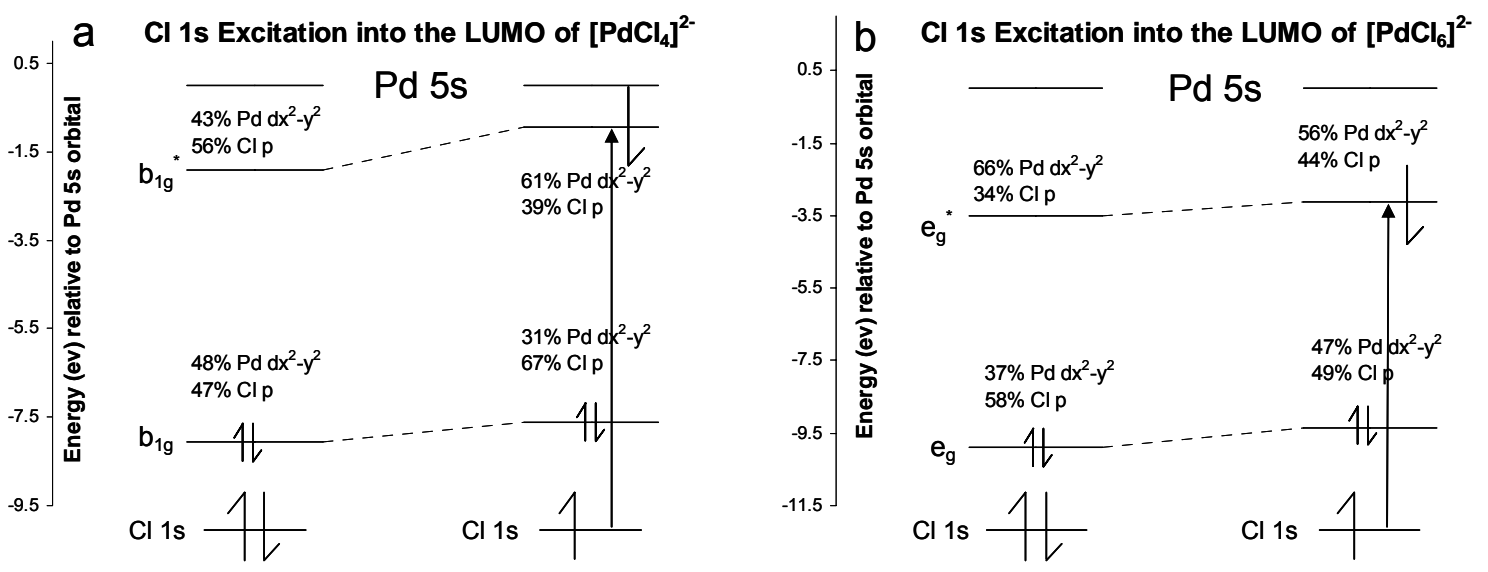

Figure 19. Excitation of an electron from the $\mathrm{Cl} 1 \mathrm{~s}$ orbital to the a) LUMO $\mathrm{b}_{1 \mathrm{~g}}$ * in $\left[\mathrm{PdCl}_{4}\right]^{2-}$ and b)LUMO e ${ }_{\mathrm{g}}{ }^{*}$ in $\left[\mathrm{PdCl}_{6}\right]^{2-}$ using the TZP all electron basis set for both $\mathrm{Pd}$ and $\mathrm{Cl}$ and the BP86 exchange function in ADF. The occupied orbitals between the bonding and antibonding $\mathrm{b}_{1 \mathrm{~g}}$ and $\mathrm{e}_{\mathrm{g}}$ orbitals are omitted for clarity.

An excitation of a Pd $2 p$ electron into the LUMO $b_{1 \mathrm{~g}}{ }^{*}$ of $\left[\mathrm{PdCl}_{4}\right]^{2-}$ or LUMO $\mathrm{e}_{\mathrm{g}}{ }^{*}$ for $\left[\mathrm{PdCl}_{6}\right]^{2-}$ designed to simulate the Pd L-edge pre-edge excitation is seen in Figure 20. The core vacancy results in both the anti-bonding LUMO $\mathrm{b}_{1 \mathrm{~g}}{ }^{*}$ and $\mathrm{e}_{\mathrm{g}}{ }^{*}$ and their bonding counterparts lowering in energy relative to the Pd 5s orbital. Concurrent with the orbital energy drop in $\left[\mathrm{PdCl}_{4}\right]^{2-}$, the $\mathrm{Cl} 3 \mathrm{p}$ orbital character in the LUMO increases while the $\mathrm{Pd}$ $4 \mathrm{~d}$ orbital character decreases. Once again, the reverse trend is observed in $\left[\mathrm{PdCl}_{6}\right]^{2-}$. Upon electronic relaxation after excitation, the $\mathrm{Cl} 3 \mathrm{p}$ orbital character decreases while the $\mathrm{Pd} 4 \mathrm{~d}$ orbital character increases in the LUMO. 

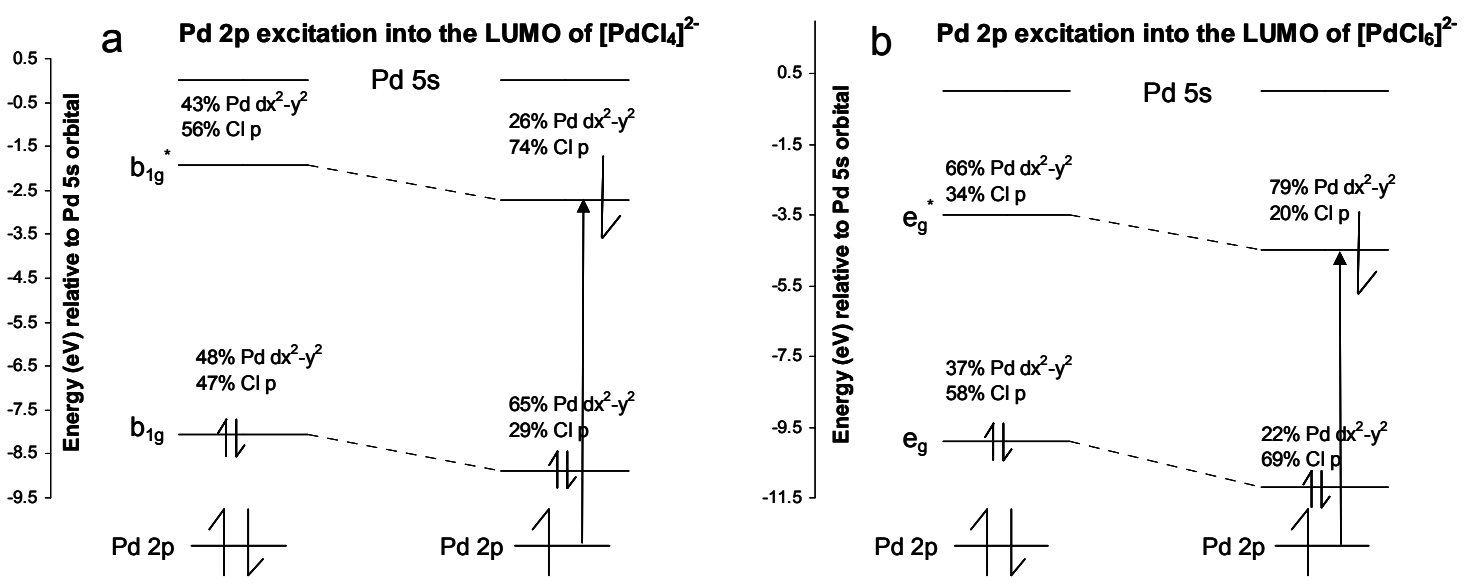

Figure 20. Excitation of an electron from the Pd $2 p$ orbital to the a) LUMO $b_{1 g} *$ in $\left[\mathrm{PdCl}_{4}\right]^{2-}$ and b)LUMO e ${ }_{\mathrm{g}}{ }^{*}$ in $\left[\mathrm{PdCl}_{6}\right]^{2-}$ using the TZP all electron basis set for both $\mathrm{Pd}$ and $\mathrm{Cl}$ and the BP86 exchange function in ADF. The occupied orbitals between the bonding and antibonding $\mathrm{b}_{1 \mathrm{~g}}$ and $\mathrm{e}_{\mathrm{g}}$ orbitals are omitted for clarity 


\section{ANALYSIS}

\section{Analysis of the $\mathrm{Cl} \mathrm{K}$-edge}

The rising edge position is a measure of the transition energy from the $\mathrm{Cl} 1 \mathrm{~s}$ to the $4 \mathrm{p}$ orbitals. Because the $\mathrm{Cl} 4 \mathrm{p}$ orbitals are involved in bonding only to a limited extent, a change in the rising edge-inflection point is indicative of a change in the energy of the $\mathrm{Cl}$ 1s orbital, which directly correlates with the effective nuclear charge of the $\mathrm{Cl}$. The $\mathrm{Cl}$ K-edge rising edge position of $\mathrm{D}_{4 \mathrm{~h}}\left[\mathrm{PdCl}_{4}\right]^{2-}$ at $2825.0 \mathrm{eV}$ compared to $2824.0 \mathrm{eV}$ for the $\mathrm{Cl}$ ligands in $\left[\mathrm{ZnCl}_{4}\right]^{2-}$ and $2826.9 \mathrm{eV}$ for $\left[\mathrm{PdCl}_{6}\right]^{2-}$. To explain this trend, it is noted that each $\mathrm{Cl}$ in the hexachloro complex has $4 \mathrm{Pd} 4 \mathrm{~d}$ orbital holes to donate into while the chlorines in the tetrachloro complex only has 2 electron holes for donation. The $\mathrm{Zn}$ in the $\left[\mathrm{ZnCl}_{4}\right]^{2-}$ is $\mathrm{d}^{10}$ and doesn't have any d orbital holes to donate into. Further discussion of the rising edge positions occurs throughout the analysis.

The most intense pre-edge peak positions were located at 2821.5 and $2820.2 \mathrm{eV}$ for $\left[\mathrm{PdCl}_{4}\right]^{2-}$ and $\left[\mathrm{PdCl}_{6}\right]^{2-}$, respectively. The difference between the locations of the preedge peaks is due to both the energies of the Pd d manifolds as well as the energies of the core $\mathrm{Cl} 1 \mathrm{~s}$ orbitals. The $\mathrm{d}$ manifold shift is quite pronounced when comparing an $\mathrm{O}_{\mathrm{h}}$ $\mathrm{Pd}(\mathrm{IV})$ species to a square planar $\mathrm{Pd}(\mathrm{II})$. Although the $\left[\mathrm{PdCl}_{6}\right]^{2-}$ chlorines have a greater charge than the square planar chlorines in $\left[\mathrm{PdCl}_{4}\right]^{2-}$, the pre-edge feature is $1.6 \mathrm{eV}$ lower in energy in the hexacho complex indicating that the $\mathrm{d}$ manifold is lower in the $\mathrm{O}_{\mathrm{h}}$ complex. This is expected for $\left[\mathrm{PdCl}_{6}\right]^{2-}$ as the $\mathrm{Pd}$ has a greater $\mathrm{Z}_{\mathrm{eff}}$. 
Assuming that there is a linear relationship between nuclear charge and the $\mathrm{Cl} \mathrm{K}$ edge rising edge inflection point as reported in the literature ${ }^{14}$, then experimental information can be obtained about $\mathrm{Pd} 5 \mathrm{~s} / 5 \mathrm{p}$ and $\mathrm{Cl} 4 \mathrm{~s} / 3 \mathrm{~d} / 4 \mathrm{p}$ mixing by the comparison of the $\mathrm{Cl} \mathrm{K}$-edge rising edge inflection points and $\mathrm{Pd}-\mathrm{Cl}$ covalencies. Observing that $\mathrm{Pd}-\mathrm{Cl}$ covalencies of $23 \%$ and $33 \% \mathrm{Cl}$ character per bond were found in $\left[\mathrm{PdCl}_{4}\right]^{2-}$ and $\left[\mathrm{PdCl}_{6}\right]^{2-}$, respectively, and that the rising edge position of $\left[\mathrm{PdCl}_{6}\right]^{2-}$ is $1.9 \mathrm{eV}$ greater than $\left[\mathrm{PdCl}_{4}\right]^{2-}$ points to additional mixing of the $\mathrm{Cl}$ and $\mathrm{Pd}$ orbitals in $\left[\mathrm{PdCl}_{6}\right]^{2-}$. The calculated AIM charges in Table 11 confirm that the difference in the rising edge positions is not due to the effective nuclear charges as the chlorines on $\left[\mathrm{PdCl}_{6}\right]^{2-}$ have a charge of -0.55 compared to -0.66 on $\left[\mathrm{PdCl}_{4}\right]^{2-}$. This mixing means that the $\mathrm{Pd} 4 \mathrm{~d}$ character in the $\mathrm{Pd}-\mathrm{Cl}$ bond of $\left[\mathrm{PdCl}_{6}\right]^{2-}$ can not be assumed to be the remainder not accounted for in the $\mathrm{Cl} \mathrm{K}$ edge pre-edge peak intensity and must be considered when developing the Pd L-edge transition dipole integral. This is discussed further in the Pd L-edge section.

The most intense pre-edge peaks in Figure 11 are assigned to transitions into the doubly unoccupied LUMO $b_{1 \mathrm{~g}}{ }^{*}$ for $\left[\mathrm{PdCl}_{4}\right]^{2-}$ and quadruply unoccupied LUMO $\mathrm{e}_{\mathrm{g}}{ }^{*}$ for $\left[\mathrm{PdCl}_{6}\right]^{2-}$. The $\mathrm{b}_{1 \mathrm{~g}}{ }^{*}$ orbital (pictured in Figure 21a) is a combination of the Pd based $4 d_{x^{2}-y^{2}}$ and $\mathrm{Cl}$ based $3 p$ orbitals while the the $e_{g}{ }^{*}$ orbital (pictured in Figure 21b,c) is a combination of the $\mathrm{Pd}$ based $4 \mathrm{~d}_{\mathrm{x}^{2}-\mathrm{y}^{2}}, 4 \mathrm{~d}_{\mathrm{z}^{2}}$, and $\mathrm{Cl}$ based $3 \mathrm{p}$ orbitals. The shoulders at the higher energy side of the pre-edge peaks in Figure 4 were assigned to excited state satellite transitions. Excited state calculations performed in $\mathrm{ADF}$ on $\left[\mathrm{PdCl}_{4}\right]^{2-}$ shown in Figure 19a support this assertion by revealing the collapse of the $\mathrm{Cl}$ orbitals upon an excitation from the $\mathrm{Cl} 1 \mathrm{~s}$ to the $\mathrm{LUMO} \mathrm{b}_{1 \mathrm{~g}}{ }^{*}$ leading to new orbitals available to accept the 
excitation from the core. The resulting higher energy LUMO gives rise to a higher energy satellite peak. Likewise, similar phenomena occurs in $\left[\mathrm{PdCl}_{6}\right]^{2-}$ as calculations on the excitation of a Cl 1s electron into the LUMO $\mathrm{e}_{\mathrm{g}}{ }^{*}$, illustrated in Figure 19b, show similar energy changes.
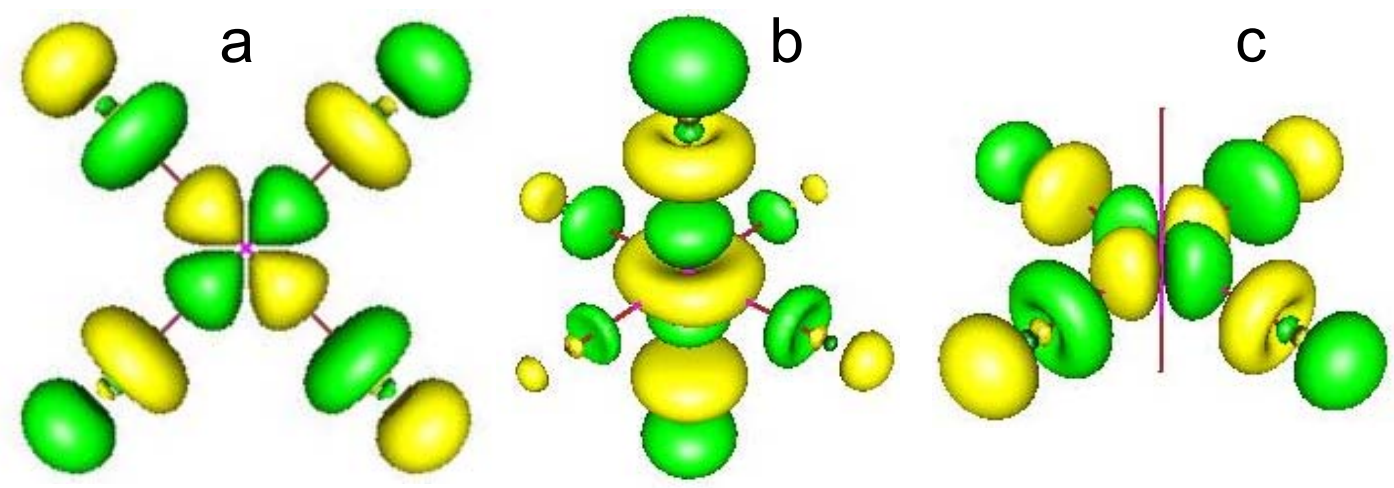

Figure 21. Molecular orbital contour plots of the a) LUMO $b_{1 g}{ }^{*}$ for $\mathrm{D}_{4 \mathrm{~h}}\left[\mathrm{PdCl}_{4}\right]^{2-}$, b) LUMO Pd $\mathrm{d}_{\mathrm{z}^{2}}$ and $\mathrm{Cl} 3 \mathrm{p}$ of degenerate $\mathrm{e}_{\mathrm{g}}{ }^{*}$ set and c) LUMO Pd $\mathrm{d}_{\mathrm{x}^{2}-\mathrm{y}^{2}}$ and $\mathrm{Cl} 3 \mathrm{p}$ of degenerate $\mathrm{e}_{\mathrm{g}}{ }^{*}$ set for $\mathrm{O}_{\mathrm{h}}\left[\mathrm{PdCl}_{6}\right]^{2-}$. Transitions from the $\mathrm{Cl} 1 \mathrm{~s}$ and $\mathrm{Pd} 2 \mathrm{p}$ orbitals into these LUMO's gives rise to the XAS pre-edge features seen in the $\mathrm{Cl} \mathrm{K}, \mathrm{Pd} \mathrm{L}_{\mathrm{III}}$ and $\mathrm{L}_{\mathrm{II}^{-}}$ edges.

\section{Analysis of the Pd L-edge Spectra}

The rising edge position of the Pd L-edges should be complimentary to the $\mathrm{Cl} \mathrm{K}$ edge as a greater effective nuclear charge on the $\mathrm{Cl}$ means a lower effective nuclear charge on the $\mathrm{Pd}$ and lower energy $\mathrm{Pd} 2 \mathrm{p}$ to $4 \mathrm{~d}$ transition. The relatively high energy rising edge position of $3185.0 \mathrm{eV}$ for the hexachloro complex compared to $3180.0 \mathrm{eV}$ for the tetrachloro complex is evidence of $\mathrm{Pd} 5 \mathrm{~s} / 5 \mathrm{p}$ orbital mixing in $\left[\mathrm{PdCl}_{6}\right]^{2-}$. This information is vital as an experimental tool for determining the minor contributions that the other orbitals make to the palladium-chlorine bond has not yet been developed. 
As with the $\mathrm{Cl} \mathrm{K}$-edge, the effective nuclear charge and the Pd 4d manifold shift must be considered when analyzing the $\mathrm{Pd} \mathrm{L}_{\mathrm{III}}$ pre-edge peak positions. The pre-edge peaks are located at 3175.8 and $3177.8 \mathrm{eV}$ for $\left[\mathrm{PdCl}_{4}\right]^{2-}$ and $\left[\mathrm{PdCl}_{6}\right]^{2-}$, respectively. Noticing that the rising-edge position of $\left[\mathrm{PdCl}_{6}\right]^{2-}$ is nearly $5 \mathrm{eV}$ greater than $\left[\mathrm{PdCl}_{4}\right]^{2-}$ and that the pre-edge feature is only $3 \mathrm{eV}$ greater points to a lower energy $\mathrm{Pd} \mathrm{d}$ manifold in the hexachloro complex. This is expected when comparing an $\mathrm{O}_{\mathrm{h}} \mathrm{d}^{6}$ metal to a $\mathrm{D}_{4 \mathrm{~h}} \mathrm{~d}^{8}$ metal.

The most intense pre-edge features for the $\left[\mathrm{PdCl}_{4}\right]^{2-}$ L-edges are assigned to a transition from the Pd $2 \mathrm{p}$ to the LUMO $b_{1 \mathrm{~g}}{ }^{*}$ while the same feature is assigned to the transition into the $\mathrm{LUMO} \mathrm{e}_{\mathrm{g}}{ }^{*}$ for $\left[\mathrm{PdCl}_{6}\right]^{2-}$. Lower energy satellite peaks are thought to be present in the $\left[\mathrm{PdCl}_{4}\right]^{2-}$ L-edges but hidden due to its proximity to the primary preedge feature. As an electron is removed from the $\left[\mathrm{PdCl}_{4}\right]^{2-} \mathrm{Pd} 2 \mathrm{p}$ orbital and placed in the LUMO $b_{1 \mathrm{~g}}{ }^{*}$ the $\mathrm{Pd} \mathrm{d}$ manifold collapses due to a greater effective nuclear charge lowering the energy of the LUMO $\mathrm{b}_{1 \mathrm{~g}}{ }^{*}$. The second derivative of the hexachloro complexes L-edge spectra in Figure 12 reveals that this lower energy satellite is resolved. The reason for the appearance of this satellite in the $\left[\mathrm{PdCl}_{6}\right]^{2-} \mathrm{L}$-edge spectra and not in the spectra of the $\mathrm{Pd}(\mathrm{II})$ complexes is probably due to the greater effective nuclear charge on the $\operatorname{Pd}(\mathrm{IV})$ center causing the d-orbitals, and therefore, the electronic states to have greater energy separation. The satellite peak switches from a higher energy shoulder to a lower energy shoulder moving from the $\mathrm{Cl} \mathrm{K}$-edge to the Pd L-edge. The $\mathrm{Cl} 1$ s core hole lowers the energy of higher unoccupied orbitals. These lower lying unoccupied orbitals then mix with the LUMO giving rise to higher energy satellite peak. Conversely, the 
electronic relaxation caused by the $2 \mathrm{p}$ core hole in $\mathrm{Pd}$ is faster than the excited state recombination to ground state and thus a lower energy satellite feature arises.

Application of the Calibrated Level of Theory and

$\underline{\mathrm{Pd} \text { L-edge Dipole Integrals on } \mathrm{PdCl}_{2}}$

The MO contour plots of the LUMO and LUMO+1 in Figure 22a and b show the anti-bonding orbitals being probed by XAS for a model of $\mathrm{PdCl}_{2}$. Although this model does not reproduce the experimental XAS $\mathrm{Pd}-\mathrm{Cl}$ covalency, it is useful for visualization of the molecular orbitals. The orientation of the $\mathrm{Cl} 3 \mathrm{p}$ orbital lobes is different in the bridging and terminal Cl's with the terminal $\mathrm{Cl} 3 \mathrm{p}$ orbital lobes pointing directly at the $\mathrm{Pd}$ to form a $\sigma$ bond with the $\operatorname{Pd} \mathrm{d}_{\mathrm{xy}}$ (or $\mathrm{d}_{\mathrm{x} 2-\mathrm{y}} 2$ depending on the coordinate definition) orbital and the bridging $\mathrm{Cl} 3 \mathrm{p}_{\mathrm{x}}$ and $3 \mathrm{p}_{\mathrm{y}}$ orbital lobes rotated $45^{\circ}$ relative to the terminal $\mathrm{Cl} \mathrm{p}$ orbitals. The bridging $\mathrm{Cl} \mathrm{p}_{\mathrm{x}}$ forms a sigma bond with the,+- combination of $2 \mathrm{Pd} \mathrm{d}_{\mathrm{xy}}$ orbitals (LUMO) and the $\mathrm{Cl} \mathrm{p}_{\mathrm{y}}$ forms a second $\sigma$ bond with the,++ combination of $2 \mathrm{Pd}$ $\mathrm{d}_{\mathrm{xy}}$ orbitals (LUMO+1). A Pd-Pd bonding interaction would cause the LUMO+1 in Figure 22 to be much higher in energy than the LUMO. Clearly this is not the case as this energy separation is $<0.05 \mathrm{eV}$ for all the models in Table 9.

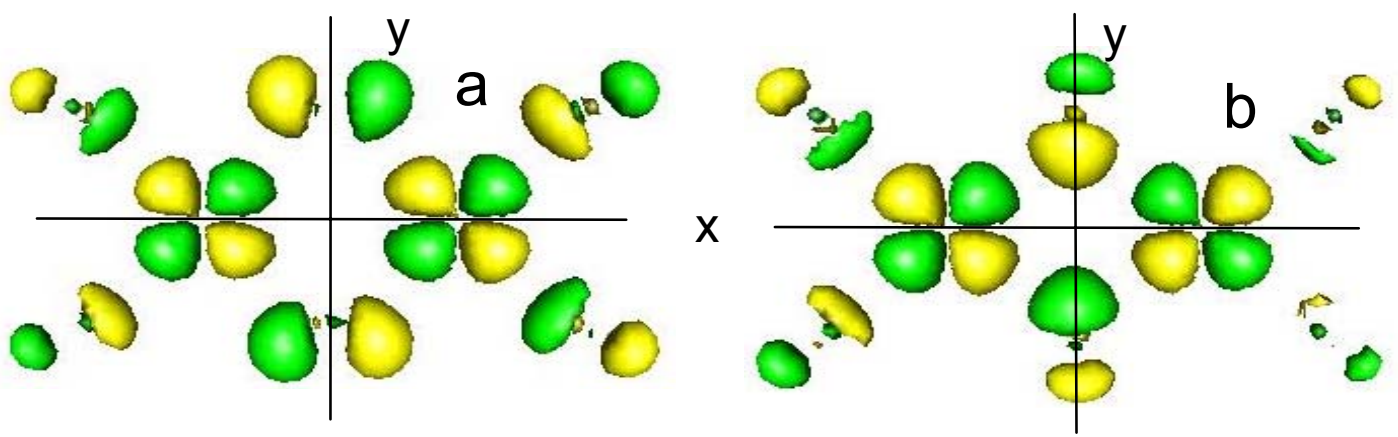

Figure 22. The LUMO (a) and LUMO+1 (b) MO contour plots of $\mathrm{Pd}_{2} \mathrm{Cl}_{6}$ showing the different overlap of the terminal and bridging $\mathrm{Cl}$ 's with the Pd centers. 
Because the L-pre-edge peak positions and rising edge positions of $\mathrm{PdCl}_{2}$ and $\left[\mathrm{PdCl}_{4}\right]^{2-}$ shown in Figure 12 are at nearly the same energy, the Pd's have the same effective nuclear charge and thus the same Pd L-edge dipole integrals apply. Tables 13 and 14 list the peak positions, intensities, HHLW, $\mathrm{D}_{0}$ 's, and $\mathrm{Pd}$ covalency for $\mathrm{PdCl}_{2}$ using the dipole integrals for the three separate methods developed on $\left[\mathrm{PdCl}_{4}\right]^{2-}$ at both the ALS and the SSRL. The average Pd covalency was found to be $50 \%$ per $\mathrm{Pd} 4 \mathrm{~d}$ orbital hole. It is believed that similar satellite transitions to the $\left[\mathrm{PdCl}_{4}\right]^{2-}$ and $\left[\mathrm{PdCl}_{6}\right]^{2-}$ spectra are occurring in $\mathrm{PdCl}_{2}$ because of the similarity of the complexes and the presence of the satellites in the $\mathrm{Cl} \mathrm{K}$-edge spectra. However, these satellite transitions are not resolvable in the Pd L-edges due to its proximity to the main pre-edge feature.

Table 13. $\mathrm{PdCl}_{2} \mathrm{~L}_{\mathrm{III}}{ }^{-}$and $\mathrm{L}_{\mathrm{II}}$-edge data measured at the ALS and SSRL and its quantitative analysis.

\begin{tabular}{|c|c|c|c|c|c|c|c|}
\hline $\begin{array}{c}\mathrm{PdCl}_{2} \\
\text { edge }\end{array}$ & $\begin{array}{l}\text { location } \\
\text { and setup }\end{array}$ & $\begin{array}{l}\text { rising edge } \\
\text { inflection } \\
\text { point }(\mathrm{eV})\end{array}$ & $\begin{array}{c}\text { peak } \\
\text { position }(\mathrm{eV})\end{array}$ & $\begin{array}{l}\text { intensity } \\
\text { of peak }\end{array}$ & $\begin{array}{c}\text { HHLW } \\
(\mathrm{eV}) \\
\end{array}$ & $\begin{array}{l}\Sigma D_{0} \\
(\mathrm{eV})\end{array}$ & $\begin{array}{c}\mathrm{Pd} \mathrm{d} \\
\text { character using } \\
{\left[\mathrm{PdCl}_{4}\right]^{2-} \text { integrals }}\end{array}$ \\
\hline $\mathrm{L}_{\mathrm{III}}$ & SSRL setup B & 3181.1 & 3175.7 & 2.49 & 1.46 & 7.3 & $104 \%$ \\
\hline $\begin{array}{c}\text { absorbers (1) } \\
\text { electron holes (2) }\end{array}$ & ALS setup D & 3181.2 & 3176.2 & 1.88 & 1.59 & 6.0 & $109 \%$ \\
\hline $\mathrm{L}_{\mathrm{II}}$ & SSRL setup B & 3338.1 & 3332.6 & 2.14 & 1.38 & 5.9 & $91 \%$ \\
\hline $\begin{array}{c}\text { absorbers (1) } \\
\text { electron holes (2) }\end{array}$ & ALS setup D & 3338.7 & 3333.2 & 2.46 & 1.17 & 5.8 & $102 \%$ \\
\hline
\end{tabular}

Table 14. $\mathrm{PdCl}_{2} \mathrm{Pd} \mathrm{L} \mathrm{L}_{\mathrm{II}}+\mathrm{L}_{\mathrm{II}}$-edge data measured at the ALS and SSRL. The number of absorbers is one and the number of electron holes is two.

\begin{tabular}{|c|c|c|c|c|c|c|c|c|c|c|c|}
\hline $\begin{array}{c}\mathrm{PdCl}_{2} \\
\text { location } \\
\text { and setup }\end{array}$ & $\begin{array}{c}\mathrm{L}_{\mathrm{III}} \\
\text { peak } \\
\text { positions }(\mathrm{eV}) \\
\end{array}$ & $\begin{array}{r}\text { intensity } \\
\text { of peak }\end{array}$ & $\begin{array}{c}\text { HHLW } \\
(\mathrm{eV})\end{array}$ & $\begin{array}{r}\mathrm{L}_{\text {III }} \\
\Sigma \mathrm{D}_{0} \\
(\mathrm{eV}) \\
\end{array}$ & $\begin{array}{c}\mathrm{L}_{\|} \\
\text {peak } \\
\text { positions }(\mathrm{eV}) \\
\end{array}$ & $\begin{array}{c}\text { intensity } \\
\text { of peak }\end{array}$ & $\begin{array}{c}\text { HHLW } \\
(\mathrm{eV})\end{array}$ & $\begin{array}{r}\mathrm{L}_{\|} \\
\Sigma \mathrm{D}_{0} \\
(\mathrm{eV}) \\
\end{array}$ & $\begin{array}{r}\mathrm{L}_{111}+\mathrm{L}_{\| 1} \\
\Sigma \mathrm{D}_{0}(\mathrm{eV}) \\
\end{array}$ & $\begin{array}{c}\text { LIIIIL LII-edge } \\
\text { jumps }\end{array}$ & $\begin{array}{c}\text { Pd d } \\
\text { character using } \\
{\left[\mathrm{PdCl}_{4}\right]^{2-} \text { integrals }} \\
\end{array}$ \\
\hline SSRL setup $B$ & 3175.7 & 1.40 & 1.45 & 4.1 & 3332.6 & 0.81 & 1.35 & 2.2 & 6.3 & 0.6 & $91 \%$ \\
\hline ALS setup D & 3176.2 & 1.03 & 1.47 & 3.0 & 3333.2 & 0.82 & 1.38 & 2.3 & 5.3 & 0.6 & $103 \%$ \\
\hline
\end{tabular}


Table 15. $\mathrm{PdCl}_{2} \mathrm{Cl} \mathrm{K}$-edge data measured at ALS and SSRL.

\begin{tabular}{|c|c|c|c|c|c|c|c|c|c|c|}
\hline complex & $\begin{array}{l}\text { location } \\
\text { and setup }\end{array}$ & $\begin{array}{c}\text { rising edge } \\
\text { inflection } \\
\text { point }(\mathrm{eV}) \\
\end{array}$ & \begin{tabular}{|c} 
peak \\
position $(\mathrm{eV})$ \\
\end{tabular} & $\begin{array}{c}\text { intensity } \\
\text { of peak }\end{array}$ & $\begin{array}{c}\mathrm{HHLW} \\
(\mathrm{eV})\end{array}$ & $\begin{array}{c}\mathrm{D}_{0} \\
(\mathrm{eV}) \\
\end{array}$ & $\begin{array}{l}\sum \mathrm{D}_{0} \\
(\mathrm{eV}) \\
\end{array}$ & $\begin{array}{c}\text { total } \mathrm{Cl} 3 p \\
\text { covalence per } \\
\mathrm{d} \text { manifold hole } \\
\end{array}$ & $\begin{array}{c}\text { transition } \\
\text { dipole integral }(\mathrm{eV}) \\
\text { for bridging } \mathrm{Cl} \\
\end{array}$ & $\begin{array}{c}\text { average transition } \\
\text { dipole integral }(\mathrm{eV}) \\
\text { for bridging } \mathrm{Cl} \\
\end{array}$ \\
\hline $\mathrm{PdCl}_{2}$ & SSRL & 2826.6 & 2821.8 & 1.81 & 0.67 & 2.4 & 2.73 & $94 \%$ & 35 & \\
\hline absorbers & setup B & & 2823.2 & 0.23 & 0.67 & 0.3 & & & & 34 \\
\hline $\begin{array}{c}4 \\
\text { electron holes }\end{array}$ & $\begin{array}{c}\text { ALS } \\
\text { Setup } C^{\dagger}\end{array}$ & 2826.6 & $\begin{array}{l}2821.8 \\
2823.3\end{array}$ & $\begin{array}{l}1.67 \\
0.23\end{array}$ & $\begin{array}{l}0.68 \\
0.68\end{array}$ & $\begin{array}{l}2.3 \\
0.3\end{array}$ & 2.60 & $94 \%$ & 33 & \\
\hline 2 & $\begin{array}{c}\text { ALS } \\
\text { Setup D }\end{array}$ & 2826.6 & $\begin{array}{l}2821.8 \\
2823.2\end{array}$ & $\begin{array}{l}1.56 \\
0.22\end{array}$ & $\begin{array}{l}0.68 \\
0.68\end{array}$ & $\begin{array}{l}2.1 \\
0.3\end{array}$ & 2.4 & $94 \%$ & 31 & 31 \\
\hline
\end{tabular}

${ }^{\dagger}$ Extrapolated data due to photo reduction radiation damage.

The greater effective nuclear charge on the bridging $\mathrm{Cl}$ in $\mathrm{PdCl}_{2}$ directly affects the $\mathrm{Cl} 1 \mathrm{~s}$ orbital and thus the $\mathrm{Cl}(1 \mathrm{~s} \rightarrow 3 \mathrm{p})$ dipole integral. This requires a new $\mathrm{Cl} \mathrm{K}$-edge dipole integral for the bridging $\mathrm{Cl}$. The LUMO and $\mathrm{LUMO}+1$ of $\mathrm{PdCl}_{2}$ are a combination of the $\mathrm{Pd} \mathrm{d}_{\mathrm{xy}}$ orbital, which was quantitated in the Pd L-edge, and the $\mathrm{Cl} 3 \mathrm{p}$ orbitals with minor contributions from the $\mathrm{Pd} 5 \mathrm{~s}, 5 \mathrm{p}$ and $\mathrm{Cl} 3 \mathrm{~s}, 3 \mathrm{~d}$ orbitals. Results of electronic structure calculation presented above provide an estimate of the $\mathrm{Cl} 3 \mathrm{~s}$ and $3 \mathrm{~d}$ and $\mathrm{Pd} 5 \mathrm{~s}$ and $5 \mathrm{p}$ contributions to the ground state electronic structure. They reveal $4 \%$ total $\mathrm{Cl} 3 \mathrm{~d}$ and $3 \mathrm{~s}$ character and $2 \% \mathrm{Pd} 5 \mathrm{p}$ and $5 \mathrm{~s}$ character for $\mathrm{PdCl}_{2}$. Subtracting this from the remaining 100\% from the Pd L-edges yields $94 \% \mathrm{Pd} d$ character that should correspond to the pre-edge intensities in the $\mathrm{Cl} \mathrm{K}$-edge. The number of $\mathrm{Cl}$ absorbers is defined to be the number of $\mathrm{Cl} p$ orbitals that form a $\sigma$ bond because each $\sigma$ bond must be accounted for in the renormalization process. In $\mathrm{PdCl}_{2}$ the $\mathrm{Cl} 3 \mathrm{p}_{\mathrm{x}}$ and $3 \mathrm{p}_{\mathrm{y}}$ orbitals in each $\mathrm{Cl}$ form sigma bonds with a $\mathrm{Pd}$ resulting in four $\mathrm{Cl}$ absorbers in $\mathrm{PdCl}_{2}$. Similar the $\mathrm{Cl} \mathrm{K}-$ edge of the other $\mathrm{Pd}$ complexes measured, $\mathrm{PdCl}_{2}$ has a higher energy satellite peak. Because the peak arises from the same state as the primary pre-edge feature, it is also included in $\mathrm{D}_{0}$ and thus dipole integral calculations. $\mathrm{Cl}$ K-edge dipole integrals of $34 \mathrm{eV}$ at ALS with $\mathrm{LN}_{2}$ cooling and $31 \mathrm{eV}$ at SSRL were found for the bridging $\mathrm{Cl}^{\prime}$ 's in $\mathrm{PdCl}_{2}$. 


\section{$\underline{\text { Electronic structure calculations }}$}

It is clear in Tables 8 and 9 that the relativistic corrections in Gaussian had little effect on the geometry and covalency of both $\left[\mathrm{PdCl}_{4}\right]^{2-}$ and $\left[\mathrm{PtCl}_{4}\right]^{2-}$ while ZORA calculations in ADF showed minor geometric and covalency effects on $\left[\mathrm{PdCl}_{4}\right]^{2-}$ and greater effects in these areas on $\left[\mathrm{PtCl}_{4}\right]^{2-}$. This indicates that $\mathrm{ZORA}$ at least treats relativistic electrons differently than non-relativistic electrons. Although the 50/50 BHandHLYP functional for Pd(II), the QCISD ab initio energy correction for Pd(IV), or the $\operatorname{SDD}(\mathrm{f})$ basis set cannot be applied in ADF, it is very likely that ZORA relativistic corrections are not method dependent and would not have a significant effect on the Pd$\mathrm{Cl}$ covalency of $\left[\mathrm{PdCl}_{4}\right]^{2-}$ if these methods were employed. Further evidence that relativistic effects are insignificant in covalency calculations on $\mathrm{Pd}$ complexes comes from the literature ${ }^{75}$. The RESC method has been shown to explain the difference in reactivity between $\mathrm{Pd}$ and $\mathrm{Pt}$ monorganic complexes with two trimethylphosphine ligands for reactivity toward $\mathrm{CO}$ insertion. Experimental data shows Pd complexes to be highly reactive as catalysts in carbonylation reactions in contrast to the lack or reactivity for the Pt complexes. Table 10 shows that the RESC relativistic correction has a large effect on the activation energy and heat of formation for the $\mathrm{CO}$ insertion reaction in the $\mathrm{Pt}$ complex indicating that the relativistic effects caused by the greater nuclear charge in $\mathrm{Pt}$ compared to $\mathrm{Pd}$ are responsible for the difference in reactivity toward $\mathrm{CO}$ insertion in these complexes. Relativistic corrections showed only minor changes in the transition state and product energy for the Pd analogue ${ }^{75}$. 
Table 16. Comparison of non-relativistic and relativistic (RESC) corrections of activation energy and heat of formation in the $\mathrm{CO}$ insertion to $\mathrm{Pt}$ complex ${ }^{75}$.

Relativistic

Reactant Transition State

Product

\begin{tabular}{cccc} 
Corretion & Energy $(\mathrm{kcal} / \mathrm{mol})$ & Energy $(\mathrm{kcal} / \mathrm{mol})$ & Energy $(\mathrm{kcal} / \mathrm{mol})$ \\
\hline None & 0.0 & 20.6 & -1.5 \\
RESC & 0.0 & 33.2 & 10.9
\end{tabular}

While QCISD has been shown to both reproduce experimental XAS covalency for third row transition metal chlorides and calculate $\mathrm{Cl}$ character in a metal-chlorine bond that is greater than $\mathrm{HF}$, but less than the BP86 theories, it is apparent that this trend breaks down in fourth row transition metal chlorides because it shows neither of these behaviors for $\left[\mathrm{PdCl}_{4}\right]^{2-}$. The calculated $\mathrm{Cl}$ ovalency for Group VIIIB $\left[\mathrm{MCl}_{4}\right]^{2-}$ complexes in Figure 15 shows that $\mathrm{Pt}$ falls in line with the $\mathrm{Pd}$ for relative $\mathrm{Cl}$ covalencies of each theory while experimental XAS experimental covalency is unavailable. Noting that QCISD reproduced the experimental XAS Pd-Cl covalency of $\left[\mathrm{PdCl}_{6}\right]^{2-}$ indicates that the main difference between third and fourth or fifth row transition metals is that electron correlation methods increase the covalency compared to HF for the third row and decrease the covalency for fourth and fifth row metal complexes. Complete Active Space Multiconfiguration ${ }^{76,77}$ (CASSCF) calculations showed only a small amount of mixing for all of the Group VIIIB chloride complexes. The irregularity of the MP2 calculation (see Figure 10) is further evidence of the unusual behavior of ab initio electron correlation calculations on chloro palladium complexes. Regardless of the reason for the inadequacy of first and second order quadratic CI calculations on these planar complexes, an accurate, computationally efficient, hybrid functional method exists for computations. 


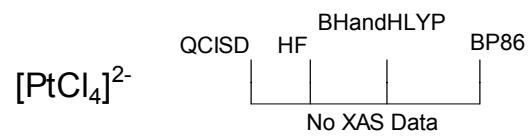

$\left[\mathrm{NiCl}_{4}\right]^{2-}$

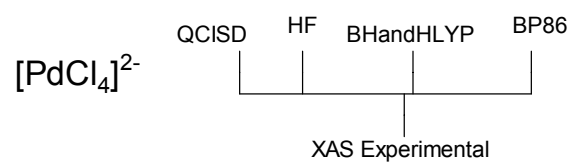

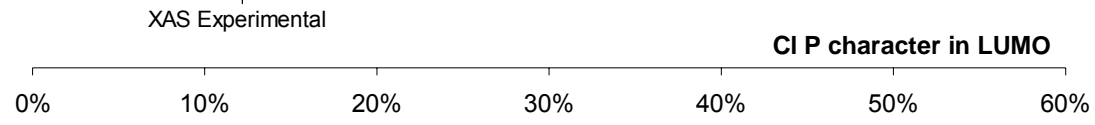

Figure 23. Calculated metal-Cl covalencies using different theories to show the difference in trends in third, fourth and fifth row transition metal chloride complexes. 


\section{DISCUSSION}

This study is an extension of the bonding description of the chlorocuprate complexes to fourth row chloro palladium complexes. The most natural and straightforward link is between $\mathrm{D}_{4 \mathrm{~h}}\left[\mathrm{CuCl}_{4}\right]^{2-}$ and $\mathrm{D}_{4 \mathrm{~h}}\left[\mathrm{PdCl}_{4}\right]^{2-}$ because it is a comparison of $\mathrm{d}^{9}$ to $\mathrm{d}^{8}$ electron configuration and third to fourth row transition metals. These spectra are shown in Figure 24. The $\mathrm{Cl} \mathrm{K}$-edge rising edge position is at $0.1 \mathrm{eV}$ greater energy in the $\mathrm{Pd}$ compared to $\mathrm{Cu}$ suggesting that the $\mathrm{Cl}$ has a higher effective nuclear charge due to more $\mathrm{Cl}$ covalency. In fact, $\mathrm{XAS}$ shows that the individual $\mathrm{Cl}$ covalency is $9.7 \%{ }^{14}$ for $\mathrm{D}_{4 \mathrm{~h}}\left[\mathrm{CuCl}_{4}\right]^{2-}$ compared to $23 \%$ for $\left[\mathrm{PdCl}_{4}\right]^{2-}$. In addition to the higher $\mathrm{Cl}$ covalency in $\left[\mathrm{PdCl}_{4}\right]^{2-}$ causing the $\mathrm{Cl} 1 \mathrm{~s}$ orbital to be lower in energy, the higher energy $\mathrm{Pd} 4 \mathrm{~d}$ manifold compared to the $\mathrm{Cu} 3 \mathrm{~d}$ manifold leads to a $0.9 \mathrm{eV}$ higher energy pre-edge feature in $\left[\mathrm{PdCl}_{4}\right]^{2-}$.

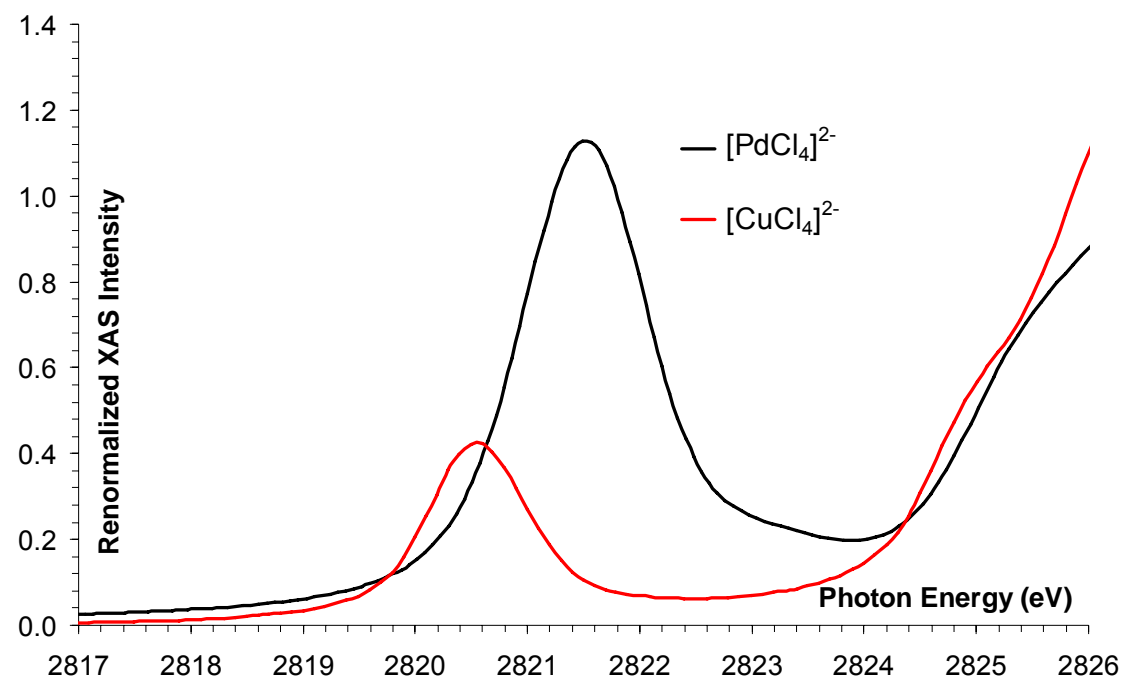

Figure 24. $\mathrm{Cl} \mathrm{K}$-edge spectra of $\left[\mathrm{CuCl}_{4}\right]^{2-}$ and $\left[\mathrm{PdCl}_{4}\right]^{2-}$. 
Each terminal $\mathrm{Cl}$ in the $\mathrm{Pd}(\mathrm{II})$ species $\left[\mathrm{PdCl}_{4}\right]^{2-}$ shows donation of $23 \% \mathrm{Cl} \mathrm{p}$ orbital to the $\mathrm{Pd}-\mathrm{Cl}$ bond. The chlorines are arranged on the $\mathrm{x}$ and $\mathrm{y}$ axis about the $\mathrm{Pd}$ with a lobe of the $\mathrm{Pd} 4 \mathrm{~d}_{\mathrm{x}^{2}-\mathrm{y}^{2}}$ orbital pointing directly at each $\mathrm{Cl}$. These lobes combine with the $\mathrm{Cl} 3 \mathrm{p}$ orbitals on the axis to form a $\sigma$ bond. Minor contributions to this bond come from $\mathrm{Cl} 3 \mathrm{~s}$ and $3 \mathrm{~d}$ orbitals through mixing.

Comparing this bonding picture to the $\mathrm{PdCl}_{2}$ species with bridging $\mathrm{Cl}$ 's, the individual $\mathrm{Cl}$ covalency goes up to $46 \%$ while the total $\mathrm{Cl}$ covalency per $\mathrm{Pd}$ stays constant. This is due to both the $\mathrm{p}_{\mathrm{x}}$ and $\mathrm{p}_{\mathrm{y}}$ orbitals on a $\mathrm{Cl}$ forming two $\sigma$ bonds with pairs of $\mathrm{Pd}(\mathrm{II})$ ions. Each $\mathrm{Cl}$ is rotated $45^{\circ}$ relative to the terminal chlorines so that orbital lobes of $\mathrm{Cl} 3 \mathrm{p}_{\mathrm{x}}$ and $3 \mathrm{p}_{\mathrm{y}}$ orbitals form $\sigma$ bonding pairs with the two respective lobes of two Pd $4 \mathrm{~d}_{\mathrm{xy}}$ orbitals. Because these two orbitals are within $0.05 \mathrm{eV}$ of each other, there is no direct Pd-Pd bonding interaction.

The bonding picture of $\left[\mathrm{PdCl}_{6}\right]^{2-}$ is simplified as each $\mathrm{Cl}$ is aligned along the axis with a lobe of a p orbital pointing directly at the $\mathrm{Pd}$ center yielding $34 \% \mathrm{Cl} 3 \mathrm{p}$ character in a $\mathrm{Pd}-\mathrm{Cl}$ bond. With no distortion from $\mathrm{O}_{\mathrm{h}}$ symmetry, the $\mathrm{Pd} 4 \mathrm{~d}_{\mathrm{x} 2-\mathrm{y}^{2}}$ and $\mathrm{d}_{\mathrm{z}}{ }^{2}$ orbitals mix to give bonding lobes that point directly at each $\mathrm{Cl}$ forming $6 \sigma$ bonds.

The spectra of $\left[\mathrm{PdCl}_{4}\right]^{2-}, \mathrm{PdCl}_{2}$, and $\left[\mathrm{PdCl}_{6}\right]^{2-}$ were measured by Sugiura in the 1980 's ${ }^{17-21}$. A few comments are made about the differences in both the spectra and spectra interpretation. Although the spectra was not previously quantitatively analyzed, it is evident that the most recent measurements have increased resolution probably due to the the better instrumentation at the newer beamlines allowing for more information to be obtained from the XAS spectra. Previously, the shoulder in the $\left[\mathrm{PdCl}_{6}\right]^{2-} \mathrm{Cl} \mathrm{K}$-pre-edge 
region was assigned to contamination of $\left[\mathrm{PdCl}_{4}\right]^{2-}$ due to photoreduction of the hexachloride. If this was the case, isobestic points would be present when comparing consecutive scans, given the intensity of the shoulder in the $\left[\mathrm{PdCl}_{6}\right]^{2-}$ spectra, the rising edge of $\left[\mathrm{PdCl}_{4}\right]^{2-}$ would also be seen. Clearly, neither of these are visible in the measurements presented here. The same comment about the shoulder and rising edge position of the hexachloride L-edge spectra can also be made.

Because there are three different methods for determining the $\operatorname{Pd}(2 p \rightarrow 4 d)$ transition dipole integrals, comments on the accuracy of each and the necessity for more than one method are made. The accuracy depends on a couple of factors. Firstly, when the length of the region that is splined is longer, two very different background subtractions that are both equally valid can be found causing the error bar for measuring both L-edges together to be greater than the error bar for measuring them separately. Secondly, both the greater intensity of the $\mathrm{L}_{\mathrm{III}}$-edge transition, which leads to a larger signal to noise ratio, and the lack of an EXAFS scattering pattern from a previous edge interfering with the spectra contribute to the $\mathrm{L}_{\mathrm{III}}$-edge having a smoother background than the $\mathrm{L}_{\mathrm{II}}$-edge. This translates to a more reliable background subtraction and normalization for the $\mathrm{L}_{\mathrm{III}}$-edge. $\mathrm{In}$ all three $\mathrm{Pd}$ complexes measured, the $\mathrm{L}_{\mathrm{III}}: \mathrm{L}_{\mathrm{II}}$-edge ratio is about 1.5 to 1.0 , while Ligand-Field Multiplet Theory ${ }^{73}$ and Atomic Multiplet Theory ${ }^{73}$ predict the ratio to be 2 to 1 . These theoretical predictions have previously been shown to differ from experimental results as vanadium and titanium $\mathrm{L}_{\mathrm{III}}: \mathrm{L}_{\mathrm{II}}$ edge ratios are close to $1: 1^{78,79}$. The consistency of this measurement on Pd complexes indicates that the edge ratio is neither chloride complex nor oxidation state dependent. Therefore, the intensity 
of the $\mathrm{L}_{\mathrm{II}}$-edge intensity can be predicted from the $\mathrm{L}_{\mathrm{III}}$-edge intensity and vica versa eliminating the need to collect both edges. It is still recommended that both edges are measured and, if possible, the covalency is calculated with all of the before mentioned methods and averaged to reduce the error bars of a covalency measurement. The importance of having three separate dipole integrals for the Pd L-edges becomes apparent when there are other absorbers present in the system causing interference with the Pd Ledge spectra. Figure 25 shows several absorbers that would interfere with the measurement of the Pd L-edges. Measuring a sample with a significant amount of one or more of these absorbers present would prevent an accurate background and/or normalization of the Pd L-edge spectra due to overlapping edges necessitating the use of the method I or method II dipole integral depending on the absorber present.

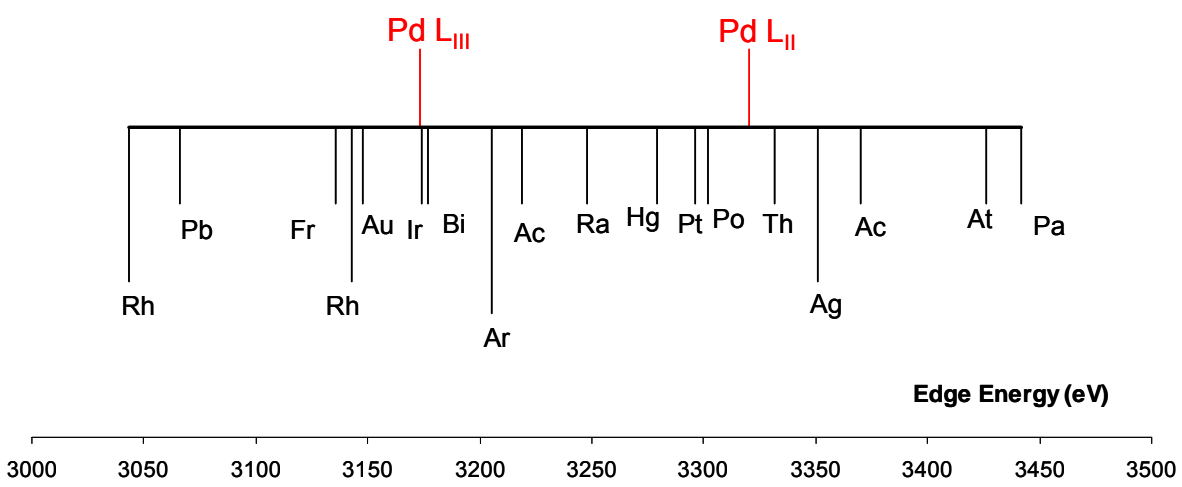

Figure 25. Energy positions of the $\mathrm{Pd} \mathrm{L}_{\mathrm{III}}$ and $\mathrm{L}_{\mathrm{II}}$-edges along with other absorbers that could interfere with Pd XAS measurements.

Applying the $\mathrm{Pd}(\mathrm{II}) \mathrm{L}$-edge dipole integrals developed for $\left[\mathrm{PdCl}_{4}\right]^{2-}$ on the $\mathrm{PdCl}_{2}$ L-edge spectra, the Pd $4 \mathrm{~d}$ orbital covalency was determined to be $52 \%$. These new dipole integrals can be applied to $\mathrm{PdCl}_{2}$ as both complexes have the same pre-edge peak 
position indicating the same effective nuclear charge $\left(Z_{\text {eff }}\right)$. The calculated charges verify this assertion. This remainder of the palladium-chlorine bond not accounted for in the Pd L-edge (along with minor $\mathrm{Pd} 5 \mathrm{~s} / 5 \mathrm{p}$ and $\mathrm{Cl} 3 \mathrm{~s} / 3 \mathrm{~d}$ character) was then used to determine a new dipole integral for the more positively charged bridging $\mathrm{Cl}$ 's. Precedence for a new dipole integral based on $Z_{\text {eff }}$ was established at the $\mathrm{S}$ K-edge as sulfide, thiolate, and enedithiolate all have unique S K-edge dipole integrals ${ }^{80}$. A shift in the $\mathrm{S}$ rising edge positions to higher energy in the order sulfide, thiolate, and enedithiolate indicates a greater $Z_{\text {eff }}$ on the $S$ in the same order. Dipole integrals of $6.54 \mathrm{eV}, 8.05 \mathrm{eV}$, and 9.15 $\mathrm{eV}$ for sulfide, thiolate, and enedithiolate, respectively, have been shown to linearly reflect the $\mathrm{S} \mathrm{Z}_{\text {eff }}$ and thus the rising edge shifts going from sulfide to thiolate $(+1.1 \mathrm{eV})$ and thiolate to enedithiolate $(+0.8 \mathrm{eV})$. Figure 26 illustrates that the new $\mathrm{Cl}$ K-edge and Pd L-edge dipole integrals and rising edge positions fit with this linear trend established at the S K-edge.

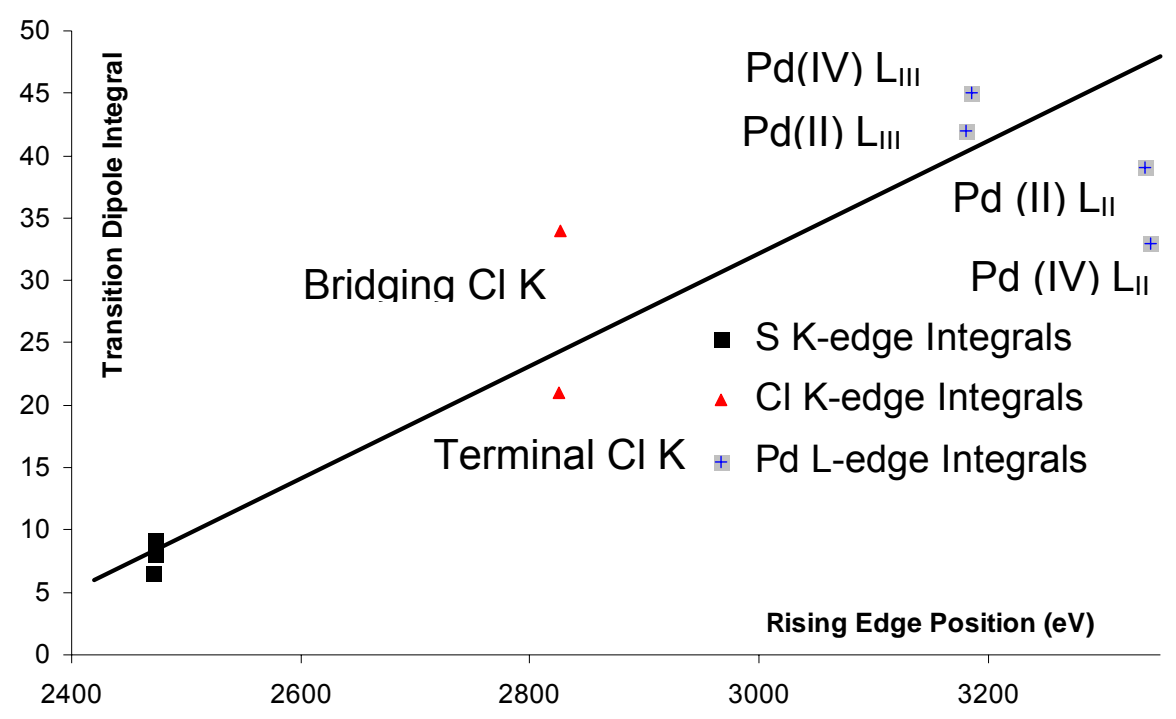

Figure 26. Plot of XAS transition dipole integrals and rising edge positions for a series at the $\mathrm{S}$ K-edge, $\mathrm{Cl} \mathrm{K}$-edge, and Pd L-edge. 
The calculated relative orbital energies and ordering of $\left[\mathrm{PdCl}_{4}\right]^{2-}$ are inconsistent with the assignments made from polarized single crystal UV/Vis absorption data ${ }^{81}$. Deeth provides an explanation of this discrepancy ${ }^{82}$. DFT uses the full molecular symmetry to generate a different set of $d$ function for each $d$ state. This leads to six electrons with amplitudes along the + and $-z$ axis and two electrons in the $x y$ plane in a low-spin planar $\mathrm{d}^{8}$ complex such as $\left[\mathrm{PdCl}_{4}\right]^{2-}$. The $\mathrm{d}_{x y}$ orbital then experiences less interelectron repulsion and thus has lower energy relative to the $d_{x z}$ and $d_{y z}$ orbitals. This reasoning is verified by the reproduction of the experimental orbital sequence when 0.6 electrons is shifted from the $d_{z^{2}}$ into the $d_{x^{2}-y^{2}}$ orbital. This caveat to the functionality of DFT does not detract from its utility for assessing the electronic structure of these complexes. The DFT orbital ordering for the $\mathrm{O}_{\mathrm{h}} \mathrm{Pd}$ remains consistent with experiment. 


\section{CONCLUSIONS AND FUTURE WORK}

The description of the experimental ground state electronic structure of $\left[\mathrm{PdCl}_{6}\right]^{2-}$ and $\left[\mathrm{PdCl}_{4}\right]^{2-}$ presented Scheme 5 has immediate application in the spectroscopic calibration of DFT calculations. Ligand covalency is a key indicator of reactivity providing validity to this calibration method. While the 50/50 density functional and HF exchange is an effective computational method for treating $\mathrm{Pd}(\mathrm{II})$ complexes, only the highest level ab initio calculations can reproduce $\mathrm{Pd}(\mathrm{IV}) \mathrm{XAS}$ covalency. Clearly a new computational method is needed for $\mathrm{Pd}(\mathrm{IV})$ complexes as QCISD to too expensive to perform protential energy surface calculations for larger systems. The BHandHLYP functional is relatively close to the $\left[\mathrm{PdCl}_{6}\right]^{2-}$ experimental XAS $\mathrm{Pd}-\mathrm{Cl}$ covalency and is recommended for use on all $\mathrm{Pd}$ complexes.

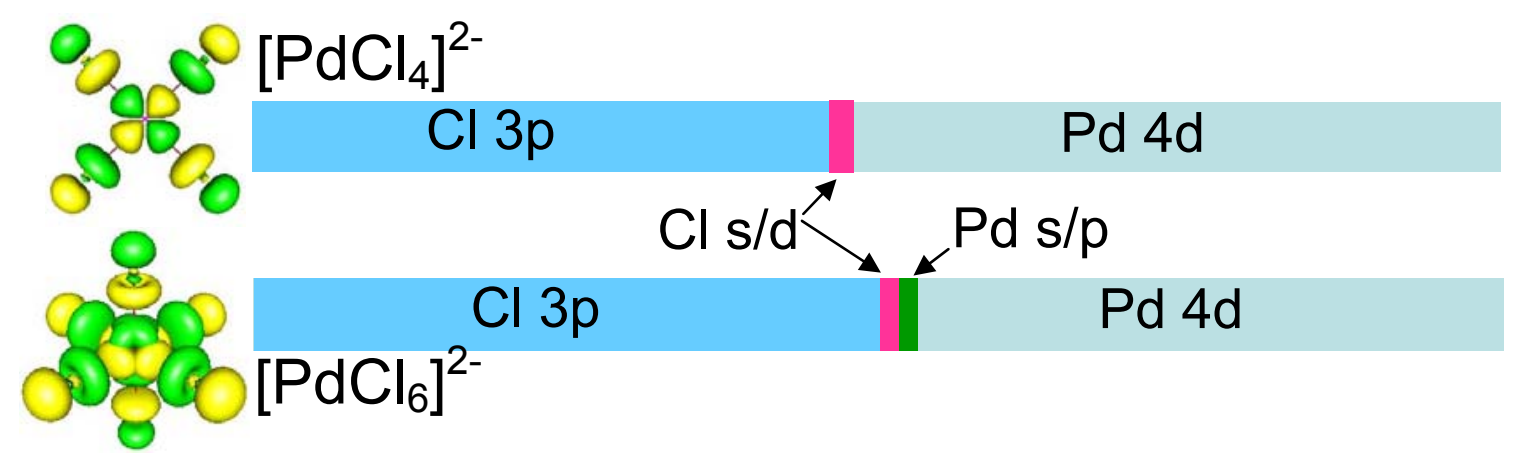

Scheme 5. The experimental ground state electronic structure of $\left[\mathrm{PdCl}_{4}\right]^{2-}$ and $\left[\mathrm{PdCl}_{6}\right]^{2-}$. Calibrated electronic structure calculations estimated the minor $\mathrm{Cl} 3 \mathrm{~s} / 3 \mathrm{~d}$ contributions. $\mathrm{Pd} 5 \mathrm{~s} / 5 \mathrm{~d}$ contributions were estimated from their relative rising L-edge positions. 


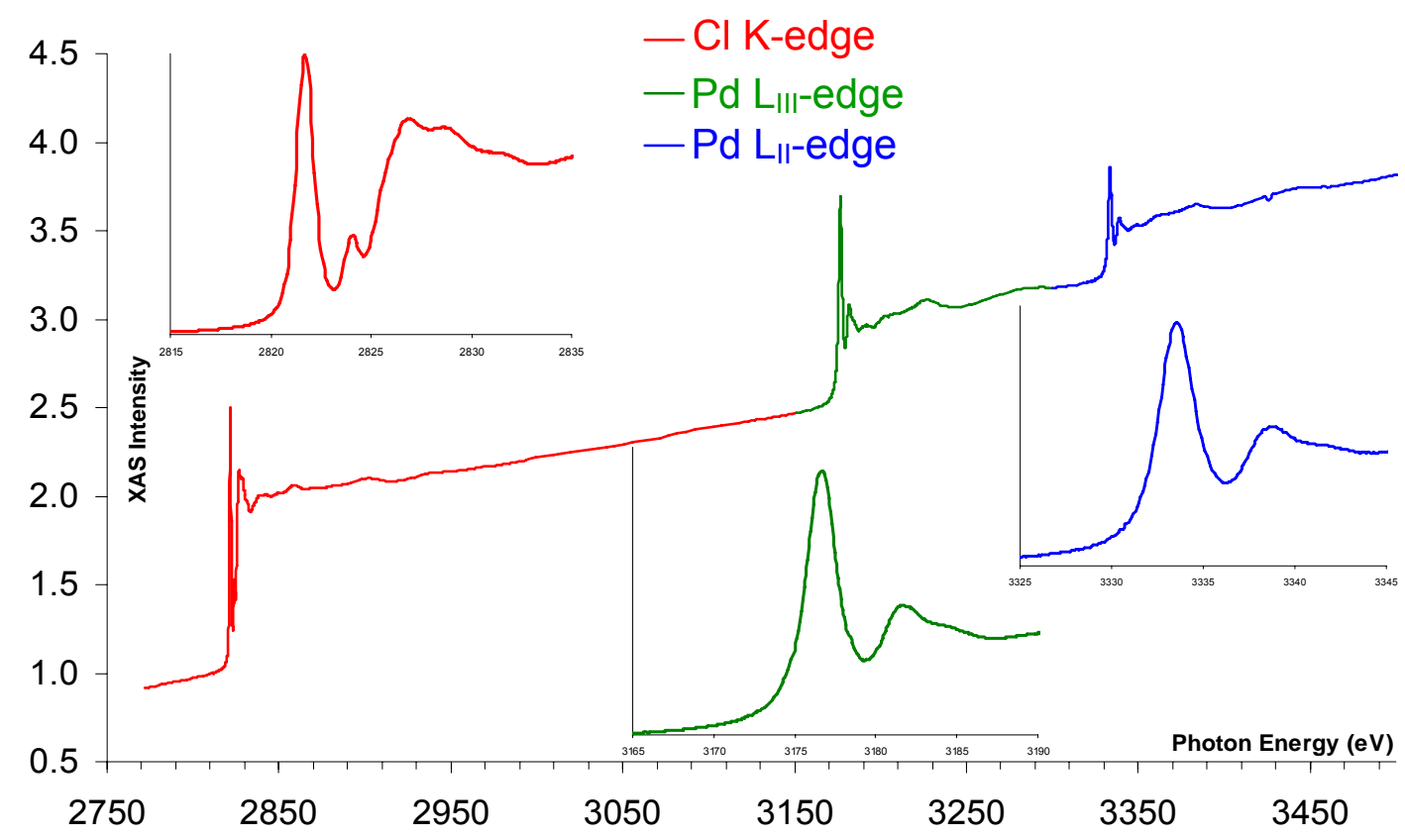

Figure 27. XAS Cl K-edge (red), $\mathrm{Pd} \mathrm{L} \mathrm{L}_{\mathrm{III}}$-edge (green) and $\mathrm{Pd}_{\mathrm{II}}$-edge (blue) spectra of $\left(\mathrm{PCy}_{3}\right)_{2} \mathrm{PdCl}_{2}$ showing the pre-edge features as insets that can be used to quantitate the covalency in Pd-ligand bonds.

This study developed the quantitation of Pd d orbital covalency in a Pd-Ligand bond from Pd L-edge XAS. The first application of this method was performed on $\mathrm{PdCl}_{2}$. After the $\mathrm{Pd} 4 \mathrm{~d}$ character in the $\mathrm{Pd}-\mathrm{Cl}$ bond was quantitated, the dipole integral for the bridging $\mathrm{Cl}$ in $\mathrm{Pd}-\mathrm{Cl}$ was calculated. $\mathrm{XAS}$ can now be extended to study the electronic structure of chloro phosphino palladium complexes. The raw data in Figure 27 for the $\mathrm{Pd} \mathrm{L}$-edges and $\mathrm{Cl} \mathrm{K}$-edge of $\left(\mathrm{PCy}_{3}\right)_{2} \mathrm{PdCl}_{2}$ show pre-edge features at each edge that can be used to quantitate the $\mathrm{Cl}$ and $\mathrm{Pd}$ character in the ground state electronic structure. In a similar fashion to the development of the Pd L-edge dipole integrals and the bridging $\mathrm{Cl} \mathrm{K}$-edge dipole integral, the $\mathrm{P} \mathrm{K}$-edge dipole integral can be obtained from the pre-edge features of the $\left(\mathrm{PCy}_{3}\right)_{2} \mathrm{PdCl}_{2} \mathrm{Pd} \mathrm{L}-\mathrm{Cl} \mathrm{K}$ - and $\mathrm{P} \mathrm{K}$-edge spectra in Figure 27 
and 28. This technique could then be extended to study the bonding in catalytically active palladium phosphine, allyl, and olefin complexes.

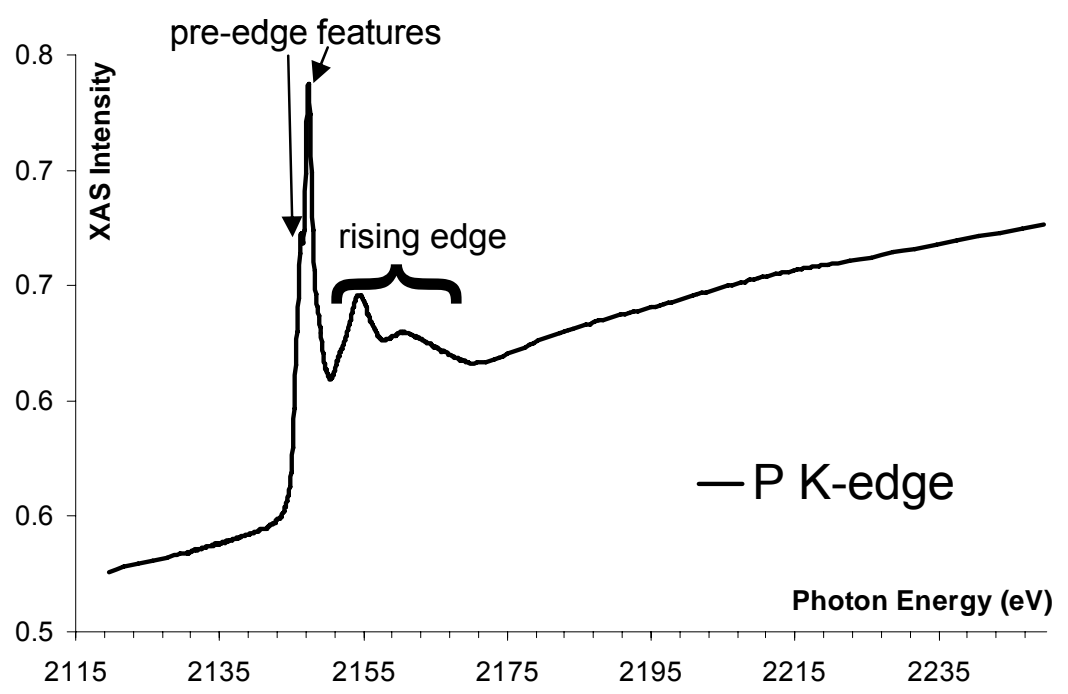

Figure 28. Phosphorus K-edge spectra of $\left(\mathrm{PCy}_{3}\right)_{2} \mathrm{PdCl}_{2}$ showing pre-edge features that can be used in the development of the $\mathrm{P}$ K-edge dipole integral and to quantitate the covalency in Pd-P bonds.

Portions of this research were carried out at the Stanford Synchrotron Radiation Laboratory, a national user facility operated by Stanford University on behalf of the U.S. Department of Energy, Office of Basic Energy Sciences. The SSRL Structural Molecular Biology Program is supported by the Department of Energy, Office of Biological and Environmental Research, and by the National Institutes of Health, National Center for Research Resources, Biomedical Technology Program. Portions of this research was carried out at the Advanced Light Source. The Advanced Light Source is supported by the Director, Office of Energy Research, Office of Basic Energy Sciences, Materials Sciences Division of the US Department of Energy undercontract No. DE-AC0376SF00098.S. 


\section{REFERENCES CITED}

1. Beletskaya, I.P.; Cheprakov, A.V. The Heck Reaction as a Sharpening Stone of Palladium Catalysis. Chem. Rev. 2000, 100, 3009

2. Bedford, B.; Cazin, C.S.J.; Holder, D. The development of palladium catalysts for C-C and C-heteroatom bond forming reactions of aryl chloride substrates. Coord. Chem. Rev. 2004, 248, 2283

3. Mizoroki, T.; Mori, K.; Ozaki, A. Arylation of Olefin with aryl iodide catalyzed by palladium. Bull. Chem. Soc. Jpn. 1971, 44, 581.

4. Heck, R.F.; Nolly, J.P. Palladium-catalyzed vinylic hydrogen hydrogen substitution reactions with aryl, benzy, and styryl halides. J. Org. Chem. 1972, 37, 2320 .

5. Deeth, R.J.; Smith, A.; Brown, J.M.; Electronic control of the regiochemistry in palladium-phosphine catalyzed intramolecular Heck reactions. J. Am. Chem. Soc. 2004, 126, 7144.

6. Mo, J.; Xu, L.; Xiao, J. Ionic liquid-promoted, highly regioselective Heck arylation of electron-rich olefins by aryl halides. J. Am. Chem. Soc. 2005, 127 , 751.

7. Tsurugi, K.; Nomura, N.; Aoi, K. Palladium-catalyzed allylic substitution reaction: oxidative addition versus dissociation in an olefin-palladium(0) complex. Tetrahedron Lett. 2002, 43, 469.

8. Grove, N.R.; Kohl, P.A.; Allen, S.A.B.; Jayaraman, S.; Shick, R. Functionalized polynorbornene dielectric polymers: adhesion and mechanical properties. 1999, 37,3003 .

9. Barnes, D.A.; Benedikt, G.M.; Goodall, K.H.; Hullihen, K.; Jayaraman, S.; McDougall, C.; McIntosh, L.H.; Rhodes, L.F.; Shick, R. Advanced materials for electronic applications by polymerization of cyclic olefins using late transition metal catalysts. Proceeding of MetCon '98 Worldwide Metallocene Conf., Houston, TX 1998.

10. Janiak, C.; Lassahn, P.G. Metal catalysts for the vinyl polymerization polymerization of norbornene. J. Mol. Cat. A. 2001, 166, 193. 
11. Lipian, J.; Mimna, R. A.; Fondran, J. C.; Yandulov, D.; Shick, R. A.; Goodall, B. L.; Rhodes, L. F.; Huffman, J. C. Addition polymerization of norbornene-type monomers. High activity cationic allyl palladium catalysts. Macromolecules. 2002, 35, 8969 .

12. Lassahn, P.G.; Janiak, C.; Oh, J.S. Borane activators for late-transition metal catalysts in norbornene polymerization. Macro. Mol. R. Comm. 2002, 23, 16.

13. Hodgson, K.O.; Hedman, B.; Solomon, E.I. X-ray absorption edge spectroscopy of ligands bound to open-shell metal ions: Chlorine K-edge studies of covalency in $\mathrm{CuCl}_{4}{ }^{2-}$. J. Am. Chem. Soc. 1990, 112, 1643.

14. Shadle, S.E.; Hedman, B.; Hodgson, K.O.; Solomon, E.I. Ligand K-edge X-ray absorption spectroscopy as a probe of ligand-metal bonding: Charge donation and covalency in copper-chloride systems. Inorg. Chem. 1994, 33, 4235.

15. Shadle, S.E.; Hedman, B.; Hodgson, K.O.; Solomon, E.I. Ligand K-edge X-ray absorption spectroscopic studies: Metal-ligand covalency in a series of transition metal tetrachlorides. J. Am. Chem. Soc. 1995, 117, 2259.

16. Solomon, E.I. Inorganic spectroscopy-An overview. Comments Inorg. Chem. 1984, 3, 225

17. Sugiura, C. Electron transfer band in the chlorine K-X-ray absorption spectra of some transition metal chlorides. J. Chem. Phys. 1973, 59, 4907.

18. Sugiura, C. X-ray spectra and electronic band structures of $\mathrm{PdCl}_{2}$ and $\mathrm{CdCl}_{2}$. J. Chem. Phys. 1975, 62, 1111.

19. Sugiura, C.; Ohashi, M.; "White line" in the chlorine K X-ray absorption spectra of $\mathrm{K}_{2} \mathrm{PdCl}_{4}, \mathrm{~K}_{2} \mathrm{PtCl}_{4}, \mathrm{~K}_{2} \mathrm{PdCl}_{6}, \mathrm{~K}_{2} \mathrm{PtCl}_{6}$. J. Chem. Phys. 1983, 78, 88.

20. Sugiura, C.; Muramatsu, S.; Palladium $\mathrm{L}_{\mathrm{III}} \mathrm{X}$-ray absorption-edge structures of $\mathrm{K}_{2} \mathrm{PdCl}_{6}, \mathrm{~K}_{2} \mathrm{PdCl}_{4},\left(\mathrm{NH}_{4}\right)_{2} \mathrm{PdCl}_{2}$, and trans-[ $\left.\mathrm{Pd}\left(\mathrm{NH}_{3}\right)_{2} \mathrm{Cl}_{2}\right]$. J. Chem. Phys. 1985, $82,2191$.

21. Sugiura, C.; Muramatsu, S.; Influence of ligands on the X-ray absorption nearedge structure of palladium(II) complex compounds. J. Chem. Phys. 1986, 86, 5269.

22. Helmholtz, L.; Kruth, R.F.; The crystal structure of cesium chlorocuptrate, $\mathrm{Cs}_{2} \mathrm{CuCl}_{4}$, and the spectrum of the chlorocuprate ion. J. Am. Chem. Soc. 1952, 74, 1176. 
23. George, G.N.; EDG_FIT, Stanford Synchrotron Radiation Laboratory, Stanford Linear Accelerator Center, Stanford University, Stanford CA, USA.

24. Gaussian 03, Revision C.02, M. J. Frisch, G. W. Trucks, H. B. Schlegel, G. E. Scuseria, M. A. Robb, J. R. Cheeseman, J. A. Montgomery, Jr., T. Vreven, K. N. Kudin, J. C. Burant, J. M. Millam, S. S. Iyengar, J. Tomasi, V. Barone, B. Mennucci, M. Cossi, G. Scalmani, N. Rega, G. A. Petersson, H. Nakatsuji, M. Hada, M. Ehara, K. Toyota, R. Fukuda, J. Hasegawa, M. Ishida, T. Nakajima, Y. Honda, O. Kitao, H. Nakai, M. Klene, X. Li, J. E. Knox, H. P. Hratchian, J. B. Cross, C. Adamo, J. Jaramillo, R. Gomperts, R. E. Stratmann, O. Yazyev, A. J. Austin, R. Cammi, C. Pomelli, J. W. Ochterski, P. Y. Ayala, K. Morokuma, G. A. Voth, P. Salvador, J. J. Dannenberg, V. G. Zakrzewski, S. Dapprich, A. D. Daniels, M. C. Strain, O. Farkas, D. K. Malick, A. D. Rabuck, K. Raghavachari, J. B. Foresman, J. V. Ortiz, Q. Cui, A. G. Baboul, S. Clifford, J. Cioslowski, B. B. Stefanov, G. Liu, A. Liashenko, P. Piskorz, I. Komaromi, R. L. Martin, D. J. Fox, T. Keith, M. A. Al-Laham, C. Y. Peng, A. Nanayakkara, M. Challacombe, P. M. W. Gill, B. Johnson, W. Chen, M. W. Wong, C. Gonzalez, and J. A. Pople, Gaussian, Inc., Pittsburgh PA, 2004.

25. Takazawa, H.; Ohba, S.; Saito, Y. Electron-density distribution in crystals of dipotassium tetrachloropalladate(II) and dipotassium hexachloropalladat(IV), $\mathrm{K}_{2}\left[\mathrm{PdCl}_{4}\right]$ and $\mathrm{K}_{2}\left[\mathrm{PdCl}_{6}\right]$ at $120 \mathrm{~K}$. Acta Cryst. 1988, B44, 580.

26. Wells, A.F. The crystal structure of palladous chloride $\mathrm{PdCl}_{2}$. Zeitschr. $f$. Kristographie. 1938, 100, 189.

27. Becke, A.D. Density-functional exchange-energy approximation with correct asymptotic behavior. Phys. Rev. A 1988, 38, 3098.

28. Perdew, J.P. Density-functional approximation for the correlation energy of the inhomogeneous electron gas. Phys. Rev. B 1986, 33, 8822.

29. Roothan, C.C. J. New developments in molecular orbital theory. Rev. Mod. Phys. 1951, 23, 69.

30. Pople, J.A.; Nesbet, R.K. Self-consistent orbitals for radicals. J. Chem. Phys. 1954, 22, 571.

31. McWeeny, R.; Dierksen, G. Self-Consistent Perturbation Theory. II. Extension to Open Shells. J. Chem. Phys. 1968, 49, 4852.

32. Igel-Mann, G.; Stoll, H.; Preuss, H. Pseudopotentials for main group elements (IIIA through VIIA). Mol. Phys. 1988, 65, 1321. 
33. Stevens, W.J.; Basch, H.; Krauss, M. Compact effective potentials and efficient shared-exponent basis sets for the first- and second-row atoms. J. Chem. Phys. 1984, 81, 6026.

34. Dolg, M.; Stoll, H.; Preuss, H.; Pitzer, R.M. Relativistic and correlation effects for element 105 (hahnium, Ha): a comparative study of $\mathrm{M}$ and $\mathrm{MO}(\mathrm{M}=\mathrm{Nb}, \mathrm{Ta}, \mathrm{Ha})$ using energy-adjusted ab initio pseudopotentials. J. Phys. Chem. 1993, 97, 5852.

35. Hay, P.J.; Wadt, W.R. Ab initio effective core potentials for molecular calculations. Potentials for $\mathrm{K}$ to Au including the outermost core orbitals. $J$. Chem. Phys. 1985, 82, 299.

36. Jasien, P.G. Relativistic compact effective potentials and efficient, sharedexponent basis sets for the third-, fourth-, and fifth-row atoms. Can. J. Chem. 1992, 70,612 .

37. Cundari, T.R.; Stevens, W.J. Effective core potential methods for the lanthanides J. Chem. Phys. 1993, 98, 5555

38. Hehre, W.J.; Ditchfield, R.; Stewart, R.F.; Pople, J.A. Self-Consistent Molecular Orbital Methods. IV. Use of Gaussian Expansions of Slater-Type Orbitals. Extension to Second-Row Molecules. J. Chem. Phys. 1970, 52, 2769.

39. Gordon, M.S.; Binkley, J.S.; Pople, J.A.; Pietro, W.J.; Hehre, W.J. Self-consistent molecular-orbital methods. 22. Small split-valence basis sets for second-row elements. J. Am. Chem. Soc. 1983, 104, 2797.

40. Francl, M.M.; Petro, W.J.; Hehre, W.J.; Binkley, J.S.; Gordon, M.S.; DeFrees, D.J.; Pople, J.A. Self-consistent molecular orbital methods. XXIII. A polarizationtype basis set for second-row elements. J. Chem. Phys. 1982, 77, 3654.

41. McLean, A.D.; Chandler, G.S. Contracted Gaussian basis sets for molecular calculations. I. Second row atoms, $Z=11-18$. J. Chem. Phys. 1980, 72, 5639.

42. Huzinaga, S.; Miguel, B. A comparison of the geometrical sequence formula and the well-tempered formulas for generating GTO basis orbital exponents. Chem. Phys. Lett. 1990, 175, 289.

43. Huzinaga, S.; Klobukowski, M. Well-tempered Gaussian basis sets for the calculation of matrix Hartree-Fock wave functions. Chem. Phys. Lett. 1993, 212 , 260. 
44. Godbout, N.; Salahub, D.R.; Andzelm, J.; Wimmer, E. Optimization of Gaussiantype basis sets for local spin density functional calculations. Part I. Boron through neon, optimization technique and validation. Can. J. Chem. 1992, 70, 560.

45. Pietro, W.J.; Hehre, W.J. Molecular orbital theory of the properties of inorganic and organometallic compounds. 3.STO-3G basis sets for first-and second-row transition metals. J. Comp. Chem. 1983, 4, 241.

46. Dobbs, K.D.; Hehre, W.J. Molecular orbital theory of the properties of inorganic and organometallic compounds. 5. Extended basis sets for first-row transition metals. J. Comp. Chem 1987, 8, 880.

47. Jansen, G.; Hess, B.A. Relativistic all electron configuration interaction calculation of ground and excited states of the gold hydride molecule. Phys. Rev. A 1989, 39, 6016.

48. Nakajima, T.; Hirao, K. A new relativistic theory: a relativistic scheme by eliminating small components (RESC). Chem. Phys. Lett. 1999, 302, 383.

49. ADF 2005.01: Department of Theoretical Chemistry, Free University of Amsterdam: Amsterdam, The Neterlands, 2005.

50. Velde, G.T.; Beckelhaupt, F.M.; Baerends, E.J.; Guerra, C.F.; Van Gisbergen, S.J.A.; Snijders, J.G.; Ziegler, T. Chemistry with ADF J. Comput. Chem. 2001, 22, 931

51. van Lenthe, E., et al. Relativistic regular two-component Hamiltonians. Int. J. Quantum Chem. 1996, 57, 281.

52. Perdew, J.P.; Burke, K.; Ernzerhof, M. Generalized gradient approximation made simple. Phys. Rev. Lett. 1996, 77, 3865.

53. Perdew, J.P.; Burke, K.; Ernzerhof, M. $\mathrm{K}^{+}$Emission in symmetric heavy ion reactions at subthreshold energies. Phys. Rev. Lett. 1997, 78, 1396.

54. Burke, K.; Perdew, J.P.; Wang, Y. Electronic density functional theory: Recent progress and new directions. Plenum, 1998.

55. Perdew, J.P. Electronic structure of solids '91. Akademie Verlag, Berlin, 1991.

56. Becke, A.D. Density-functional thermochemistry. III. The role of exact exchange. J. Chem. Phys. 1993, 98, 5648. 
57. Head-Gordon, M.; Pople, J.A.; Frisch, M.J. Quadratically convergent simultaneous optimization of wave function and geometry. Int. J. Quant. Chem.. 1989, 23, 291.

58. Frisch, M.J.; Head-Gordon, M.; Pople, J.A. A direct MP2 gradient method. Chem. Phys. Lett. 1990, 166, 275.

59. Frisch, M.J.; Head-Gordon, M.; Pople, J.A. Semidirect algorithms for the MP2energy and gradient. Chem. Phys. Lett. 1990, 166, 281.

60. Krishnan, R.; Pople, J.A. Approximate fourth-order perturbation theory and the electron correlation energy. Int. J. Quant. Chem. 1978, 14, 91.

61. Pople, J.A.; Krishnan, R.; Schlegel, H.B.; Binkley, J.S. Electron correlation theories and their application to the study of simple reaction potential surfaces. Int. J. Quant. Chem. XIV 1978, 14, 545.

62. Cizek, J. On the use of the cluster expansion and the technique of diagrams in calculations of correlation effects in atoms and molecules. Adv. Chem. Phys. 1969, 14, 35.

63. Purvis, G.D.; Bartlett, R.J. A full coupled-cluster singles and doubles model: The inclusion of disconnected triples. J. Chem. Phys. 1982, 76, 1910.

64. Scuseria, G.E.; Janssen, C.L.; Schaefer, H.F. An efficient reformulation of the closed-shell coupled cluster single and double excitation (CCSD) equations. $J$. Chem. Phys. 1988, 89, 7382.

65. Scuseria, G.E.; Schaefer, H.F. Is coupled cluster singles and doubles (CCSD) more computationally intensive than quadratic configuration interaction (QCISD)?. J. Chem. Phys. 1989, 90, 3700.

66. Pople, J.A.; Head-Gordon, M.; Raghavachari, K. Quadratic configuration interaction. A general technique for determining electron correlation energies. $J$. Chem. Phys. 1987, 87, 5968.

67. Kirkwood, J.G. Theory of Solutions of Molecules Containing Widely Separated Charges with Special Application to Zwitterions. J. Chem. Phys. 1934, 2, 351.

68. Onsager, L. Electric Moments of Molecules in Liquids. J. Am. Chem. Soc. 1936, 58, 1486.

69. Biegler-Konig, F,; Schonbohm, J. AIM2000.2.0 2002. 
70. Foster, J.P.; Weinhold, F. Natural hybrid orbitals. J. Am. Chem. Soc. 1980, 102, 7211.

71. Singh, U.C.; Kollman, P.A. An approach to computing electrostatic charges for molecules. J. Comp. Chem. 1984, 5, 129.

72. Frisch, A.; Frisch, M.; Trucks, G.W.; Gaussian 03 User's Reference. Gaussian, Inc. Carnegie Office Park, Bldg. 6 Carnegie, PA.

73. de Groot, F. High resolution X-ray emission and X-ray Absorption spectroscopy. Chem. Rev. 2001, 101, 1779.

74. Solomon, E.I.; Hedman, B.; Hodgson, K.O.; Dey, A.; Szilagyi, R. Ligand K-edge X-ray absoption spectroscopy: covalency of ligand-metal bonds. Coord. Chem. Rev. 2005, 249, 97.

75. Kayaki, Y.; Tsukamoto, H.; Kaneko, M.; Shimizu, I.; Yamamoto, A.; Tachikawa, M.; Nakajima, T. Experimental and theoretical studies on the course of $\mathrm{CO}$ insertion into Pt-C and Pd-C bonds in neutral and cationic complexes, $\left[\mathrm{MR}(\mathrm{Cl})\left\{\mathrm{P}\left(\mathrm{CH}_{3}\right)_{3}\right\}_{2}\right]$ and $\left[\mathrm{MR}\left\{\mathrm{P}\left(\mathrm{CH}_{3}\right)_{3}\right\}_{2}(\mathrm{~s})\right]^{+} \mathrm{BF}_{4}{ }^{-}\left(\mathrm{M}=\mathrm{Pt}, \mathrm{Pd}, \mathrm{R}=\mathrm{CH}_{3}, \mathrm{C}_{6} \mathrm{H}_{5}\right.$, $\mathrm{s}=$ coordinated solvent). J. Organomatallic Chem. 2001, 622, 199.

76. Dykstra, C.E. An examination of the Brueckner condition for the selection of molecular orbitals in correlated wavefunctions. Chem. Phys. Lett. 1977, 45, 466

77. Hohenberg, P.; Kohn, W. Inhomogeneous electron gas. Phys. Rev. 1964, 136, B864

78. Rehr, J.J. Excited state electronic structure and the theory of x-ray spectra. $J$. Phys.: Conden. Matt. 2003, 15, S647.

79. Fink, J. 2p absorption spectra of the 3d elements. Phys. Rev. B. 1985, 32, 4899.

80. Szilagyi, R. K.; Lim, B. S.; Glaser, T.; Holm, R. H.; Hedman, B.; Hodgson, K. O.; Solomon, E. I. Description of the ground state wave functions of Ni dithiolenes using sulfur K-edge X-ray absorption spectroscopy. J. Am. Chem. Soc. 2003, 125, 9158.

81. Rodgers, M.L.; Martin, D.S. Single-crystal optical absorption spectra for magnustype salts of palladium and platinum. Polyhedron 1987, 6, 225.

82. Deeth, R.J. Ligand field and density functional descriptions of the d-states and bonding in transition metal complexes. Faraday Discuss. 2003, 124, 379. 
APPENDIX A

DATA WORKUP AND FITTING 


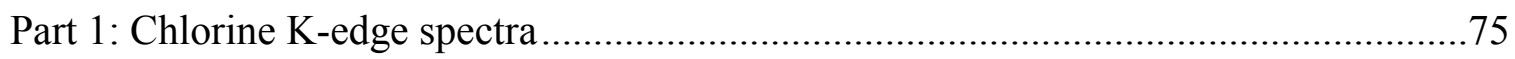

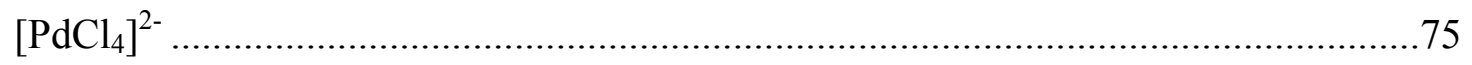

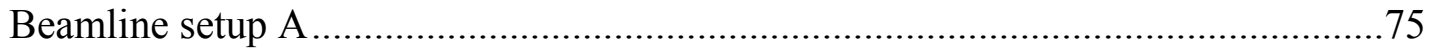

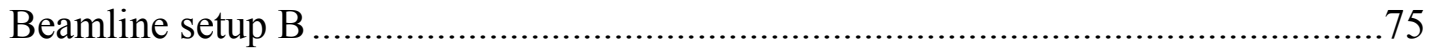

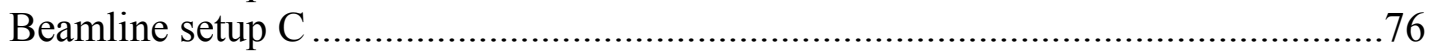

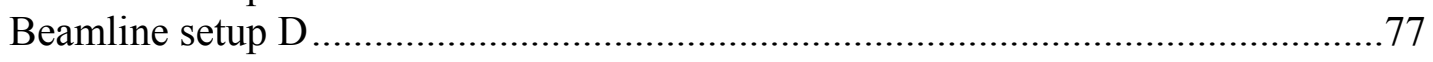

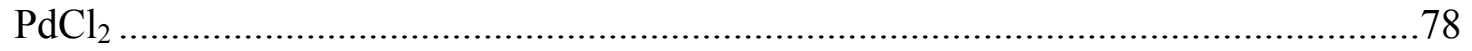

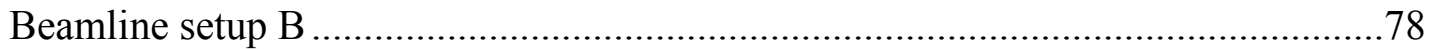

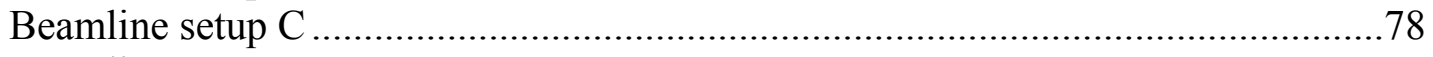

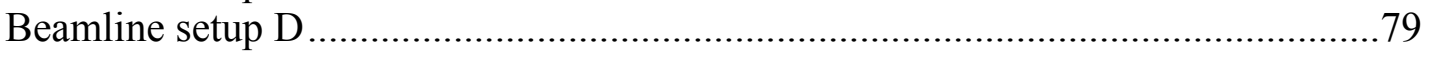

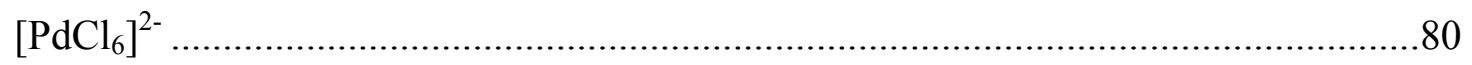

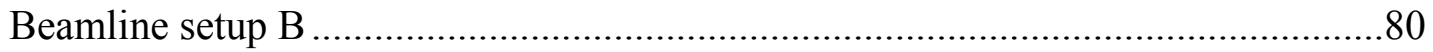

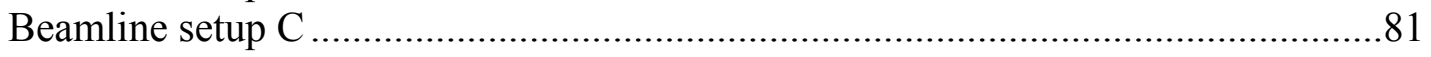

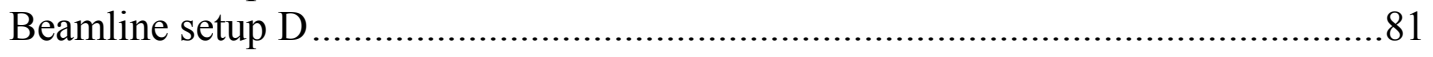

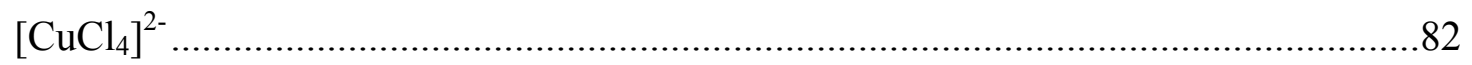

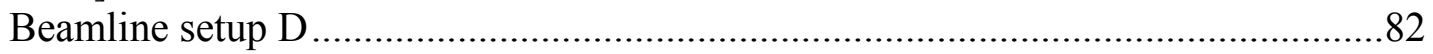

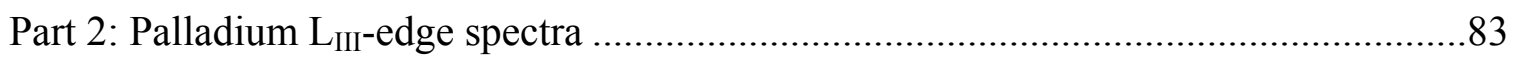

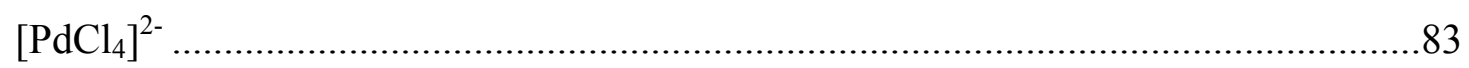

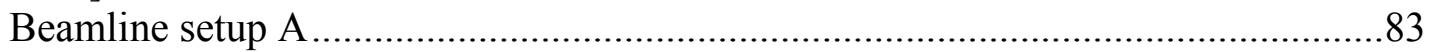

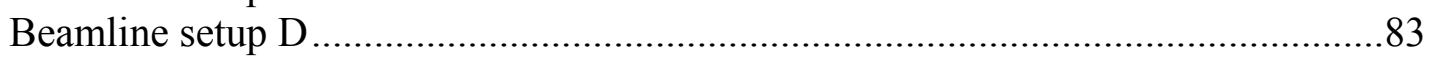

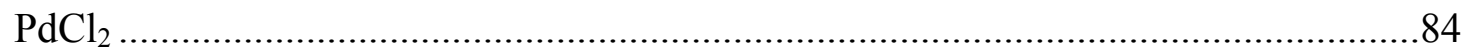

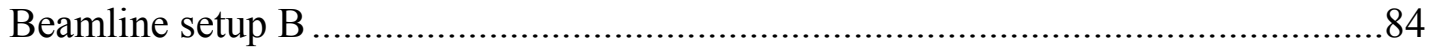

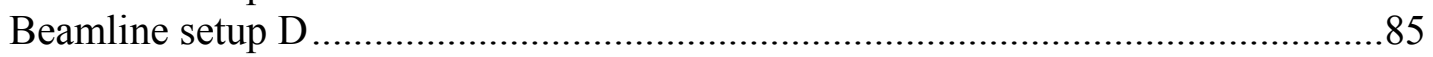

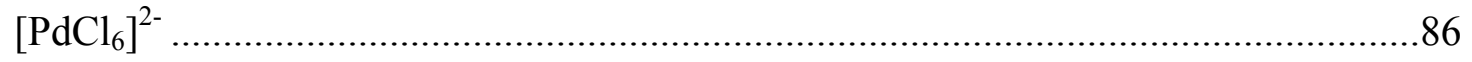

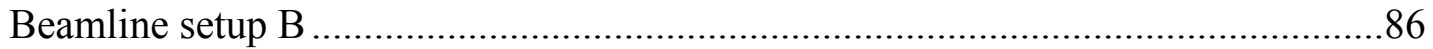

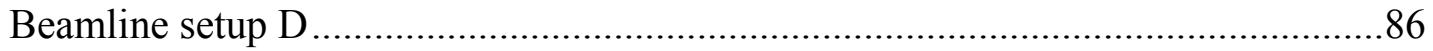

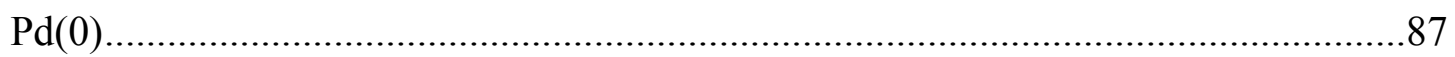

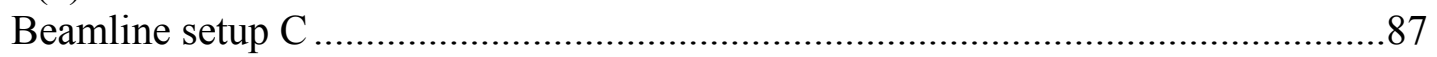

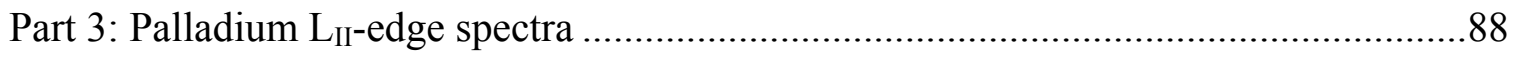

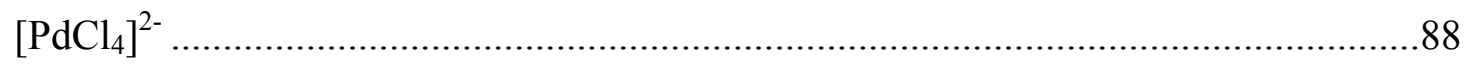

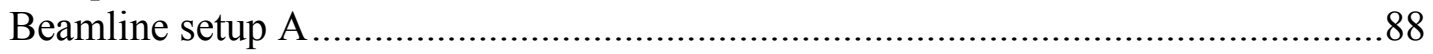

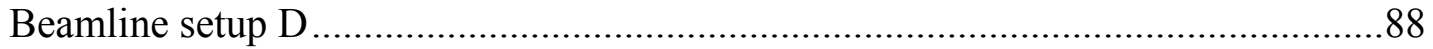




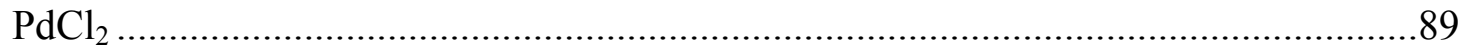

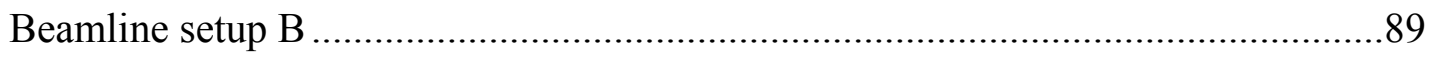

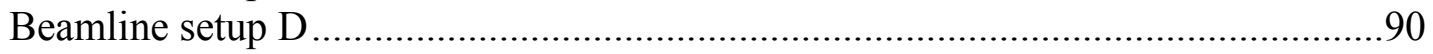

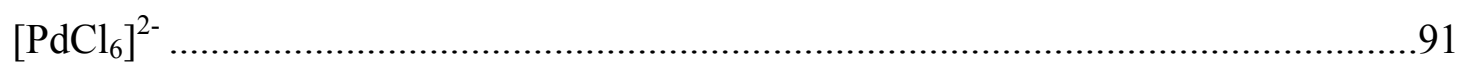

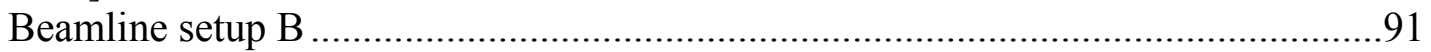

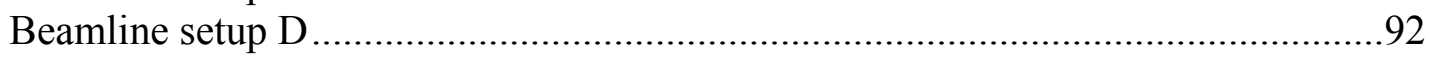

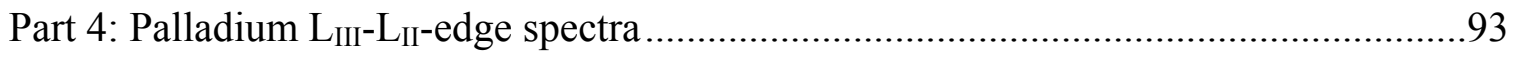

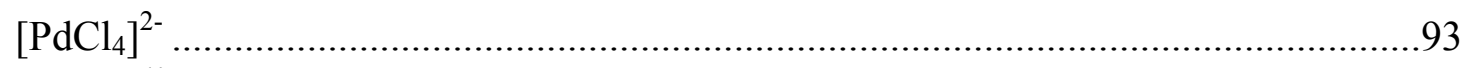

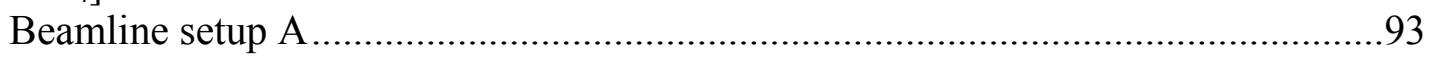

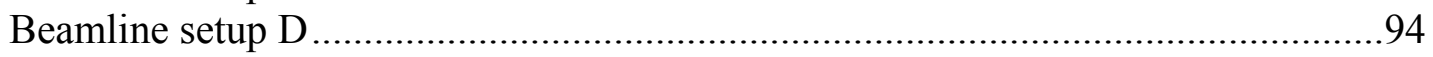

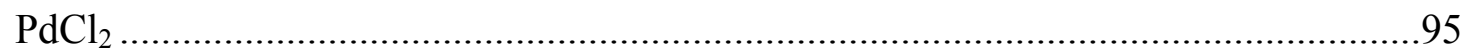

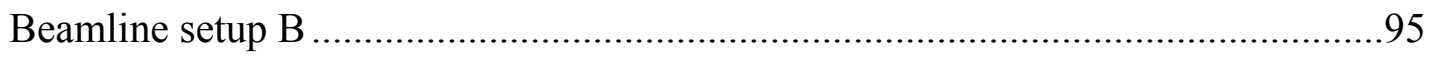

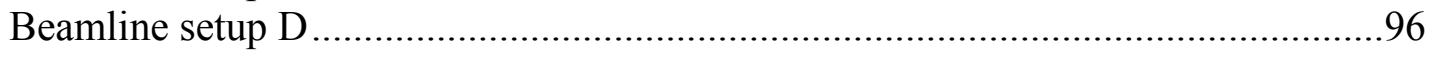

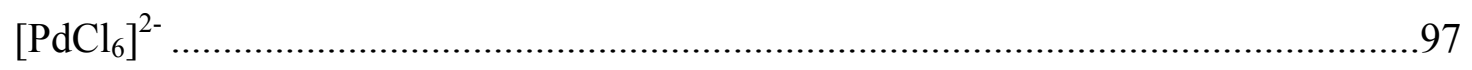

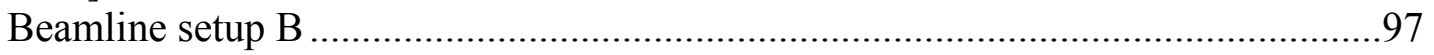

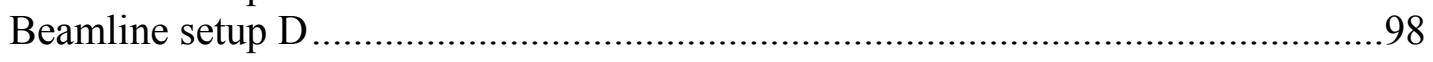

Beamline setup A: The data were collected at SSRL beamline 6.2 July 19-22, 2004.

Beamline setup B: The data were collected at SSRL beamline 6.2 March 27-April 4, 2005

Beamline setup C: The data were collected at ALS beamline 9.3.1 March 4-7, 2004 at room temperature

Beamline setup D: The data were collected at ALS beamline 9.3.1 November 813, 2004 while being cooled with liquid nitrogen. 
$\left[\mathrm{PdCl}_{4}\right]^{2-} \mathrm{Cl} \mathrm{K}$-edge measure at SSRL (beamline setup A)
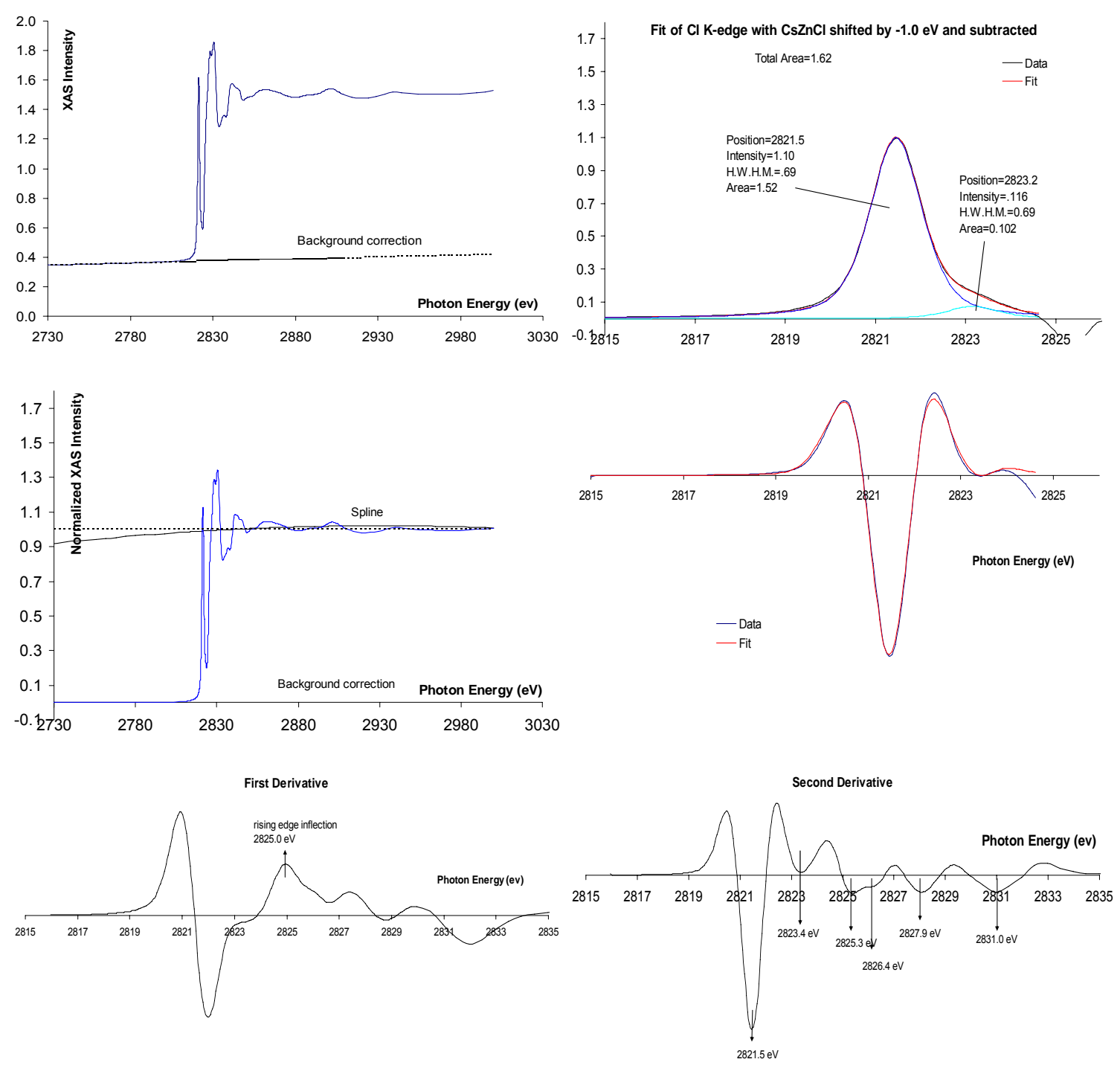

$\left[\mathrm{PdCl}_{4}\right]^{2-} \mathrm{Cl}$ K-edge measure at SSRL (beamline setup B)
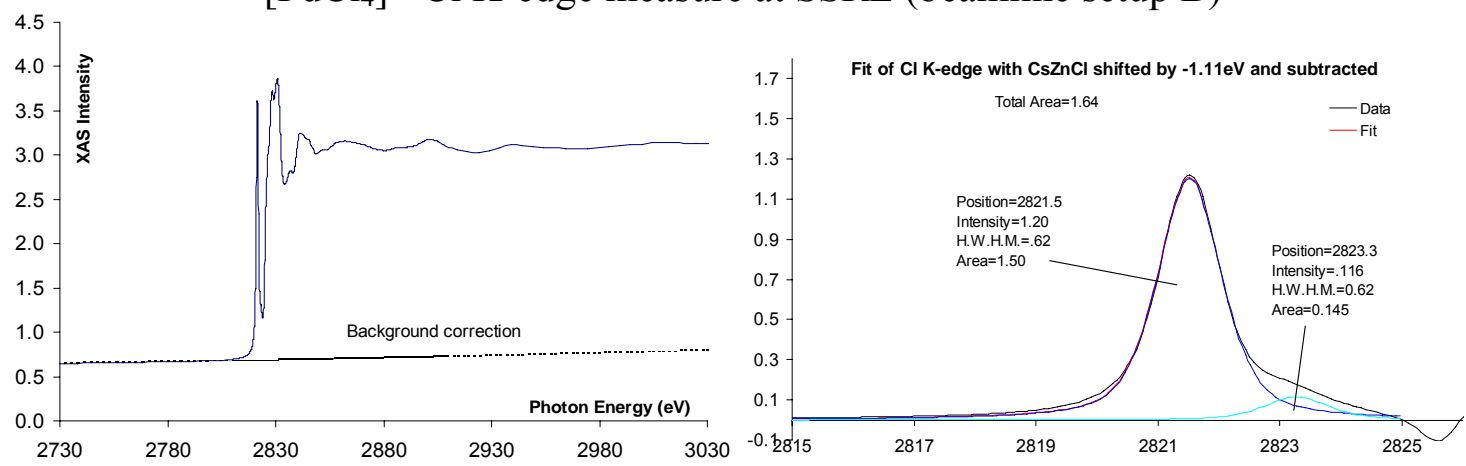


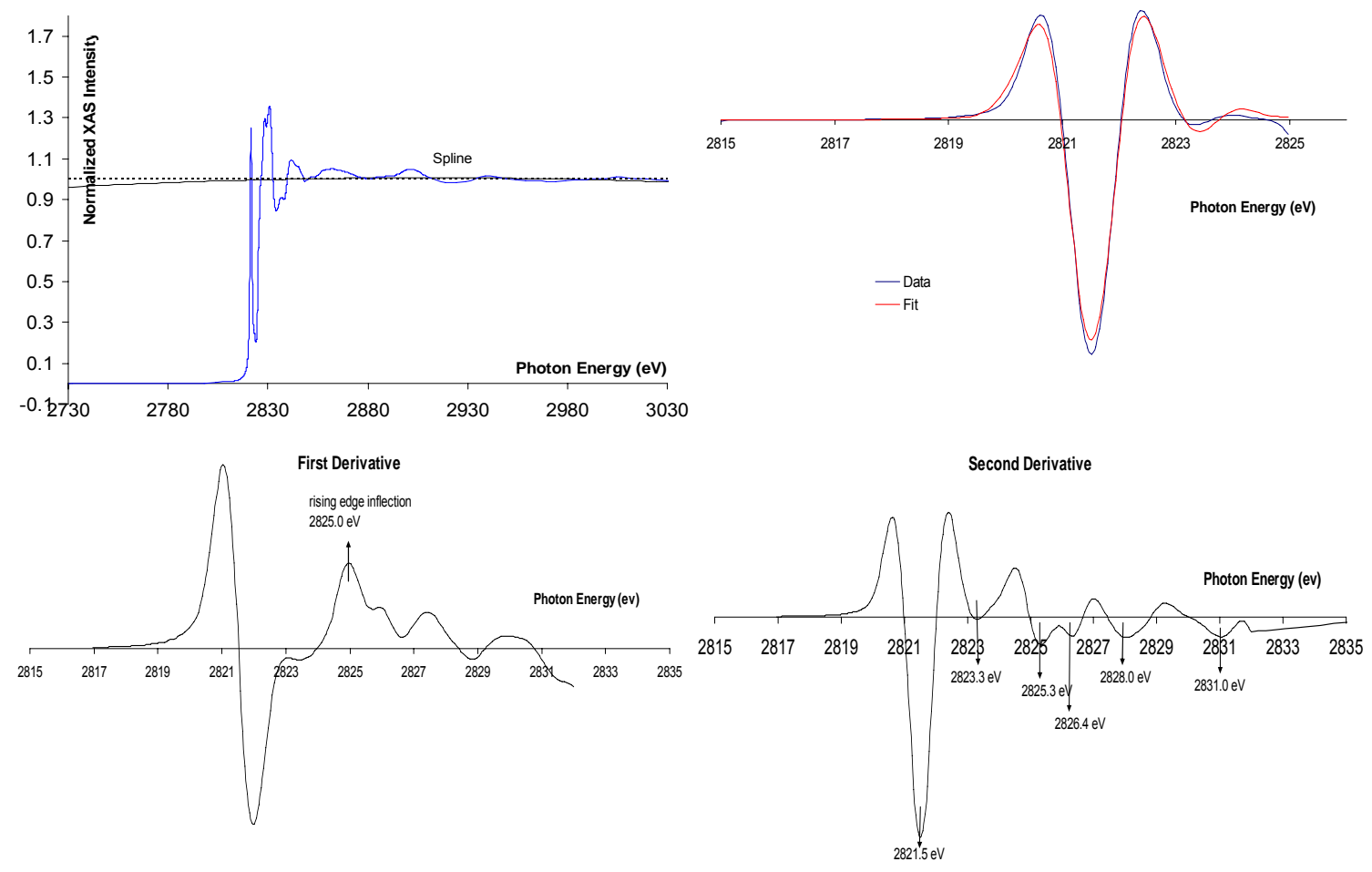

$\left[\mathrm{PdCl}_{4}\right]^{2-} \mathrm{Cl} \mathrm{K}$-edge measure at ALS (Beamline setup C)

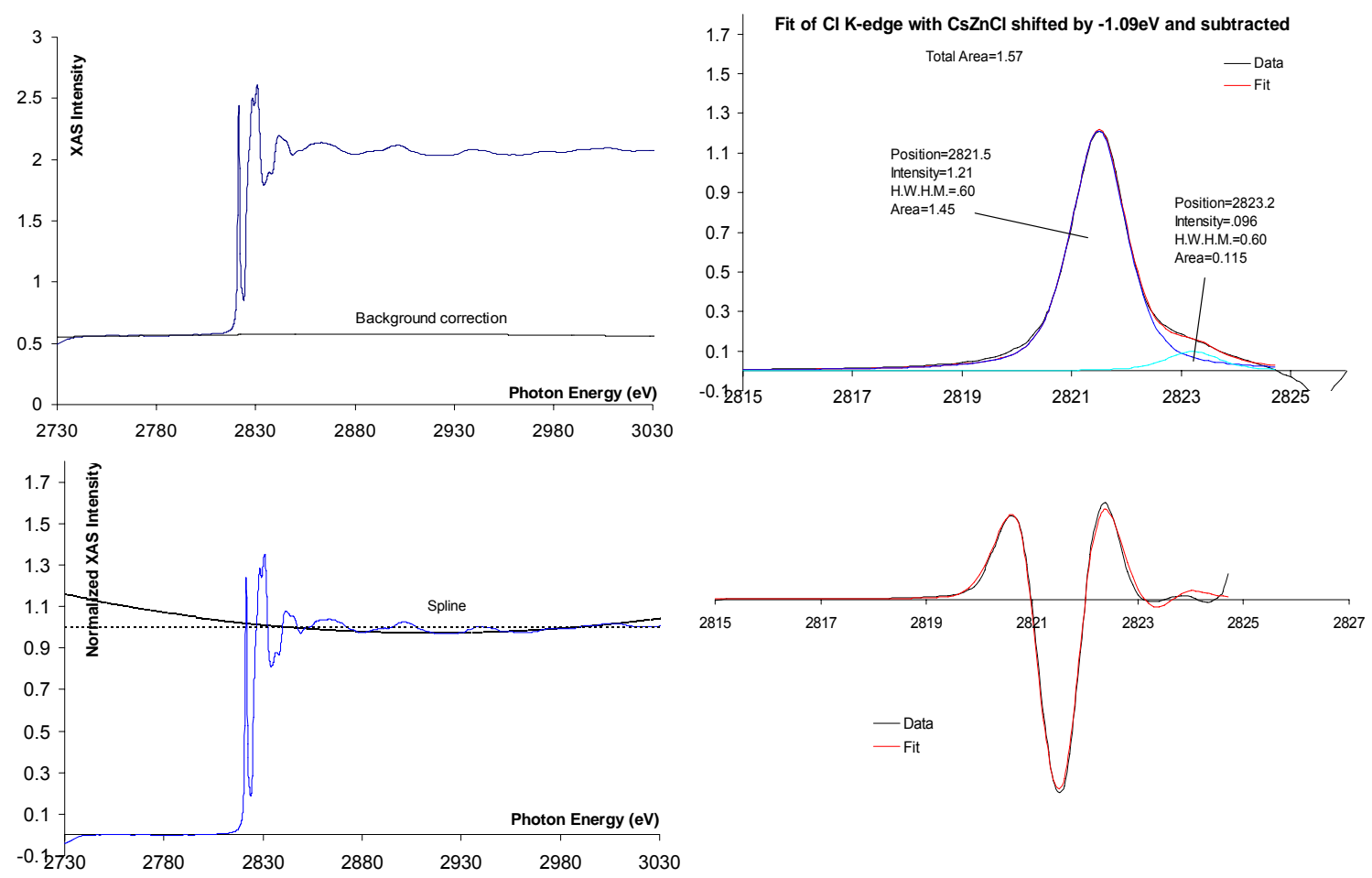



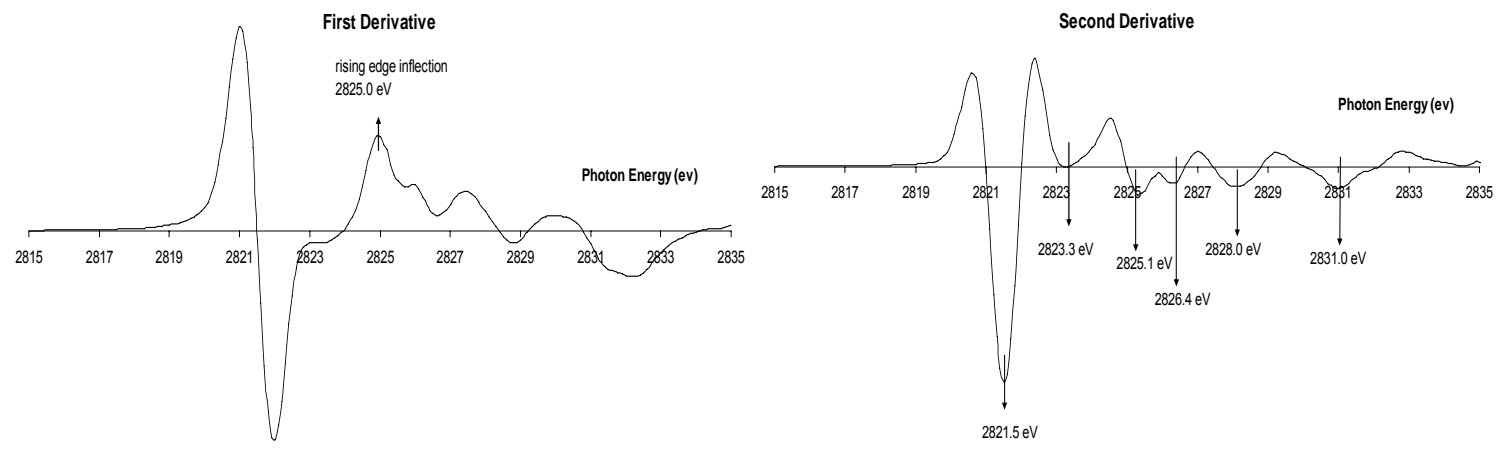

$\left[\mathrm{PdCl}_{4}\right]^{2-} \mathrm{Cl} \mathrm{K}$-edge measure at ALS (Beamline setup D)
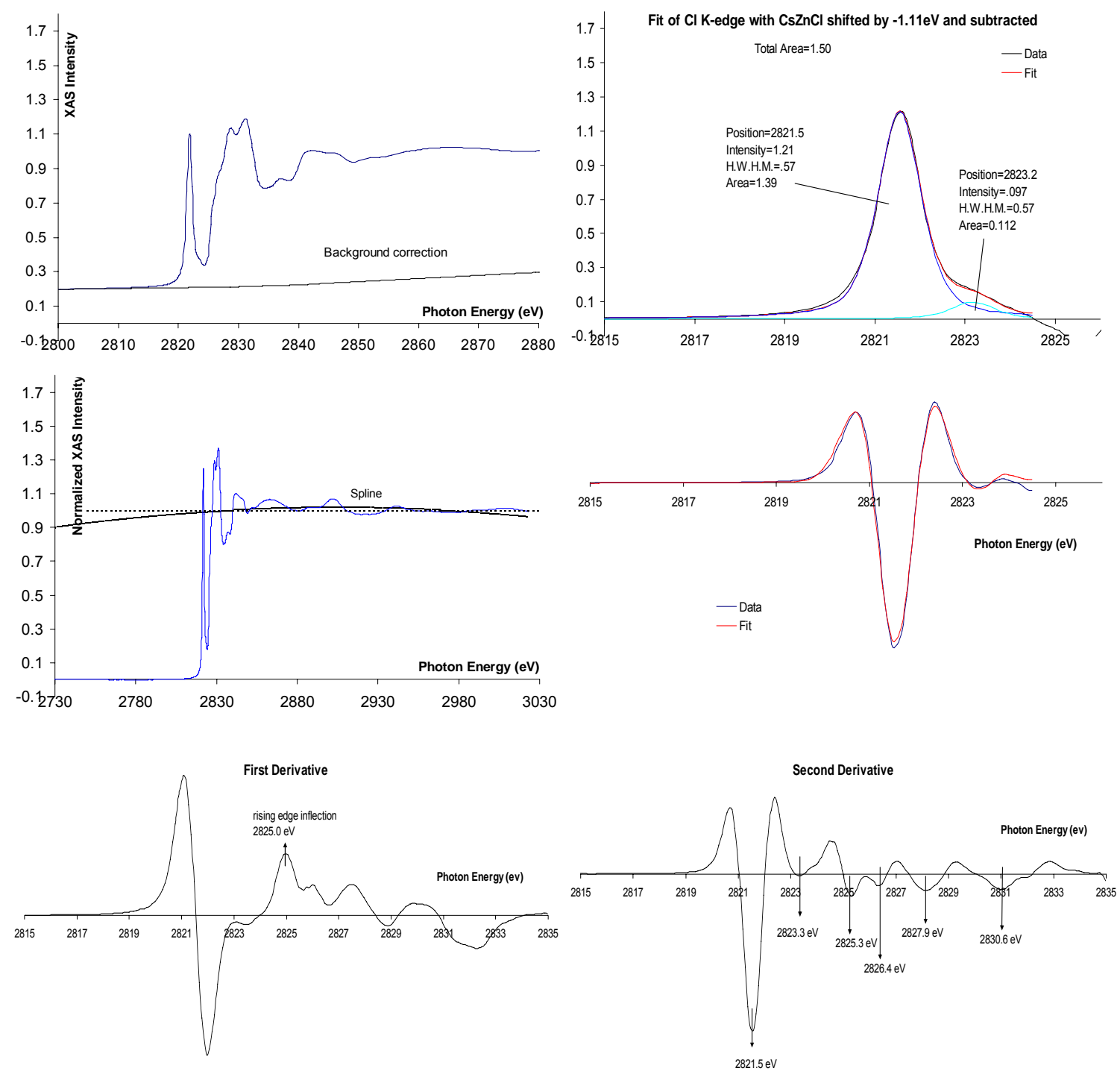
$\mathrm{PdCl}_{2} \mathrm{Cl}$ K-edge measure at SSRL (Beamline setup B)
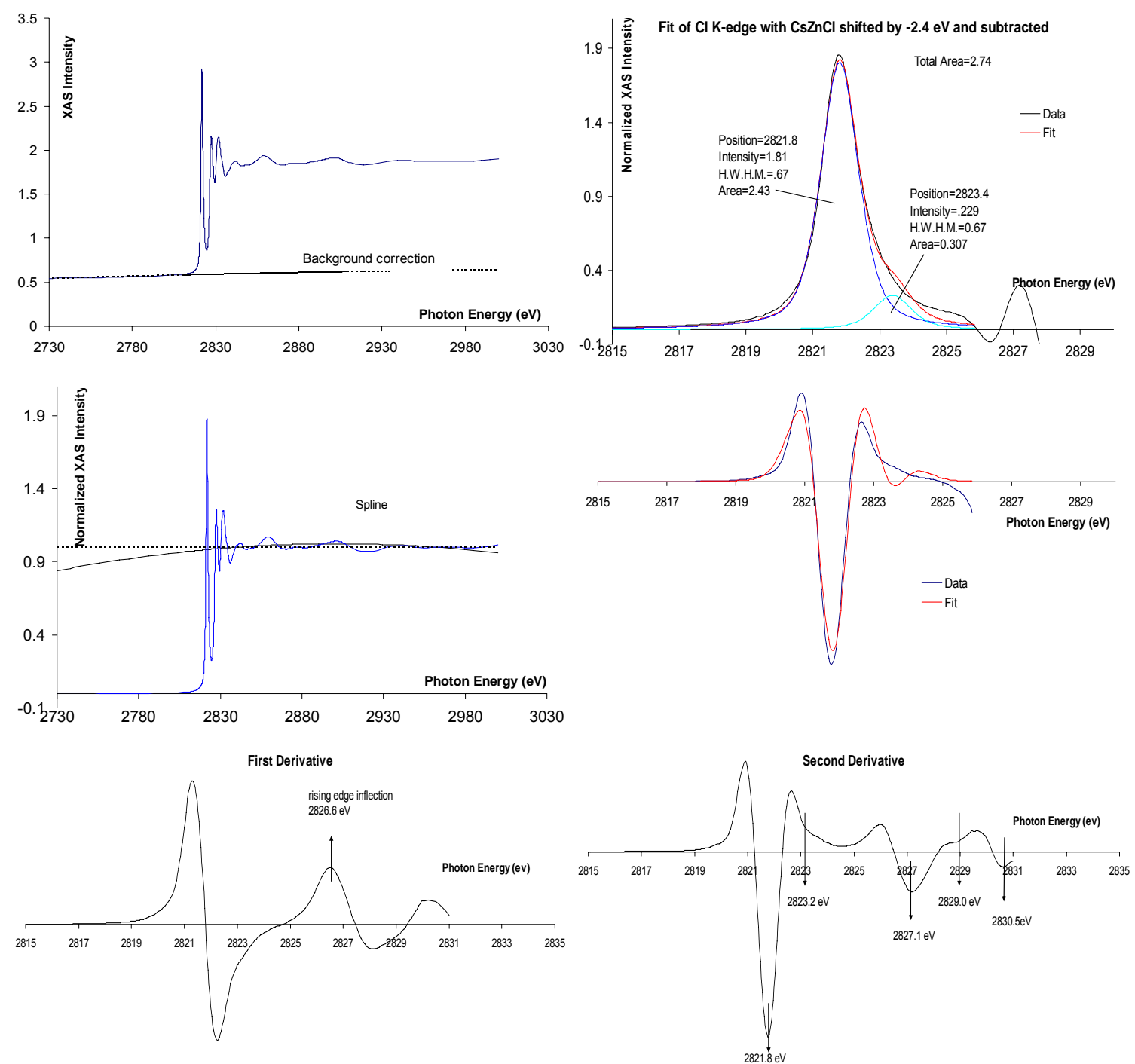

$\mathrm{PdCl}_{2} \mathrm{Cl}$ K-edge measured at ALS (Beamline setup C)

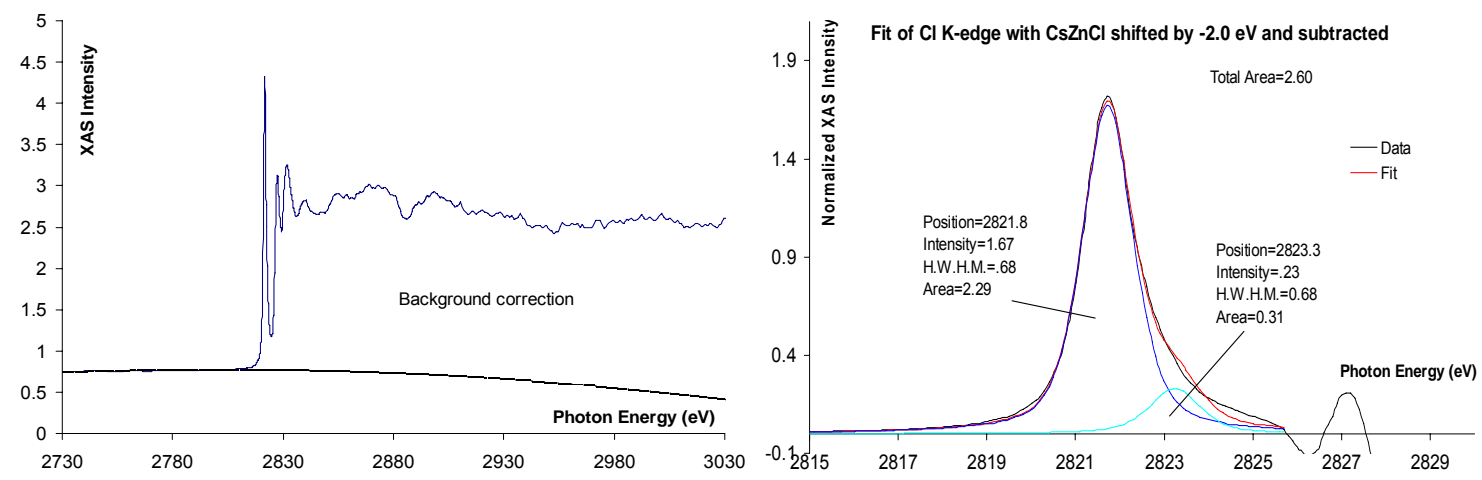



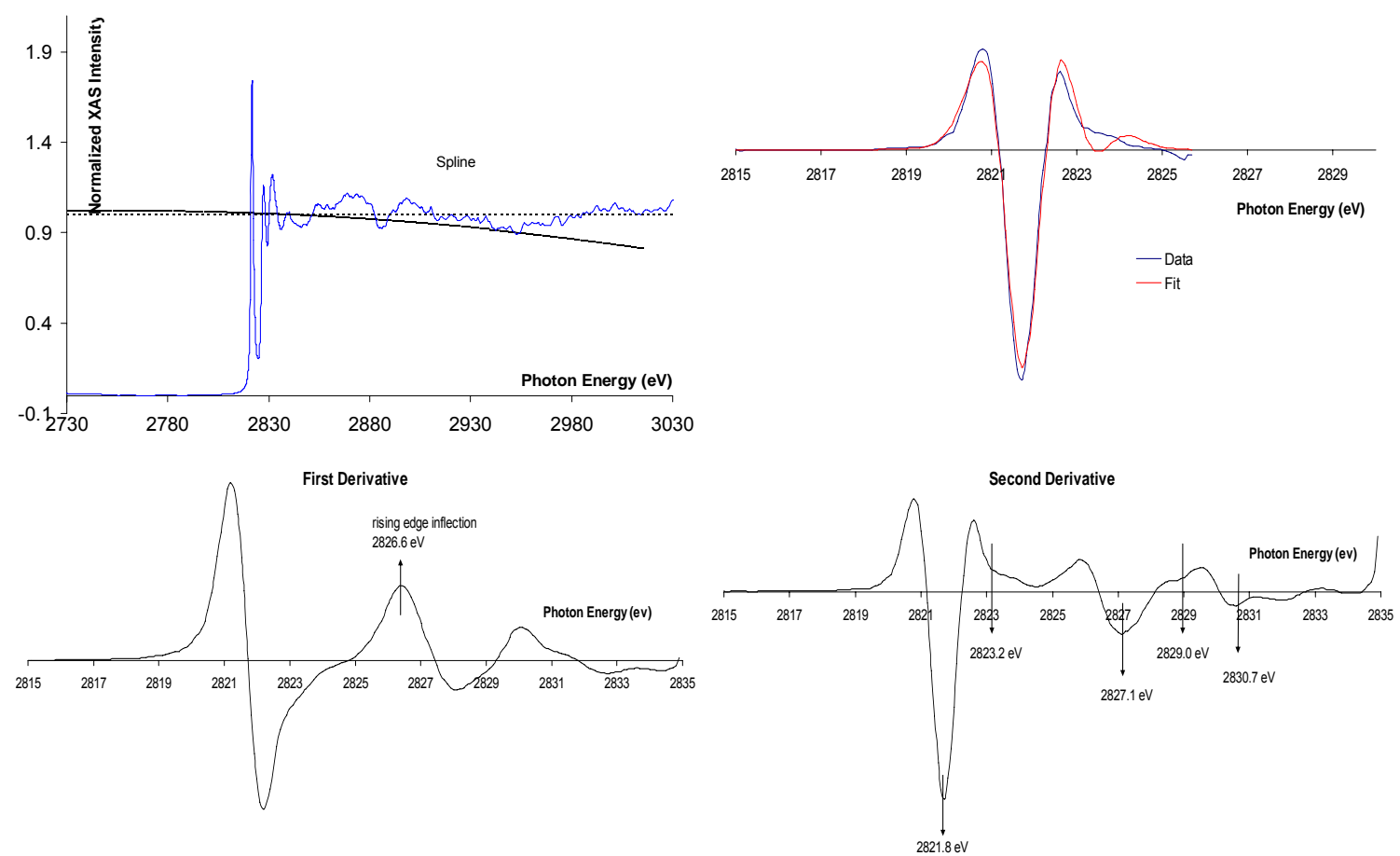

$\mathrm{PdCl}_{2} \mathrm{Cl}$ K-edge measured at ALS (Beamline setup D)

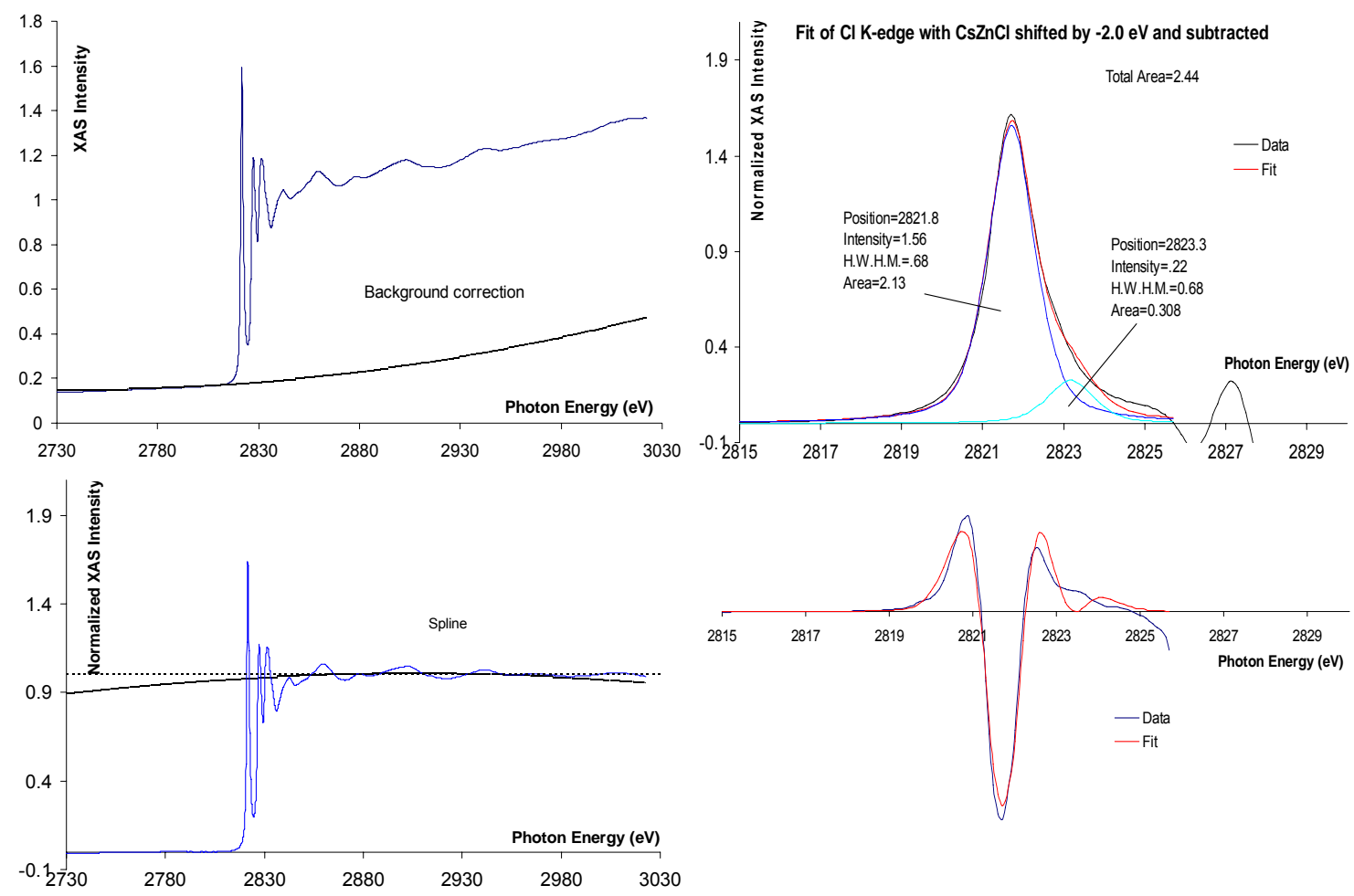



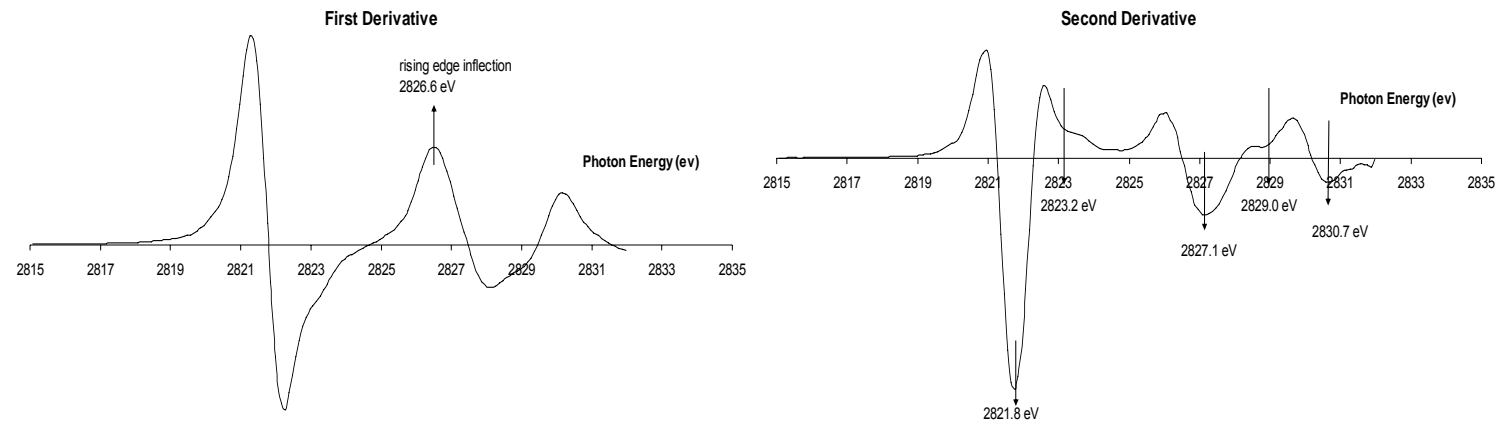

$\left[\mathrm{PdCl}_{6}\right]^{2-} \mathrm{Cl} \mathrm{K}$-edge measure at SSRL (Beamline setup B)
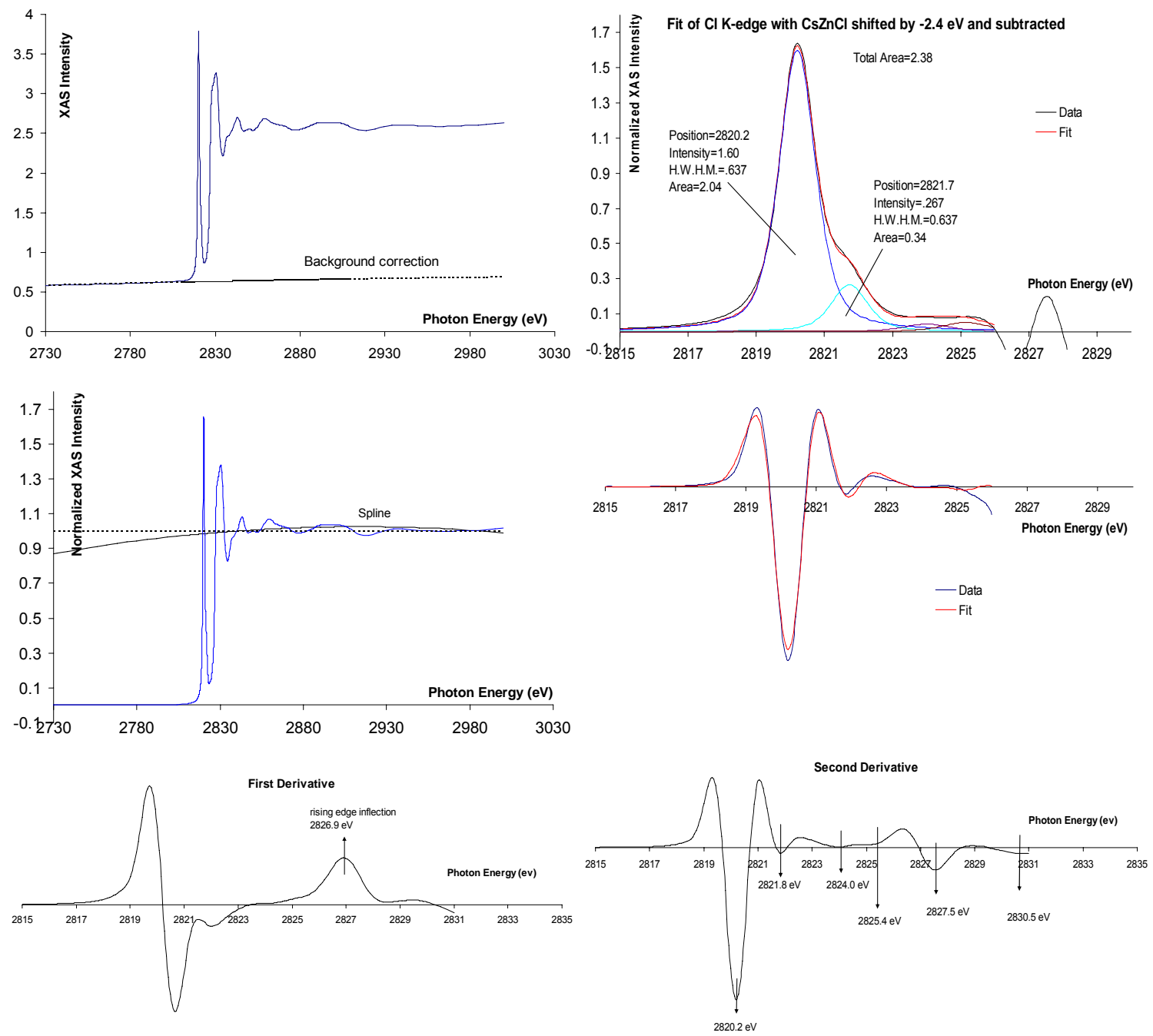
$\left[\mathrm{PdCl}_{6}\right]^{2-} \mathrm{Cl} \mathrm{K}$-edge measure at ALS (Beamline setup C)
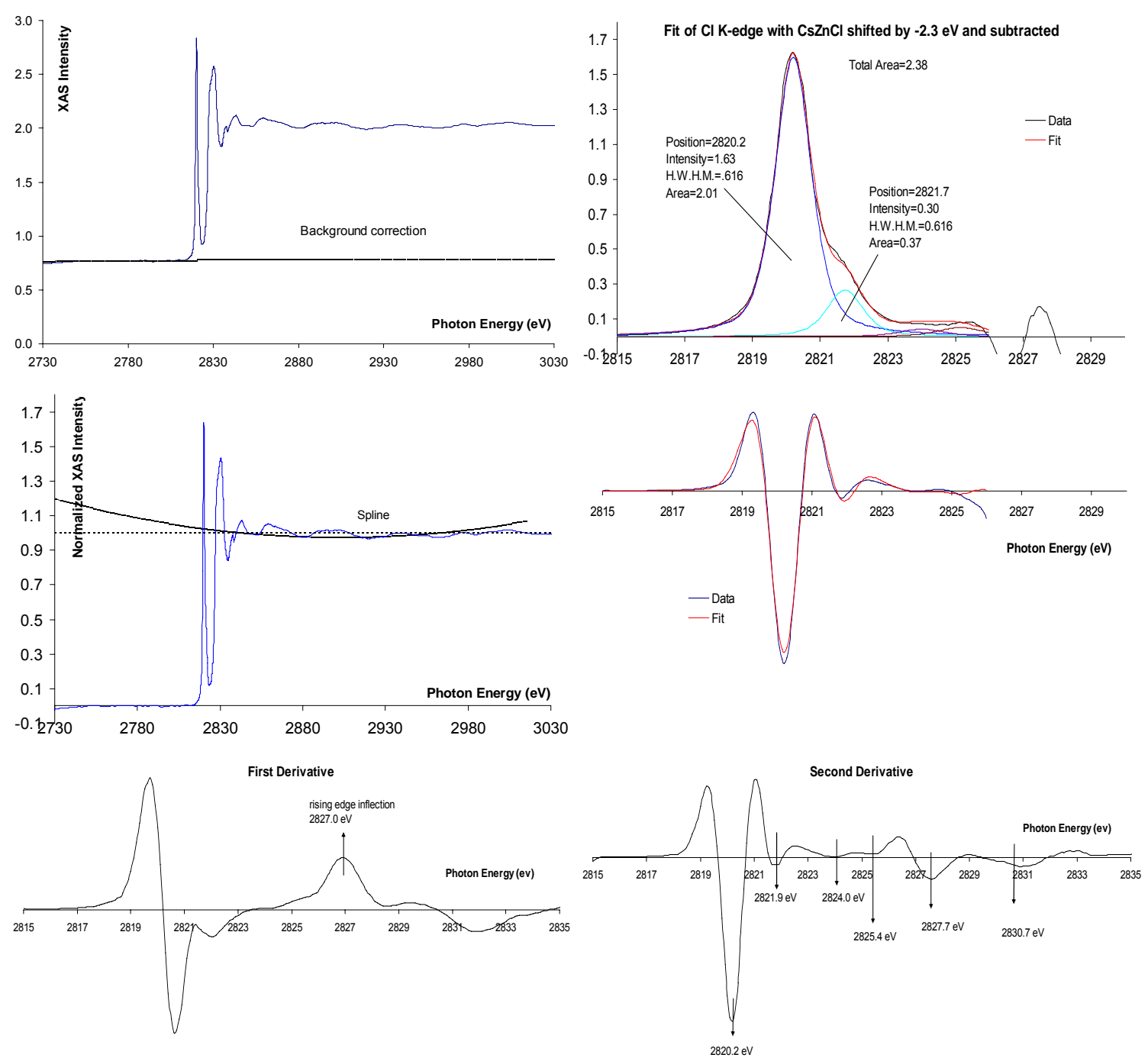

$\left[\mathrm{PdCl}_{6}\right]^{2-} \mathrm{Cl} \mathrm{K}$-edge measure at ALS (Beamline setup D)
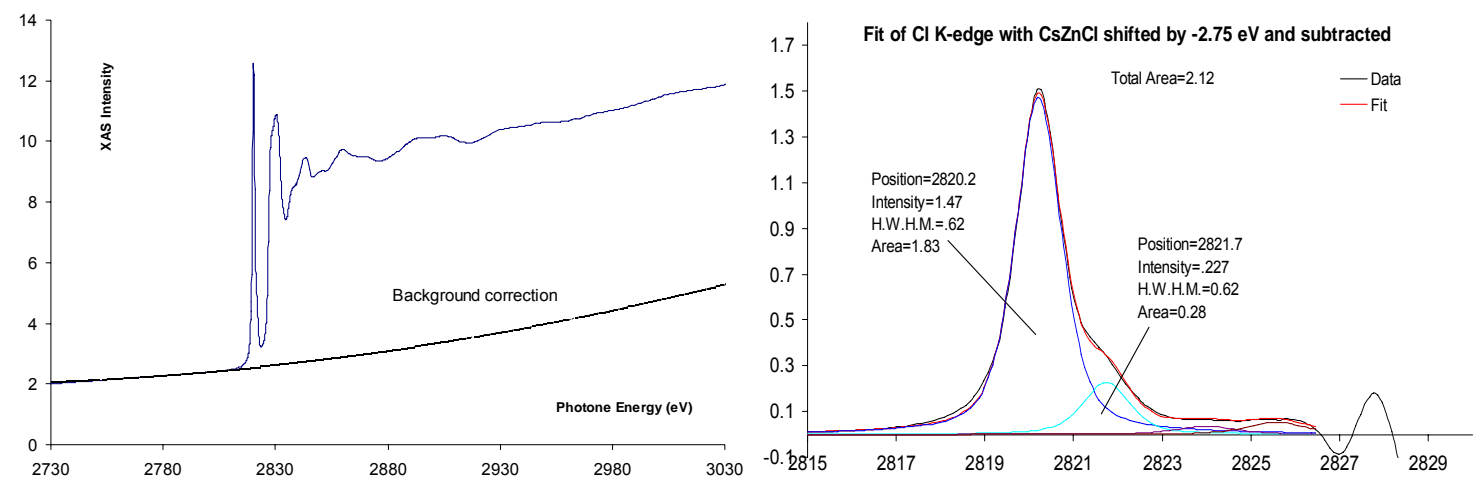


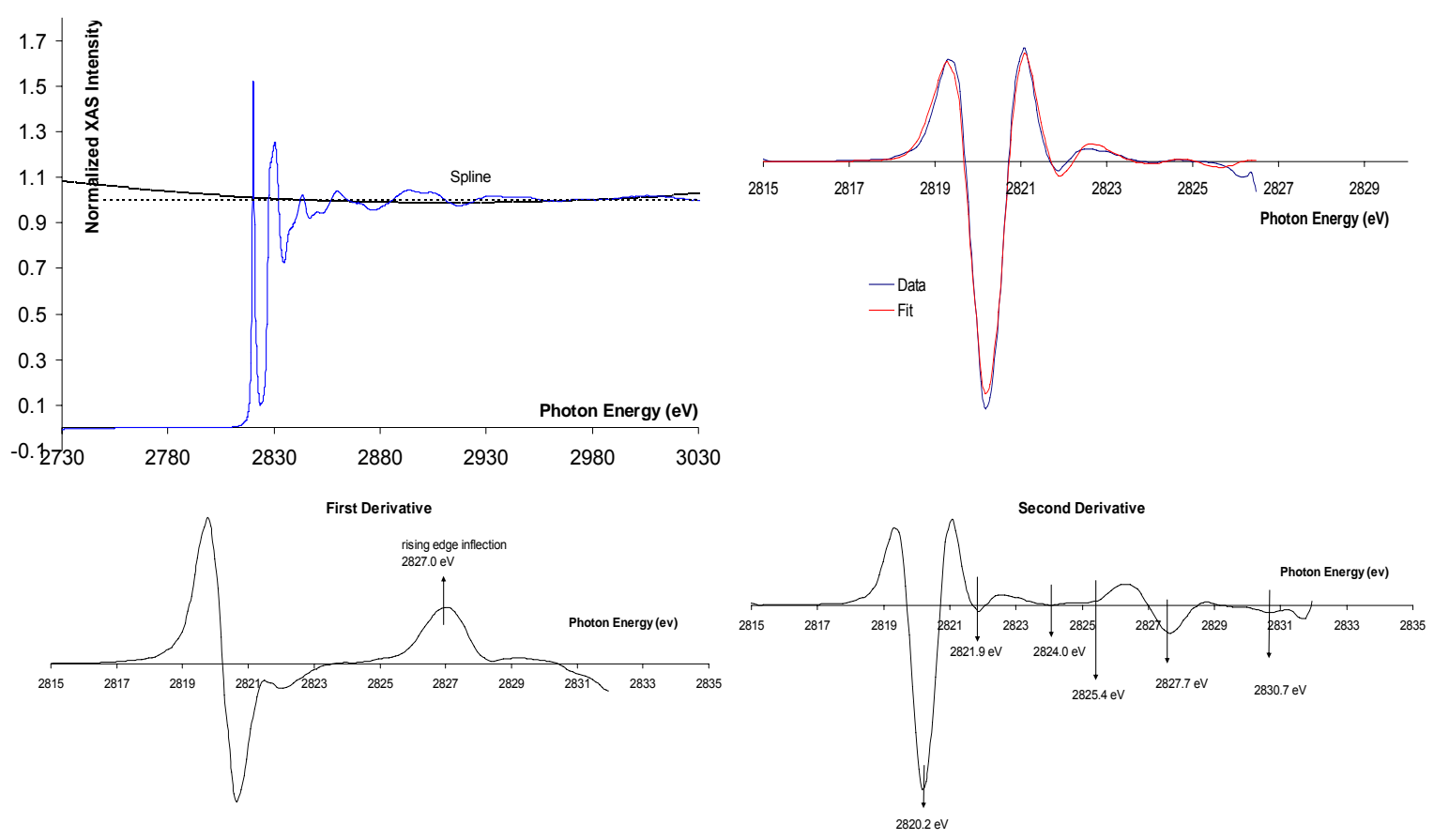

$\left[\mathrm{CuCl}_{4}\right]^{2-} \mathrm{Cl} \mathrm{K}$-edge measured at ALS (Beamline setup D)
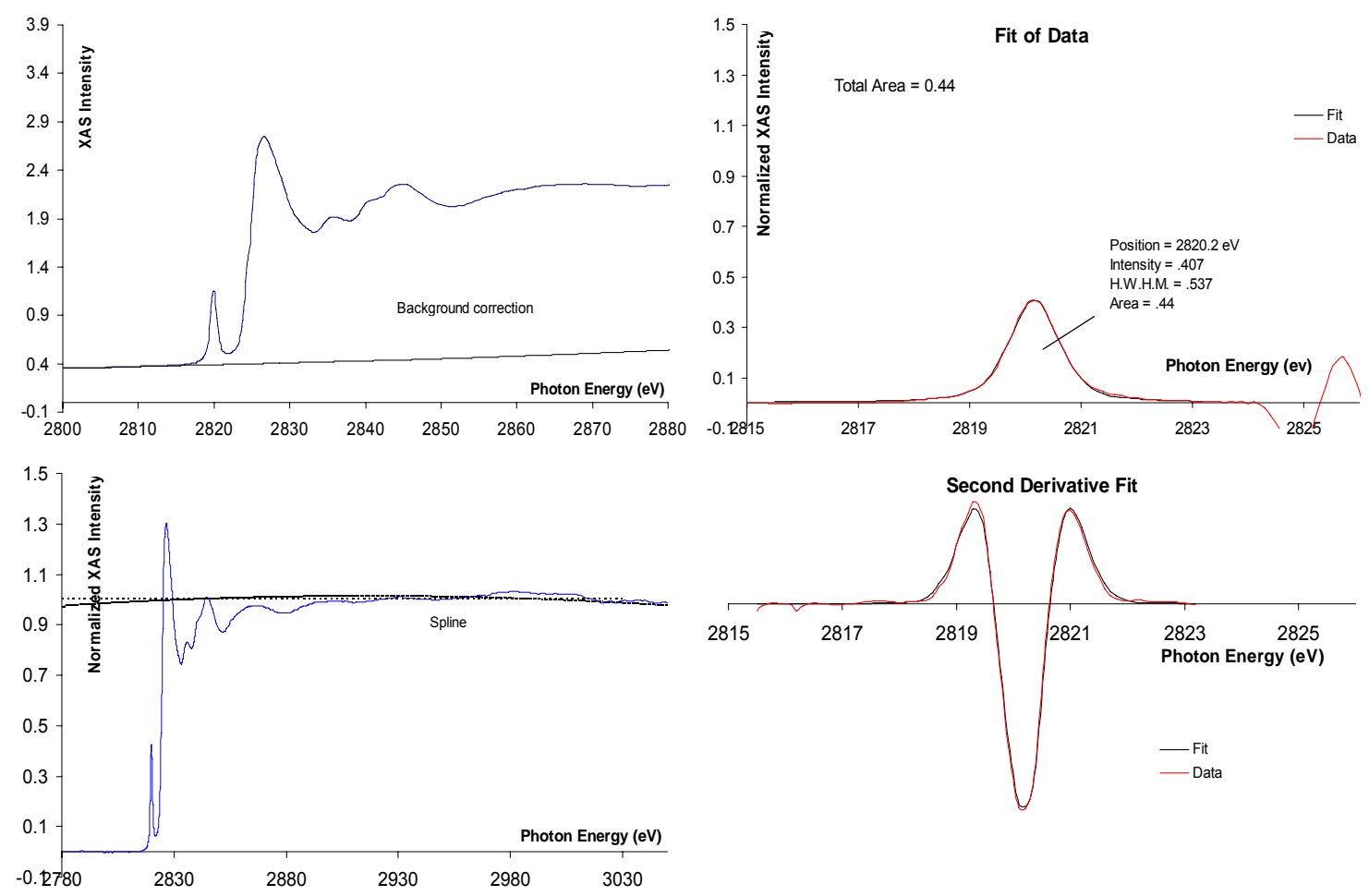
83

$\left[\mathrm{PdCl}_{4}\right]^{2-} \mathrm{Pd} \mathrm{L}_{\mathrm{III}}$-edge measured at SSRL (Beamline setup A)
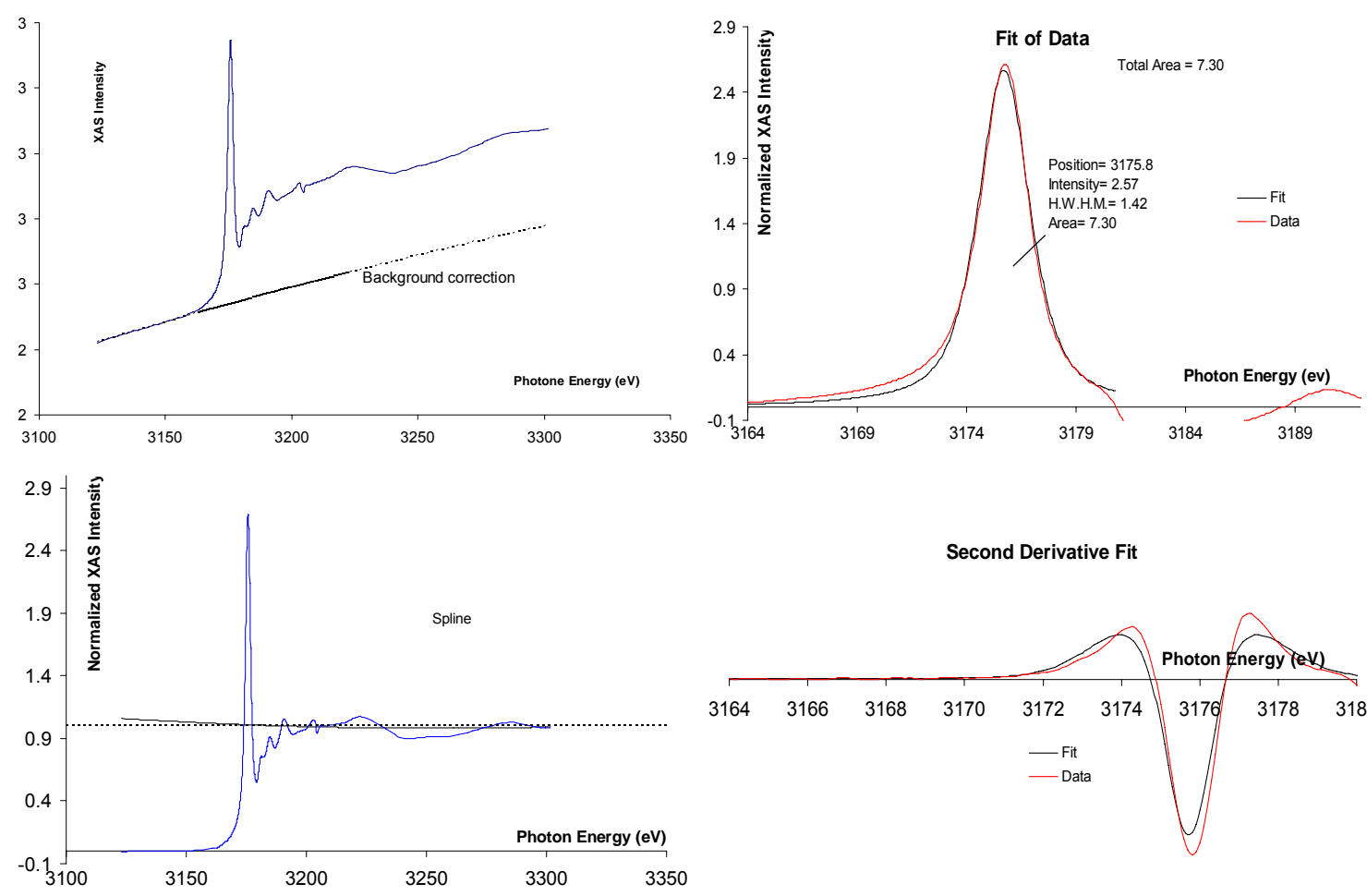

Second Derivative Fit
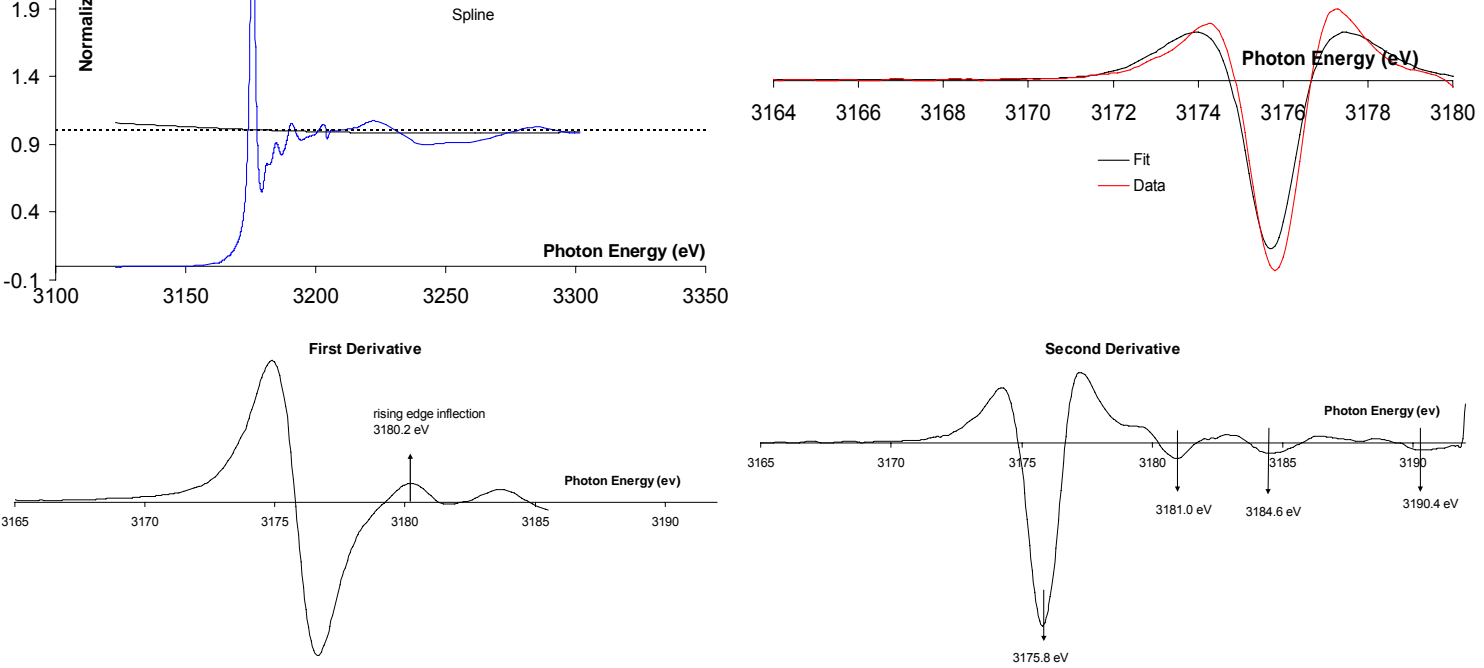

$\left[\mathrm{PdCl}_{4}\right]^{2-} \mathrm{Pd} \mathrm{L} \mathrm{L}_{\mathrm{III}}$-edge measured at ALS (Beamline setup D)
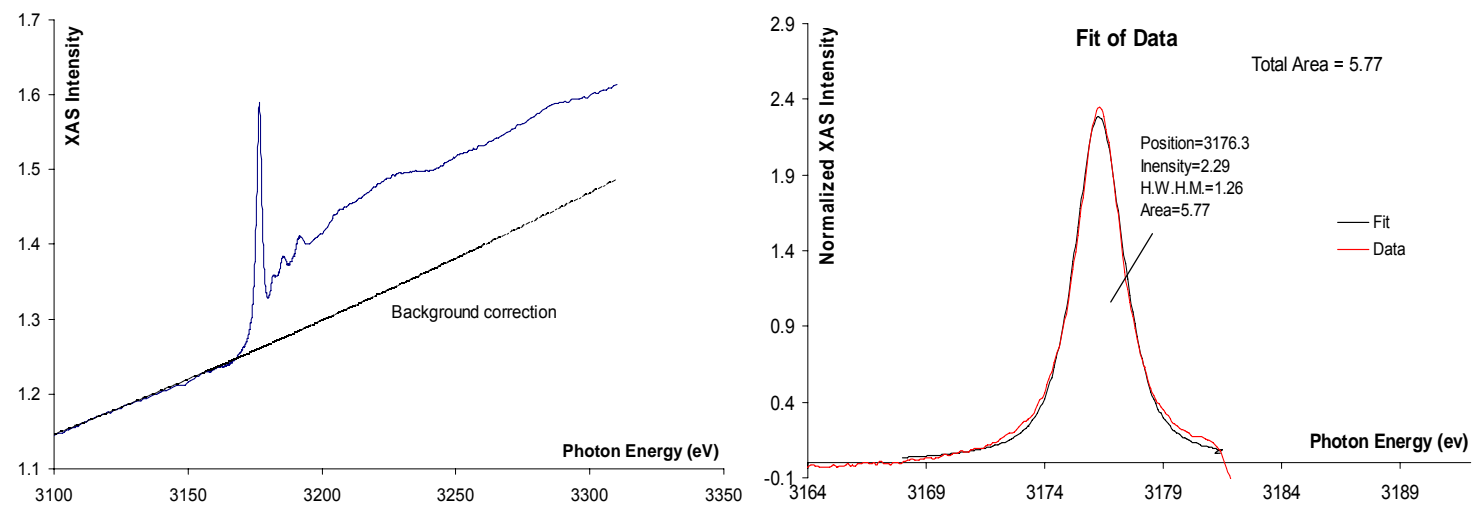

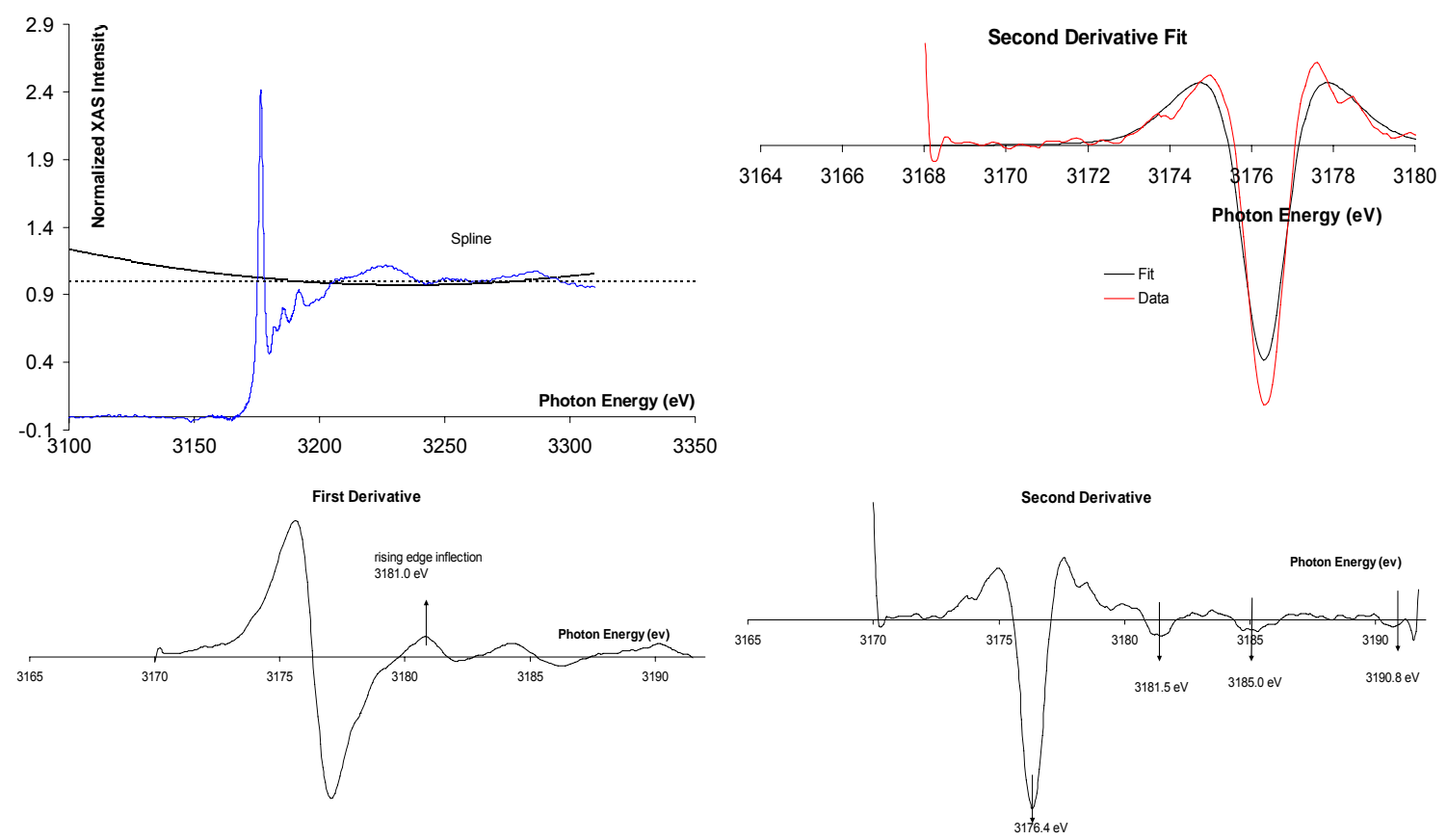

$\mathrm{PdCl}_{2} \mathrm{Pd} \mathrm{L}_{\mathrm{III}}$-edge measured at SSRL (Beamline setup B)
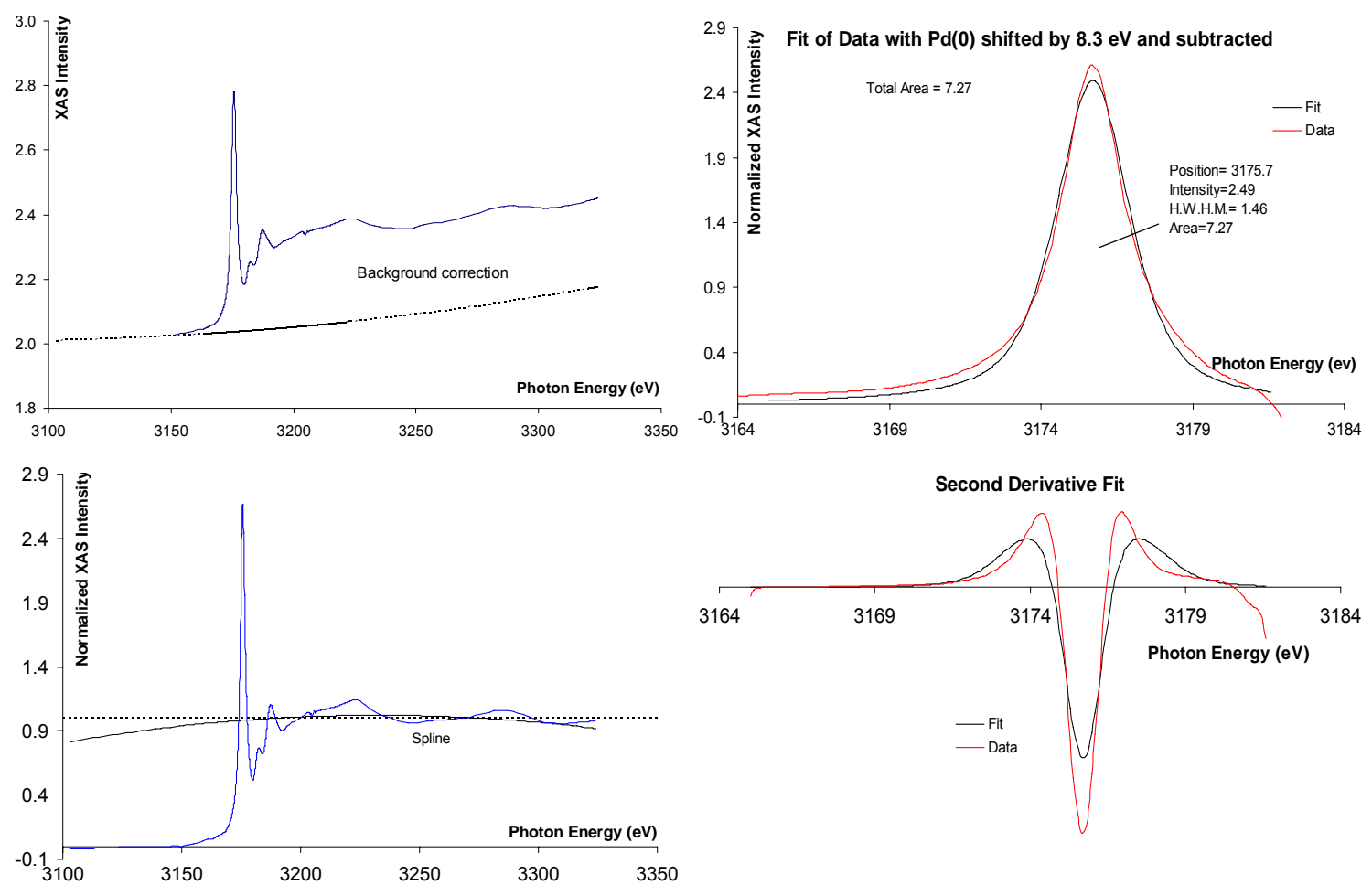

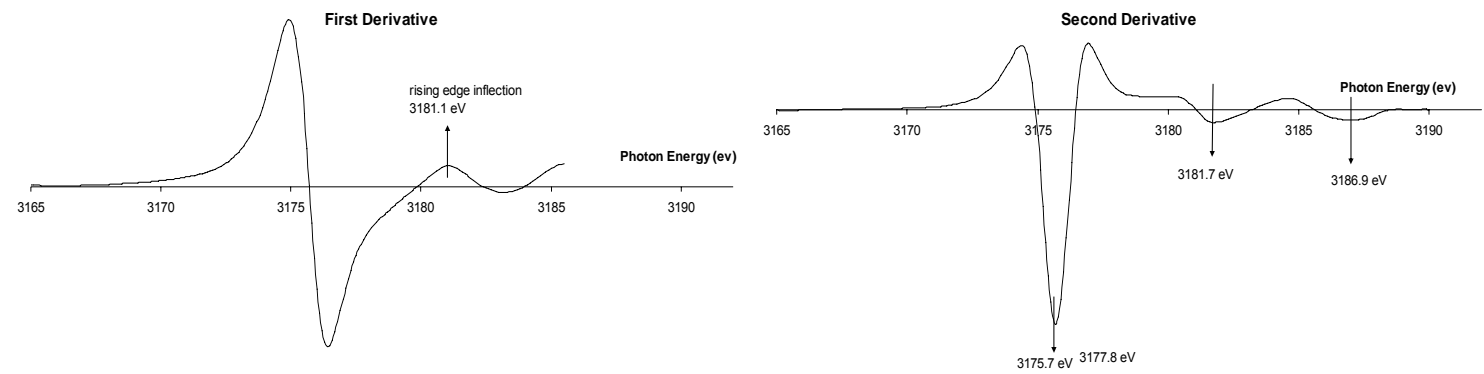

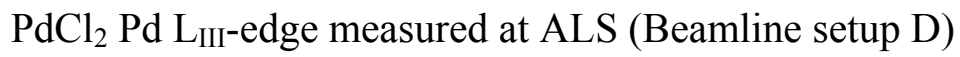
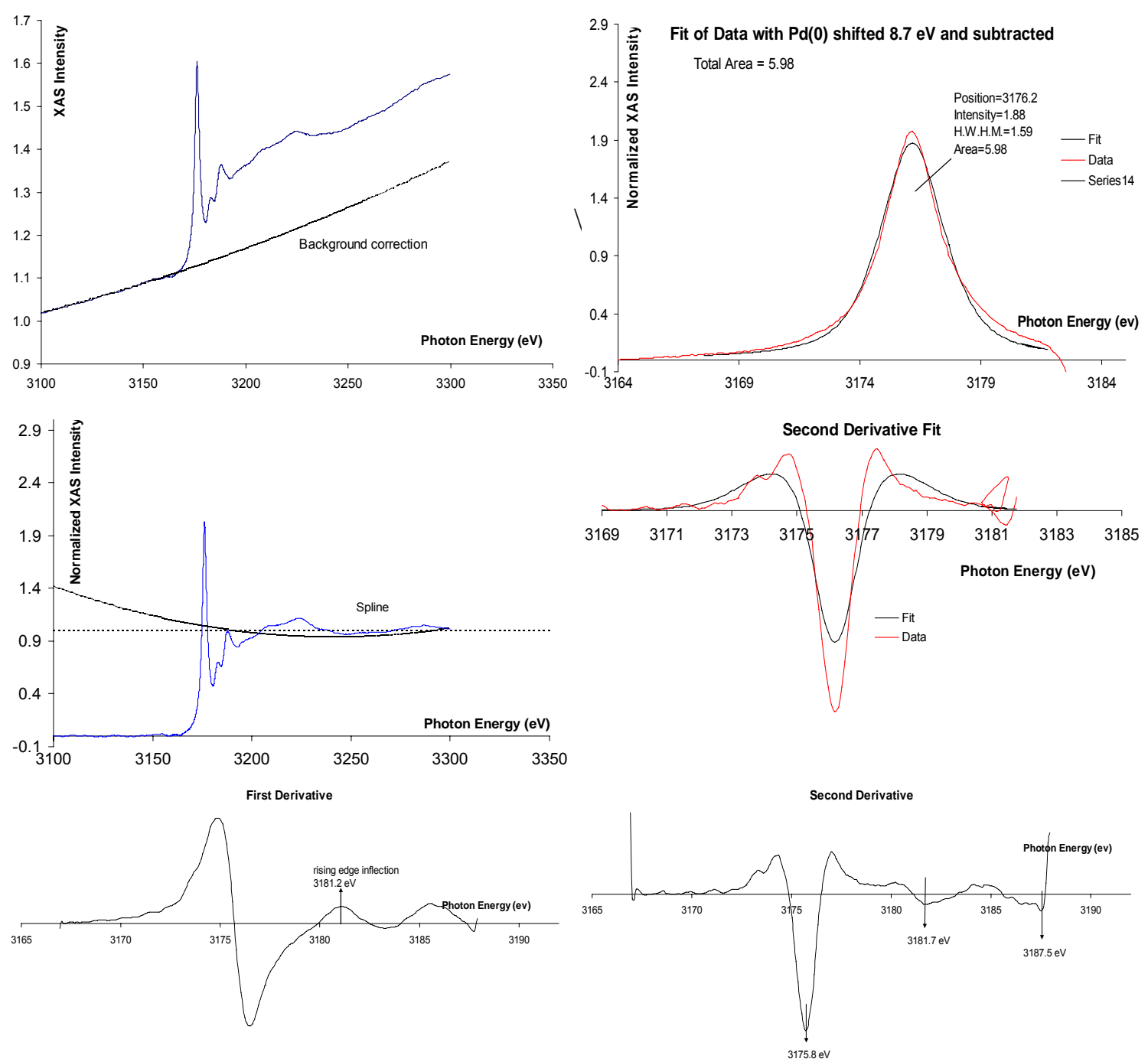


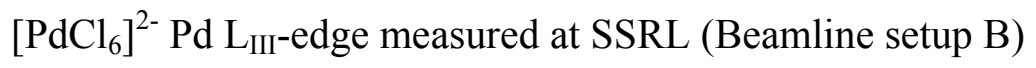
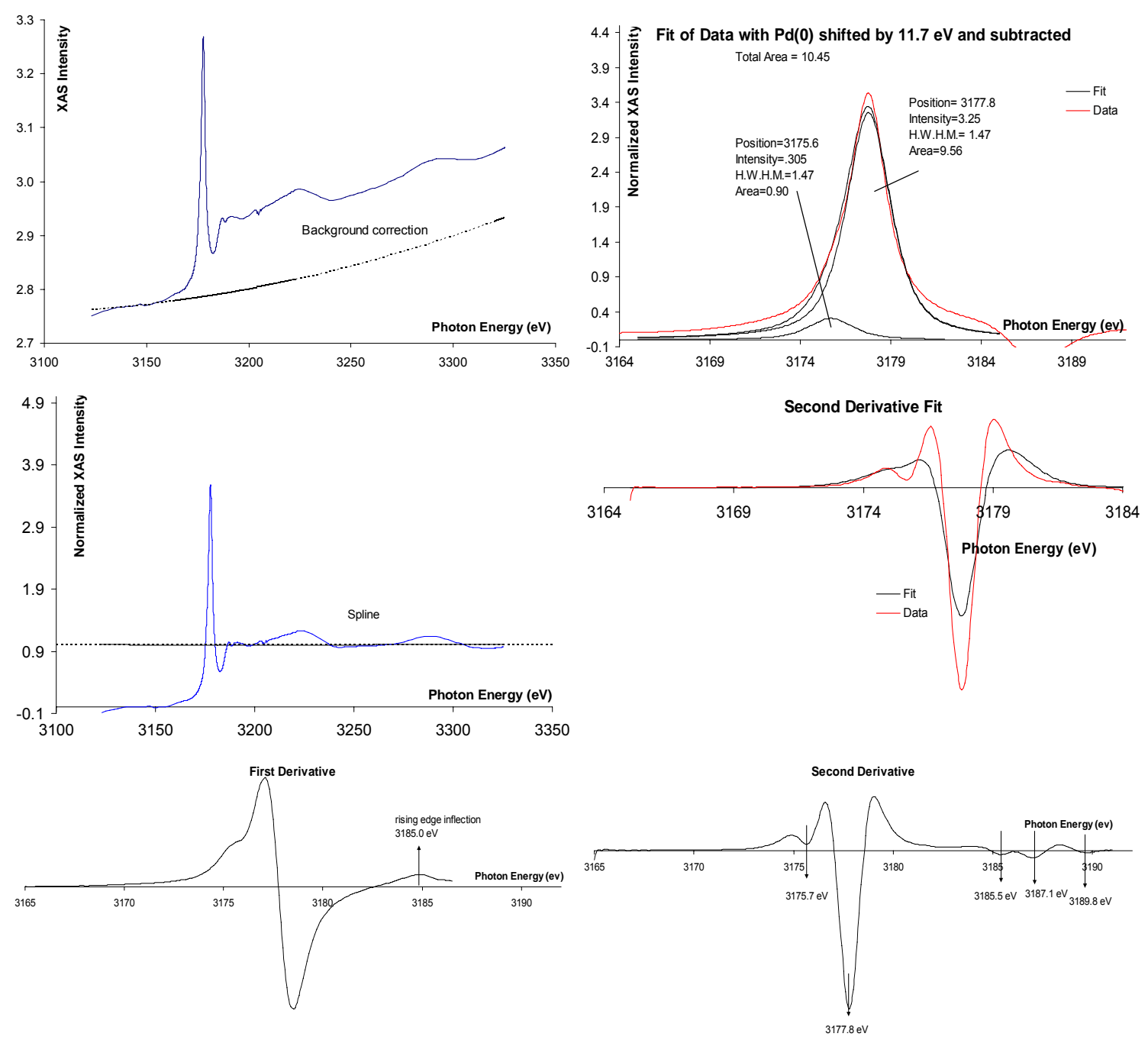

$\left[\mathrm{PdCl}_{6}\right]^{2-} \mathrm{Pd} \mathrm{L} \mathrm{LIII}$-edge measured at ALS (Beamline setup D)
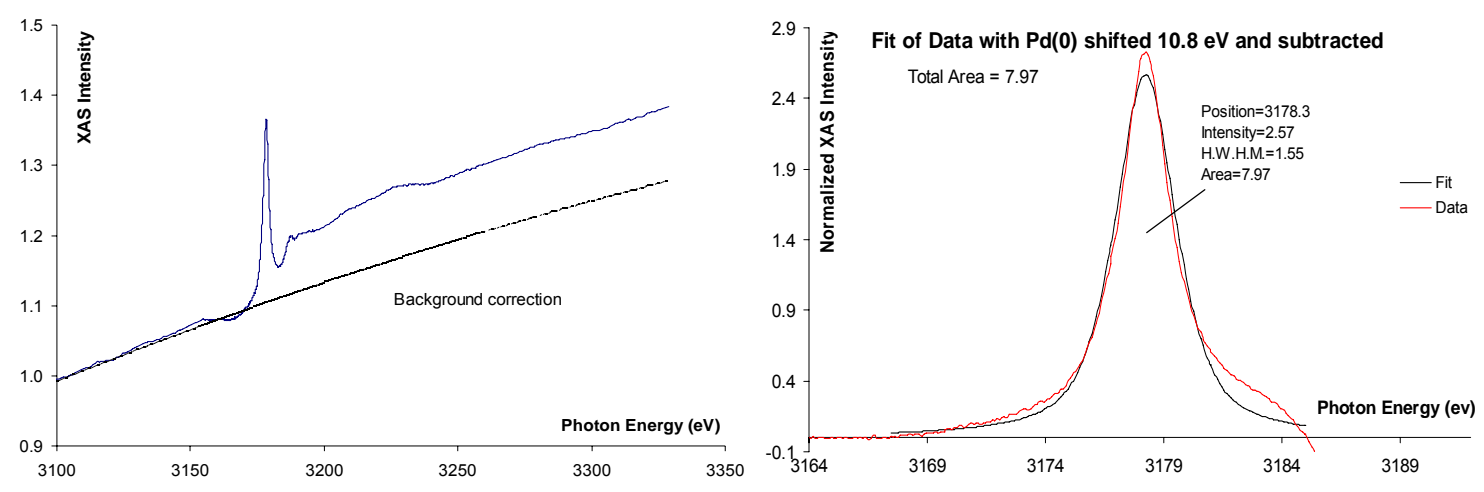

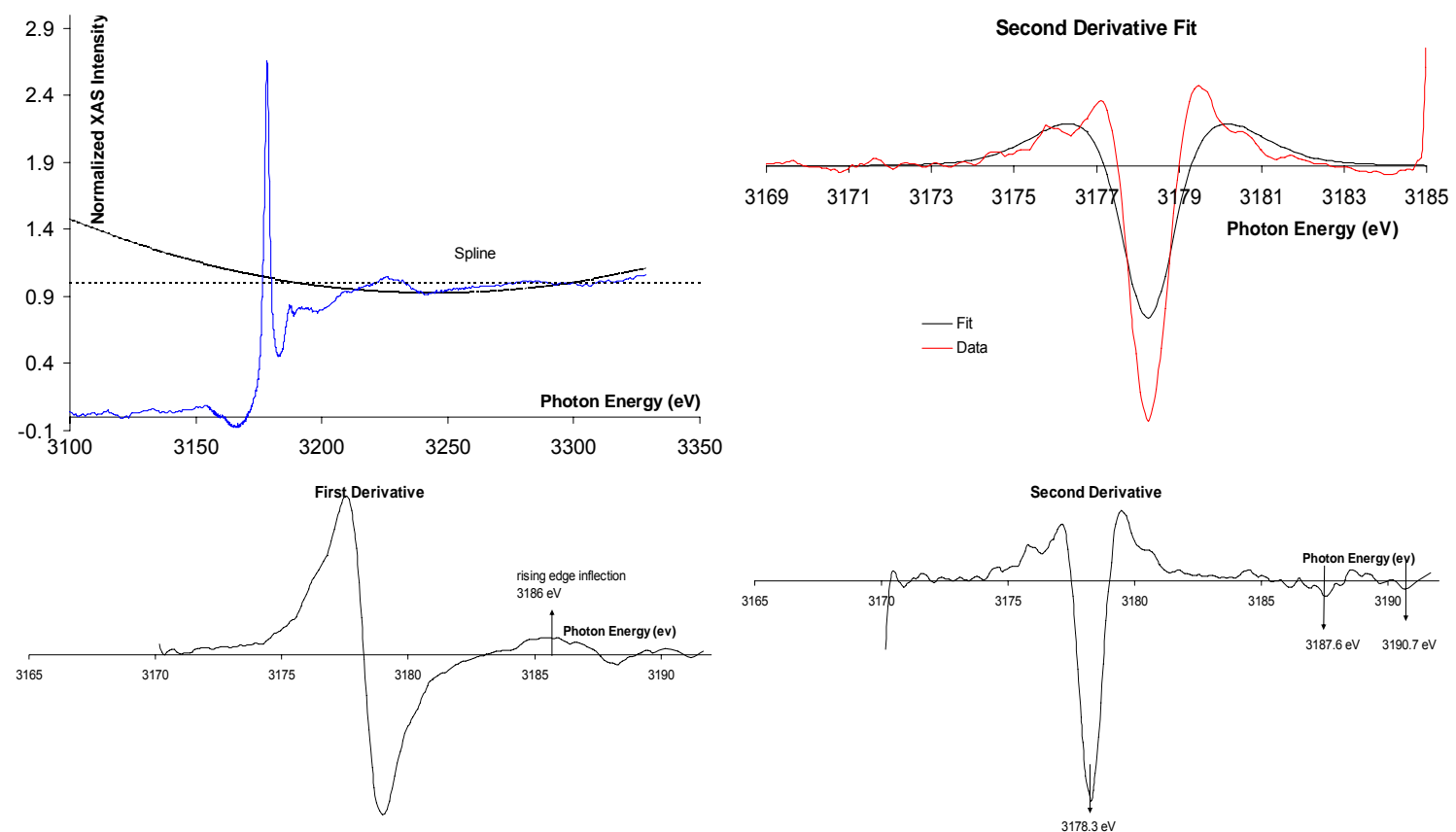

$\operatorname{Pd}(0) \operatorname{Pd} \mathrm{L}_{\text {III }}$-edge measure at ALS (Beamline setup C)
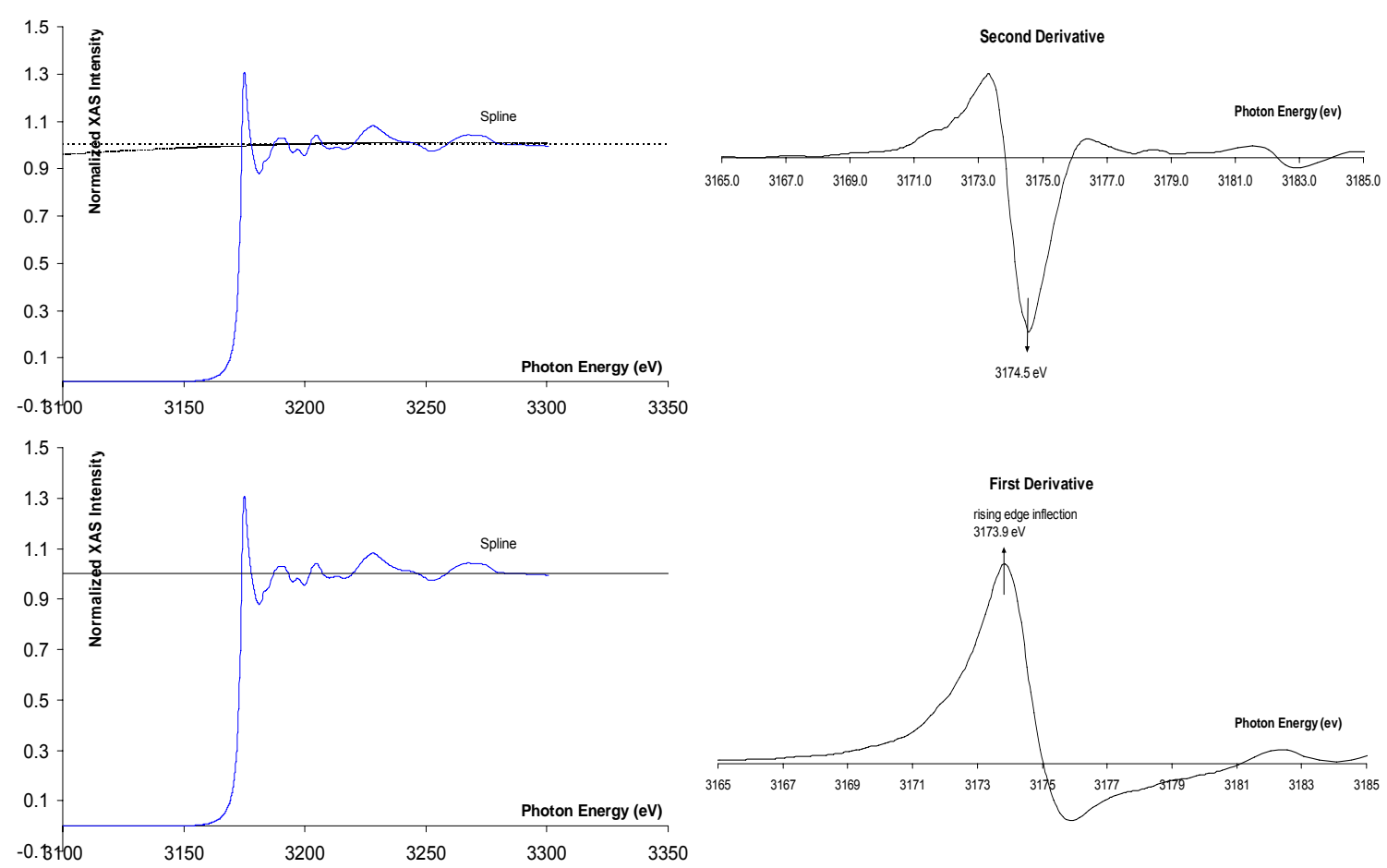
$\left[\mathrm{PdCl}_{4}\right]^{2-} \mathrm{Pd} \mathrm{L}_{\mathrm{II}}$-edge measured at SSRL (Beamline setup A)
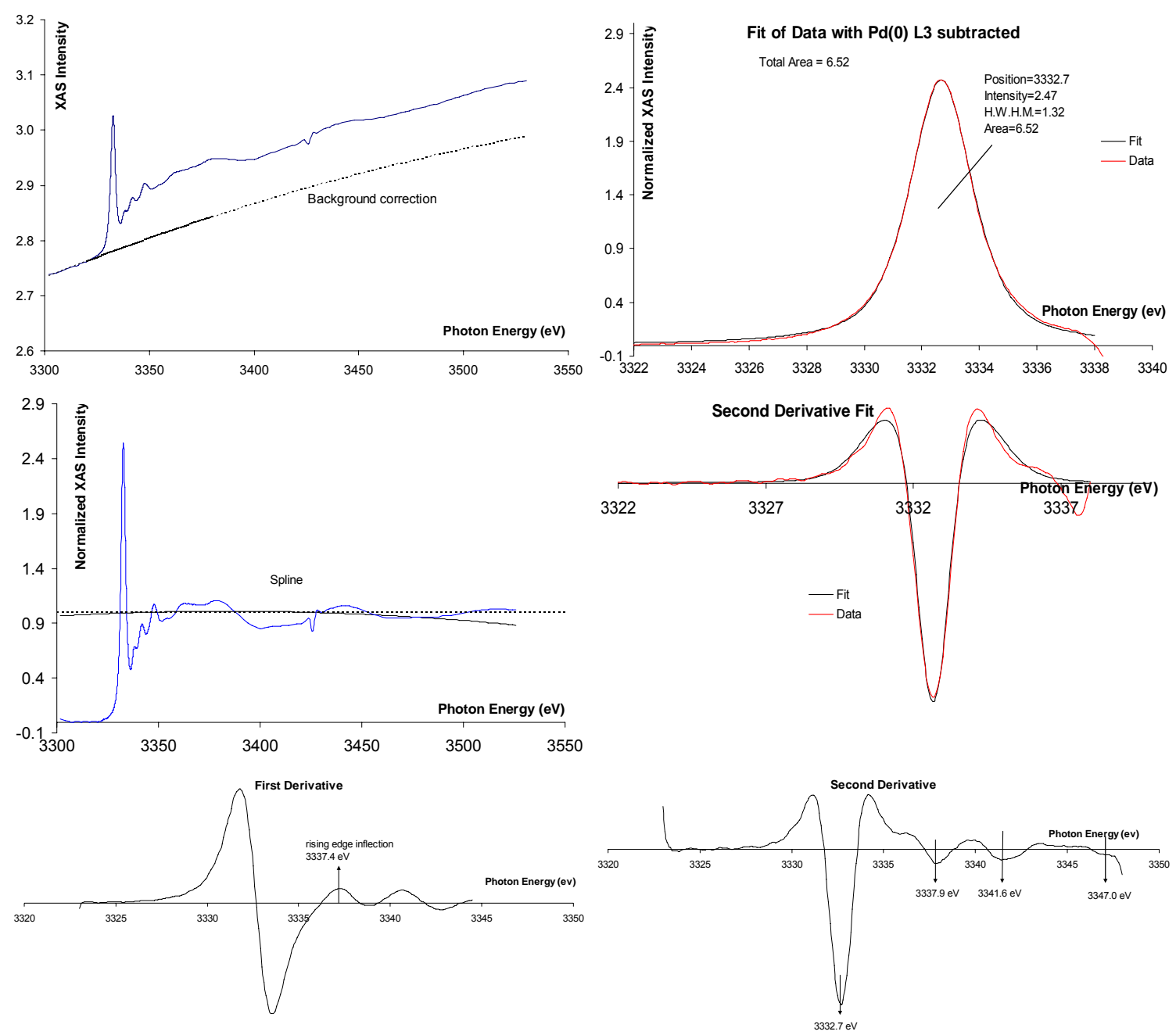

$\left[\mathrm{PdCl}_{4}\right]^{2-} \mathrm{Pd} \mathrm{L} \mathrm{LII}_{\mathrm{II}}$-edge measured at ALS (Beamline setup D)
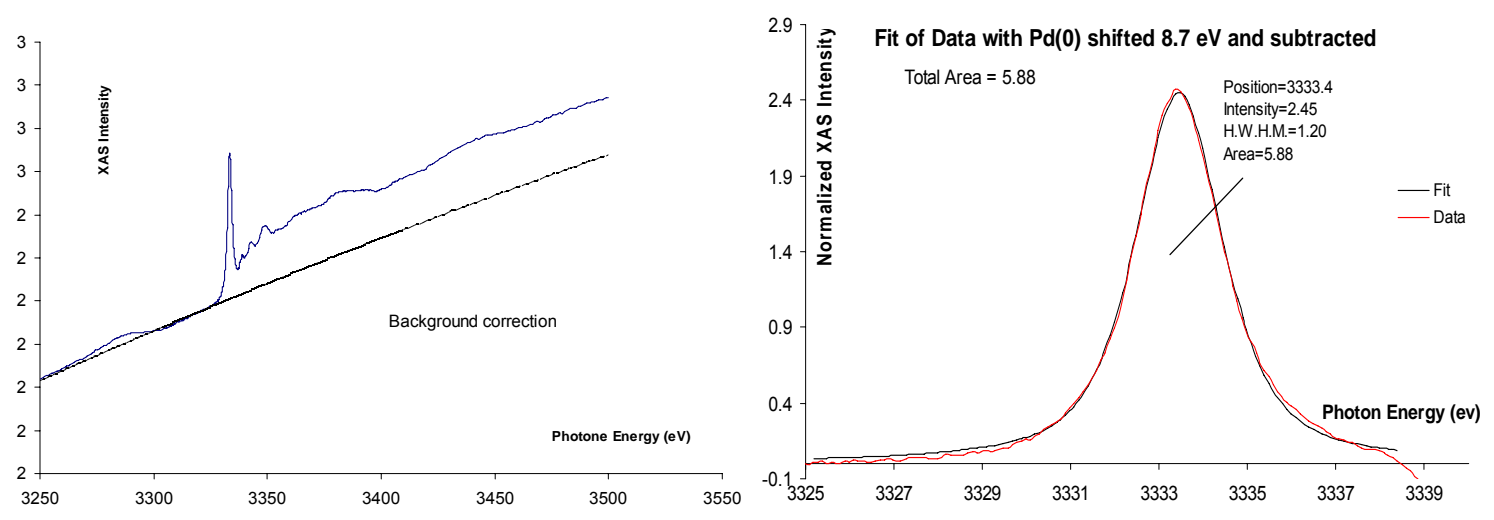

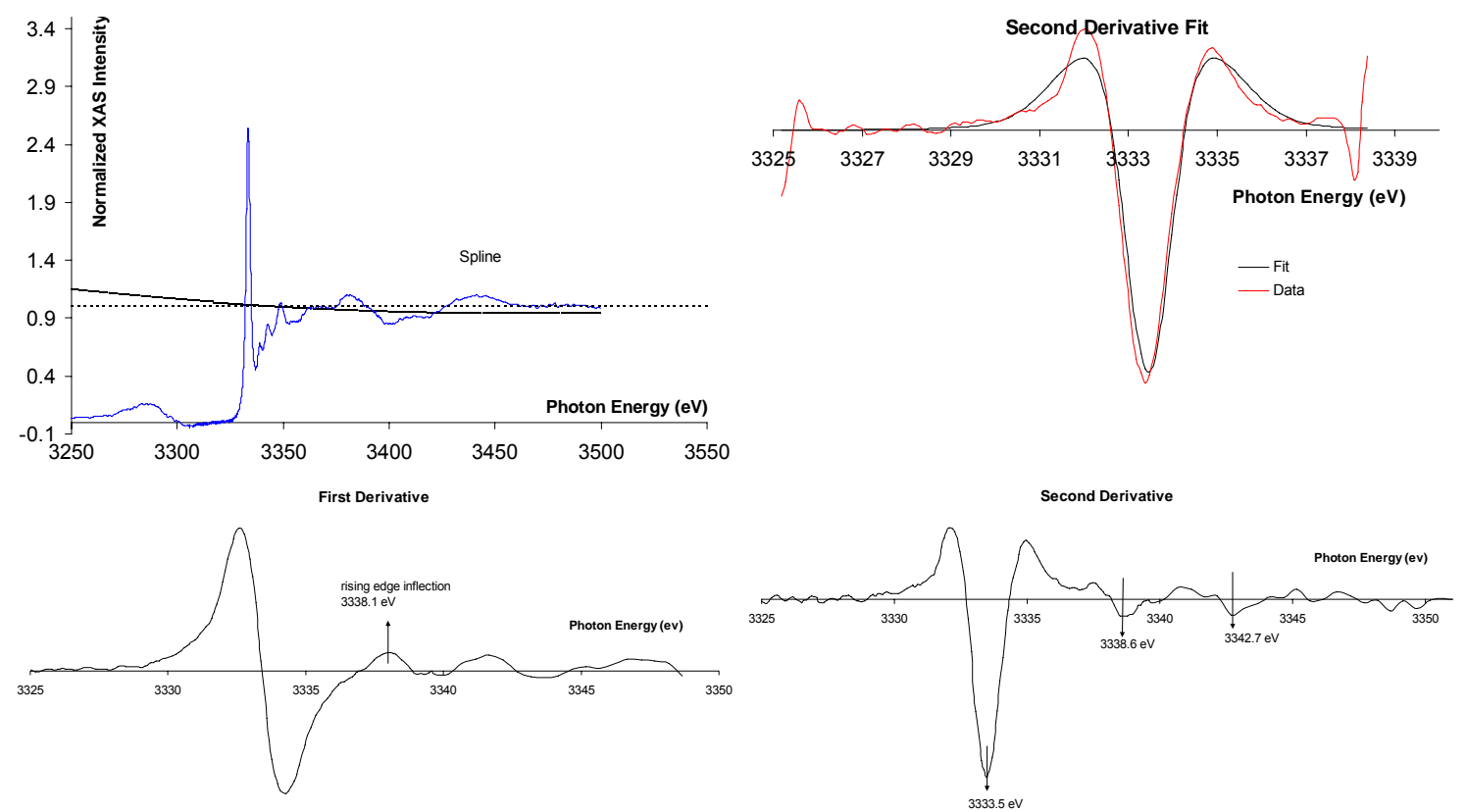

$\mathrm{PdCl}_{2} \mathrm{Pd} \mathrm{L} \mathrm{II}$-edge measured at SSRL (Beamline setup B)
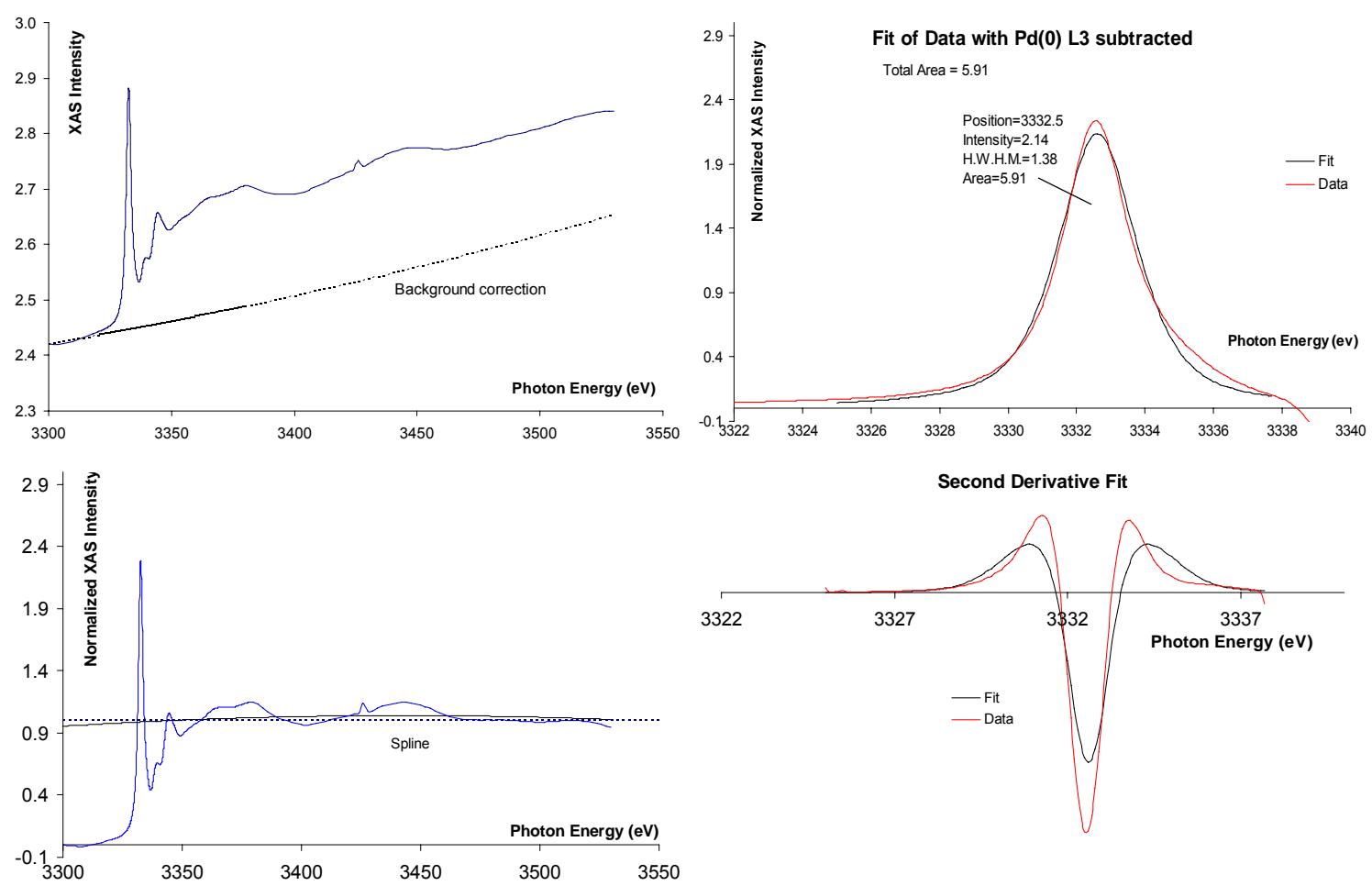

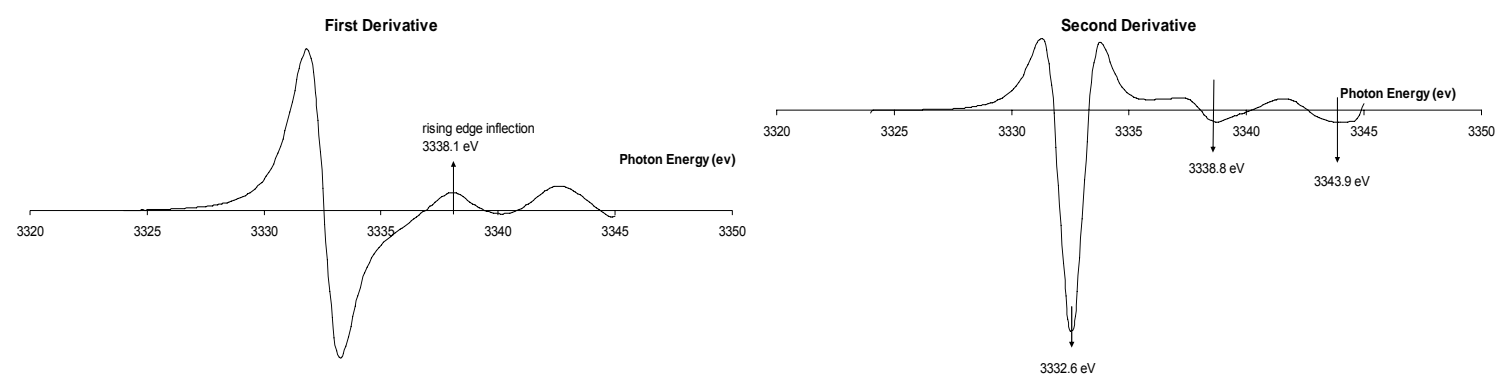

$\mathrm{PdCl}_{2} \mathrm{Pd} \mathrm{L}_{\mathrm{II}}$-edge measured at ALS (Beamline setup D)
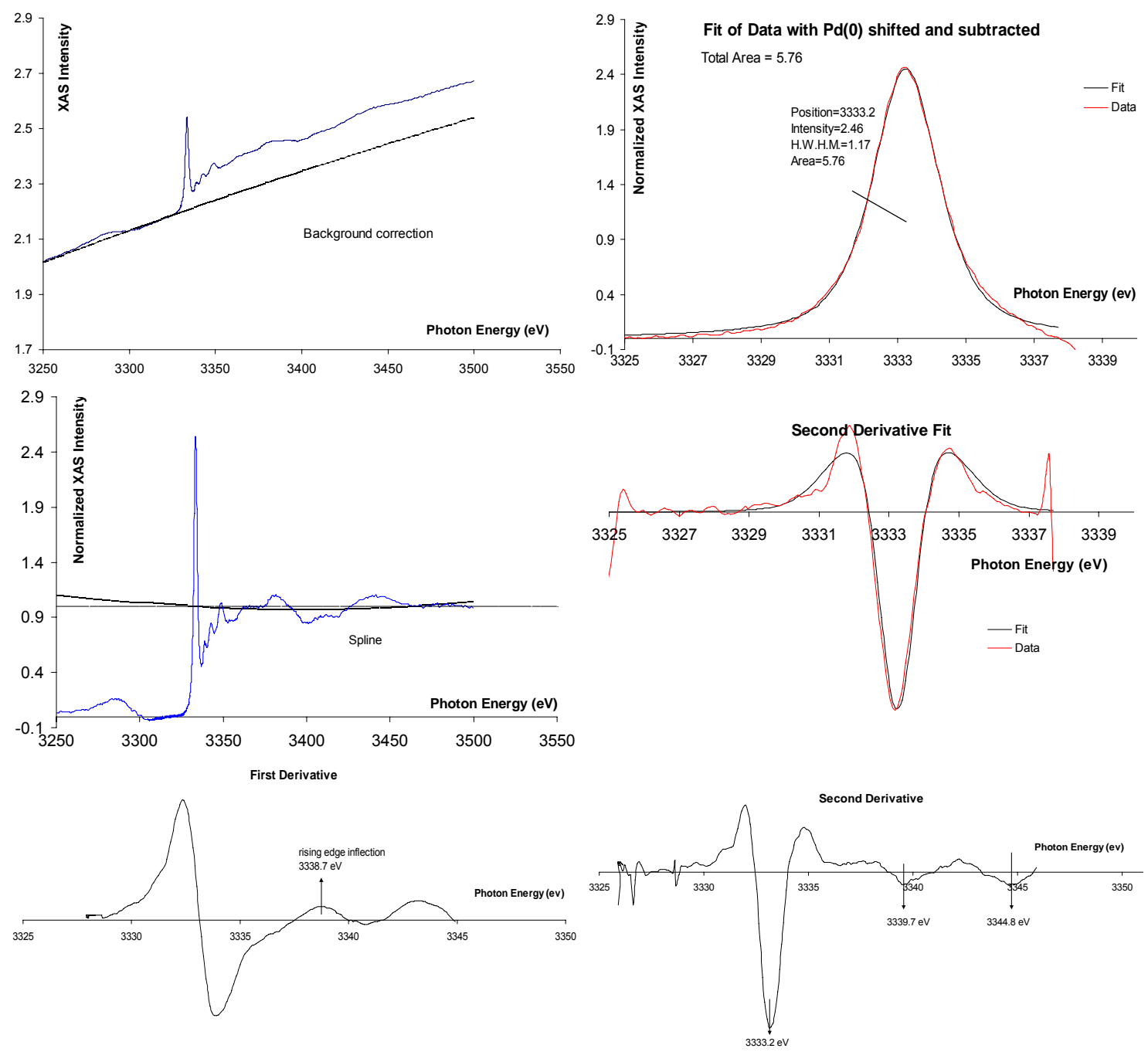


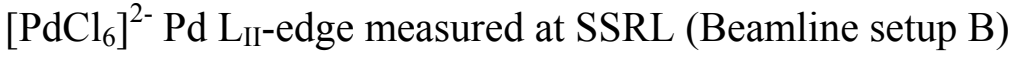
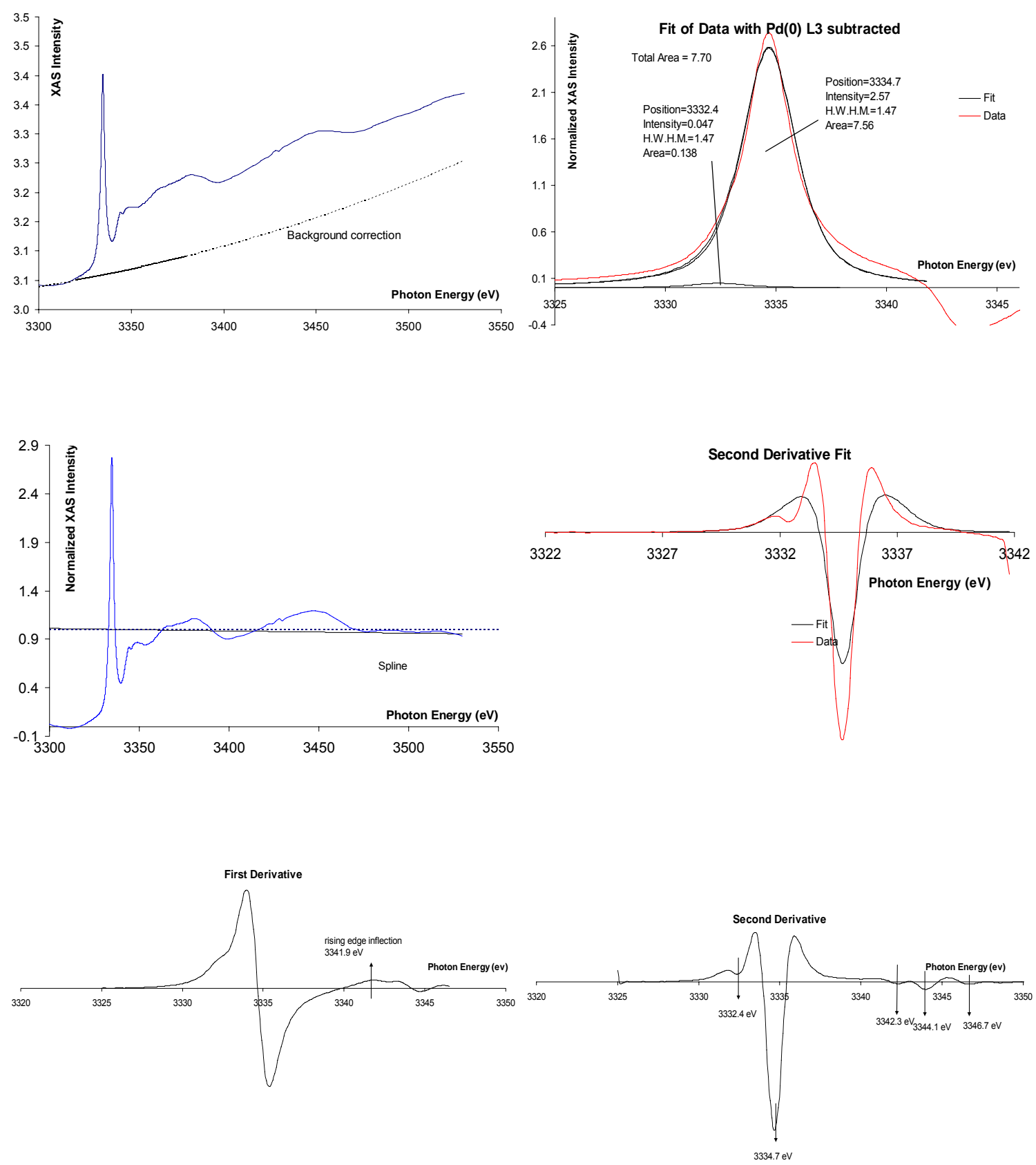


\section{$\left[\mathrm{PdCl}_{6}\right]^{2-} \mathrm{Pd} \mathrm{L} \mathrm{L}_{\mathrm{II}}$-edge measure at ALS (Beamline setup D)}
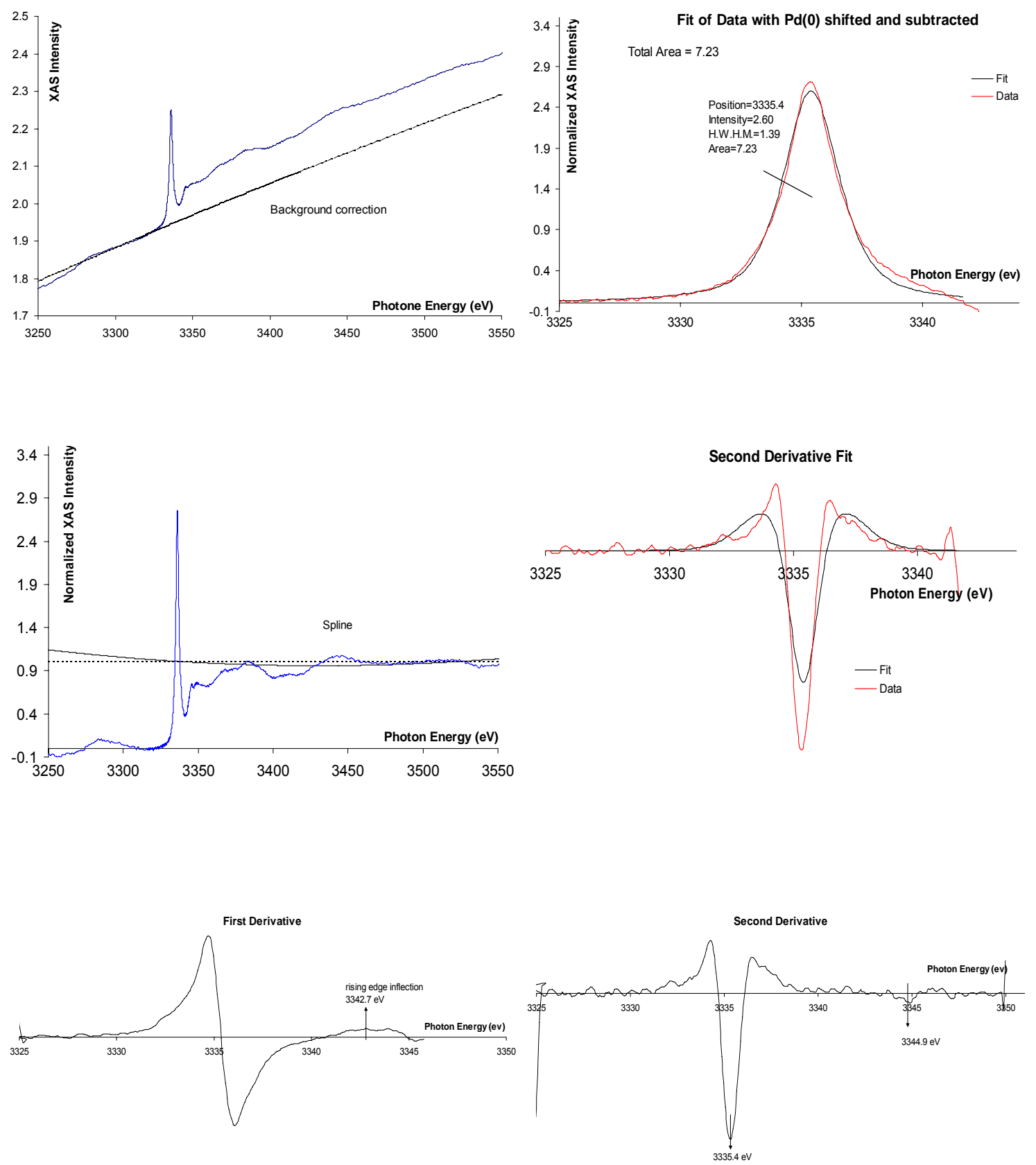
$\left[\mathrm{PdCl}_{4}\right]^{2-} \mathrm{Pd} \mathrm{L} \mathrm{L}_{\mathrm{III}}+\mathrm{L}_{\mathrm{II}}$-edges measured together at SSRL (Beamline setup A)
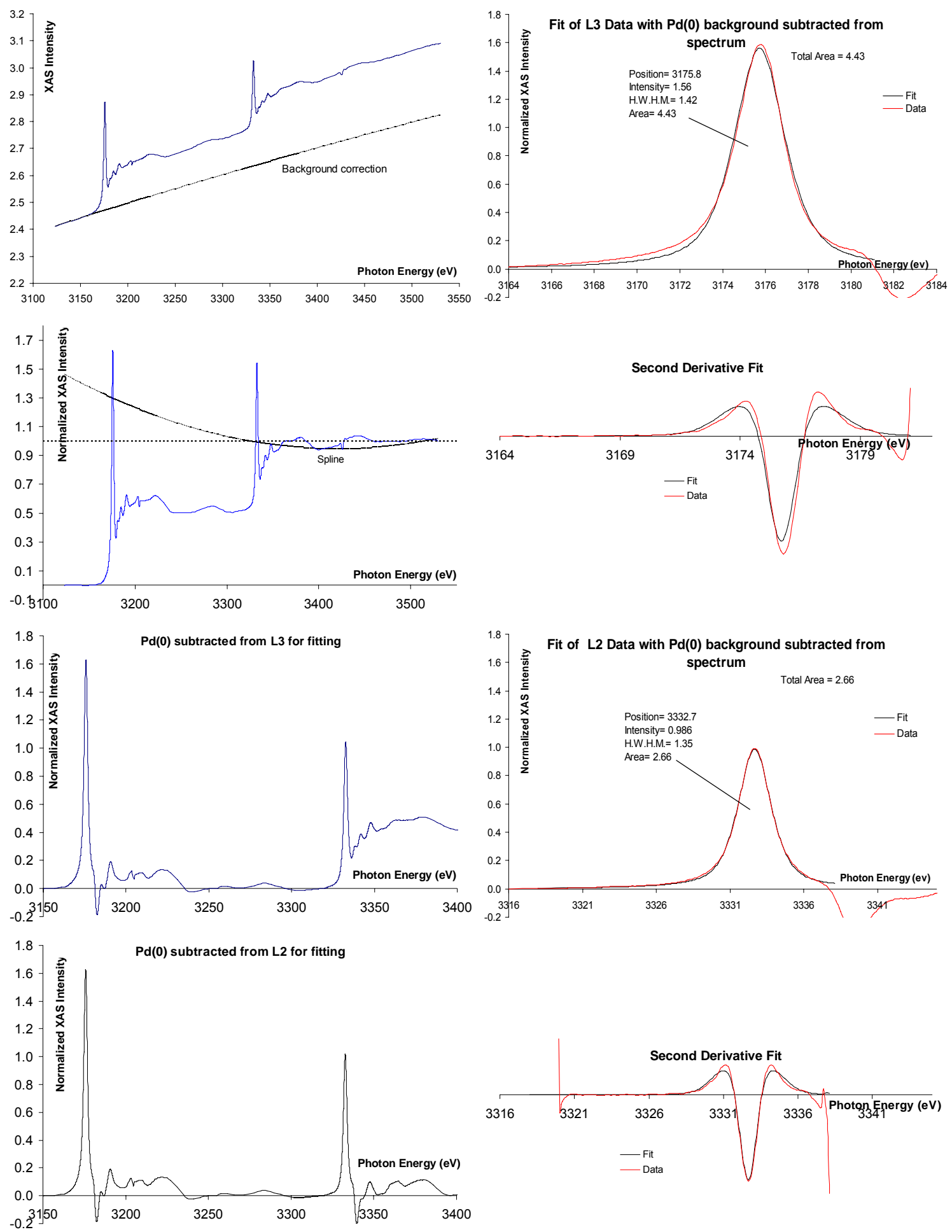
$\left[\mathrm{PdCl}_{4}\right]^{2-} \mathrm{Pd} \mathrm{L}_{\mathrm{III}}+\mathrm{L}_{\mathrm{II}}$-edges measured at ALS (Beamline setup D)
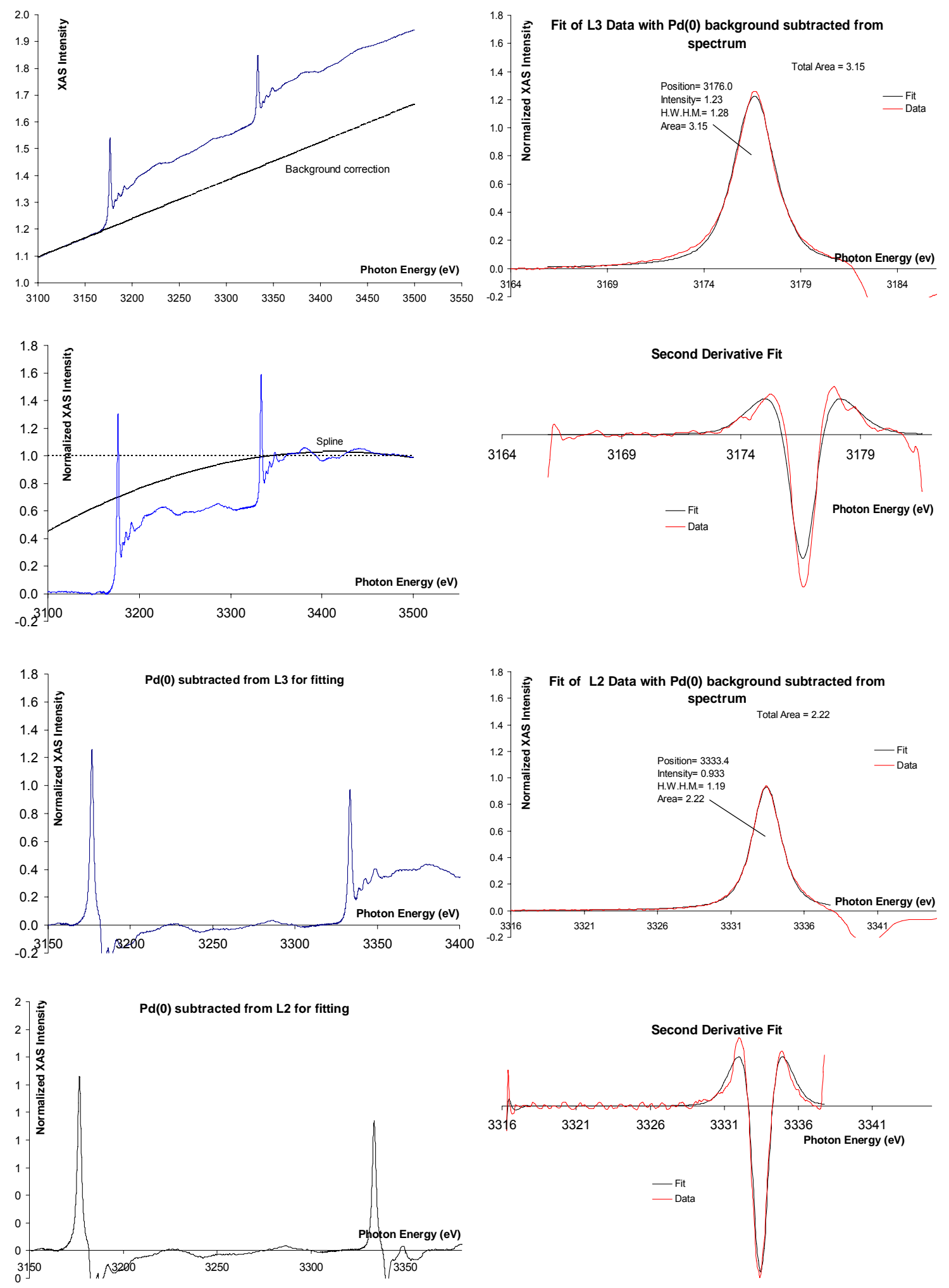
$\mathrm{PdCl}_{2} \mathrm{Pd} \mathrm{L}_{\mathrm{III}}+\mathrm{L}_{\mathrm{II}}$-edges measured together at SSRL (Beamline setup B)
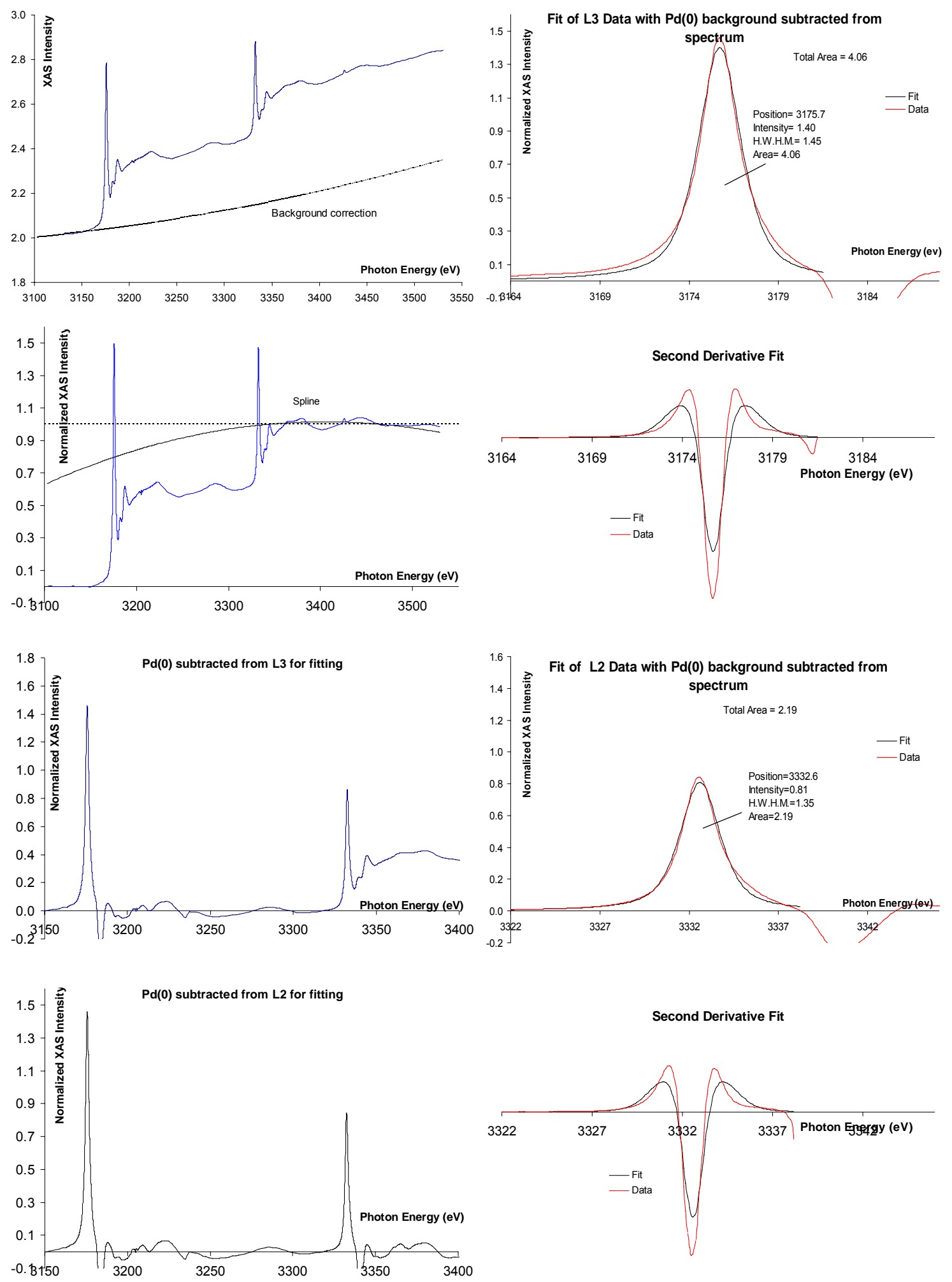
$\mathrm{PdCl}_{2} \mathrm{Pd} \mathrm{L}_{\mathrm{III}}+\mathrm{L}_{\mathrm{II}}$-edges measured at ALS (Beamline setup D)
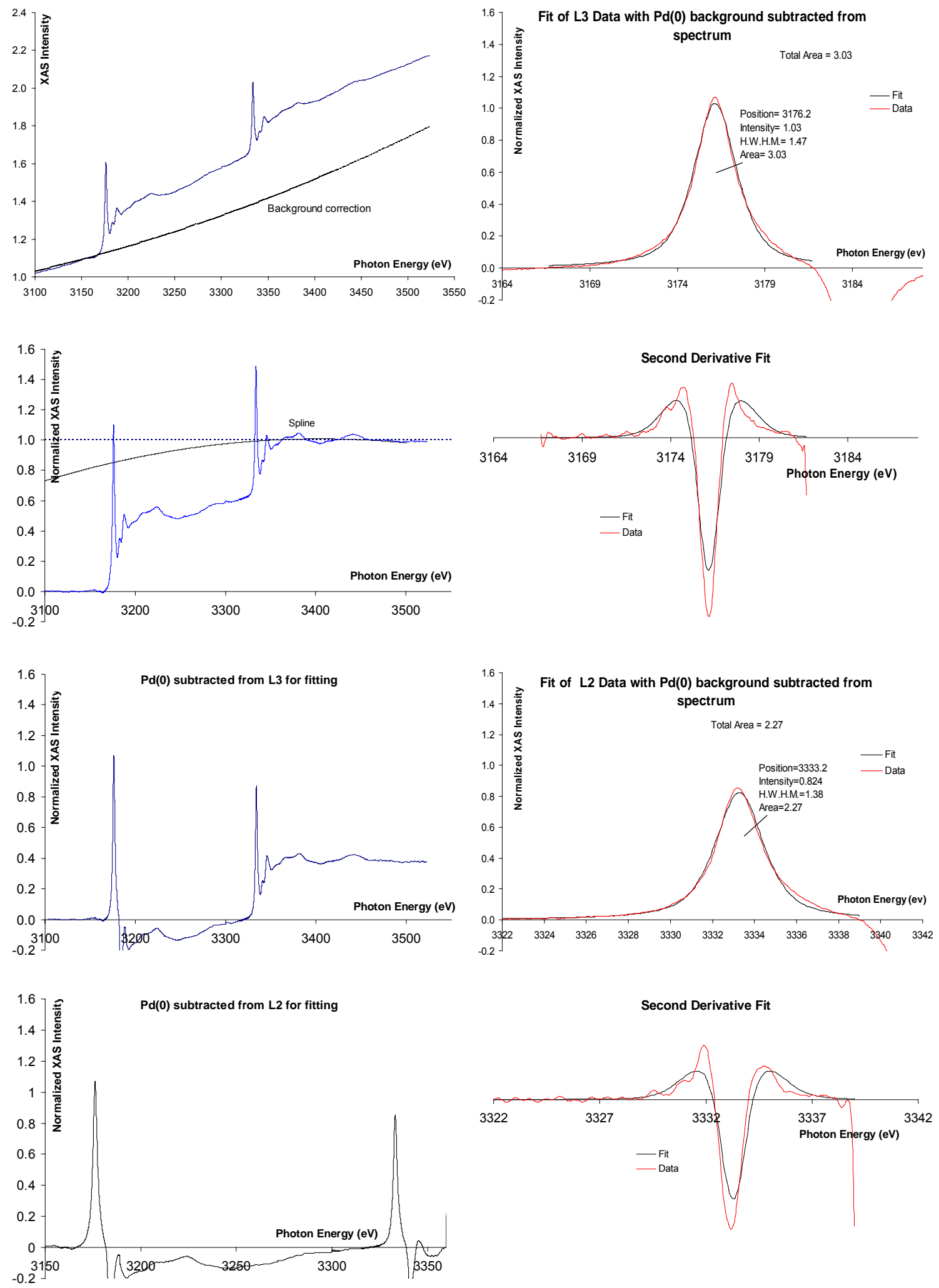
$\left[\mathrm{PdCl}_{6}\right]^{2-} \mathrm{Pd} \mathrm{L} \mathrm{L}_{\mathrm{III}}+\mathrm{L}_{\mathrm{II}}$-edges measured together at SSRL (Beamline setup B)
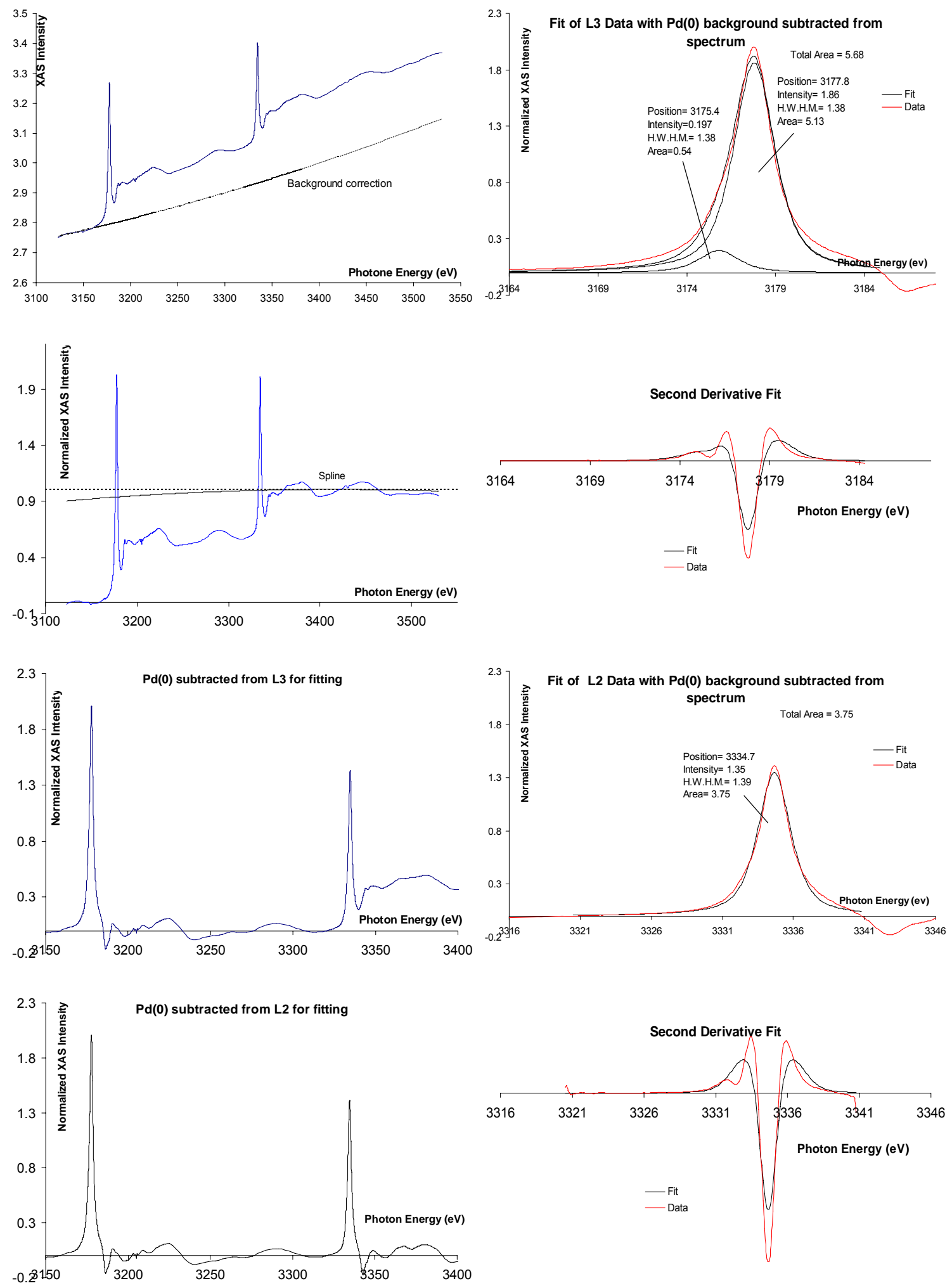


\section{$\left[\mathrm{PdCl}_{6}\right]^{2-} \mathrm{Pd} \mathrm{L}_{\mathrm{III}}+\mathrm{L}_{\mathrm{II}}$-edges measured at ALS (Beamline setup D)}
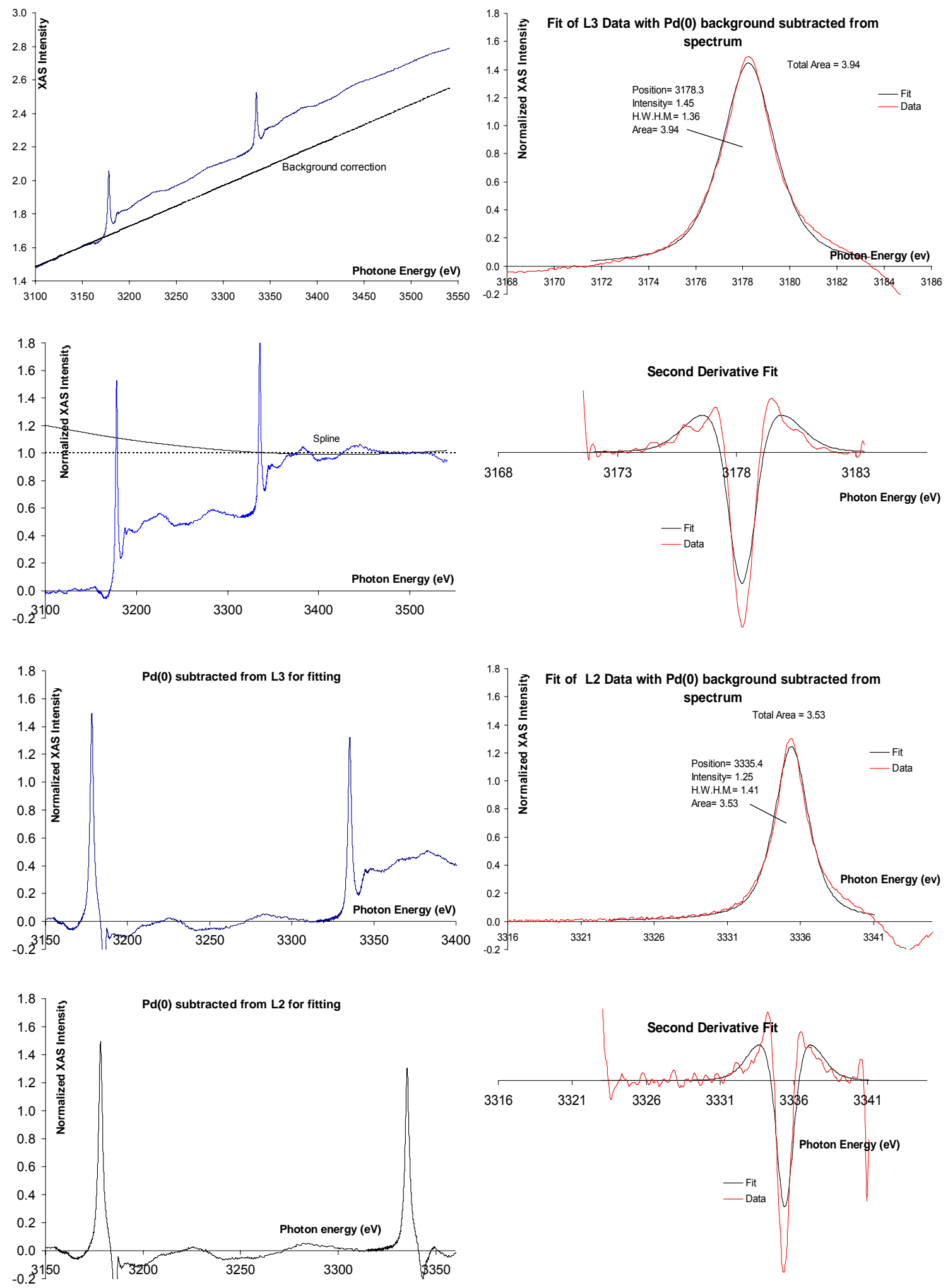